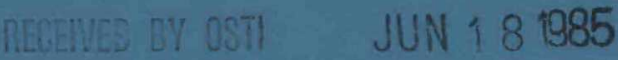

\section{MAGNUM-2D Computer Code: Users Guide}

January 1985

Richard L. England Niall W. Kline BCS Richland, Inc.

Karen J. Ekblad BCS Seattle, Inc.

Robert G. Baca Rockwell Hanford Operations

Prepared for Rockwell Hanford Operations, a Prime Contractor to the U.S. Department of Energy under Contract DE-ACO6-77RL01030 Richland, Washington 


\section{DISCLAIMER}

This report was prepared as an account of work sponsored by an agency of the United States Government. Neither the United States Government nor any agency Thereof, nor any of their employees, makes any warranty, express or implied, or assumes any legal liability or responsibility for the accuracy, completeness, or usefulness of any information, apparatus, product, or process disclosed, or represents that its use would not infringe privately owned rights. Reference herein to any specific commercial product, process, or service by trade name, trademark, manufacturer, or otherwise does not necessarily constitute or imply its endorsement, recommendation, or favoring by the United States Government or any agency thereof. The views and opinions of authors expressed herein do not necessarily state or reflect those of the United States Government or any agency thereof. 


\section{DISCLAIMER}

Portions of this document may be illegible in electronic image products. Images are produced from the best available original document. 


\section{DISCLAIMER}

This report was prepared as an account of work sponsored by an agency of the United States Government. Neither the United States Government nor any agency thereof, nor any of their employees, makes any warranty, express or implied, or assumes any legal liability or responsibility for the accuracy, completeness, or usefulness of any information, apparatus, product, or process disclosed, or represents that its use would not infringe privately owned rights. Reference herein to any specific commercial product, process, or service by trade name, trademark, manufacturer, or otherwise, does not necessarily constitute or imply its endorsement, recommendation, or favoring by the United States Government or any agency thereof. The views and opinions of authors expressed herein do not necessarily state or reflect those of the United States Government or any agency thereof.

Printed in the United States of America

\section{DO NOT MICROFILM COVER}


This report was prepared as an account of work sponsored by an agency of the United States Government. Neither the United States Government nor any agency thereof, nor any of their employees, makes any warranty, express or implied, or assumes any legal liability or responsibility for the accuracy, completeness, or usefulness of any information, apparatus, product, or process disclosed, or represents that its use would not infringe privately owned rights. Reference herein to any specific commercial product, process, or service by trade name, trademark, manufacturer, or otherwise does not necessarily constitute or imply its endorsement, recommendation, or favoring by the United States Government or any agency thereof. The views and opinions of authors expressed herein do not necessarily state or reflect those of the United States Government or any agency thereof.

\section{MAGNUM-2D Computer Code: Users Guide}

Date Manuscript Completed: January 1985

\author{
Richard L. England \\ Niall W. Kline \\ BSC Richland, Inc.
}

Karen J. Ekblad

BSC Seattle, Inc.

\section{Robert G. Baca}

Rockwell Hanford Operations

Prepared for Rockwell Hanford Operations, a Prime Contractor to the U.S. Department of Energy under Contract DE-AC06-77RL01030
RHO-BW-CR--143P

DE85 013315

\section{Rockwell International}

Rockwell Hanford Operations P.O. Box 800

Richland. Washington 99352 


\section{ABSTRACT}

In this report, information relevant to the general use of the MAGNUM-2D computer code is presented. This computer code was developed for the purpose of modeling (i.e., simulating) the thermal and hydraulic conditions in the vicinity of a waste package emplaced in a deep geologic repository. The MAGNUM-2D code computes (1) the temperature field surrounding the waste package as a function of the heat generation rate of the nuclear waste and thermal properties of the basalt and (2) the hydraulic head distribution and associated groundwater flow fields as a function of the temperature gradients and hydraulic properties of the basalt.

MAGNUM-2D is a two-dimensional numerical model for transient or steadystate analysis of coupled heat transfer and groundwater flow in a fractured porous medium. The governing equations consist of a set of coupled, quasilinear partial differential equations that are solved using a Galerkin finite-element technique. A Newton-Raphson algorithm is embedded in the Galerkin functional to formulate the problem in terms of the incremental changes in the dependent variables. Both triangular and quadrilateral finite elements are used to represent the continuum portions of the spatial domain. Line elements may be used to represent discrete conduits. 


\section{CONTENTS}

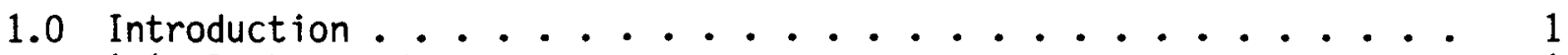

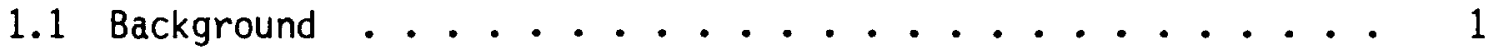

1.2 Purpose and Scope ................ 2

2.0 Mathematical Framework .............. 2

2.1 Governing Equations ............... 2

2.2 Spatial Discretization .............. 6

2.3 Initial Conditions ............... 9

2.4 Boundary Conditions ................ 9

2.5 Numerical Solution Method .............. 10

3.0 General Input Considerations . . . . . . . . . . 12

3.1 Mode 1 Generation ................ 12

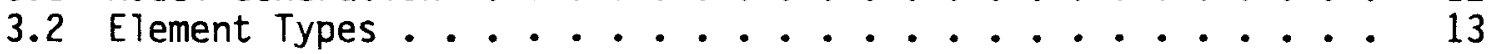

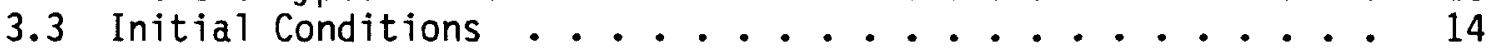

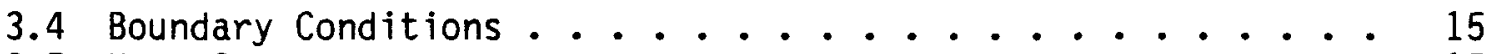

3.5 Heat Sources ................. 15

3.6 Time Stepping ................. 17

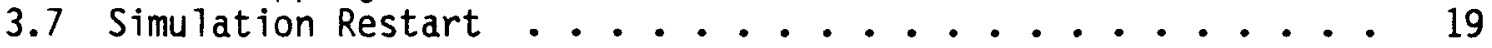

3.8 Execution Control ................ 20

3.9 Data Input Records .............. 20

4.0 Input Preparation ............... 23

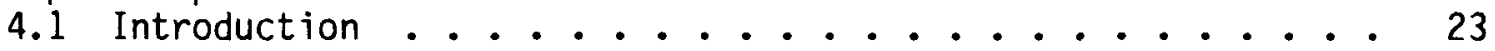

4.2 Input Data Description and Discussion ......... 23

4.3 Input Data Format Summary ............. 35

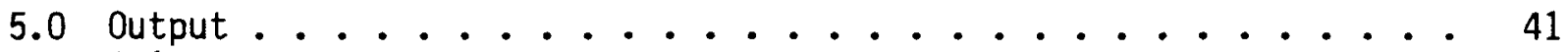

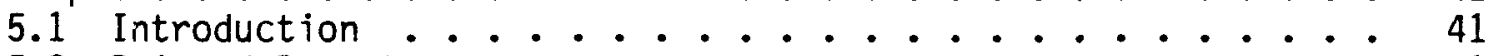

5.2 Printed Report ................ 41

5.2 .1 Banner Page .................. 41

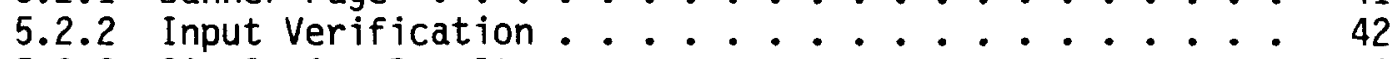

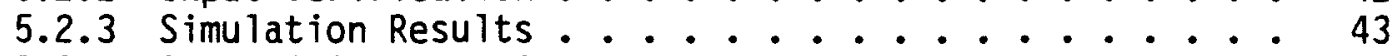

5.2 .4 Gauss Point Locations ................ 43

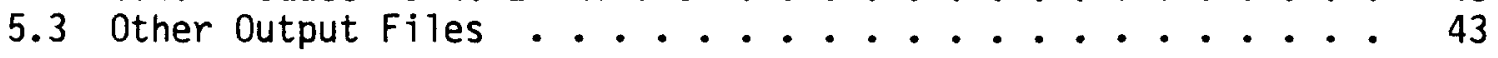

6.0 Nomenclature ...................... 45

7.0 References .................... 47

Appendixes:

A. Program Internals .................... A-1

B. Preprocessors ................ B-1

C. Postprocessors ................... C-1

D. Example Cases .................. . . D-1

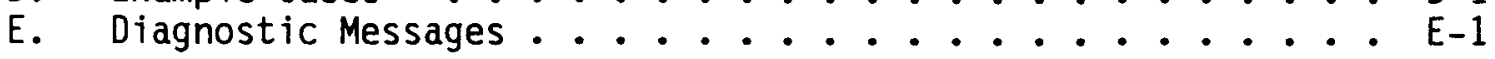


FIGURES:

1. Locations of Nodes and Gauss Points for Quadratic-Shape Functions ................. 7

2. Locations of Nodes and Gauss Points for Linear-Shape Functions. . . . . . . . . . . . 8

3. Typical Volumetric Heat Generation Profile . . . . . . . 16

4. Gauss Points in Local Coordinates for Quadratic Elements . . 44

TABLES:

1. Coefficients of Relative Heat Generation . . . . . . . 17 


\subsection{INTRODUCTION}

\subsection{BACKGROUND}

A suite of numerical models (i.e., computer codes) has been developed and interfaced for use in assessing the long-term isolation performance of a repository in basalt (DOE 1982). These models are based primarily on deterministic approaches (Estey et a 1. 1985; Kline et a 1. 1983); however, certain codes are formulated on a probabilistic framework (Baca et a 1. 1984b; Sagar and Clifton 1983; Clifton et a 1. 1983). The numerical models are grouped by space scale into three categories:

1. Waste package scale (very near-field) models

2. Repository scale (near-field) models

3. Regional scale (far-field) models.

The waste package scale models provide predictions of the temperature and flow field around the waste package and radionuclide release rates from the waste package and/or emplacement horizon. The repository scale models are designed to calculate groundwater flow paths and traveltimes, the largescale temperature field around the repository, and radionuclide concentrations and releases. Results from the repository scale analys is provide boundary conditions for regional scale predictions of groundwater traveltimes to and cumulative releases at the boundary of the accessible environment.

This report focuses on one of the deterministic waste package scale models designated as MAGNUM-2D. The MAGNUM-2D code is a two-dimensional finite-element code applicable to a fractured porous medium. This computer code is capable of simulating the coupled or uncoupled processes of heat transfer in a water/rock system and groundwater flow in an inhomogeneous anisotropic medium. In addition, it provides the capability of simulating flow in discrete conduits or fractures (macroscale discontinuities). The conceptual modeling approach is based on representing the physical system by a two-dimensional cross section. Three-dimensional systems with axial symmetry can also be modeled with MAGNUM-2D. A set of support codes and graphics software has been developed and interfaced with the MAGNUM-20 code to (1) generate, manipulate, and display the finite-element grid; (2) compute and plot pathlines/streamlines and traveltimes; and (3) plot contours, spatial cross sections, and time histories for temperature and hydraulic head. In addition, the data files generated by MAGNUM-2D are arranged to be used directly by the CHAINT computer code (Baca et a1. 1984a), which simulates the transport of dissolved radionuclides.

This users guide provides detailed instructions regarding the use of the MAGNUM-2D computer code for waste package scale analys is of coupled groundwater flow and heat transfer. It also contains descriptions of input data requirements, as well as sample input and output for test cases. 
RHO-BW-CR-143P

\subsection{PURPOSE AND SCOPE}

The MAGNUM-2D computer code was developed by the Basalt Waste Isolation Project (BWIP) at Rockwell Hanford Operations (Rockwe 11) for use in studies of nuclear waste disposal in deep geologic repositories (Baca et al. 1984a, 1984b; Baca et a1. 1981). Subsequent enhancements as well as ongoing maintenance are provided by Boeing Computer Services Richland, Inc., Richland, Washington. This document is intended to serve as a users guide for version 3.1 of the code as it exists at the BWIP computing facility. It is noteworthy that earlier versions of MAGNUM-2D have been implemented on a UNIVAC 1100/44 and a CRAY 1 , as well as PRIME minicomputers. The current version is installed on a PRIME 750 minicomputer network. Although the BWIP version of MAGNUM-2D is maintained and used in a PRIME operating environment, transportability of the code has been given high priority. Features of the current version of the MAGNUM-2D computer code as described herein are machine independent except for the isolated service subroutines noted in Appendix A.

The format and content of this users guide are with respect to guidance given by the U.S. Nuclear Regulatory Commission (Silling 1983). The partial differential equations solved by MAGNUM-2D and the numerical method are discussed in Section 2.0. The general usage considerations and capabilities are discussed in Section 3.0, while detailed instructions for inputting a given problem are given in Section 4.0. The output obtainable from MAGNUM-2D is described in Section 5.0. The possible machine/environment dependencies are discussed in Appendix A. Included as Appendixes B and C are descriptions and short discussions of several preprocessors and postprocessors that may be used to assist in preparation of the input data for MAGNUM-2D and the interpretation of the output data. The input data and output listings for some example problems, along with examples of plots generated by preprocessor and postprocessor graphics programs, are given in Appendix D. Diagnostic messages generated by MAGNUM-20 are tabulated in Appendix E.

\subsection{MATHEMATICAL FRAMEWORK}

\subsection{GOVERNING EQUATIONS}

The MAGNUM-2D computer code is designed to simulate steady-state and time-dependent coupled processes of buoyancy-driven fluid flow in a fractured porous medium and advective and conductive heat transfer in a porous continuum. The code is applicable to problems that can be formulated in two dimensions over rectangular or axially symmetric cylindrical domains. The mathematical model is founded on the physical laws of fluid continuity and conservation of momentum and energy (Fahien 1983; Malvern 1969). Discussions on the theoretical bases may be found in Baca et al. (1984a); however, for completeness, the governing equations are also given here. 
The equation governing nonisothermal flow balance in a porous continuum as written in indicial notation for a Cartesian coordinate system is.

$$
S_{S} \frac{\partial h}{\partial t}=\frac{\partial}{\partial x_{j}}\left[K_{i j}\left(\frac{\partial h}{\partial x_{j}}+\delta_{b} \delta_{i 2}\right)\right]+\gamma \frac{\partial T}{\partial t}
$$

where

$$
\begin{aligned}
S_{S} & =\text { specific storage of the porous rock matrix } \\
h & =\text { hydraulic head } \\
t & =\text { the time coordinate } \\
x_{i} & =\text { space coordinates }(x, y) \\
K_{i j} & =\text { principa) hydraulic conductivities of the rock matrix } \\
\delta_{b} & =\text { density disparity } \\
\delta_{i 2} & =\text { the Kronecker delta } \\
\gamma & =\text { thermal coupling coefficient } \\
T & =\text { temperature of the water/rock system. }
\end{aligned}
$$

Note that the principal axes of the hydraulic conductivity tensor are assumed to coincide with the coordinate axes and, hence, only components of flow in the principal directions are considered. Furthermore, the density disparity and thermal coupling coefficient are given by

$$
\delta_{b}=\frac{\rho-\rho_{0}}{\rho^{\star}}
$$

and

$$
\gamma=\phi B \text {, respectively }
$$

where

$$
\begin{aligned}
& \rho=\text { fluid density as a function of location }(x, y) \text { and time } \\
& \rho_{0}=\text { initial fluid density as a function of vertical location }(y) \\
& \rho^{\star}=\text { reference fluid density }
\end{aligned}
$$




$$
\begin{aligned}
& \phi=\text { effective porosity } \\
& B=\text { bulk modulus of fluid. }
\end{aligned}
$$

The equation governing nonisothermal flow balance in a fracture as written for a local one-dimensional coordinate system is

$$
S_{f} \frac{\partial h}{\partial t}=\frac{\partial}{\partial L}\left[K_{f}\left(\frac{\partial h}{\partial L}+\delta_{b}^{\prime}\right)\right]+\gamma \frac{\partial T}{\partial t}
$$

where

$S_{f}=$ specific storage in the fracture

$L=$ local space coordinate

$K_{f}=$ hydraulic conductivity of (filled or unfilled) fracture

$\delta_{b}^{\prime}=$ component of the density disparity along $L$.

For an unfilled fracture, the hydraulic conductivity is determined by (Snow 1969)

$$
K_{f}=\frac{g e^{2}}{12 v}
$$

where

$$
\begin{aligned}
& g=\text { acceleration due to gravity } \\
& e=\text { fracture aperture } \\
& v=\text { kinematic viscosity of the fluid. }
\end{aligned}
$$

Under the assumption that the fluid and rock mass are in thermal equilibrium at all times (Combarnous and Bories 1975), the governing thermal energy balance equation written for Cartesian coordinates using indicial notation is

$$
S_{t} \frac{\partial T}{\partial t}+\rho c_{f} q_{i} \frac{\partial T}{\partial x_{i}}=\frac{\partial}{\partial x_{i}}\left(D_{t i} \frac{\partial T}{\partial x_{j}}\right)+Q
$$


where

$$
\begin{aligned}
S_{t} & =\text { heat capacity of the fluid/rock system } \\
c_{f} & =\text { specific heat of the fluid } \\
q_{i} & =\text { component of the Darcy velocity vector }\left(-K_{i j} \frac{\partial h}{\partial x_{j}}\right) \\
D_{t i} & =\text { effective thermal conductivity } \\
Q & =\text { volumetric rate of heat generation. }
\end{aligned}
$$

Moreover,

$$
S_{t}=\phi \rho C_{f}+(1-\phi) \rho_{s} c_{s}
$$

where

$$
\begin{aligned}
& \rho_{S}=\text { bulk density of the rock } \\
& c_{S}=\text { specific heat of the rock, }
\end{aligned}
$$

and

$$
D_{t x}=\phi D_{f}+(1-\phi) D_{S x}+\left(\alpha_{L} q_{x}^{2}+\alpha_{T q_{y}}^{2}\right) \frac{\rho^{C_{f}}}{\bar{q}}
$$

and

$$
D_{t y}=\phi D_{f}+(1-\phi) D_{s y}+\left(\alpha_{T} q_{x}^{2}+\alpha_{L} q_{y}^{2}\right) \frac{\rho^{C_{f}}}{\bar{q}}
$$

where

$$
\begin{aligned}
& D_{f}=\text { thermal conductivity of the fluid } \\
& D_{S}=\text { thermal conductivity of the rock } \\
& \alpha_{L}=\text { longitudinal dispersivity } \\
& \alpha_{T}=\text { transverse dispersivity } \\
& \bar{q}=\left(q_{x}^{2}+q_{y}^{2}\right)^{1 / 2}, \text { the groundwater speed. }
\end{aligned}
$$


Again, as with the flow equation, cross-product terms are assumed to be negligible. Heat transfer along a fracture is handled analagously to flow in the fracture (i.e., in one dimension).

The MAGNUM-2D computer code is programmed to solve the governing equations in Cartesian or radial coordinates ( $\mathrm{Eq} .1,4$, and 6 ) subject to initial and boundary conditions using a Galerkin finite-element method. The flow equations are solved simultaneously. The flow and heat transfer equations are solved in alternating sequence. The units of the constants, coefficients, and state variables are given in the nomenclature list comprising Section 6.0.

\subsection{SPATIAL DISCRETIZATION}

The finite-element method employed by MAGNUM-2D in solution of the governing equations (Eq. 1,4 , and 6 ) is implemented in a fashion that affords substantial flexibility in discretization of the spatial domain. An arbitrarily shaped planar domain may be discretized over a Cartesian global coordinate system as long as it is topologically connected and has a continuous boundary. A bounded disk, cylinder, or annulus may be discretized over a radial global coordinate system. In practice, this latter case amounts to representation of a vertical cross section in Cartesian coordinates and specification of an appropriate angle of revolution. Note that in a radial coordinate system, a line element superimposed on a vertical cross section of a cylinder defines a surface intersecting the cylinder.

Linear or quadratic Lagrangian one-dimensional elements (Huyakorn and Pinder 1983) may be used to represent a one-dimensional domain. Isoparametric triangular and/or serendipity elements (Huyakorn and Pinder 1983) may be used in combination with line elements for discretization of a two-dimensional domain. Both linear and quadratic Langrangian shape functions may be used with the two-dimensional elements as well.

Typical one- and two-dimensional elements show the placement of nodes (denoted by Roman numerals) and Gauss points (denoted by Arabic numerals) for quadratic-shape functions in Figure 1 and the same for linear-shape functions in Figure 2. Note that the transport variables, $h$ and $T$, are defined at the nodes, and the Darcy velocities, $U$ and $V$, are defined at the Gauss points.

Guidance for selection of element types and shape functions is provided in Sections 3.1 and 3.2. Detailed descriptions of MAGNUM-2D input options and formats are given in Section 4.0. Automated procedures for construction of a complete finite-element grid system is outlined in Appendix B. Twodimensional plots of a grid system used for an example problem may be found in Appendix 0 . 


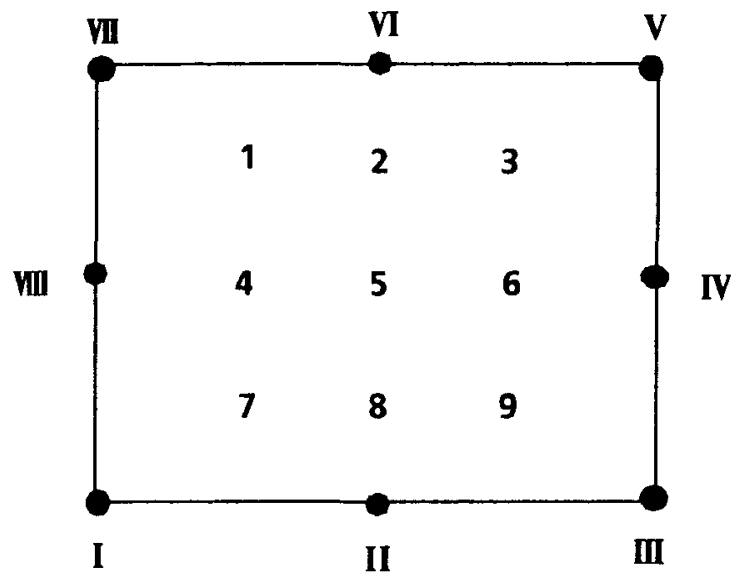

(a)

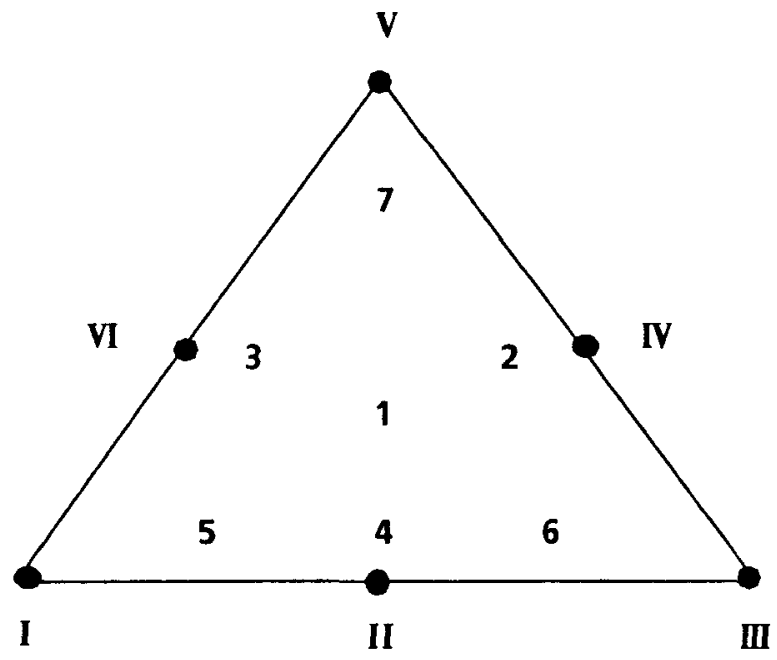

(b)

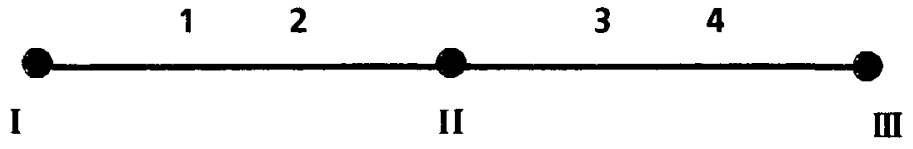

(c)

PS84-2131-1

FIGURE 1. Locations of Nodes and Gauss Points for Quadratic-Shape Functions (a) Quadrilateral Element, (b) Triangular Element, and (c) Line Element. 


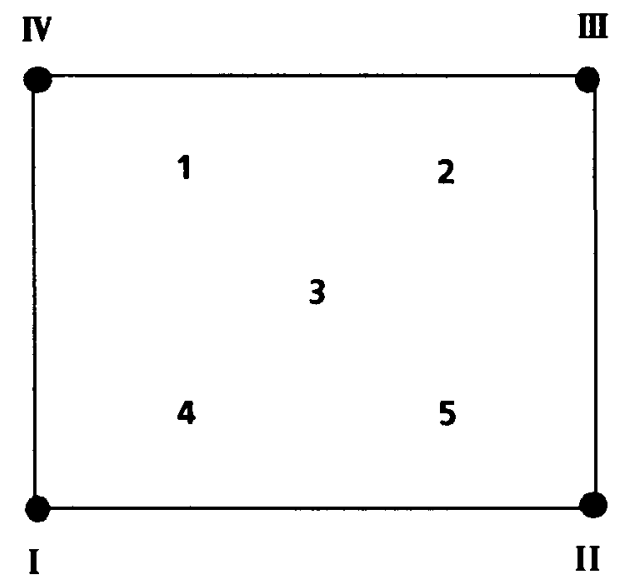

(a)

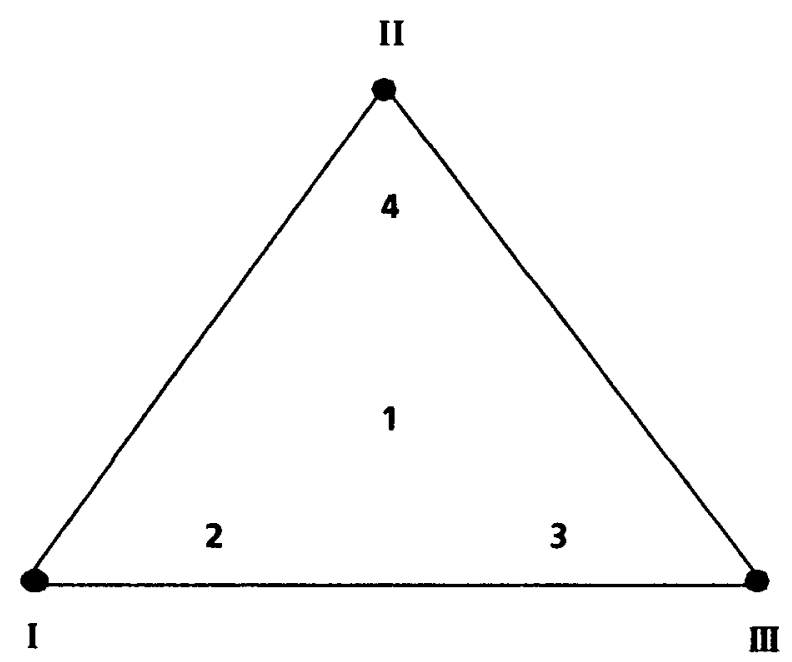

(b)

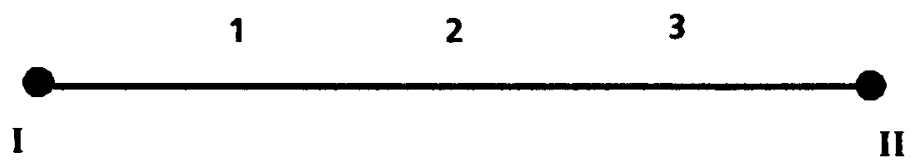

(c)

FIGURE 2. Locations of Nodes and Gauss Points for Linear-Shape Functions (a) Quadrilateral Element, (b) Triangular Element, and (c) Line Element. 


\subsection{INITIAL CONDITIONS}

Solutions of the governing equations (Eq. 1, 4, and 6) are dependent upon the initial conditions of the state variables $h$ and $T$. To facilitate the present as well as later discussions, let $F$ denote a generalized state variable (i.e., either $h$ or $T$ ) and let $F_{k}^{l}$ denote the value of $F$ at the $k$ th node at the $e^{\text {th }}$ time step. Then, a global initial condition may be written

$$
F_{k}^{0}=\text { constant, } \quad 1 \leq k \leq N P
$$

where NP denotes the total number of nodes in the spatial domain. If no initial conditions are specified for $F$, then Equation 10 is assumed where the constant is taken to be zero. Explicit specification of the above form (Eq. 10) is easily accomplished according to instructions given in Section 4.0. Alternately, a spatially varying initial condition may be written

$$
F_{k}^{0}=F\left(x_{k}, y_{k}, t^{0}\right), \quad 1 \leq k \leq N P \text {. }
$$

Use of this form requires specification of the initial value of $F$ at each node. Manual setup of the input corresponding to this form (Eq. 11) can be tedious if NP is large, and hence there exists a preprocessor that provides automated generation of an initial condition file as described in Appendix B.

The foregoing description of initial conditions is germane to transient analysis of fluid flow and/or heat transfer. However, MAGNUM-2D is also equipped to perform steady-state solution of the governing equations. In this case, starting values for solution of the steady-state distribution of $F$ may be specified in the same manner as initial conditions.

\subsection{BOUNDARY CONDITIONS}

The MAGNUM-2D computer code is generally applicable to problems involving solution of Equations 1, 4, and 6 over a doma in meeting the requirements given in Section 2.2. However, MAGNUM-2D is utilized primarily in the analysis of waste package scale phenomena. At this scale differentials (i.e., gradients) are typically smal1, and hence the default boundary condition for $F$ is taken from

$$
\left.\frac{\partial F}{\partial z}\right|_{x=x_{B}, y=y_{B}}=0
$$


where $\left(x_{B}, y_{B}\right)$ denotes a boundary node and $z$ is a coordinate normal to the boundary. Optionally, one may specify a Dirichlet boundary condition for $F$ at any boundary node.

Formatting of input for optional boundary conditions can prove to be tedious. To further facilitate the setup of a MAGNUM-2D simulation, a preprocessor is available to generate a boundary condition file as described in Appendix B.

\subsection{NUMERICAL SOLUTION METHOD}

The finite-element method employed by MAGNUM-2D in solution of the governing equations ( $\mathrm{Eq} .1,4$, and 6 ) is based on a Galerkin approach (Huyakorn and Pinder 1983). A substantial derivation of the method is given by Baca et a1. (1984a). A summary, along with complementary details, is provided in the following paragraphs.

Consider an arbitrarily selected element containing m nodes. Then an approximation to $F$ over the element is written

$$
F \doteq \sum_{k=1}^{m} w_{k} F_{k}
$$

where $\omega$ denotes a shape function. Let $\varepsilon$ denote the error due to the approximation (Eq. 13). Then the Galerkin approach to weighted residuals is based on minimization of the error, $\varepsilon$, through the functional

$$
x=\int_{E} w_{k} \varepsilon d E
$$

where $E$ is the current element. The finite-element equations are formulated in terms of incremental change in $F$ by using a Newton-Raphson algorithm for $\varepsilon$ in Equation 14 (Baca et a1. 1978, 1984a). Communication between fractures and the porous continuum is achieved by superposition which amounts to summing the functionals for hydraulic head in a continuum element and hydraulic head in an adjacent fracture. 
Expansion of terms for the system of finite-element equations derived for a single element is illustrated by Baca et a1. (1984a). Derivatives of $F$ with respect to time as occur in the element equations are approximated by linear combinations of differences over incremental times written

$$
\left.\frac{\partial F}{\partial t}^{\ell+1} \equiv \frac{\partial F}{\partial t}\right|_{t=t \ell+1} \doteq \theta \frac{F l+1-F \ell}{t \ell+1-t \ell}+(1-\theta) \frac{\partial F \ell}{\partial t} .
$$

The value of $\mathrm{F} \ell+1$ as used in Equation 15 is calculated from a non-iterated Hermite-Milne predictor-corrector method characterized by the two stages

$$
F^{\ell+1}=-4 F^{\ell}+5 F^{\ell-1}+\left(t \ell+1-t^{\ell}\right)\left(4 \frac{\partial F}{\partial t}^{\ell}+2 \frac{\partial F}{\partial t}^{\ell-1}\right)
$$

and

$$
F^{\ell+1} 1^{\star}=F^{\ell-1}+\frac{t \ell+1-t \ell}{3}\left(\frac{\partial F}{\partial t}^{\ell+1}+4 \frac{\partial F}{\partial t}^{\ell}+\frac{\partial F}{\partial t}^{\ell-1}\right)
$$

where $F l+1^{\star}$ is the corrected value of $F l+1$.

The weighting factor, $\theta$, in Equation 15 may be specified by the user. Suggested values range between one and two; a value of one corresponds to a first order backward difference approximation, whereas a value of two corresponds to a second order backward difference approximation.

Assembly of the blocks of element equations yields a banded system of linear algebraic equations that is solved using a Gaussian frontal-solution technique. The frontwidth of the system is a factor in the amount of memory and processing time needed to solve the system of equations (Irons and Ahmad 1980). In turn, the frontwidth is dependent upon element numbering. Hence, as described in Appendix B, there is a preprocessor available to optimize the element numbering in the respect that the frontwidth is minimized. 
RHO-BW-CR-143 P

\subsection{GENERAL INPUT CONSIDERATIONS}

\subsection{MODEL GENERATION}

The generation of a finite-element model requires careful consideration of the processes being simulated and the limitations of the finite-element technique. Detailed consideration of these points is outside the scope of this document. It is assumed that the user is versed in finite-element applications and thus needs only a discussion of the use of this particular code.

In general, the majority of the time required in formulation and generation of a finite-element model is spent in developing the grid that represents the physical domain. This consists of determination of the points that define the corners of the elements and specification of the connectivity that defines the set of nodes describing each element.

One of the advantages of the finite-element approach used in MAGNUM-2D is that it permits the use of a "graded" mesh. A graded mesh is a variable computational grid that is coarse in areas of low gradients and is fine in areas of high gradients. The significance of the graded mesh is that it permits accurate representation of the spatial domain and its boundaries, and it minimizes the space truncation error, thus optimizing the computational problem. Selection of the mesh layout is, therefore, one of the most important steps in applying the code.

Mesh generation for a practical simulation problem is generally an iterative process. For problems of coupled heat and flow, the numerical solution of the flow equations ( $\mathrm{Eq} .1$ and 4 ) usually requires the finer mesh layout (i.e., greater spatial resolution). The generation process begins with a trial mesh layout that is selected to conform with the anticipated solution field(s) and system boundaries. A test simulation is performed with MAGNUM-2D, and the results are analyzed. For cases involving fluid flow, the pathlines are calculated, plotted, and checked. From these initial results, the grid is refined as needed. This process is repeated until the simulation results show convergence to a reasonable solution.

Time may be saved in the geometry definition phase of the problem formulation by making use of the preprocessing utilities described in the appendixes, specifically, GEN and FEMESH to generate the mesh, MESHER to optimize it, PURGE to verify it, and BCGEN to identify the boundary nodes. In addition, there is a processor called PLT that displays the geometry on a graphics terminal and a family of postprocessors that assist in the analysis of the output data. 
The following guidelines should be considered in generating a twodimensional finite-element mesh.

- Quadrilateral elements should be used for most of the mesh, and if necessary, triangular elements should be used for transition regions; line elements are used for discrete fractures.

- Element aspect ratios should not exceed roughly 100.

- Midside nodes should be located in the middle third of the element side or length.

- The element numbering sequence should be continuous and should begin along the side of the grid with the fewest elements.

The MAGNUM-2D computer code uses a frontal solution algorithm developed by Hood (1976) to solve unsymmetric finite-element matrix equations. This technique is an implementation of Gaussian elimination in which the assembly of equations alternates with their solution. With respect to accuracy, the algorithm is insensitive to node numbering and independent of matrix bandwidth. The numbering of the elements, however, must be assigned in a contiguous and optimal sequence to assure computational efficiency. In general, the optimal element numbering begins along the side of the mesh with the fewest elements. A preprocessor program, designated as MESHER, has been developed that reads a finite-element mesh (element-node table and nodal coordinate list), reorders the element numbering sequence, and outputs the optimized mesh layout.

\subsection{ELEMENT TYPES}

The MAGNUM-20 computer code uses a grid system composed of quadratic and linear elements such as those depicted in Figures 1 and 2 . The grid layout is defined by an element-node table (connectivity definition) and a list of nodal coordinates (geometry definition). Node numbers for any element must be entered in a counterclockwise manner starting at any corner node. The finite-element grid consists of any combination of quadrilateral and triangular elements with line elements superimposed along element boundaries as needed.

By default, quadratic-shape functions are used to approximate the state variables, $h$ and $T$, over each finite element. This default may be overridden by specifying a "zone" as part of the input data. The state variables are approximated within the zone using quadratic-shape functions as normal, but a 11 elements outside the zone are approximated with linearshape functions. Midside nodes are automatically averaged by MAGNUM-2D for any linear zone elements, thus reducing the number of unknowns. The elements and the node numbering used for linear-shape function elements are shown in Figure 2. Using linear-shape functions in domain areas with gradually varying-state variables can save substantial computer run time. 
In addition to the zone definition technique mentioned above, the user may also specify elements with linear-shape functions directly. During input, the user enters zero or blank for a 11 midside nodes. The MAGNUM-2D computer code will detect these "zero" nodes and use the linear-shape function.

Although the shapes and sizes of the continuum elements are arbitrary, it should be noted that the aspect ratio, roughly the ratio between the height and width of the element, can be a determining factor in the accuracy of the final results of a simulation. It has been found through experience that if the user maintains an aspect ratio of less than 100 , the results will be reasonable.

The modeling of macrofeatures such as fractures will at times require a tradeoff between the best fracture geometry representation and the number and location of the continuum elements. One fracture width is allowed per material type. Several material types may be defined with their fracture widths being the only difference in the rock properties. The line element representing the fracture is treated as isotropic. Regardless of the fracture orientation in the domain, the $x$-direction conductivity value is used along the fracture length, and a zero-conductivity value is used across the fracture width. The specified fracture permeabilities must be greater than the permeability of the surrounding medium. Moreover, a line element and a continuum element cannot be assigned the same material type index.

In addition to the modeling considerations, care should be exercised in placing the continuum elements so that the various material types are in their proper orientation and location. Material types may only be specified on an element-by-element basis, so material boundaries must coincide with element boundaries.

\subsection{INITIAL CONDITIONS}

A global or local initial value of a state variable, $F$, may be specified as summarized by Equations 10 and 11 , respectively. The role of initial conditions in a simulation of transient phenomena is obvious. For a steady-state simulation, the initial conditions are taken as starting values in that the steady-state value of $F$ is

$$
F_{k}=F_{k}^{0}+\Delta F_{k}
$$

where $\Delta F_{k}$ represents the incremental change in $F$ after a single iteration.

For steady-state applications the default value of zero for starting values may be as good as any other starting value in that the steady-state value, $F_{k}$, and the amount of computer time needed to obtain it are independent of the starting value, $F_{k}^{0}$. As an exception, starting values 
of temperature may be important in steady-state flow if the user wishes to account for temperature dependence of hydraulic conductivity. A tacit assumption in this exceptional case is that the initial temperatures are actually steady-state temperatures. Of importance though is merely acquainting the user with the capability of specifying starting values for steady-state applications.

\subsection{BOUNDARY CONDITIONS}

The MAGNUM-2D computer code is designed principally for simulation of nonisothermal fluid flow and heat transfer in the vicinity of a waste container under saturated groundwater conditions. Hence aquifer leakage, recharge, and pumping are not considered in the model. Heat sources are accommodated as described in the following section. At the outer boundary of the simulation domain, as well as along the axis of symmetry for a radial coordinate system, a zero flux boundary condition is taken by default for both state variables $h$ and $T$.

Optional Dirichlet boundary conditions may be specified for either or both $h$ and $T$ at any boundary node. Note that specification of fixed temperature or head along the axis of symmetry for a radial coordinate system may be used to simulate a point, line, or cylindrical source of constant strength. No provision is made to allow any time dependent boundary conditions (except for internal heating as described in the next section).

\subsection{HEAT SOURCES}

Heat sources may be specified throughout the discretized spatial domain on an elemental basis. Use of this feature requires specification of the total number of elements to which a time-dependent heat load is applied, the numbers of the individual elements that bear the heat load uniformiy, and the temporal profile of the common heat generation rate. As an option, one may also supply a scale factor that magnifies the thermal source strength. Provision of this scaling option is intended to facilitate user transition between simulations for which the heat loads are identical up to magnitude of source strength.

Zero heat loading is set by default. Alternately, for a transient simulation involving heat transfer processes, one may specify a heat generation rate through either of two methods. The more general of the two available source strength options allows the user to input the pairs of points of the form $\left(t^{i}, Q^{i}\right)$ that define a piecewise-linear heat generation profile. An example of such a profile is depicted in Figure 3. The shaded area in this figure indicates the amount of thermal energy released per unit volume, $\Delta Q$, over a time step of size $\Delta t$. Attainment of a constant source 
strength requires a single pair of points. A step-change profile may be approximated by three pairs of points (i.e., four total points taken pairwise in increasing time). In general, a continuous piecewise-linear profile consisting of $n$ segments requires $n+1$ points.

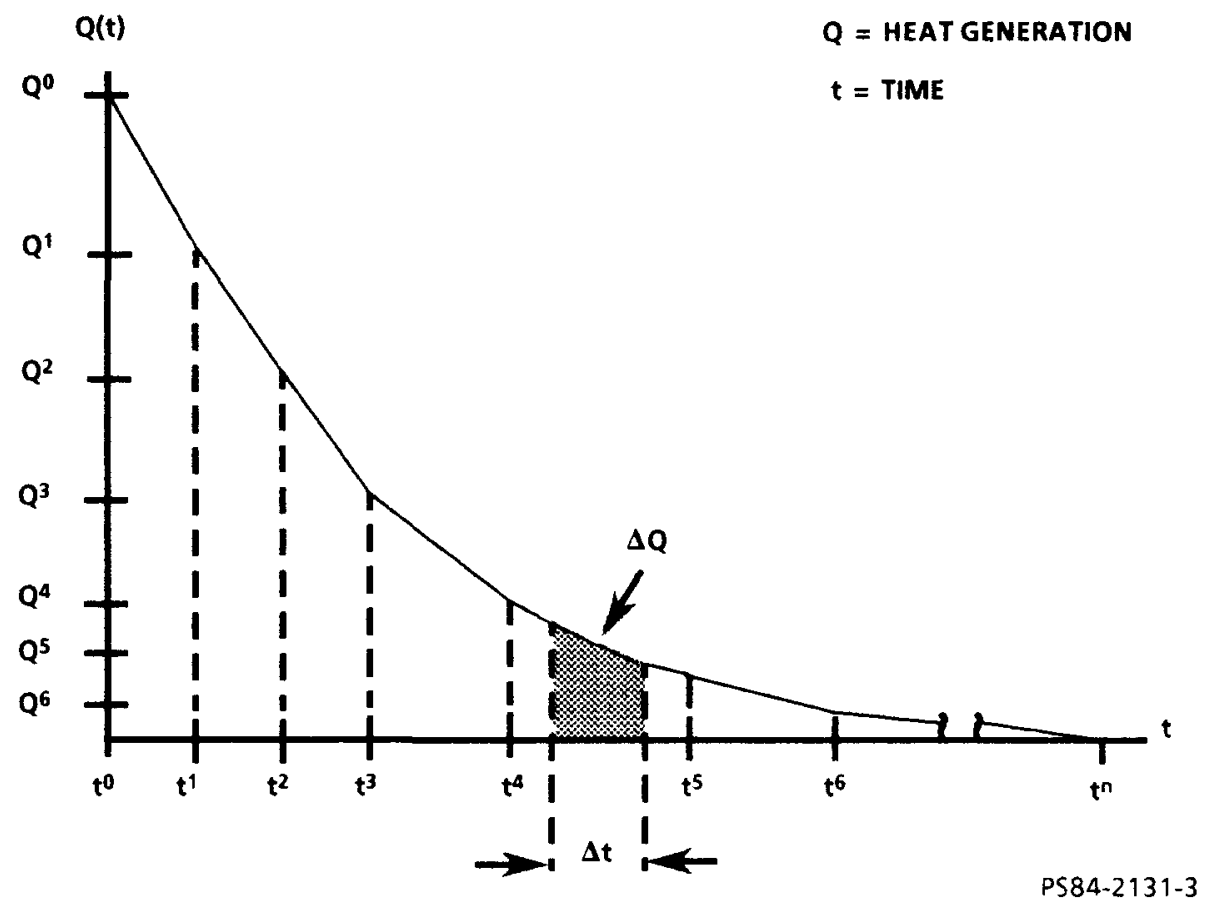

FIGURE 3. Typical Volumetric Heat Generation Profile.

The other source strength option is specially tailored to simulation of heat transfer around a waste package. In particular, under this option the source strength is the product of an initial volumetric heat load and a relative heat generation rate for 10-yr old unreprocessed spent fuel (Hardy and Hocking 1978). Use of this option requires entry of the initial heat load, $Q^{\circ}$, after which successive loads decay according to the empirical relation

$$
Q^{\ell}=Q^{\circ} \sum_{i=1}^{6} b_{i 1} e^{-b_{i 2} t^{\ell}}
$$


where the coefficients $b_{i j}$ are given in Table 1.

TABLE 1. Coefficients of Relative Heat Generation.

\begin{tabular}{l|l|l|}
\hline$i$ & \multicolumn{1}{|c|}{$b_{i 1}$} & \multicolumn{2}{|c}{$b_{i 2}$} \\
\hline 1 & 0.00756 & $2.3 \times 10^{-5}$ \\
2 & 0.0151 & $9.95 \times 10^{-5}$ \\
3 & 0.1404 & $1.75 \times 10^{-3}$ \\
4 & 0.677 & $2.166 \times 10^{-2}$ \\
5 & 0.0504 & $4.03 \times 10^{-2}$ \\
6 & 0.1093 & $2.912 \times 10^{-1}$ \\
\hline
\end{tabular}

Both of the foregoing heat source strength options are programmed only for use in a transient simulation mode. To obtain a steady-state temperature distribution around a constant heat source, one must run a transient simulation covering at least one step of strictly positive duration. This is due to the nature of the piecewise-linear profile that is used to specify a constant heat source. Alternately for steady-state heat transfer around a constant source, it may be reasonable to assume a line of symmetry across the source and run a steady-state simulation in which an appropriate Dirichlet boundary condition is specified along a segment of the axis of symmetry.

\subsection{TIME STEPPING}

The time steps for a transient simulation may be subdivided into groups of equally sized steps. The number of steps of any given size is arbitrary. The user need only specify the step size and number of steps for each group of time steps as described in Section 4.0.

Apart from the procedural task of inputting time-step data is the need for criteria to gage step sizes. As a rule of thumb, a beginning time-step size should not be greater than the characteristic time

$$
\Delta t_{c h} \equiv \min \frac{S(\Delta x)^{2}}{\Gamma}
$$


where

$$
\begin{aligned}
S & =\text { generalized storage coefficient }\left(S_{S} \text { or } S_{t}\right) \\
\Gamma & =\text { generalized conductivity }\left(K \text { or } D_{t}\right) \\
\Delta x & =\text { internodal distance }
\end{aligned}
$$

and the minimum is taken over all pairs of adjacent nodes aligned in the principal direction of the gradient of $F$. A solution of the flow equations (Eq. 1 and 4 ) at the $e^{\text {th }}$ time step is generally stable as long as

$$
1 \leq k \leq N P\left\{\frac{h_{k}^{\ell}-h_{k}^{\ell-1}}{h_{k}^{\ell-1}}\right\} \leq 10^{-4}
$$

is maintained for the current step as well as all previous steps. Moreover, an empirical guideline for assessing the effectiveness of time steps during solution of the temperature equation (Eq. 6) is

$$
1 \leq k \leq N P\left\{\frac{T_{k}^{\ell}-T_{k}^{\ell-1}}{t^{\ell}-t^{\ell-1}}\right\} \leq 10^{-2} .
$$

Time steps chosen so that temporal changes of state variables are within the suggested limits (Eq. 21 and 22) will generally lead to stable results. However, gross undershoot of both criteria (Eq. 21 and 22) may be indicative of computational inefficiency.

Further considerations regarding computational efficiency stem from the need to update the stiffness matrix and load vector during time-stepping. The load vector must be updated at each time step. In the stiffness matrix, the temporal and spatial gradients of the dependent variables are differentiated with respect to themselves. The time derivative reduces to the weighting factor divided by the time-step size, while the spatial derivatives of the dependent variables reduce to spatial derivatives of the weighting function.

For two special cases, all the coefficients of the stiffness matrix are constant. These two cases are isothermal flow and uncoupled heat

conduction. The stiffness matrix will change only when the time-step size is altered. Limiting the frequency of time-step size changes in these cases will significantly improve the efficiency of the simulations. 
In contrast, when both the heat and flow equations are solved, the stiffness matrix must be reformed and inverted at each time step. Moreover, fluid density is thermally dependent, and hydraulic conductivity exhibits a weak temperature dependence due to viscosity changes. Conductivity and density values in the flow equations are updated based on temperatures from the previous time step, a technique known as "quasi-linearization." The diffusion term in the heat equation is linearized by assuming a constant diffusion coefficient, $D_{t}$, throughout the temperature range of interest, but the advection term must still be updated at each time step. Other coefficients are constant over time.

Run-time options described in Section 4.0 determine whether the flow and thermal equations are both being solved and whether they are coupled or uncoupled. The uncoupled solution uses thermal data from the first time step to solve the flow equation at all subsequent times. Groundwater systems vary slowly over time, so the error incurred is usually minimal if the time step is smal1. Computational savings are great. A parametric study of the domain should be implemented, however, before assuming uncoupled simulations are valid.

The simulation time in a transient run can be divided into several time intervals with different time-step sizes. Small time steps may be used when a thermal load is applied or after other abrupt changes in aquifer properties. At each time step, the incremental change in the dependent variables is found for each node. These incremental values are added to the previous time-step results to give the head and temperature values

throughout the domain. State variables and their gradients are then updated based on these new data; thermally dependent coefficients are recalculated; the new matrix and load vector are formed; and the system of equations is solved. This procedure is repeated until the final simulation time is reached.

\subsection{SIMULATION RESTART}

Restart capabilities are particularly useful in simulations that span long time periods relative to the time-step size. The first interval of time steps can be checked for errors before continuing an extensive run. After a given time period, perturbations in the system can be simulated by changing values in the input data file and restarting the run. For instance, changes in fracture permeabilities and apertures could be used to account for other factors such as stress coupling effects.

The user flags the initial run to generate the restart output file by using parameter ICF to specify a logical unit number (LUN). The file so generated will contain data from the last time step completed. When the restart run is started, the LUN entered as ICF is specified as the input file using parameter IRS. 
Note that the data file used as the initial input must be provided in its entirety, but modifications may be made to material properties or other parameters. No modifications may be made to the geometry.

\subsection{EXECUTION CONTROL}

Execution control parameters make up most of the parameters on the second and third input records. These two cards specify items such as the simulation mode, temperature options, moisture (fluid flow) options, type of initial conditions, output specifiers, and all of the LUNs used for files. In several cases, values entered in these records are used later during input to control the number of values to be entered (e.g., the number of nodes or elements). Note that not all the controlling parameters are located in these records. In some cases, they may immediately precede the table of values to be entered.

The LUN or file numbers entered on the third card often serve a dual capacity, e.g., the parameter IRS for restart. If this value is blank or zero, no restart is performed. When IRS is a positive number, it specifies the LUN to be read for restart and simultaneousiy indicates that a restart run is being made.

Details of a11 the input data may be found in Section 4.0 broken down by card type and parameter. Any interaction between control values and input data is fully explained in context.

\subsection{DATA INPUT RECORDS}

The input for MAGNUM-2D consists of a sequence of 80-character "card images." A11 the input is entered in fixed-length fields as defined in the following sections and consists of numeric or alphanumeric (character) data. It is entered in a manner consistent with the conventions of the FORTRAN programming language, of which an abbreviated description will be found in this section.

The input records are divided into a series of fields, each field being a fixed, predetermined number of characters in length. These fields may be used to enter either numeric or alphanumeric data. In the case of numeric data, there are two types: integer and real.

Integer numbers are entered as a string of numerals ( 0 through 9) with no decimal points. They may be preceded by an algebraic sign (+ or -), if required, and should not have any commas or blanks embedded in them. Examples are as follows:

$$
\begin{array}{lr}
\text { - } & 100 \\
\text { - } & -53
\end{array}
$$




$$
\begin{aligned}
& -\quad 0 \\
& -\quad+1025 \text {. }
\end{aligned}
$$

In the descriptions that follow, an integer value is specified by using the FORTRAN editing code of Ixx, where the I stands for integer, and the $x x$ is a number indicating the length of the field that will contain the integer number. Examples are as follows:

- $\quad$ I5 - Integer field 5 digits long

- 110 - Integer field 10 digits long.

All integers entered must fit within the field specified, or erroneous results will occur.

Real numbers can be entered in two forms. The first is called a real fixed-point number and is entered as a string of numerals with a decimal point. If required, they may be preceded by an algebraic sign and should not have any commas or blanks embedded in them. Examples are as follows:

$$
\begin{array}{ll}
- & 3.14159 \\
\text { - } & 2034 \\
\text { - } & -1.0 \\
\text { - } & +2.57
\end{array}
$$

In the descriptions that follow, a real fixed-point value is specified by using the FORTRAN editing code of Fxx.xx, where the $F$ stands for real fixed, and the $x x$ is a number indicating the length of the field that will contain the real number. The $x x$ that follows the decimal point indicates the number of decimal places that will be assumed if no decimal point is entered. Examples are as follows.

- F10.2 - Real number in a field 10 digits long with an assumed decimal point two places to the left of the last digit. A number entered as 1024 will be interpreted as the value 10.24 .

- F10.0 - Real number in a field 10 digits long with no assumed decimal point. A number entered as 1024 will be interpreted as the value 1024.

Al1 numbers entered must fit within the field specified, or erroneous results will occur.

A real floating-point number consists of a string of numerals with a decimal point and may be preceded by a sign (as in the real fixed point number). However, the real floating-point number is followed by an $E$ and up 
to a two-digit number (three digits on some machines) which indicate the power of 10 by which the preceding real fixed-point number should be multiplied to produce the correct order of magnitude. The power of 10 value, called the exponent, may be a signed number as well. Examples are as follows:

$$
\begin{aligned}
& \text { - } 1.24 \mathrm{E} 2=124.0 \\
& \text { - }-10.45 E 4=-104500.0 \\
& \text { - }-45.63 E-4=-0.004563 \\
& \text { - } 3141592 \mathrm{E}-6=3.141592 \text {. }
\end{aligned}
$$

In the descriptions that follow, a real floating-point value is specified by using the FORTRAN editing code of Exx.Xx, where the $E$ stands for floating point, and the $x x$ is a number indicating the length of the field that will contain the number. The $x x$ that follows the decimal point indicates the number of decimal places that will be assumed if no decimal point is entered as follows.

- E10.2 - Real number in a fie1d 10 digits long with an assumed decimal point two places from the right of the last digit. A number entered as 1024 or as $1.024 \mathrm{E} 1$ wi11 be interpreted as the value 10.24 .

- E10.0 - Real number in a field 10 digits long with no assumed decimal point. A number entered as 1024 will be interpreted as the value 1024.

A11 numbers entered must fit within the field specified, or erroneous results will occur.

Alphanumeric (character) data are often entered for titling purposes. These data consist of a string of characters of the users choice, not exceeding the input field length in number. Examples are as follows:

- THIS IS AN EXAMPLE TITLE 24 character string

- anOther line

12 character string.

In the descriptions that follow, an alphanumeric value is specified by using the FORTRAN editing code of $A x x$, where the $A$ stands for alphanumeric, and the $x x$ is a number indicating the length of the field that will contain the characters. Examples are as follows:

- A10 - A field of 10 is available for character input. The characters may be entered anywhere within the field.

All characters entered must fit within the field specified, or erroneous results will occur. 


\subsection{INPUT PREPARATION}

\subsection{INTRODUCTION}

Preparation of input for a MAGNUM-2D simulation consists of a series of interrelated but identifiable steps. These steps are as follows:

1. Construction of a suitably discretized geometric model that takes into account the materials comprising the various regions of the model

2. Definition of the initial and boundary conditions

3. Definition of the material properties

4. Definition of the program control parameters and time-step sequences.

While the following discussion will not follow these points in the order given, each item should be kept in mind to ensure that a complete data set representing the problem is developed.

The actual input data for MAGNUM-2D are entered in a very definite, controlled order. In some cases, data entered early in a data set control the type and quantity of data entered later. Care should be taken to ensure that the values entered in these cases are consistent, since errors of this nature can be difficult to pinpoint.

Al1 the card types available to the user for input are presented and the parameters that are entered on each card are described in Section 4.2 . A summary is given in Section 4.3 of the card types giving FORTRAN variable names, short definitions, field lengths, and input editing codes for easy reference during setup of simulation input. In both sections, the card types are given in order of their occurrence in an input stream.

\subsection{INPUT DATA DESCRIPTION AND DISCUSSION}

A detailed, in-depth description of each input parameter is given in this section. Numbers that appear in parentheses represent allowable values for some parameters that only have a limited number of choices.

Card Type A

Title Card

TITLE - This parameter is a string of up to 80 characters that may be input to describe the analysis. It is limited to one card. This parameter wi 11 be output as part of the header on the MAGNUM-2D printout. 
IMODE - This parameter flags whether the simulation being performed is time dependent (0) or steady-state (1). If steady state is indicated, the input for the dynamic control data below is still required but is ignored in the simulation. No convergence criteria are required.

Data files for transient runs can be used for steady-state runs without modifications. Reset variable IMODE from 0 to 1 , and only one iteration will be taken. Time steps and thermal loads in the input file will be ignored.

ITEMP - This parameter indicates how the temperatures are handled or used. The options are to ignore heat flow calculations (0), to simulate heat flow (1), to uncouple the heat flow/fluid flow calculations (2), and to utilize temperature input without performing the heat flow analysis $(-1)$.

If ITEMP $=0$, the hydrodynamic flow equation is solved without any heat transfer. An initial run of the flow at steady state can be used to determine the initial conditions for transient runs.

If ITEMP $=1$, a coupled thermal-flow simulation is performed. Incremental changes in the dependent variables, head and temperature, are solved by a system of simultaneous equations. The calculated thermal values are used to update the temperature-dependent coefficients in the conductivity matrix and in the load vector at each time step. The coupled simulation requires the most computer time because the matrix to be inverted is large, and it must be updated at each time step.

If ITEMP $=2$, the thermal equation is uncoupled from the flow equation. This can save computer time. The flow equations are solved alone, and the head values are used to solve the thermal equations. At the next time step, the new temperature values are used to update the conductivity matrix and the load vector in the flow equation. The large matrix in the coupled simulation has been broken into two smaller matrices that are solved alternately, thus reducing the computation time.

If ITEMP $=-1$, MAGNUM-2D uses temperature results from a previous run. While thermal fields strongly affect the groundwater flow patterns, the thermal regime is only slightly influenced by the flow. Therefore thermal output from a previous simulation can be used repeatedly in a flow simulation sensitivity analysis.

IMOIST - This parameter indicates how fluid flow will be handled. The options are to simulate fluid flow (1), to ignore fluid flow (0), and to assume steady flow (2) at each time step.

If IMOIST $=0$, the thermal equation is solved without fluid flow. All the thermal transport is by conduction through the rock with no advection. 
If IMOIST $=1$, a hydrodynamic simulation is invoked. The values of IMODE and ITEMP together determine the nature of the hydrodynamic simulation.

If IMOIST $=2$, steady-state flow is computed at each time step, regardless of whether or not the temperature equation is being solved.

NP - This parameter indicates the number of node points needed to define the model used for the current simulation. It is used to control the geometry input later. This value should be entered properly even if the geometry is to be entered from an external geometry file. The nodal point count on the file is checked against it.

NE - This parameter indicates the number of elements needed to define the model used for the current simulation. Later, it is used to control the geometry input. This value should be entered properly even if the geometry is to be entered from a geometry file. The element count on the binary file is checked against it.

NMAT - This parameter indicates the number of different material or rock types that will be used in the model. Later, it is used to control the material data input.

ICND - This parameter indicates the type of initial conditions to be used for this simulation. Two choices are available. The first is to read one input record to define the initial conditions for all node points (0). The second is to read one record for each node (1). This parameter is used to control the type of input needed later.

If the initial conditions are unknown, one card can be used to define all nodes with the same initial value estimate, i.e., ICND $=0$. In steadystate flow problems, the initial head values are unimportant because the algorithm calculates head values at the unknown nodes based on known boundary values. The first few time steps of a transient flow simulation, however, can be influenced by the initial head conditions, so a reasonable estimate is needed. A steady-state, flow only run, with variable ICND $=0$ and file unit ICSV specified, can be used to generate and save head values. The ICSV file may then be used for initial condition input in a subsequent transient run.

In contrast, initial temperature values are important in both steadystate and transient heat problems. The density and viscosity are based on these reference values. One initial condition card can be used, but the temperature chosen should be representative of the system (alternatively, see TREF). If file unit ICSV is specified, the data from a steady-state, heat flow only simulation can be used as the initial conditions in a transient run. 
Initial condition files can also be created by a preprocessor program ICGEN. The ICGEN or ICSV initial condition file must be inserted into the data deck at the appropriate location (see card type $\mathrm{J}$ ). To signal that there is one initial condition card per node, set ICND $=1$.

IECH - This parameter controls the echoing or parroting of the input data. The choices are to echo only part of the data (0) or all the data (1).

If $\mathrm{IECH}=0$, the principal problem specifications, specified boundary conditions, rock hydraulic properties, and heat generation history will be printed in tabular form. If $\mathrm{IECH}=1$, the input geometry, initial conditions, and element connectivity will be printed in addition to the above default output.

IALL - This parameter controls the diagnostic printout available during the simulation. Either no printout is available (0) or a listing of data showing convergence may be obtained (1).

If $\mathrm{IALL}=1$, the maximum change in head or temperature is printed at each time step. Extremely large changes might indicate instability in the solution. The maximum change in state variables may also be used as a convergence criteria. If the value is close to zero for several time steps, the transient problem has probably reached steady state. This information is useful, e.g., in convection ce 11 simulations with a constant heat source. The default of IALL $=0$ provides none of the above output.

IVELP - This parameter controls the printout of the velocities at each Gauss point. The user may choose no printout (0) or printout for all the nodes (1). Regardless of the choice, the data will still be written to the binary velocity output file specified as IVEL.

IPRT - This parameter controls the frequency of output to the binary results file specified as ISV. The output may be generated at each time step (0), or at the print frequency specified below (1). A choice of (0) may result in a very large file being produced, since many time steps may occur for a simulation to finish and the data for each node will be written each time step. A choice of (1) will cause the output to the binary file to correspond to the printed output.

NSYS - This parameter controls the type of coordinate system to be used in defining the simulation model. The choices are Cartesian (0) or radial about the $y$ axis (1).

Card Type C

File Assignments

The MAGNUM-2D computer code is designed to allow data to be read from or written to a mass storage device. To te 11 the program where to read or write, the user must provide the LUNs of the files that are being used. 
Each system will have a slightly different way of associating LUNs with files so the system documentation should be consulted for advice on how to accomplish this. The default input unit (defined internally) is IC $=5$, and the output unit is IOUT $=6$.

IRS - This logical unit is used as the input file for restarting a simulation. The file should be the one specified as ICF (see below) in the previous run. Note that for restarting a simulation, all the data must be re-input, but some may not be used.

ISV - This logical unit is used to save the results of the simulation for later processing. It contains the heads and/or temperatures generated and is designed to be used by the various postprocessors available for MAGNUM-2D. The data is saved on this file at the time-step frequency specified by parameter IPRT discussed previously.

ICF - This logical unit is used to save the data necessary to restart the simulation at a later time. It is the file that is used as IRS when restarting.

IGI - This logical unit is used as input for the geometry that has been created using a preprocessor or has been saved (see below) from a previous simulation using the same model. This file may be a binary or coded file. If the initial attempt to read as a coded file fails, a binary read is used. Binary files are recommended to reduce $I / 0$ time.

$\underline{I G}$ - This logical unit is used to save the geometry defined in the current simulation for later use. It could be used as IGI (see above) when needed.

IVEL - This logical unit is used to save the data necessary for computing the velocity field. Its intended use is for the PATH program, but other postprocessors may also utilize it. The contents of this file are material properties (with corrections due to temperatures), density disparity, and head values at each time step.

The Darcy velocities can be calculated by interpolation at any interior point of an element. The sister program CHAINT uses this file as input to the solute transport simulation. Several postprocessor graphics programs use the IVEL file; e.g., the VELPLT program plots the velocity vector field, and the program PATH can be used to plot the streamlines or the pathlines of the flow field.

INPT - This logical unit is used as input for the temperature field generated by another simulation. Its format is the same as the ISV file (see above) allowing the results of an earlier temperature simulation to be used as input. MAGNUM-2D will use the precalculated temperatures in the INPT file for the current flow simulation. IMOIST must equal one when this option is used. 
ICSV - This logical unit is used to save the final conditions of temperature and head calculated at the end of the current simulation as a coded file so that they can be edited into data for a later simulation. Refer to the parameter ICND when this data is to be used in a later run.

\section{Card Type D}

\section{Constants Definition}

SSF - This parameter specifies the starting time for the simulation. It is typically set to 0.0. Restarted simulations will automatically start at the ending time of the previous run.

ALFA - This parameter specifies the weighting factor, $\theta$, to be used in the simulation. It should be a value between 1 and 2 , i.e., $1<\theta<2$. The time derivatives of the dependent variables are approximated by the difference expression (Eq. 15). When $\theta=1$, the expression is a backward difference of the fully implicit kind with maximum damping. The CrankNicolson approximation is invoked when $\theta=2$. A commonly used value for $\theta$ is 1.8 .

TREF - This parameter specifies the reference temperature to be used when calculating the initial densities and viscosities from the reference density and viscosity respectively (as long as TREF >0.05).

Using this parameter, the user may specify a reference temperature that is different than the starting temperature and correctly model the buoyancy/viscosity effects. The properties of viscosity and density are modeled as a one-dimensional Hermitian expansion as are the coupling coefficients. The temperature range is from $0.0-300.0{ }^{\circ} \mathrm{C}$

\section{Card Type E Dynamic Control Card}

This card type is used to specify the time-step information for the simulation. The total time for the simulation is broken into intervals that are arbitrary in length and are in turn further broken into equally sized time steps. This scheme for variation of time step size allows the user to tailor MAGNUM-20 to each problem. After perturbations occur in the model, small time steps allow adaptation to rapid changes. Larger time steps are adequate when the model response is slow.

NTS - This parameter specifies the number of time steps to be used in a specific time interval. Typically, the user would specify more time steps of shorter duration for those time intervals suspected of having more variation in the heads and/or temperatures. 
NTSG - This parameter specifies the frequency at which the results of the simulation will be printed; i.e., every NTSG time steps a printout of the current results will be created. As an example, consider NTS = 25 and NTSG $=4$. The results will be six printouts corresponding to the time steps $4,8,12,16,20$, and 24 .

DLT - This parameter specifies the actual time allotted to each time step. It is specified in years. As an example, consider the previous example of NTS $=25$ and NTSG $=4$. If $D L T=10.0$, then the time interval will be $250 \mathrm{yr}$ long ( 25 time steps of $10.0 \mathrm{yr}$ each) and will have printout corresponding to $40,80,120,160,200$, and $240 \mathrm{yr}$.

\section{Card Type F Control Factors}

SCALEX - This parameter allows the user to apply a uniform scale factor to the $x$-dimensions of a model without having to modify the input data.

SCALEY - This parameter allows the user to apply a uniform scale factor to the y-dimensions of a model without having to modify the input data.

In order to decrease the amount of time needed to complete the simulation but maintain accuracy in the region of greatest variation, the elements in the mesh may be split into two groups by using the following parameters to define a zone. Within this zone, the elements will use a quadratic-shape function, while outside it, the elements will use a linearshape function.

ZONEL - This parameter specifies the left boundary for the quadratic zone and is given in meters.

ZONER - This parameter specifies the right boundary for the quadratic zone and is given in meters.

ZONET - This parameter specifies the top boundary for the quadratic zone and is given in meters.

ZONEB - This parameter specifies the bottom boundary for the quadratic zone and is given in meters.

If these four parameters are entered as zeros or are left blank, the state variables will be approximated with quadratic-shape functions over all elements.

Card Type G Element (connectivity) Definition

This card type should be omitted if a data file is being used for geometry input, i.e., if IGI is nonzero on card type C. The number of sets of the following parameters should correspond to the value entered for NE (number of elements) on card type $B$. 
$\underline{J}$ - This parameter specifies the element number being entered. The element numbers are used as indices to arrays, so they must be contiguous starting with one, but need not be entered in any specific order.

NOP - This parameter specifies the node numbers that define the element. There may be up to eight nodes per element, and they must be entered counterclockwise starting from any corner node. If a quadraticshape function element is being specified, a11 eight nodes must be entered. If only the four corner nodes are entered (with the midside node entries being blank or zero), then a linear-shape function element is assumed. If a triangular element is needed, it may be specified in a similar manner by entering six nodes for a triangular quadratic element or the three corner nodes (with blank or zero midside nodes) for a linear quadratic element. Line elements are entered in a similar fashion; the choices being either three nodes for a quadratic-shape function or two nodes for a linear-shape function. (See Section 3.2.)

IMAT - This parameter specifies the material type used for this element. It must correspond to one of the material types defined on the following type $M$ cards.

NFIXH - This parameter specifies the order in which this element will be considered during the solution phase of the simulation. These values may be input by the user but are typically modified by one of the preprocessors which optimizes the model geometry.

Card Type $\mathrm{H} \quad$ Coordinate (Geometry) Definition

This card type should be omitted if a data file is being used for geometry input, i.e., if IGI is nonzero on card type $C$. The number of sets of the following parameters should correspond to the value entered for NP (number of node points) on card type B.

$\underline{N}$ - This parameter specifies the number of the node being entered. Like the elements, the nodes need not be entered sequentially; but node numbers must be contiguous and start with one.

$\operatorname{CORD}(N, 1)$ - This parameter specifies the $x$-coordinate of the node in global coordinates.

$\operatorname{CORD}(N, 2)$ - This parameter specifies the $y$-coordinate of the node in global coordinates.

Card Type J

Initial Condition Definition

The use of this card type is controlled by the variable ICND, which was entered on card type $B$. Two modes of use exist. If ICND $=0$, a single card of this type is used to define the initial conditions for head and/or 
temperature for every node in the mode1. If ICND $=1$, MAGNUM-2D expects to find one initial condition card, as described here, for each node in the mode 1 .

Note that if a restart simulation is being performed, the initial condition specification must be present for the restart run to be valid.

$\underline{N}$ - This parameter specifies the node for which the initial condition is being entered. This parameter is ignored if ICND $=0$.

T1 - This parameter specifies the temperature to be used initially for the node(s) in question. It is entered in degrees Celsius.

T2 - This parameter specifies the hydraulic head to be used initially for the node(s) in question. It is entered in meters.

Card Type K1 Dirichlet Boundary Condition Nodes nodes.

A zero flux Neumann condition is assumed at all unspecified boundary

KSPEC - This parameter specifies the number of nodes at which constant head and/or temperature boundary conditions will be specified.

Card Type K2 Dirichlet Boundary Condition Values

The number of sets of the following parameters is controlled by the value entered for KSPEC above. One set is entered for each node at which a boundary condition is to be specified.

$\underline{N}$ - This parameter specifies the node number at which the boundary condition is being specified.

NFIX - This parameter specifies the type of boundary conditions being specified. It consists of a two-digit integer number that may have a one entered in either place. A one entered in the tens place indicates that a temperature value is being entered while a one in the ones place indicates that a hydraulic head value is being entered.

BVAL(1) - This parameter specifies the actual boundary condition value to be used for temperature at the node in question. It is specified in degrees Celsius.

BVAL(2) - This parameter specifies the actual boundary condition value to be used for hydraulic head at the node in question. It is specified in meters. 
As an example of the boundary condition specifications, consider the following example card images:

$\begin{array}{llll}13 & 10 & 103 . & 11 . \\ 28 & 01 & & 5.7 \\ 57 & 11 & 95 . & 10.6\end{array}$

The first entry specifies the boundary condition for Node 13 as temperature only (10), indicating a value of $103.0{ }^{\circ} \mathrm{C}$. The second entry specifies the boundary condition for Node 28 as head only (01) with a value of $5.7 \mathrm{~m}$. The last entry specifies the boundary conditions for Node 57 as temperature and head $(11), 95.0^{\circ} \mathrm{C}$ and $10.6 \mathrm{~m}$, respectively.

Note that in the first entry, even though a value is entered for head or temperature (in this case head), unless the appropriate flag is set, that value will be ignored.

\section{Card Type M Material Properties}

This card type set defines the properties of the materials comprising the model $(a)$. The number of material properties to be specified was entered on card type B as NMAT. Each entry must consist of two cards, so the number of material property definition cards must be NMAT*2. Note that some of the properties are anisotropic. If this capability is not required, specify the property to be the same in both directions.

The Card 1 parameters are as follows.

$\underline{L}$ - This parameter specifies the material type number. This is the number $\bar{r}$ referred to in the element definition as IMAT.

CVM - This parameter specifies the specific heat of the rock, $C_{S}$, for this material type in joules per kilogram-degree Celsius $\left[\mathrm{J} /\left(\mathrm{kg}^{\circ}{ }^{\circ} \mathrm{C}\right)\right]$.

$\operatorname{TKK}(L, 1)$ - This parameter specifies the thermal conductivity of the rock in the $x$-direction, $D_{S x}$, for this material type in joules per secondmeter-degree Celsius $\left[\mathrm{J} /\left(\mathrm{s} \cdot \mathrm{m} \cdot{ }^{\circ} \mathrm{C}\right)\right]$.

$\operatorname{TKK}(L, 2)$ - This parameter specifies the thermal conductivity of the rock in the $y$-direction, $D_{s y}$, for this material type in joules per secondmeter-degree Celsius $\left[\mathrm{J} /\left(\mathrm{s} \cdot \mathrm{m} \cdot{ }^{\circ} \mathrm{C}\right)\right]$.

(a) In this context material properties are synonymous to rock properties in that the saturating fluid is assumed to be water and the reference water properties are hard coded with the following values: $\rho^{\star}=985 \mathrm{~kg} / \mathrm{m}^{3}$, $\mathrm{C}_{f}=4174 \mathrm{~J} /\left(\mathrm{kg} \cdot{ }^{\circ} \mathrm{C}\right), D_{f}=2.008 \times 10^{7} \mathrm{~J} /\left(\mathrm{m} \cdot \mathrm{yr} \cdot{ }^{\circ} \mathrm{C}\right)$, and the compressibility of water is $4.6 \times 10^{-10}$ Pascals. 
POROS(L) - This parameter specifies the effective porosity, $\phi$, of the rock for this material type. It is a dimensionless number.

HKAX - This parameter specifies the hydraulic conductivity in the $x$-direction, $K_{x x}$, for this material type in meters per second $(\mathrm{m} / \mathrm{s})$.

HKAY - This parameter specifies the hydraulic conductivity in the $y$-direction, $k_{y y}$, for this material type in meters per second $(\mathrm{m} / \mathrm{s})$.

NME - This parameter may be used to assign a name to this rock type. It is optional and may be up to eight characters in length. It is printed with the echoed data.

The Card 2 parameters are as follows.

$S P 1$ - This parameter specifies the specific storage, $S_{S}$, of this material type. Its units are $1 / \mathrm{m}$.

RHOM - This parameter specifies the bulk density, $\rho_{S}$, of this material

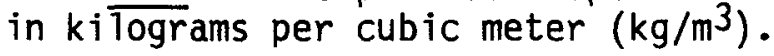

ALPAL - This parameter specifies the longitudinal dispersivity, $\alpha_{L}$, of this material in meters $(m)$.

ALPAT - This parameter specifies the transverse dispersivity, aT, of this material in meters $(m)$.

WIDTH - This parameter specifies the thickness or width of fractures, $e$, used in the model. It is used only for fracture elements and must be zero for continuum elements. It is specified in meters $(m)$.

Card Type $P$

Thermal Loading Control

This card type must exist for every simulation. If no thermal loads are applied, this is indicated using the parameter NLD as described below. Flow only simulations automatically ignore any thermal data.

Note also that no thermal loads are allowed for a steady-state run. An i11-formed problem may result if this is attempted.

NLD - This parameter specifies the number of elements in the model that will be considered as heat source elements. If no thermal loads are to be applied to the model, this parameter should be entered as a zero or a blank card.

NLT - This parameter specifies the number of thermal load data points, i.e., the number of times and corresponding loads that will be input. This parameter is ignored if NLD $=0$ above. For a transient problem, if $N L T=0$, a piecewise exponential decay will be applied to the single initial thermal load defined on card type R1 below. The decay function is given in Equation 19. In this case FORTRAN variable QT contains the current source strength. 
SCF - This parameter specifies a scale factor that is applied to the thermal load values. This parameter is ignored if NLD $=0$ above.

\section{Card Type 0}

Heat Source Elements

This card type is ignored if $N L D=0$ on card type $P$.

NLE(I) - This parameter specifies the element numbers of the elements that are to be considered as the heat sources in the model. The number of these elements is controlled by the parameter NLD on card type P above. Each record (or line) may contain at most 16 fields, and the records may be repeated as many times as needed.

Card Type R1

Initial Thermal Load Definition for Exponential Decay

This card type is ignored if NLD $=0$ on card type $P$, and is only used if $N L T=0$ and $N L D \neq 0$.

Q0 - This parameter specifies the initial thermal load, $Q^{\circ}$, to be used for the exponential decay for all the elements entered in card type $Q$. It is given as joules per year-cubic meter $\left[\mathrm{J} /\left(\mathrm{yr} \cdot \mathrm{m}^{3}\right)\right]$.

\section{Card Type R2}

\section{Thermal Load Definition}

This card type is ignored if NLD $=0$ on card type $P$, and is only used if $N L T \neq 0$ and NLD $\neq 0$.

The loading is specified by defining a set of points in time at which the thermal load is known. The range of times input must bracket or coincide with the range covered by the simulation. Any times used by the simulation but not input are interpolated as long as the input times bracket the time required. Thus, this interpolation requires that a minimum of two time/load pairs be input.

TLE(I) - This parameter specifies the time of the thermal load being entered for the next parameter. It is given in years $(y r)$.

QLE(I) - This parameter specifies the thermal load for the time entered above in joules per year-cubic meter $\left[\mathrm{J} /\left(\mathrm{yr} \cdot \mathrm{m}^{3}\right)\right]$.

These time and load values are input in pairs, up to four per card, until NLT values have been entered. Recall that NLT was defined as the number of thermal loads on card type $P$ above. Repeat this card type as many times as needed. 
4.3 INPUT DATA FORMAT SUMMARY

Card Type A

1-80 TITLE

$20 A 4$

Card Type B

01-05 IMODE

I5

06-10 ITEMP

11-15 IMOIST

I5

16-20 NP

I5

21-25 NE

I5

26-30 NMAT

I5

31-35 ICND

I5

36-40 IECH

I5

41-45 IALL

I5

I5
Title Card

Title or description of this analysis, up to 80 characters.

\section{Control Parameters}

Simulation Mode

$=0$ Time-dependent analysis.

$=1$ Steady-state analysis.

Temperature Option

$=0$ No heat flow in this analysis.

$=1$ Temperature simulation.

= 2 Temperature simulation uncoupled from fluid flow (i.e., $q_{i} \frac{\partial T}{\partial x_{i}}=0$ ).

$=-1$ Temperature input from external file.

Fluid Flow Option

$=0$ No fluid flow simulation.

$=1$ Fluid flow simulation.

$=2$ Steady-state flow simulation at each time step.

Number of Nodes in the Model

Number of Elements in the Model

Number of Rock Types in the Model

(Number of Material Types)

Initial Condition Type

$=0$ Read only one card to define ICs.

$=1$ Read one card per node to define ICs.

Input Bata Echo Switch

$=0$ Echo selected portion of the input data.

$=1$ Echo all the input data.
Diagnostic Printout

$=0$ Display no diagnostics.

$=1$ Print diagnostics regarding convergence. 
46-50 IVELP

51-55 IPRT

56-60 NSYS

Velocity Print Control (IMOIST $\neq 0$ only)

$=0$ Do not print velocities.

$=1$ Print velocities.

Binary Results File (ISV) Creation Flag

$=0$ Write at each time step.

$=1$ Write at the print frequency requested by the user (NTSG below).

Coordinate System Control

$=0$ Cartesian coordinate system used.

$=1$ Radial coordinate system used (radial about the $X=0$ line: Y axis).

Card Type C

01-05 IRS

File Assignments

Restart input data file (generated by an earlier MAGNUM-2D run.

06-10 ISV

Binary results file (contains head and temperature results for each node in the mode 1).

11-15 ICF

Restart output data file (to be generated for use by a later MAGNUM-2D run).

16-20 IGI

Geometry input file (optional and supersedes the geometry input parameters requested later).

21-25 IG

I5

Geometry output file. The input geometry data is written to this binary file for subsequent use.

26-30 IVEL

Velocity output file. This binary file may be used as input for the PATHLINE program (see the appendixes for more information) or other postprocessing.

31-35 INPT

Temperature input file.

36-40 ICSV

Initial condition output file. The state of the simulation is written (in coded form) to this file for subsequent use as an initial condition file. 
Card Type D

01-10 SSF

11-20 ALFA

21-30 TREF

Card Type E

01-05 NTS(I)

I5

06-10 NTSG(I)

11-20 DLT(I)

Card Type F

01-10 SCALEX

11-20 SCALEY

21-30 ZONEL

31-40 ZONER

41-50 ZONET

51-60 ZONEB

Card Type G
Constants Definition

F10.1 Initial time, $t^{\circ}$ (in $y r$ ).

F10.1 Weighting factor $(1<\theta<2)$.

F10.1 Temperature for computing reference densities and viscosities. Set $\mathrm{TREF}=0.0$ to use initial temperature distribution, instead of TREF.

Dynamic Control Card

(This card is repeated as needed. Terminate this card type set with NTS=9999.)

Number of time steps.

I5 Printout frequency.

F10.1 Time steps in years.

\section{Control Factors}

F10.1 Scale factor for the x-coordinates.

F10.1 Scale factor for the $y$-coordinates.

F10.1 Left boundary for quadratic element generation zone.

F10.1 Right boundary for quadratic element generation zone.

F10.1 Top boundary for quadratic element generation zone.

F10.1 Bottom boundary for quadratic element generation zone.

Element (connectivity) Definition

The number of cards for this card type set is controlled by the parameter NE defined earlier. OMIT this card type set if a geometry input file is used, $i . e$. , if IGI is NOT equal to zero. 


\begin{tabular}{|c|c|c|c|}
\hline $01-05$ & J & I5 & Element number. \\
\hline $06-45$ & $\operatorname{NOP}(J, K)$ & 815 & $\begin{array}{l}\text { Up to eight node numbers for elements } \\
\text { listed counterclockwise. }\end{array}$ \\
\hline $46-50$ & $\operatorname{IMAT}(\mathrm{J})$ & I5 & $\begin{array}{l}\text { Element type (material type). The number } \\
\text { entered must correspond to one of the } \\
\text { parameters specified as } L \text { under card } \\
\text { type } M \text { below. }\end{array}$ \\
\hline $51-55$ & NFIXH(J) & I5 & $\begin{array}{l}\text { Element ordering array. This parameter } \\
\text { is the number of the jth element to } \\
\text { process and may be used to optimize the } \\
\text { solution of the matrix equations by } \\
\text { modifying the bandwidth. }\end{array}$ \\
\hline \multicolumn{3}{|c|}{ Card Type $\mathrm{H}$} & Coordinate (Geometry) Definition \\
\hline & & & $\begin{array}{l}\text { The number of cards for this card type } \\
\text { set is controlled by the parameter NP } \\
\text { def ined earlier. OMIT this card type set } \\
\text { if a geometry input file is used, i.e., } \\
\text { if IGI is NOT equal to zero. }\end{array}$ \\
\hline $01-05$ & $N$ & I5 & Node number. \\
\hline $06-17$ & $\operatorname{CORD}(N, 1)$ & F12.3 & $x$-coordinate (in $\mathrm{m}$ ). \\
\hline $18-29$ & $\operatorname{CORD}(N, 2)$ & $\mathrm{F} 12.3$ & $y$-coordinate (in $m$ ). \\
\hline \multicolumn{3}{|c|}{ Card Type J } & Initial Condition Definition \\
\hline $01-10$ & $N$ & 110 & $\begin{array}{l}\text { Node number (not used if ICND }=0 \text { as } \\
\text { discussed earlier on card type B). }\end{array}$ \\
\hline $11-20$ & $\mathrm{~T} 1$ & F10.1 & Temperature $\left(\right.$ in $\left.{ }^{\circ} \mathrm{C}\right)$ ). \\
\hline $21-30$ & $\mathrm{~T} 2$ & F10.1 & Hydraulic head (in $\mathrm{m}$ ). \\
\hline \multicolumn{4}{|c|}{$\begin{array}{l}\text { Note that if ICND }=0 \text {, only one card of this type is required. It will } \\
\text { define the initial head and temperature at all nodes. If ICND }=1 \text {, then, } \\
\text { NP cards of this type must be supplied (one for each node). }\end{array}$} \\
\hline \multicolumn{3}{|c|}{ Card Type K1 } & Dirichlet Boundary Condition Nodes \\
\hline $01-05$ & KSPEC & I5 & $\begin{array}{l}\text { Number of nodes at which boundary } \\
\text { conditions will be specified. }\end{array}$ \\
\hline
\end{tabular}


Card Type K2

$01-10 \quad N$

19-20 NFIX

21-30 BVAL(1)

31-40 BVAL(2)

Card Type $M$

01-10 L

$11-20 \quad$ CVM

21-30 TKK $(L, 1)$

31-40 TKK $(L, 2)$

41-50 POROS(L)

51-60 HKAX

61-70 HKAY

73-80 NME

11-20 SP1

21-30 RHOM

31-40 ALPAL
Dirichlet Boundary Condition Values

I10 Node number.

I2 Specified value node type indicator. This is a two-digit number, where the tens place represents temperature, and ones place represents hydraulic head. 0 = >unspecified, 1 = > specified.

F10.1 Specified temperature (in ${ }^{\circ} \mathrm{C}$ ).

F10.1 Specified hydraulic head (in $\mathrm{m}$ ).

Material Properties.

There will be twice NMAT cards in this card type set where NMAT was defined earlier on card Type $A$ as the number of material types.

I10 Material type number.

F10.1 Specific heat, $C\left[\right.$ in $\left.J /\left(\mathrm{kg} \cdot{ }^{\circ} \mathrm{C}\right)\right]$.

F10.1 Thermal conductivity in the $x$-direction, $D_{S x}\left[\right.$ in $\left.\mathrm{J} /\left(\mathrm{s} \cdot \mathrm{m} \cdot{ }^{\circ} \mathrm{C}\right)\right]$.

F10.1 Thermal conductivity in the $y$-direction, $D_{\text {sy }}\left[\right.$ in $\left.\mathrm{J} /\left(\mathrm{s} \cdot \mathrm{m} \cdot{ }^{\circ} \mathrm{C}\right)\right]$.

F10.1 Effective porosity, $\phi$ (fraction).

F10.1 Hydraulic conductivity in the $x$-direction, $K_{x x}$ (in $\left.\mathrm{m} / \mathrm{s}\right)$.

F10.1 Hydraulic conductivity in the $y$-direction, $k_{y y}($ in $\mathrm{m} / \mathrm{s}$ ).

A8

Material type name identifier (optional).

Begin the Second Card

F10.1 Specific storage, $S_{S}(1 / m)$.

F10.1 Bulk density, $\rho_{S}\left(\right.$ in $\left.\mathrm{kg} / \mathrm{m}^{3}\right)$.

F10.1 Longitudinal dispersivity, $\alpha_{L}$ (in $m$ ). 
$\begin{array}{ll}41-50 & \text { ALPAT } \\ 51-60 & \text { WIDTH }\end{array}$

Card Type P

01-05 NLD

06-10 NLT

11-20 SCF

\section{Card Type 9}

01-80 NLE

Card Type R1

01-10 Q0

Card Type R2

01-10 TLE(1)

11-20 QLE(1)
F10.1 Transverse dispersivity, $\alpha_{T}$ (in $\mathrm{m}$ ).

F10.1 Fracture thickness (in m).

Thermal Loading Control

This card type must be entered whether thermal loading is being specified or not.

I5

Number of heat source elements. $N L D=0$ indicates that no loading will occur.

I5

Number of thermal load points to be specified. Ignore if $N L D=0$.

F10.2 Scale factor. Ignore if NLD $=0$.

Heat Source Elements

Omit this card type if parameter NLD $=0$ on card type $P$.

Element number to which heat sources are applied (16 values may be entered on a single card). There must be NLD values entered where NLD was defined on the previous card. This card type may be repeated as many times as needed.

Thermal Load Definition

Omit this card type if parameter NLD $=0$ on card type $P$.

F10.0 Initial thermal load, $Q^{\circ}\left[\mathrm{J} /\left(\mathrm{yr} \cdot \mathrm{m}^{3}\right)\right]$.

Thermal Load Definition

Omit this card type if parameter NLD $=0$ on card type $P$.

F10.0 Time of thermal load, $t^{1}(\mathrm{yr})$.

F10.0 Thermal load at this time, $Q^{1}\left[\mathrm{~J} /\left(\mathrm{yr} \cdot \mathrm{m}^{3}\right)\right]$. 


\begin{tabular}{|c|c|c|c|}
\hline $21-30$ & $\operatorname{TLE}(2)$ & $\mathrm{F} 10.0$ & Time of second thermal load point, $t^{2}$. \\
\hline $31-40$ & $\mathrm{QLE}(2)$ & F10.0 & Thermal load, $Q^{2}$, at the time $t^{2}$. \\
\hline $41-80$ & & & $\begin{array}{l}\text { Continue entering time and load input } \\
\text { in pairs, up to four per card, until NLT } \\
\text { values have been entered. Repeat this } \\
\text { card type as many times as needed. } \\
\text { NLT was def ined as the number of thermal } \\
\text { loads on card type } P \text { above. }\end{array}$ \\
\hline
\end{tabular}

\subsection{OUTPUT}

\subsection{INTRODUCTION}

The output from the MAGNUM-2D program is available in two forms. The first is the printed output that reports on the input data, the parameters that were set, the events that took place during execution, the heads and temperatures calculated at the various time steps, the duration of the run (in model time), and so on. The second form of output is composed of the various binary data files that are created for use by postprocessing programs and further analys is by other simulation programs such as CHAINT. This section will give an overview and some explanation of the printed report and the possible use of each of the binary files.

\subsection{PRINTED REPORT}

The MAGNUM-2D program generates one printed report file. The contents of this report may be modified by the input data using the parameters IECH, IALL, and IVELP, which appear on card type B. These parameters are described in Sections 4.2 and 4.3. Their effects will be pointed out in the following discussion.

For examples of the output report, see Appendix $D$.

\subsubsection{Banner Page}

The formatted report begins with a banner page that announces (1) the version and revision of MAGNUM-2D, (2) the day, date, and time of the run that generated the printout, and (3) the unique identifier assigned to the run. This identifier is placed on all the mass storage files and is displayed by the graphics postprocessors. It acts as an "audit" trail, allowing the user to ensure a match between printout and graphic results. 


\subsubsection{Input Verification}

The next section of the output is the input verification section, which is divided into output "Tables." Note that in the output tables, temperature and head values are given in degrees Celsius and meters, respectively. As a reminder, column headers are $T(C)$ for temperature and $H(M)$ for head.

The "PRINCIPAL PROBLEM SPECIFICATIONS" are printed in output Table 1. This is an echo of the parameters input on card types B, C, F, D, and $E$. The card types are echoed in the order just given, and the parameters on each card type are echoed in the input order (see Section 4.2).

The "NODE POINT COORDINATES" are printed in output Table 2. This is an echo of the node point locations as defined for the problem. It is simply a table of node numbers and the corresponding $x$ - and $y$-coordinates. This table is not produced if IECH $=0$.

The "ELEMENT/NODE CONNECTIVITY" is printed in output Table 3 . This is an echo of the connectivity defined for the problem, e.g., the node numbers that define the corner and midside nodes of the elements defining the model. It is simply a table of element numbers and the corresponding node numbers that define the element (up to the maximum of eight nodes). These are given in the order that MAGNUM-2D encountered them. Note that the table also includes the rock type and the order used in solving the matrix equations. (This may be modified or defined manually or by using a geometry preprocessor such as MESHER.) This table is not produced if IECH $=0$.

The "INITIAL CONDITIONS" are printed in output Table 4 . This is an echo of the initial conditions defined by the user or generated by MAGNUM-2D at the request of the user on card type $\mathrm{J}$. It consists of a list of the node numbers at which the initial conditions are defined, and the temperature and head values are specified at those nodes. This table is not produced if $\mathrm{IECH}=0$.

The "SPECIFIED BOUNDARY CONDITIONS" are printed in output Table 5. This is an echo of the Dirichlet boundary conditions input on card type K1 and K2. It contains the node at which the boundary condition is applied, the type (using the same code as specified on input for temperature, head, or both), and the temperature and head input.

The "ROCK PROPERTIES" are printed in output Table 6. This is an echo of the properties input on card type $M$. The entries in this table are arranged in a two-dimensional array. The rows represent the actual properties (identified by name and units), and the columns represent the various rock or material types (identified by number and by user defined name).

The "HEAT GENERATION HISTORY" is printed in output Table 7. This is an echo of the thermal loading and heat source information input on card types $P, Q$, and $R$. The card types are echoed in the order just given, and the parameters on each card type are echoed in the input order (as described in Section 4.2 ). 


\subsubsection{Simulation Results}

The title entered by the user on card type $A$ is printed in the upper left corner of each page of simulation results. The next line announces the results time in years, or that the results are for steady state. The table that follows gives the head and/or temperature values for each node point in the mode1. The user will note asterisks occurring beside some of the head/temperature values. These mark the specified boundary conditions.

If the user specified $I A L L=1$ diagnostic output will be printed. This consists of some convergence criteria, namely, the iteration number, the maximum change in the temperature/head value, and the maximum relative correction made.

When MAGNUM-2D reaches a time step for which velocity output has been requested and IVELP $=1$, the velocity results are printed. This output takes the form of a two-dimensional matrix with the rows representing the elements (with the $x$ and $y$ velocities as subdivisions) and the columns representing the Gauss points.

\subsubsection{Gauss Point Locations}

Occasionally, it is necessary to consider the velocity distribution within a single element. Because the velocities are computed from heads interpolated to the Gauss points, the Gauss point locations are of interest. The location of the points in the three element types and their numbering relative to the node point numbering order are shown in Figures 1 and 2 .

The actual location of each of the Gauss points is given in Figure 4 for the case of quadratic-shape functions.

\subsection{OTHER OUTPUT FILES}

The input/output file LUNs are all specified on card type C, "File Assignments." The parameters associated with output files are ISV, ICF, IG, IVEL, AND ICSV. The use of some of these files may be clarified by the data flow diagrams in Appendix A. Each of the above files is a binary file, except as noted otherwise.

ISV MAGNUM-2D Flow and Temperature File. It contains both the head and temperature values at each node for each user-specified time step. This data may be used to generate contours, time-histories, and spatial cross sections. 
(a)

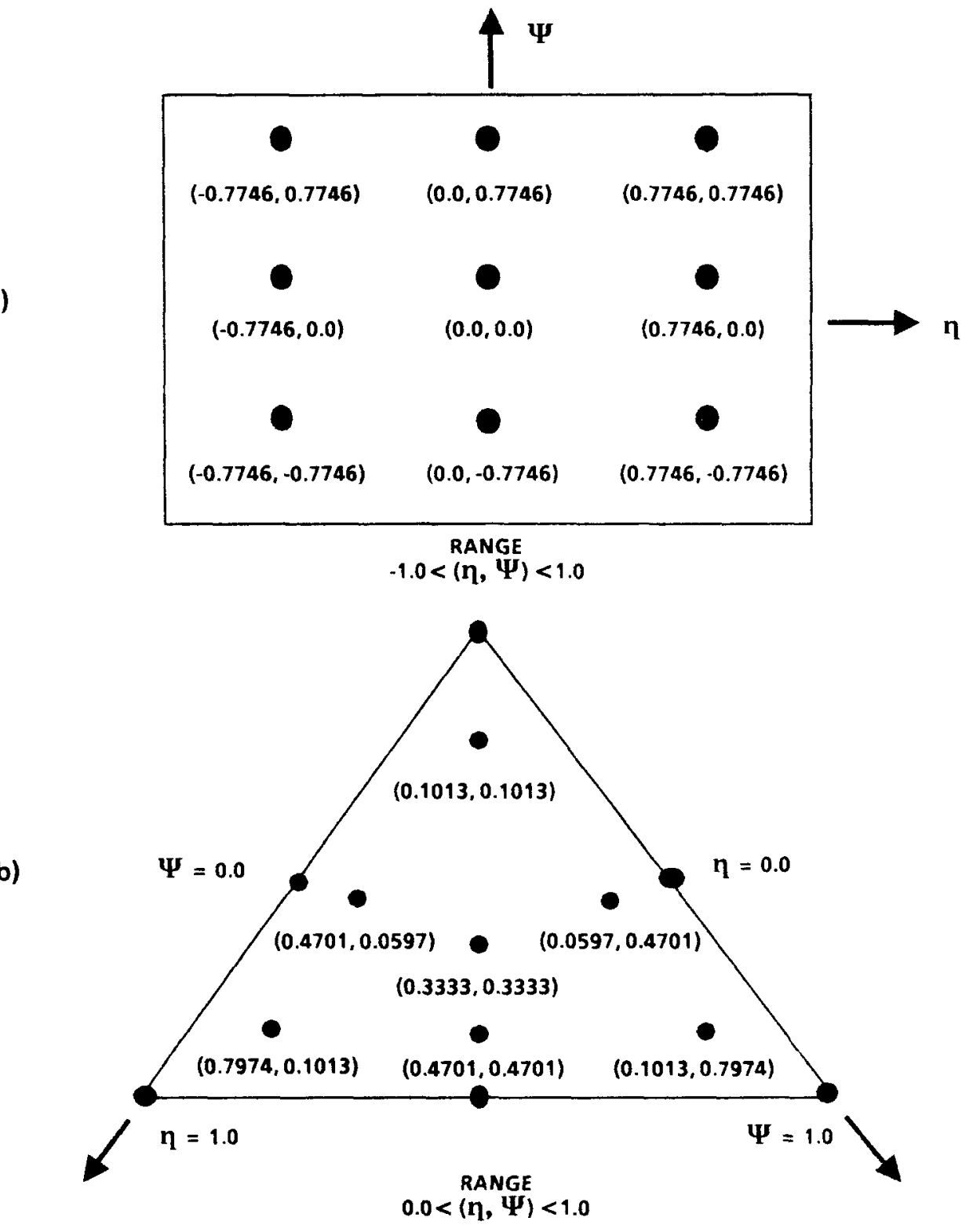

(b)

(c)

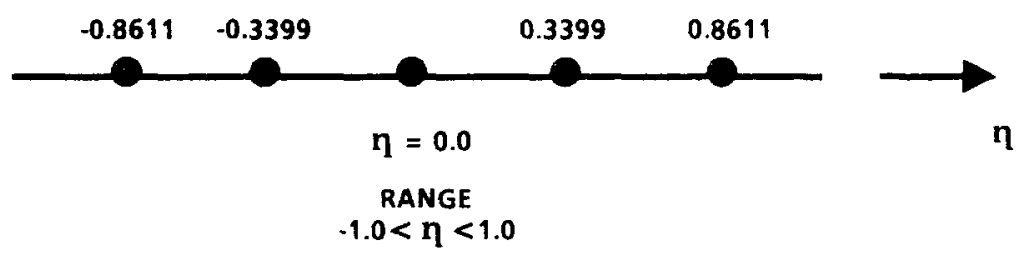

FIGURE 4. Gauss Points in Local Coordinates $n, \Psi$ for (a) Quadratic Quadrilateral, (b) Quadratic Triangle, and (c) Quadratic Line Elements. 
ICF MAGNUM-2D Restart Data File. It contains all the necessary data needed to restart the simulation from the time step at which the file was produced. When MAGNUM-2D is flagged to produce this file, it will indicate that the restart file was generated by printing a message to that effect after the head and temperature printout. The time step at which this message is printed is the time step at which the restarted run will commence.

IG MAGNUM-2D Geometry File. This file is a convenience only. It allows the user to save the geometry on a mass storage file for later use if, for instance, the original input was on cards or some other media. This file is simply a geometry file and may be used in the same fashion as any file that had been created using preprocessors.

IVEL MAGNUM-2D Velocity File. It contains the velocity data in binary form. This file may be utilized by the CHAINT program for radionuclide solute transport. It may also be used by the postprocessor programs VELPLT to plot the velocity vectors, or PATH to plot pathlines or streamlines.

ICSV MAGNUM-2D Initial Condition File. It contains the information necessary to define, as initial conditions, the state of every node in the model at the end of the current simulation. This file is a coded or ASCII file and may be used in an editing session to generate the input data for a later simulation.

\subsection{NOMENCLATURE}

Symbol

$\mathrm{S}_{\mathrm{S}}$

h

$\mathrm{t}$

$\mathrm{K}$

$x, y$

$\delta_{\mathrm{b}}$

$\delta_{\mathbf{i j}}$

$\gamma$

$\mathrm{T}$
Interpretation

Specific storage of rock

Hydraulic head

Time coordinate

Hydraulic conductivity of rock

Global space coordinates

Density disparity in rock

Kronecker delta

Thermal coupling coefficient

Temperature
Units

$1 / \mathrm{m}$

m

yr

$\mathrm{m} / \mathrm{s}$

m

$--$

$--$

${ }^{1}{ }^{\circ} \mathrm{C}$

${ }^{\circ} \mathrm{C}$ 
Symbol$$
\rho
$$

$\rho_{0}$

$\rho \star$

$\phi$

B

$S_{f}$

$k_{f}$

L

$\delta_{b}^{\prime}$

g

e

$v$

$S_{t}$

$c_{f}$

q

$D_{t}$

Q

$\rho_{S}$

$c_{s}$

$D_{f}$

$\mathrm{D}_{\mathrm{S}}$

$\alpha$

$\bar{q}$

\section{Interpretation}

Fluid density

Initial density

Reference density

Effective porosity

Bulk modulus of fluid

Specific storage of fracture

Hydraulic conductivity of fracture

Local coordinate of fracture

Density disparity in fracture

Acceleration due to gravity

Fracture aperture

Viscosity

Bulk heat capacity

Specific heat of fluid

Component of specific discharge

Effective thermal diffusivity

Therma1 source

Density of rock

Specific heat of rock

Thermal conductivity of fluid

Thermal conductivity of rock

Dispersivity

Groundwater speed
Units

$\mathrm{kg} / \mathrm{m}^{3}$

$\mathrm{kg} / \mathrm{m}^{3}$

$\mathrm{kg} / \mathrm{m}^{3}$

$1 /{ }^{\circ} \mathrm{C}$

$1 / \mathrm{m}$

$\mathrm{m} / \mathrm{s}$

m

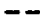

$\mathrm{m} / \mathrm{s}^{2}$

m

$\mathrm{m}^{2} / \mathrm{s}$

$\mathrm{J} /\left(\mathrm{kg} \cdot{ }^{\circ} \mathrm{C}\right)$

$\mathrm{J} /\left(\mathrm{kg} \cdot{ }^{\circ} \mathrm{C}\right)$

$\mathrm{m} / \mathrm{s}$

$\mathrm{J} /\left(\mathrm{m} \cdot \mathrm{s} \cdot{ }^{\circ} \mathrm{C}\right)$

$\mathrm{J} /(\mathrm{kg} \cdot \mathrm{s})$

$\mathrm{kg} / \mathrm{m}^{3}$

$\mathrm{J} /\left(\mathrm{kg} \cdot{ }^{\circ} \mathrm{C}\right)$

$\mathrm{J} /\left(\mathrm{m} \cdot \mathrm{s} \cdot{ }^{\circ} \mathrm{C}\right)$

$\mathrm{J} /\left(\mathrm{m} \cdot \mathrm{s} \cdot{ }^{\circ} \mathrm{C}\right)$

m

$\mathrm{m} / \mathrm{s}$ 


\begin{tabular}{|c|c|c|}
\hline Symbol & Interpretation & Units \\
\hline $\mathrm{F}$ & Generalized state variable & -- \\
\hline NP & Total number of nodes & -- \\
\hline$z$ & Norma1 coordinate & $m$ \\
\hline$\omega$ & Shape function & -- \\
\hline$\varepsilon$ & Residual & -- \\
\hline$x$ & Galerkin functional & -- \\
\hline E & Finite element & -- \\
\hline$\theta$ & Weighting factor & -- \\
\hline$\Delta \mathrm{F}$ & Incremental change in $F$ & -- \\
\hline$b$ & Heat generation coefficients & -- \\
\hline S & Generalized storage coefficient & -- \\
\hline$\Gamma$ & Generalized conductivity & -- \\
\hline$\Delta x$ & Internodal distance & -- \\
\hline$\Delta t_{c h}$ & Characteristic time & -- \\
\hline$\eta, \psi$ & Local coordinates & $\mathrm{m}$ \\
\hline
\end{tabular}

\subsection{REFERENCES}

Baca, R. G., I. P. King, and W. R. Norton (1978), "Finite Element Models for Simultaneous Heat and Moisture Transport in Unsaturated Soils, "in Proceedings of Second International Conference on Finite Elements in Water Resources, Pentech Press, London, England; also RHO-SA-31, Rockwell Hanford Operations, Richland, Washington.

Baca, R. G., D. W. Langford, and R. E. England (1981), "Analysis of Host Performance for a Nuclear Waste Repository Using Coupled Flow and Transport Mode1s," in Proceedings of the Workshop on Near-Field Phenomena in Geologic Repositories for Radioactive Waste, OECD/NEA, Paris, France; also RHO-BWI-SA-140, Rockwe 11 Hanford Operations, Richland, Washington. 
Baca, R. G., R. C. Arnett, and D. W. Langford (1984a), "Modeling Fluid Flow in Fractured-Porous Rock Masses by Finite-Element Techniques," International Journal for Numerical Methods in Fluids, Vol. 4, pp. 337-348; a1so RHO-BW-SA-297 P.

Baca, R. G., J. C. Sonnichsen, M. K. Altenhoffen, and D. W. Langford (1984b), "Application of Finite Element Models on the Evaluation of Engineered Barriers for a Mined Geologic Repository," in Proceedings of the Fifth International Conference on Finite Elements in Water Resources, University of Connecticut; also RHO-BW-SA-312 P, Rockwe 11 Hanford Operations, Richland, Washington.

Clifton, P. M., R. G. Baca, and R. C. Arnett (1983), "Stochastic Analysis of Groundwater Traveltimes for Long-Term Repository Performance Assessment," in the proceeding of symposium on Scientific Bas is for Nuclear Waste Management; al so RHO-BW-SA-323A P, Rockwel1 Hanford Operations, Richland, Washington.

Combarnous, M. A. and S. A. Bories (1975), "Hydrothermal Convections in Saturated Porous Media," Advanced Hydrosciences, 10.

DOE (1982), Site Characterization Report for the Basalt Waste Isolation Project, DOE/RL 82-3, 3 Voi., Rockwe11 Hanford Operations for the U.S. Department of Energy, Washington, D.C.

Estey, S. A., R. C. Arnett, D. R. Aichele (1985), Users Guide for MAGNUM 3D: A Three-Dimensional Groundwater Flow Numerical Model, RHO-BW-ST-67 P, Rockwell Hanford Operations, Richland, Washington.

Fahien, R. W. (1983), Fundamentals of Transport Phenomena, McGraw-Hill Book Company, New York, New York.

Hardy, M. P. and G. Hocking (1978), Numerical Modelling of Rock Stresses Within a Basaltic Nuclear Waste Repository: Phase II - Parametric Design Studies, RHO-BWI-C-23, Department of Civil and Mineral Engineering, University of Minnesota, Minneapolis, Minnesota.

Hood, P. (1976), "Frontal Solution Program for Unsymmetric Matrices," International Journal for Numerical Methods in Engineering, Vol. 10.

Huyakorn, P. S. and G. F. Pinder (1983), Computational Methods in Subsurface Flow, Academic Press, New York, New York.

Irons, B. M. and S. Ahmad (1980), Techniques of Finite Elements, John Wiley and Sons, Inc., New York, New York.

Kline, N. W., A. K. Runchal, and R. G. Baca (1983), PORFLO Computer Code: Users Guide, RHO-BW-CR-138 P, Rockwell Hanford Operations, Richland, Washington.

Malvern, L. E. (1969), Introductions to the Mechanics of a Continuous Medium, Prentice-Hal1, Inc., Englewood Cliffs, New Jersey. 
Sagar, B. and P. M. Clifton (1983), Numerical Modeling of Parametric Uncertainties in Flow Through Porous Media: Development of PORSTAT., RHO-BW:-CR-140P, Rockwel1 Hanford Operations, Richland, Washington.

Silling, S. A. (1983), Final Technical Position on Documentation of Computer Codes for High-Level Waste Management, NUREG-0856, U.S. Nuclear Regulatory Commission, Washington, D.C.

Snow, D. T. (1969), "Anisotropic Permeability of Fractured Media," Water Resources, $\underline{5}(6)$. 
RHO-BW-CR-143P

This page intentionally left blank. 
APPENDIX A

PROGRAM INTERNALS

\section{INTRODUCTION}

MAGNUM-2D is written in FORTRAN 77 and is currently operational on the Basalt Waste Isolation Project PRIME 750 computer system. Earlier development work was performed on a UNIVAC 1100/40, and an early version was converted to a CRAY 1. Attempts were made to use standard FORTRAN 77, but some PRIME specific functions were used in isolated incidents. These will be pointed out in the following sections.

\section{SUBROUTINES: FUNCTIONAL DESCRIPTIONS}

This subsection lists the modules comprising the MAGNUM-2D program and gives a brief explanation of the function of each.

MAGNUM-2D The main program that controls the simulation by calling the appropriate subroutines. The MAGNUM-2D program initiates the solution for each time interval. For transient solutions, the dependent variables and their gradients are predicted for the next time step. The flow and temperature file, the initial condition file, and the restart data file are written in this module.

BANNER Prints a banner page including the date and time at which the run is initiated. This subroutine also generates the unique run identifier.

INPUTS Reads control option parameters, file unit assignments, time step parameters, scale factors, geometry data, initial and boundary conditions, and material properties.

ZONE Determines the pointer array which designates midside modes that are to be eliminated from computation. Mixed-order triangular or quadrilateral elements are constructed in transition zones.

LOADQ Reads and/or computes the thermal loading rate for the source elements.

HEADR Writes file headers to external files and reads the header record from the temperature input file, if specified.

SETUP Sets up a pointer array for the element matrix and computes the total array storage requirement.

FPROP A one-dimensional Hermitian polynomial expansion is used to approximate values of the viscosity, density, and coupling coefficient as functions of temperature.

VPROP Computes density disparity and temperature correction to hydraulic conductivity. 
FRONT Performs a Gauss elimination procedure with partial pivoting using a frontal solution method for unsymmetric matrices.

STIFF Forms the coefficient matrices for each finite element. Gaussian quadrature is used to numerically integrate the element equations.

RESOL Performs the back substitution for the updated right-hand sides. The algorithm is based on the frontal solution approach.

RIGHTSD Forms the right-hand side load vectors which take into account updated coefficients and source terms.

VEL Computes the Darcian velocity at the Gauss points from the hydraulic head and conductivity values. The velocities are written to the velocity file by this subroutine.

WRT Performs mass transfer of pivotal rows to the scratch file according to a flag. Calls subroutine RWND (rewind file), POSIT (position file), and BINOUT (write file).

RED Reads pivotal row from scratch file for back substitution with mass transfer of data. Calls subroutines POSIT (position file) and BININ (read file).

RWND A subroutine using PRIMOS calls to rewind the scratch file.

POSIT A subroutine using PRIMOS calls to position the file pointer relative to the current location.

BININ A subroutine using PRIMOS calls to read variable length binary records from disk.

BINOUT A subroutine using PRIMOS calls to write variable length binary records to disk.

PRINT Prints out the tabular results for temperature and hydraulic head at each nodal point. Specific boundary values are indicated in the output by an asterisk. If required, this subroutine also prints out the velocities.

BLKDAT A block data routine that contains shape function and derivative evaluations at the Gauss points within the elements. The data statements contain evaluations specific to Gaussian quadrature formulas based on $2 \times 2$ Gauss points for linear-shape functions and $3 \times 3$ Gauss points for quadratic-shape functions. 
PARA This is an insert file containing the parameter statements used to define the program limits. See the next section for details.

\section{PROGRAM LIMITS}

All arrays that would need to be changed due to a need to increase the model size are dimensioned using "PARAMETER" statements. If required, the maximum limits can be increased or decreased by changing these parameters within the insert file PARA and recompiling the program. Note that PARA contains images that are included or inserted in a subroutine at compilation time. Most systems have such a facility. In PRIMOS, it is the FORTRAN "INSERT" directive.

The following parameters are used in MAGNUM-20:

MAXE

MAXP

MAXMAT

MAXH

MAXT

NMAX

NTT

$\operatorname{MAXP2}=(\operatorname{MAXP} \star 2)$
Maximum number of elements

Maximum number of node points

Maximum number of material types

Maximum number of heat source elements

Maximum number of points used to define a heat generation profile

Maximum front width of equation network array

Maximum number of time intervals

Maximum number of unknown dependent variables in R1 array, i.e., change in hydraulic head and temperature at each node.

The arrays affected by the PARAMETERS listed are given below with the names of the COMMON blocks in which they reside:

\section{COMMON /BLK1/}

$\operatorname{DLT}(\mathrm{NTT})$

Time-step size for each time interval

NTS (NTT)

Number of time steps in each time interval

NTSG(NTT)

Print frequency within each time interval

TIME (NTT)

Time at the end of each time interval 


\section{COMMON /BLK2/}

CORD (MAXP, 2)

IMAT (MAXE)

NBC (MAXP2)

NF IXH (MAXP)

NOP (MAXE , 8)

R1 (MAXP2)

ALPAL (MAXMAT)

ALPAT (MAXMAT)

BETA(MAXP)

CVM(MAXMAT)

HKAX (MAXMAT)

HKAY (MAXMAT)

POROS (MAXMAT)

Q(MAXE)

RHOM(MAXMAT)

SP1 (MAXMAT)

ST (MAXMAT)

THETA (MAXE)

TKK(MAXMAT , 2)

VISCO(MAXP) $x$ - and $y$-coordinates for each node

Material type of each element

Equation number for computational nodes

Element ordering array

List of element - node connectivity

COMMON /BLK3/

The change in state variables solved for at each node

\section{COMMON /BLK5/}

Longitudinal dispersivity (m)

Transverse dispersivity (m)

Thermal coupling coefficient

Specific heat of the rock $\left[\mathrm{J} /\left(\mathrm{kg} \cdot{ }^{\circ} \mathrm{C}\right)\right]$

Hydraulic conductivity in the $x$-direction $(\mathrm{m} / \mathrm{s})$

Hydraulic conductivity in the $y$-direction $(\mathrm{m} / \mathrm{s})$

Effective porosity

Therma 1 loads in the domain $\left[\mathrm{J} /\left(\mathrm{yr} \cdot \mathrm{m}^{3}\right)\right]$

Rock density $\left(\mathrm{kg} / \mathrm{m}^{3}\right)$

Rock specific storage $(1 / \mathrm{m})$

Heat capacity of the water-rock system $\left[\mathrm{J} /\left(\mathrm{m}^{3} \cdot{ }^{\circ} \mathrm{C}\right)\right]$

Conductivity corrections based on the change in viscosity

Thermal conductivity in the $x$ - and $y$-directions $\left[\mathrm{J} /\left(\mathrm{s} \cdot \mathrm{m} \cdot{ }^{\circ} \mathrm{C}\right)\right]$

Viscosity at the previous step 


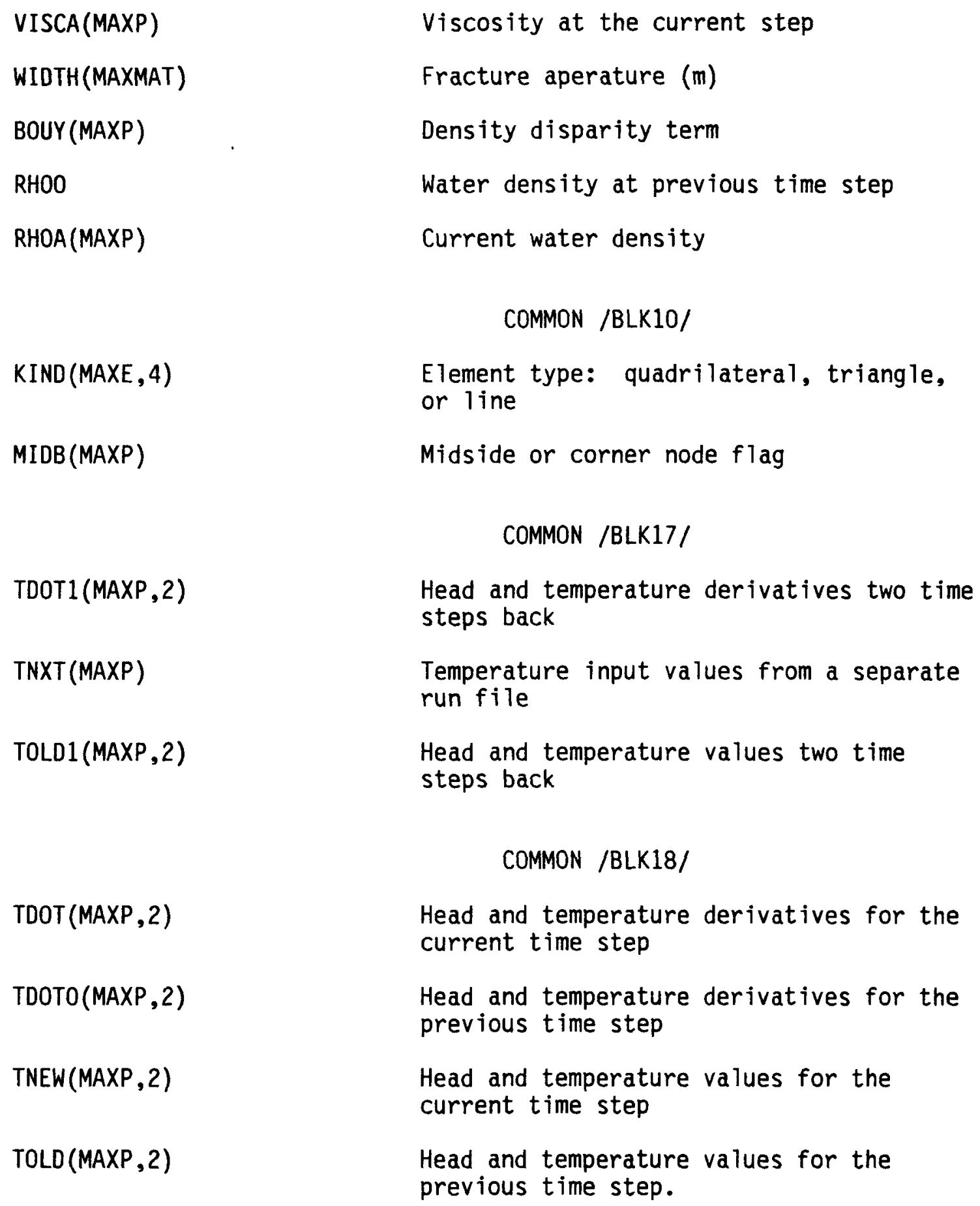

\section{FILE MANIPULATION}

A11 mass storage files used by MAGNUM-2D are referenced internally by their logical unit numbers (LUN). Each operating system has its own way of associating the LUN with the files needed or being created by an application 
program. For this reason, the user is asked to consult the operating system reference publications for the machine being used. The remainder of this section will be aimed at the PRIME operating system (PRIMOS).

\section{PREASSIGNED LOGICAL UNIT NUMBERS}

All the files except three are associated with, or may be associated with, a file previously generated, or that will be generated, by MAGNUM-2D. The first exception is LUN 16, which is used as the "out-of-core" solution scratch file. This file must be opened but is for scratch purposes only. The second and third exceptions are LUN 5 and LUN 6 (internal variables IC $=5$ and IOUT=6), which are used for the main input file and printed output file, respectively. That is, a 11 the information discussed in Section 4.2 enters MAGNUM-2D via LUN 5, and a 11 reports of the results of the analyses are printed via LUN 6. Variables IC and IOUT are set in the main program and are passed through common block INOUT where needed.

\section{THE PRIMOS FILES}

In PRIMOS the LUNs are associated with the appropriate files by using the OPEN command. It should be noted that the PRIME version OF MAGNUM-2D requires special attention to the assignment and use of LUNs. The numbers used in Section 4.2 for card type B are the FORTRAN LUNs. These have a range starting with one and going to some maximum value (consult the current PRIME FORTRAN manual). These numbers are decimal numbers. The PRIMOS LUNs, however, are octal numbers and have an offset of four relative to the ir FORTRAN counterparts. The following table shows the arrangement.

$\begin{array}{cl}\text { FORTRAN (decima1) } & \text { PRIMOS (octal) } \\ 1 & \text { user terminal } \\ 2 & \text { paper tape } \\ 3 & \text { card reader } \\ 4 & \text { serial printer } \\ 5 & 1 \\ 6 & 2 \\ 7 & 3 \\ 8 & 4 \\ 9 & 5 \\ 10 & 6 \\ 11 & 7 \\ 12 & 10 \\ 13 & 11 \\ \cdot & . \\ . & .\end{array}$


Note that the arrangement shown means that the FORTRAN LUNs 5 and 6 , for example, correspond to the PRIMOS LUNS 1 and 2, respectively.

\title{
SUBROUTINES: CONTROL AND HIERARCHY
}

A top level flowchart for the MAGNUM-2D program is shown in Figure $A-1$. In this figure the rectangular boxes denote subroutines, and the triangular boxes denote decisions. The flowchart depicts iteration in the solution at each time step; however, since applications of the code have never required more than a single iteration, the iteration limit is currently set to one. The full module hierarchy for the MAGNUM-2D program is depicted in Figure A-2.

\section{CODE AVAILABILITY}

The FORTRAN source code for MAGNUM-2D is not duplicated here for the sake of compactness, but it is available in the form of a paper listing and/or magnetic tape. Inquiries regarding MAGNUM-20 and requests for copies of the code should be directed to:

\author{
Mr. R. G. Baca \\ Rockwe 11 Hanford Operations \\ Basalt Waste Isolation Project \\ Performance Assessment Group \\ P.0. Box 800 \\ Richland, Washington 99352
}


RHO-BW-CR-143 P

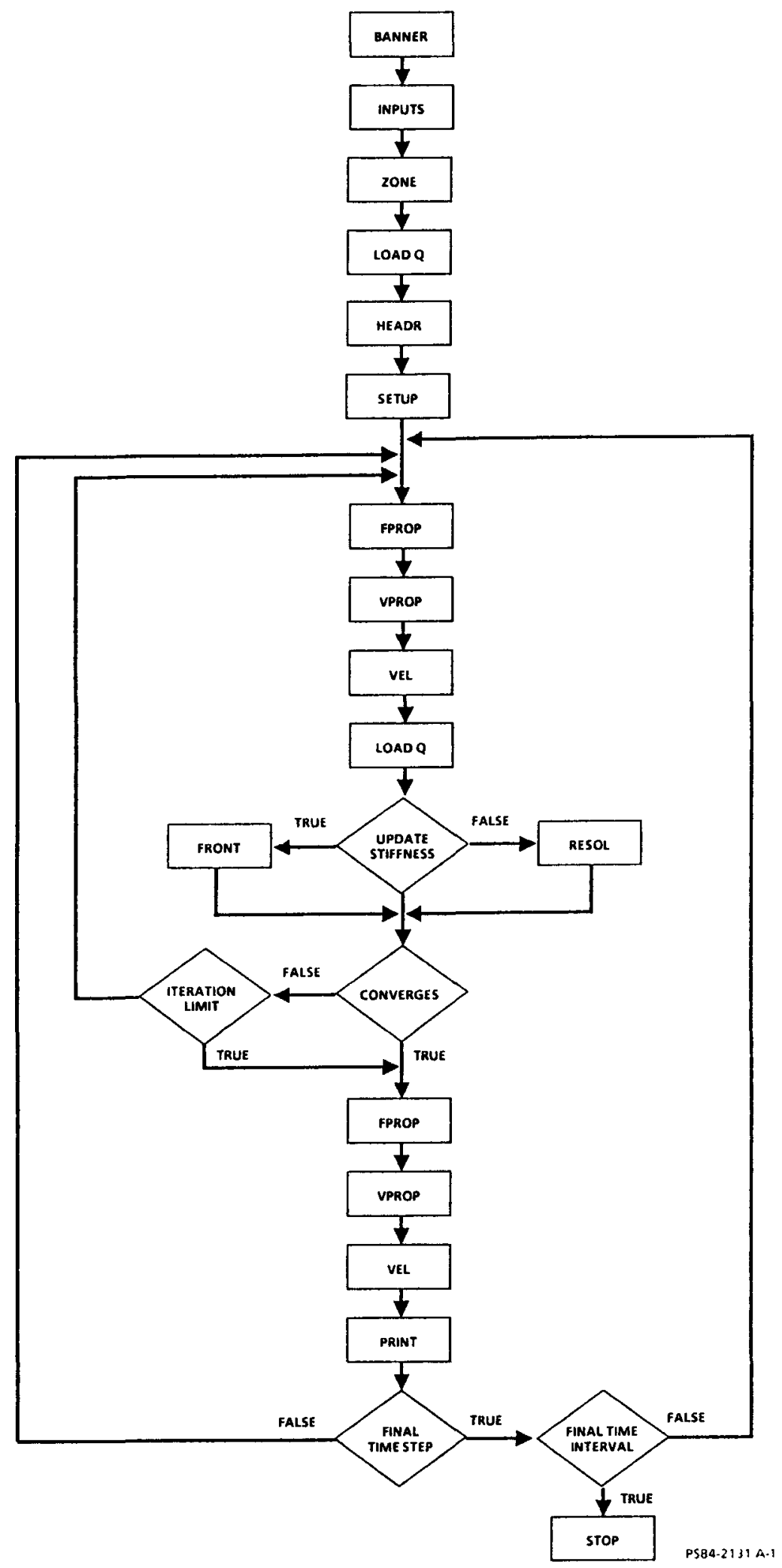

FIGURE A-1. Control Flow for MAGNUM-2D. 


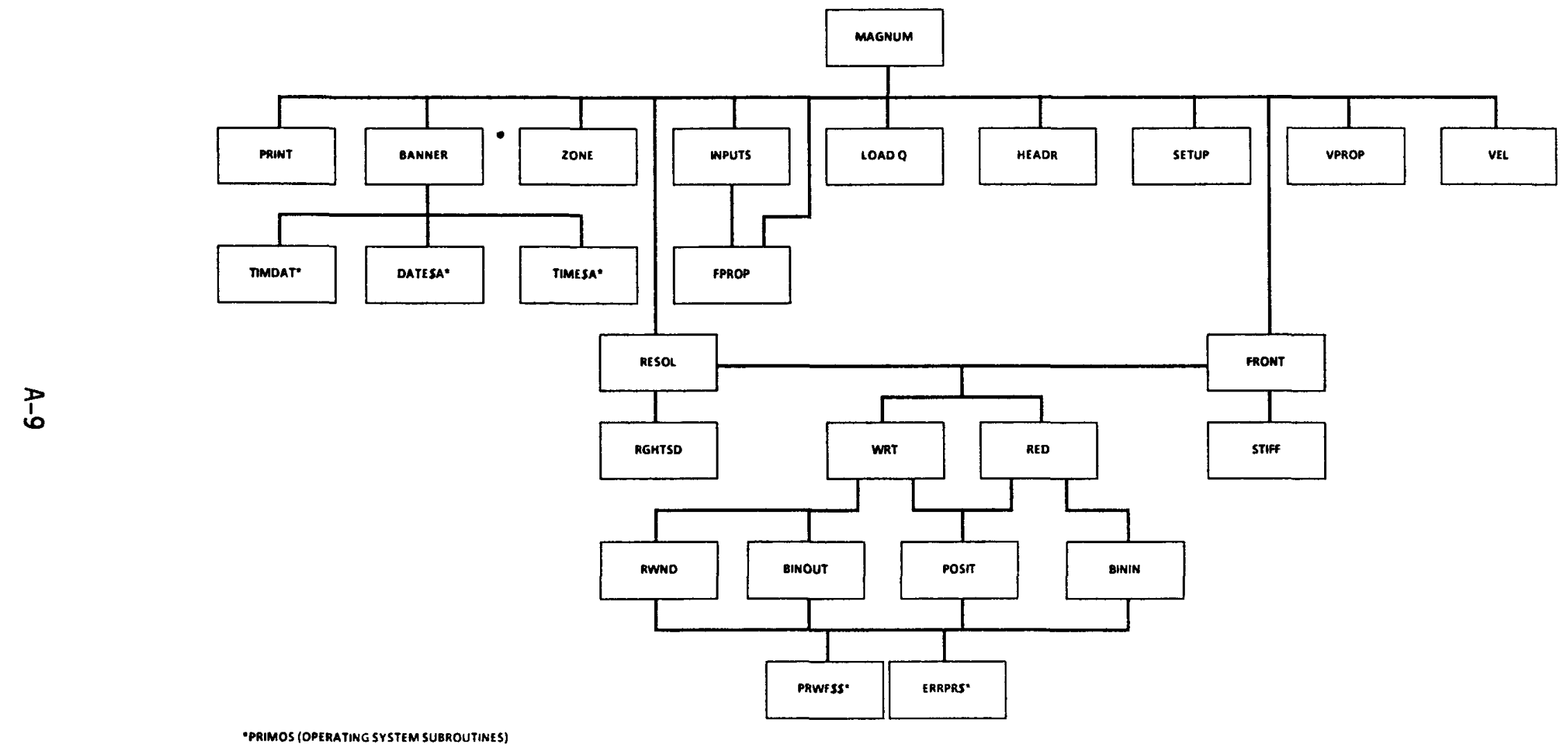

FIGURE A-2. Subroutine Hierarchy for MAGNUM 2-D. 
RHO-BW-CR-143P

This page intentionally left blank.

A-10 
RHO-BW-CR-143 P

APPENDIX B

PREPROCESSORS

\section{INTRODUCTION}

A finite-element code such as MAGNUM-2D requires an extensive input data set, including a geometry, initial conditions, and boundary conditions. The creation of this data set can be automated to some extent by providing software "tools" to help the modeler develop and handle the requisite data. The tools used to create the data, known collectively as "preprocessors," deal mostly with the input geometry data. Geometries may be created, refined, modified, optimized, verified, and plotted. Two other preprocessors exist for creating initial and boundary condition data.

This appendix lists the preprocessors available for use with MAGNUM-2D and gives a brief description of each. A brief discussion is provided of the steps that must be followed to use the preprocessors to generate a data set describing a model to be used for a simulation.

Note that this section is not intended to be an instruction manual for any of the preprocessors described herein. At present, the preprocessors are self-help interactive FORTRAN programs.

\section{MAGNUM-2D PREPROCESSORS}

The FEMESH code is used to generate arbitrarily shaped, finite-element geometries. The input for FEMESH is a coarse finite-element geometry of quadrilateral elements followed by some refinement specifications telling FEMESH how the coarse mesh is to be subdivided. This input must be in literal ASCII form. The input format for the coarse geometry is exactly like that required for the MAGNUM-2D geometry. This allows the user to generate the coarse mesh "by hand" using a standard text editor program. The user may also generate the coarse mesh using GEN and later add the refinement data by hand using an editor. The FEMESH code will generate triangular, as well as quadrilateral elements, but the input is restricted to quadrilaterals.

The GEN code is a simple processor for generating regular, rectangular finite-element geometries of quadrilateral or line elements. No prior preparation of input data is required. The program prompts the user for all required input. The output geometry may be chosen as a set of quadrilaterals or a network of 1 ine elements. The lower left-hand corner of the rectangular area generated may start at $(0.0,0.0)$, or at whatever coordinates the user requests. All the elements will have a common, userspecified material type. The data generated by GEN is written to a formatted file and may be suitably modified for use by the FEMESH code by adding the refinement data required (see FEMESH). 
The MERGE code is a processor that combines two model geometries into a single geometry. This allows the creation of large, finite-element geometries in smaller parts. The two geometries to be combined must be compatible along the sides that will become common. No overlap in the geometries being combined is allowed except in the case of line elements where the line element nodes will be merged if they coincide with the twodimensional element nodes. One of the geometries being merged may have an offset defined for the node locations during the merge. This often simplifies generation of the subgeometries.

The MESHER code reorders the elements and/or nodes of a finite-element geometry. Reordering of element numbers is performed to minimize the bandwidth for MAGNUM-2D or CHAINT during the solution phase of the programs. The technique used is not a true optimization. Instead, MESHER requires an input starting list of nodes from which a near-optimum order is generated. Several different starting lists may be compared in one MESHER run, and the best of these will be automatically retained. The starting list of nodes is best chosen as the nodes along the shortest side of the mesh. A feature of MESHER is the ability to list all the boundary nodes and to indicate the corner nodes, allowing the user to try various sides and to make comparisons.

The MOD code allows the user to make simple modifications to a geometry including node position, geometry scaling, rotating, mirroring, or translating; to change the slope, angle, material type, or connectivity; to recalculate the midside node positions; or to create new elements. This program will allow changes to be made to a binary file where an editor would be ineffectual.

The PLT code is used for plotting two-dimensional finite-element geometries. All three element types (quadrilaterals, triangles, and lines) are recognized. The plots produced are the mesh alone; the mesh with node, element, or material types numbered; single elements; and subregions of the entire mesh with all the above options. (Note: This program makes use of the DISSPLA graphics system by ISSCO. This library of FORTRAN graphics routines is necessary to run PLT on any computer system.)

The PURGE code is used to verify a geometry. Checks are made for some of the more common errors. These include errors in element connectivity specification, midside node placement, unused nodes and elements, duplicate nodes, node rotation, free elements, ill-defined elements, aspect ratios that are potentially unacceptable, elements that overlap or are distorted, and correctness of the ordering array. Obvious errors, such as unused nodes and elements, are corrected while more subtle errors are noted for the user to correct.

The REFINE code allows single elements to be divided into two smaller elements or two smaller elements to be combined into one larger element.

The TRGEN code will generate a finite-element transition geometry using triangular elements to go from a region of smaller elements to a region of larger elements. 
The BCGEN code is used to generate a boundary condition data file for input to MAGNUM-2D or CHAINT. A geometry is read from a geometry file, and a search is made for all boundary nodes. These nodes are then listed in counterclockwise order, and two user-supplied subroutines, BCHEAD and BCTEMP, are called to generate the boundary conditions for head and temperature, respectively.

The ICGEN code is used to generate an initial condition data file for input to MAGNUM-2D or CHAINT. A geometry is read from a geometry file, and the initial conditions are calculated based on position (or other appropriate variable) by a user-supplied function.

The ICMOD code is more of a utility than a preprocessor. It allows the user to convert an initial condition file to a file that looks like a binary results file. This file may be gridded and contoured for inspection. Alternately, a binary results file may be converted for use as a formatted initial condition file.

\section{DATA GENERATION WALK THROUGH}

The first step in the generation of any finite-e lement representation is the determination of the exact geometric definition of the physical system. This should include dimensions and locations of all features associated with the region being modeled, such as voids, varying material types, heat and fluid sources, etc. Once this data is collected, the modeler must determine the optimum form of the model to ensure accurate mathematical representation of the region and, therefore, accurate results. If the area of highest gradient can be identified beforehand, the modeling effort is often simplified and the model size is limited since this allows the element density to be restricted to those high-gradient regions.

A typical method for the creation of the model is for the modeler to start with a sketch of the region to be modeled. Any identifiable subregions are then indicated (i.e., subregions composed of a single material, voids, etc.), and a plan is determined, such as modeling these subregions and merging them into a whole model. This technique will be assumed in the following discussion.

A data flow diagram for the preprocessors and files discussed in this section is shown in Figure $B-1$. It is recommended that the reader follow this diagram while reading the remainder of this appendix.

Often the first program to be used, and perhaps the only one needed depending on the complexity of the model, is GEN. If it is convenient to produce the entire model or complete subregions with GEN, the task is simplified; however, GEN may also be used to generate a preliminary coarse mesh to which the refinement data is added using an editor, and this file is then run through FEMESH to refine and enhance the mesh. 
Note that in creating the mesh for subregions, care should be exercised to ensure that the boundary nodes are located at common geometric points so that merging the meshes is possible. If the points do not coincide or at least vary with a constant $x$ - or $y$-dimension offset, it will be necessary to modify a potentially large number of coordinates before merging is feasible.

If a transition zone is necessary between regions of varying element densities (i.e., between regions of suspected high and low gradients), then TRGEN may be used to produce the zone as a separate region.

The various "pieces" of the model may be combined or merged using MERGE. This program will take any two geometry files and attempt to merge them at their common node points; thus, the user may have to use this program several times depending on the number of subregions being combined. The MERGE code (like MESHER, MOD, and REFINE) has the ability to write the new geometry back into an old file or onto a new file, thus preserving the subregion data files for future use. A precaution is to maintain all the component geometries until the model generation, or some phase of it, has been verified to be correct. This allows the user to redo a portion of the geometry from the last correct phase in case a mistake is made.

At any point in the model generation procedure, the program PLT may be used to view the model. It is helpful to have hard copies of the element and node number plots at hand when merging geometries.

Often the automatically generated finite-element geometry is not sufficiently accurate or the region is too intricate to attempt defining adequate constraints for automatic generation. In these cases it is up to the modeler to amend and modify the geometry with a text editor to produce the desired results. The MOD program will allow the user to change node locations or connectivity. This is convenient when the material boundaries require specific location of elements or midside nodes do not fall where they should when generated automatically. In addition, MOD will allow the user to mirror or translate geometries so the modeler may use any symmetry in the model. The REFINE program is useful in "fine tuning" a geometry because it will allow the user to produce a fine mesh in just a few elements without defining a subregion. Both MOD and REFINE provide flexibility in "refitting" a model, that is, modifying it after it is complete for sensitivity analyses or because of features uncovered by the initial analysis.

After the model parts have been assembled and the actual node locations have been fine tuned, it is wise to run PURGE on the geometry. This ensures that many of the innocuous errors that propagate from the creation process are removed. These errors may not be large in themselves, but they may create great variations in the final simulation results if they occur in a critical location. It is probably a good idea to make at least one PLT run on the final geometry file for a final visual check. A hard copy of the node number, material type, and element number plots is essential in order to analyze the results of a simulation in detail. 
When the geometry file has been created, it may be in one of two forms: either binary or formatted (ASCII, BCD, etc.). Either of these is readable from MAGNUM-2D or CHAINT. It may be utilized by reading the file directly from mass storage (in coded or binary form) or, in the case of a coded file, it may be edited into an input file that contains all the other data necessary for the simulation (boundary conditions, material properties, and other data as contained in card types $A$ through $R$ ).

Using an editor program, the remainder of the data required for simulation as described in card types $A$ through $R$ is usually entered into a mass storage file, the MAGNUM-2D data input file. Card types $G$ and $H$, which describe the geometry, may be entered from the coded form of the geometry file or may be omitted and read from a binary or formatted mass storage file at execution time by specifying the logical unit number on card type $C$. The initial and boundary conditions, however, must be included in the MAGNUM-2D data input file. If they are few or straightforward, they may be entered directly by using the editor. If they are numerous, the two programs ICGEN and BCGEN may be used to produce files of initial and boundary conditions, respectively, which are edited into the data input file.

A data flow diagram for the MAGNUM-2D and CHAINT environment and the data files involved is shown in Figure B-2. Note that for a nonrestart job, only two input files are needed: the MAGNUM-2D data input file and the geometry file. (Only one input file is needed if the geometry input is included directly on the MAGNUM-2D data input file.) 


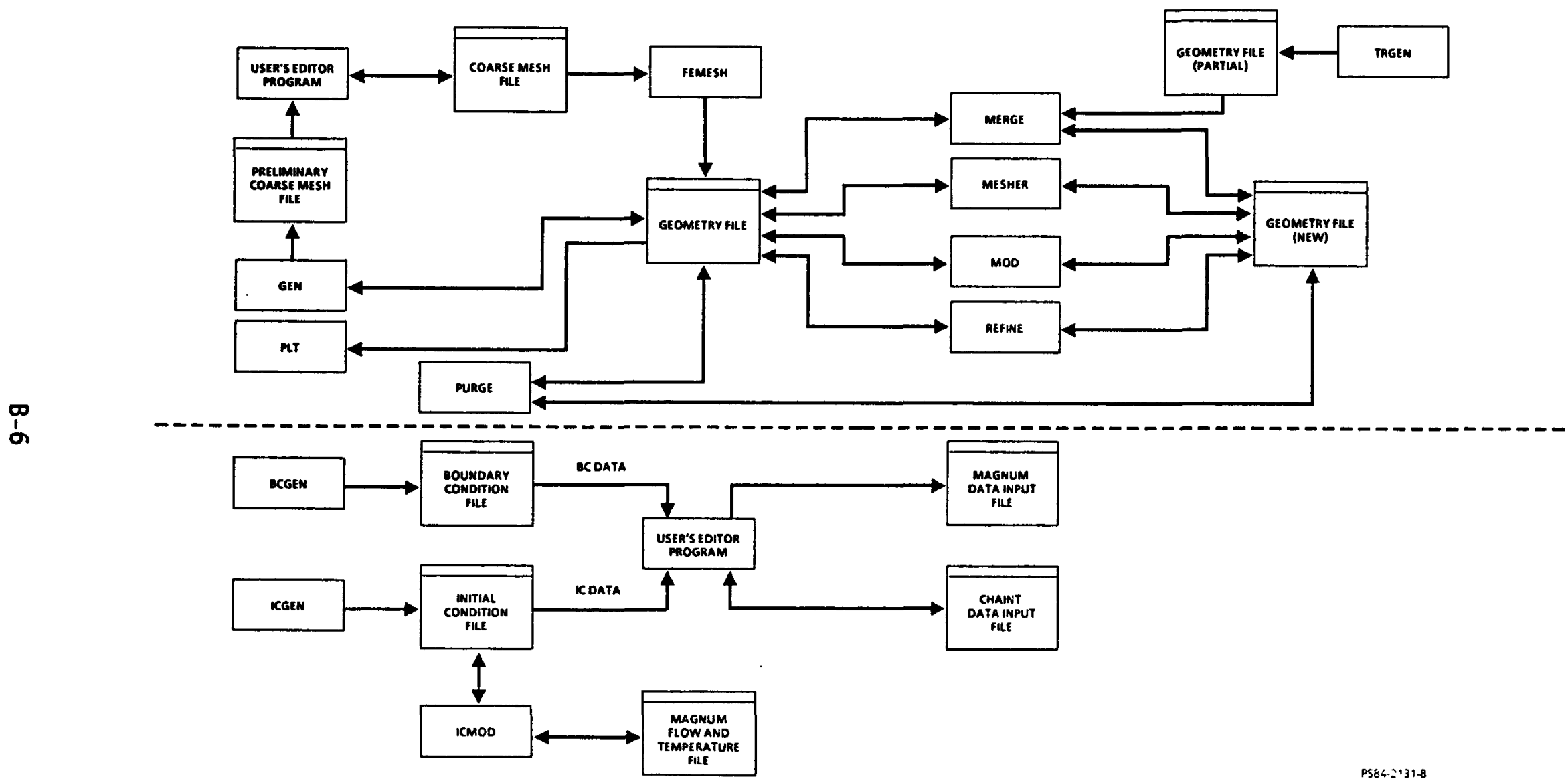

FIGURE B-1. Preprocessor Data Flow. 


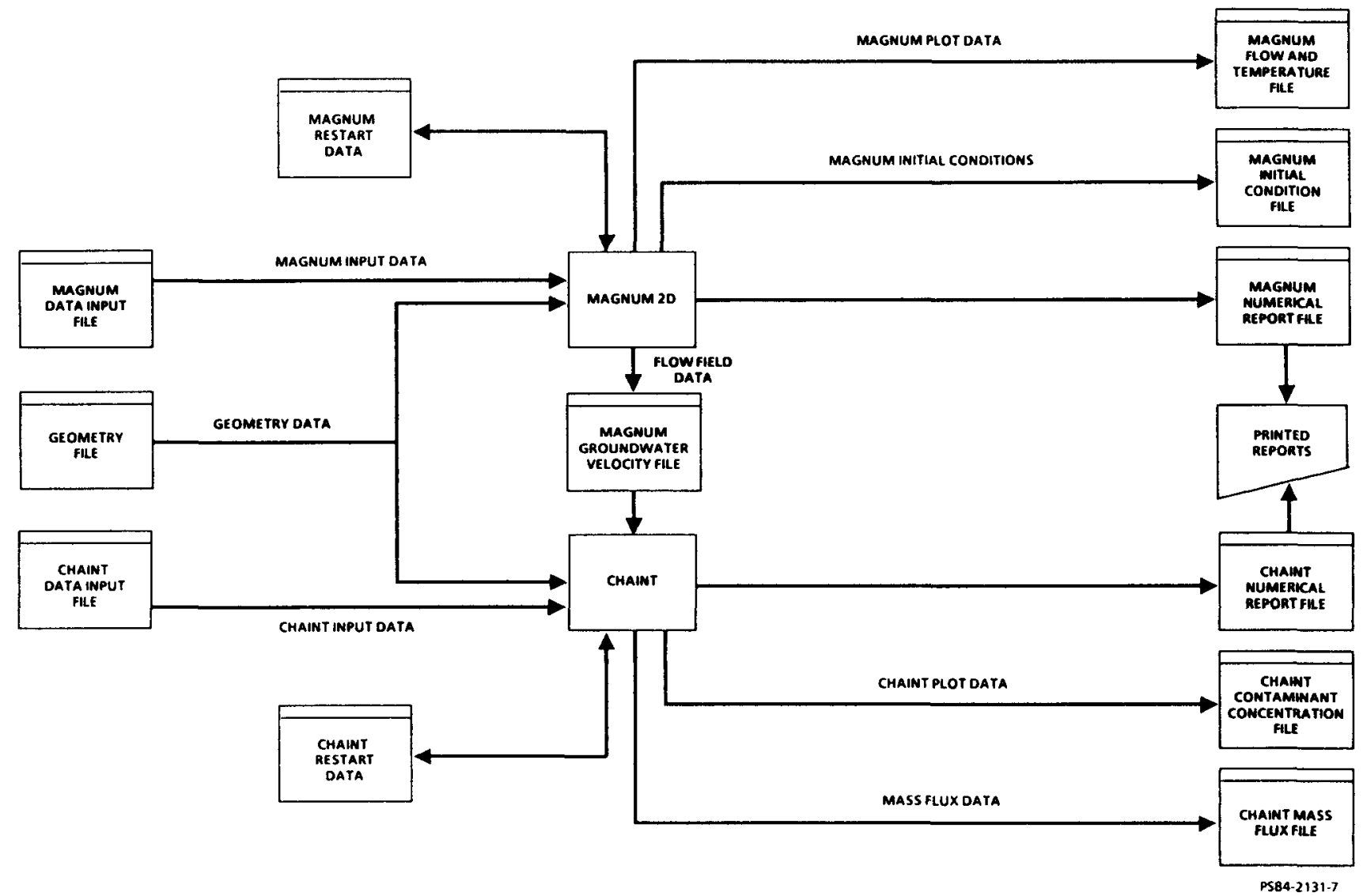

FIGURE B-2. MAGNUM/CHAINT Data Flow. 
RHO-BW-CR-143 P

This page intentionally left blank.

B-8 
APPENDIX C

POSTPROCESSORS

\section{INTRODUCTION}

A finite-element code, such as MAGNUM-2D or CHAINT, creates a large amount of output data that are often difficult to interpret in their raw form. Postprocessors provide a means of graphically displaying output data in a variety of modes. These may be two-dimensional contour plots of the results, cross-sectional plots of the data versus position, or time history plots for the data at a given location. In addition, pathiines, streamlines, velocity vectors, and mass flux data may be plotted.

This appendix lists the most commonly used postprocessors for MAGNUM-2D and gives a brief description of each.

Note that this section is not intended to be an instruction manual for any of the postprocessors described herein. Each of the graphics postprocessors is a self-help interactive FORTRAN program.

All of the graphics postprocessors utilize subroutines from the ISSCO DISSPLA graphics system. The DISSPLA graphics system is mandatory for utilization of these programs.

\section{MAGNUM-2D POSTPROCESSORS}

A data flow diagram for the postprocessors and files discussed in this section is shown in Figure $C-1$. Note from Figure $B-2$ that there are five files output from MAGNUM-2D but that only three are shown in Figure $C-1$. These are the only files that are used in postprocessing. They are the geometry file, the MAGNUM-2D groundwater velocity file, and the MAGNUM-2D flow and temperature file.

First and probably foremost is the program CHAINT. While not strictly a postprocessor, it may utilize the MAGNUM-20 groundwater velocity file as input to define the flow field to be used in solving the mass transport equations. No manipulation or modification of the file is required before its use by CHAINT.

The GRIDDER postprocessor interpolates nonregularly spaced nodal data onto a regular rectangular grid to allow contouring. The GRIDDER postprocessor ignores data associated with line elements. The sister program LEGRID will grid line elements only. They accept the MAGNUM-2D flow and temperature file as input and place the output data in an output file that may be used by CONTOUR, HISTORY, AND PARAM.

The CONTOUR postprocessor is used to draw contour line plots from data given as a function of two space variables. The MAGNUM-2D flow and temperature data must be interpolated onto a regular, rectangular grid using 
GRIDDER prior to using CONTOUR. This program is totally interactive, and the user is prompted to enter commands to set the desired plotting options, such as contour levels, background, and time plane of interest.

The HISTORY postprocessor is used to plot results as a function of time. The data histories corresponding to chosen locations in a finiteelement geometry are plotted. The histories of several points may be plotted on a single graph. The MAGNUM-2D flow and temperature data must be interpolated onto a regular, rectangular grid using GRIDDER prior to using HISTORY.

The PARAM postprocessor is used to plot data cross sections. Data are plotted as a function of $x$ or $y$, with either $y, x$, or $t$ being varied as a parameter. Several curves may be plotted on a single graph. The MAGNUM-2D flow and temperature data must be interpolated onto a regular, rectangular grid using GRIDDER prior to using PARAM.

The VELPLT postprocessor is used to plot velocity vectors from the groundwater velocity file. The vectors can be scaled or plotted at uniform lengths and may be generated with a background of the geometry boundaries. The vectors may also be drawn in their true directions or relative to the geometry background. The VELPLT postprocessor also requires the geometry file as input. The user is prompted for both file names and all directives.

The PATH postprocessor generates plots of flow paths through a twodimensional finite-element geometry. Both pathlines (time varying flow fields) and streamlines (flow at a single time plane) can be created. The path length and traveltime for each pathline or streamline are computed and printed to the terminal after each plot is complete. The user is prompted both for file names and for all directives to select subplots, time markers, background, and pathline and streamline starting points. Input data for PATH include the groundwater velocity file and the corresponding geometry file.

The PLOT1 postprocessor is used to plot the flow and temperature file on an element by element basis. A three-dimensional surface of the data is plotted along with a two-dimensional sketch of the element with written node values at each node. This program is useful as a diagnostic tool in the analysis of data anomalies. An error of insufficient geometry resolution often can be determined by examining the surface plot for data corresponding to a single element. The PLOT1 postprocessor also requires the geometry file as input. 


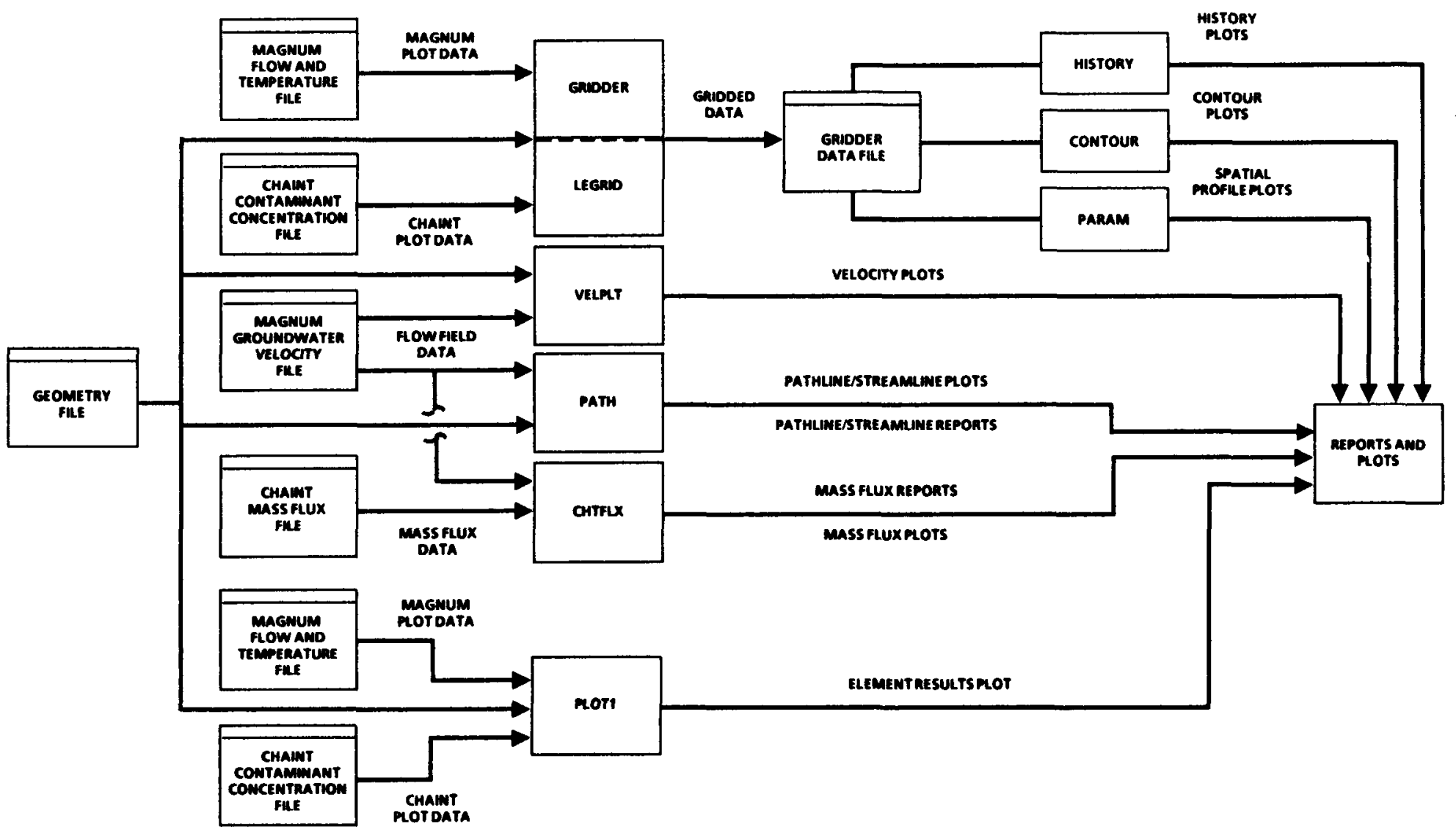

FIGURE C-1. Postprocessor Data Flow. 
RHO-BW-CR-143 P

This page intentionally left blank. 
APPENDIX D

EXAMPLE CASES

Reproduced listings of the PRIMOS commands, input, and printed output for two example problems are contained in this appendix.

The first example is a one-dimensional coupled flow and heat transfer problem with a thermal load. A single column of elements with a linear head gradient is defined from bottom to top with a single heat source specified in the element at the bottom end (element 1). The resulting head and temperature cross sections at selected times are shown in graphic form in Figures $D-1$ and D-2 as produced from the postprocessor PARAM. The geometry in this example is specified in the data input file, Listing $0-1$. The PRIMOS commands used to run this example are shown in Listing D-2. The resulting output is shown in Listing $D-3$.

The second example is a two-dimensional flow problem with heat transfer and a thermal load. The model is shown in Figures $D-3$ and $D-4$. Note that Figure $D-3$ is only the mesh; the node numbering option in the PLT program was not used. Also, Figure $0-4$ is a close-up of a specific detail on the model and includes element numbers. The model is typical of the type that might be used for a repository simulation (although much simplified) showing perhaps a bored repository with provisions for modeling the host rock, the grout or backfill, and the waste container. The semicircular area containing elements $70,71,84$, etc., are heat source elements, and both the top and bottom boundaries are specified to be at $50{ }^{\circ} \mathrm{C}$. The top boundary is also specified to have a $1.0-\mathrm{m}$ hydraulic head while the bottom is $1.2 \mathrm{~m}$. The simulation is set to run for $10 \mathrm{yr}$. Figures $D-5$ through $D-10$ show the head and temperature distributions at selected times ranging from $0-10 \mathrm{yr}$. Al1 these plots were generated using CONTOUR. Figures D-11 and D-12 show the head and temperature histories of five specific points in the model, all of which lie along the horizontal plane of symmetry. The data input file is shown in Listing D-4. Note that the geometry in this case has been defined on an external mass storage file and has been specified as LUN 11 . The PRIMOS commands used to run this example are shown in Listing D-5. Note also the specification of Unit 11 to correspond to the filename VEL. The resulting report $f i l e$ is shown in Listing $D-6$. 


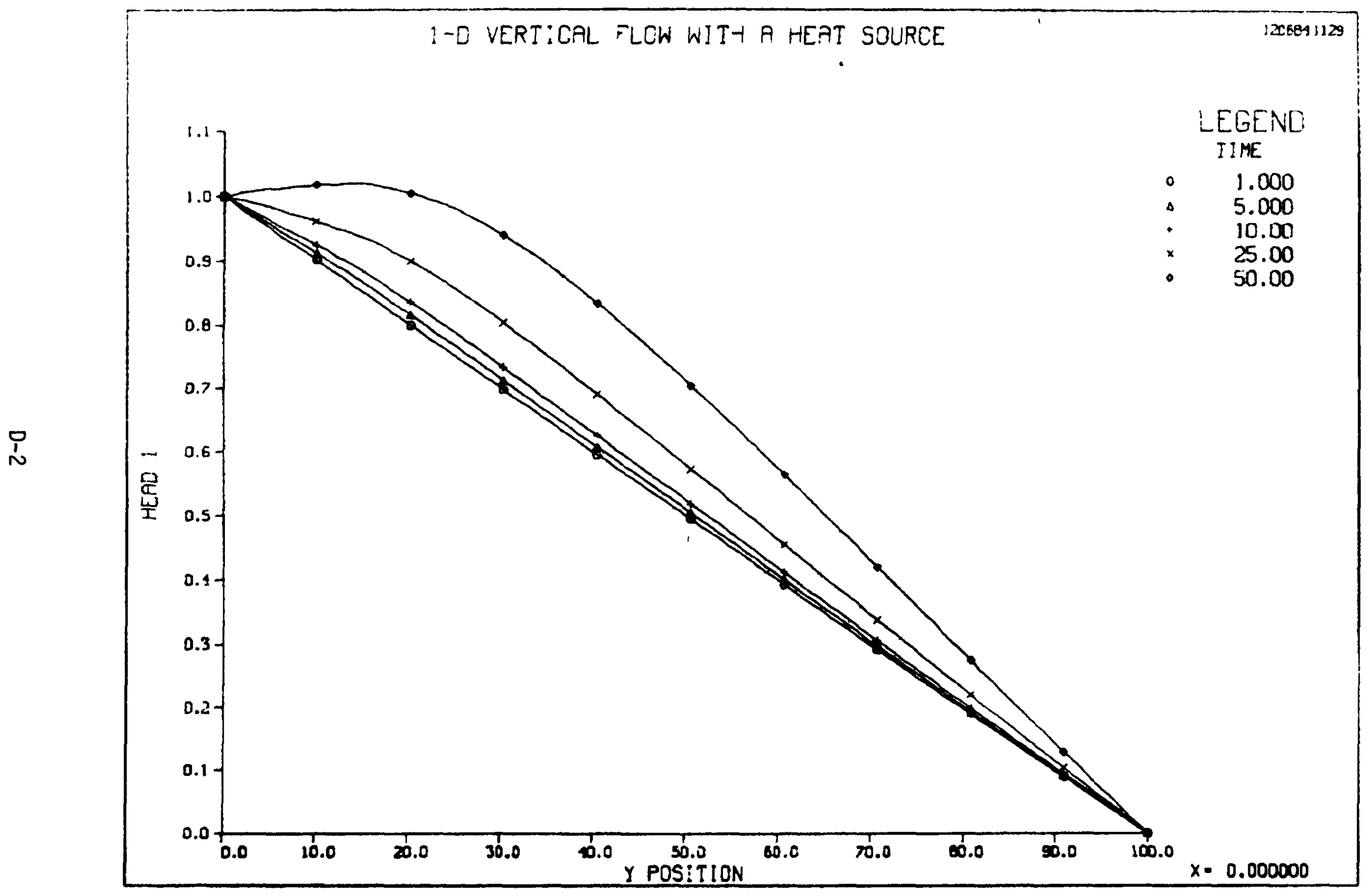

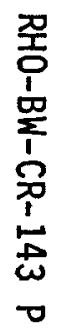

FIGURE D-1. Hydraulic Head Profiles for Test Case. One. 


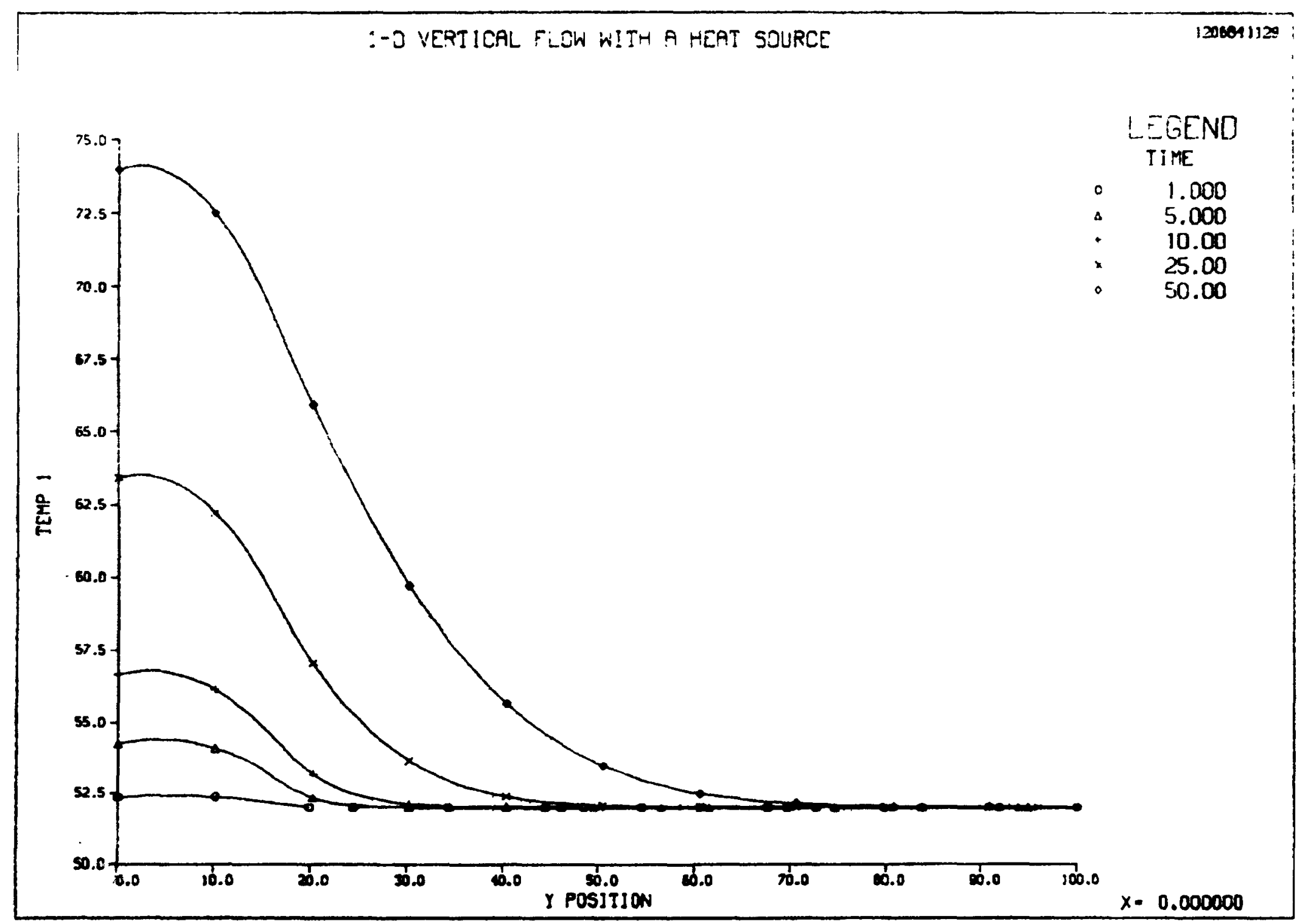

FIGURE D-2. Temperature Profiles for Test Case One. 


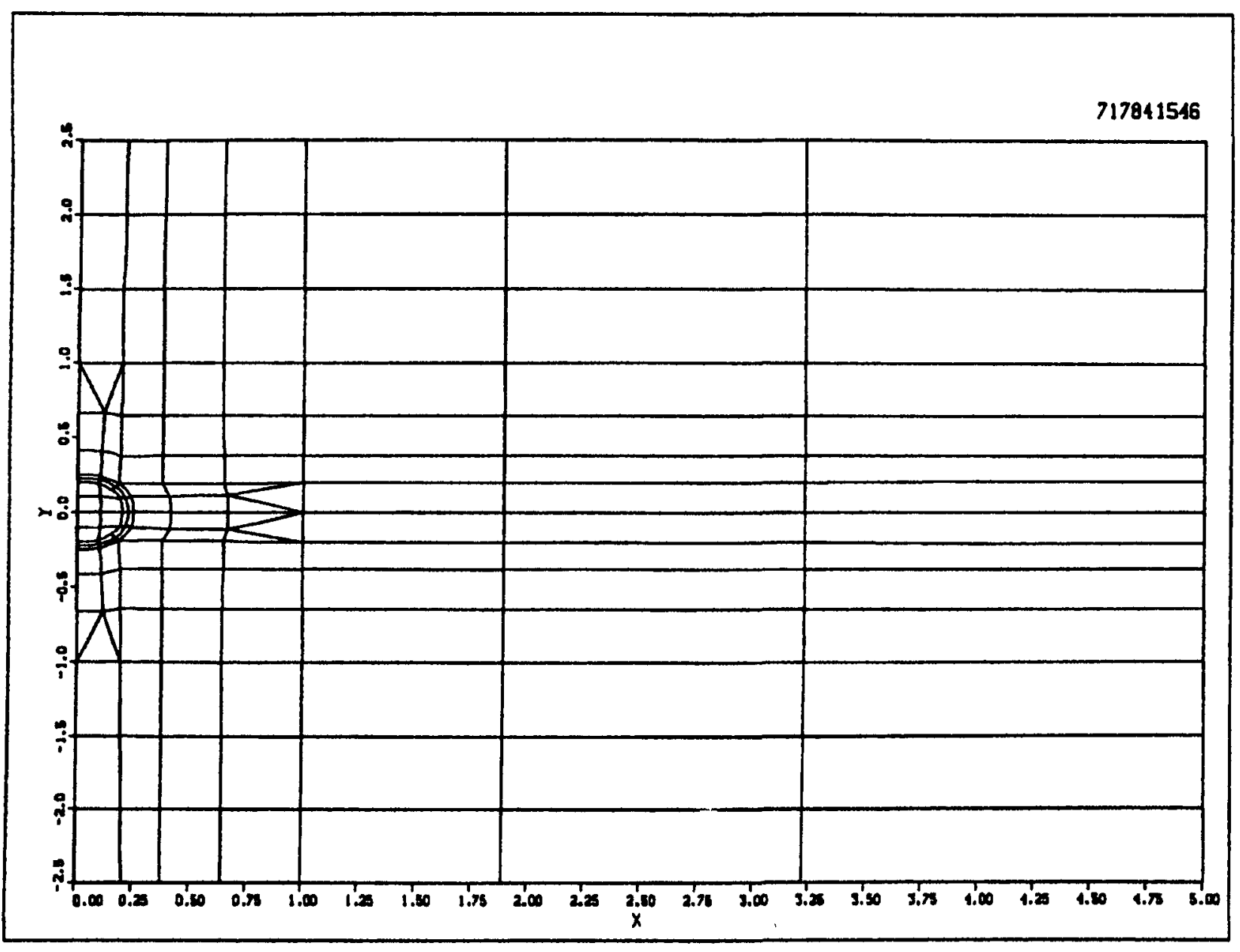

FIGURE D-3. Finite-Element Grid for Test Case Two. 


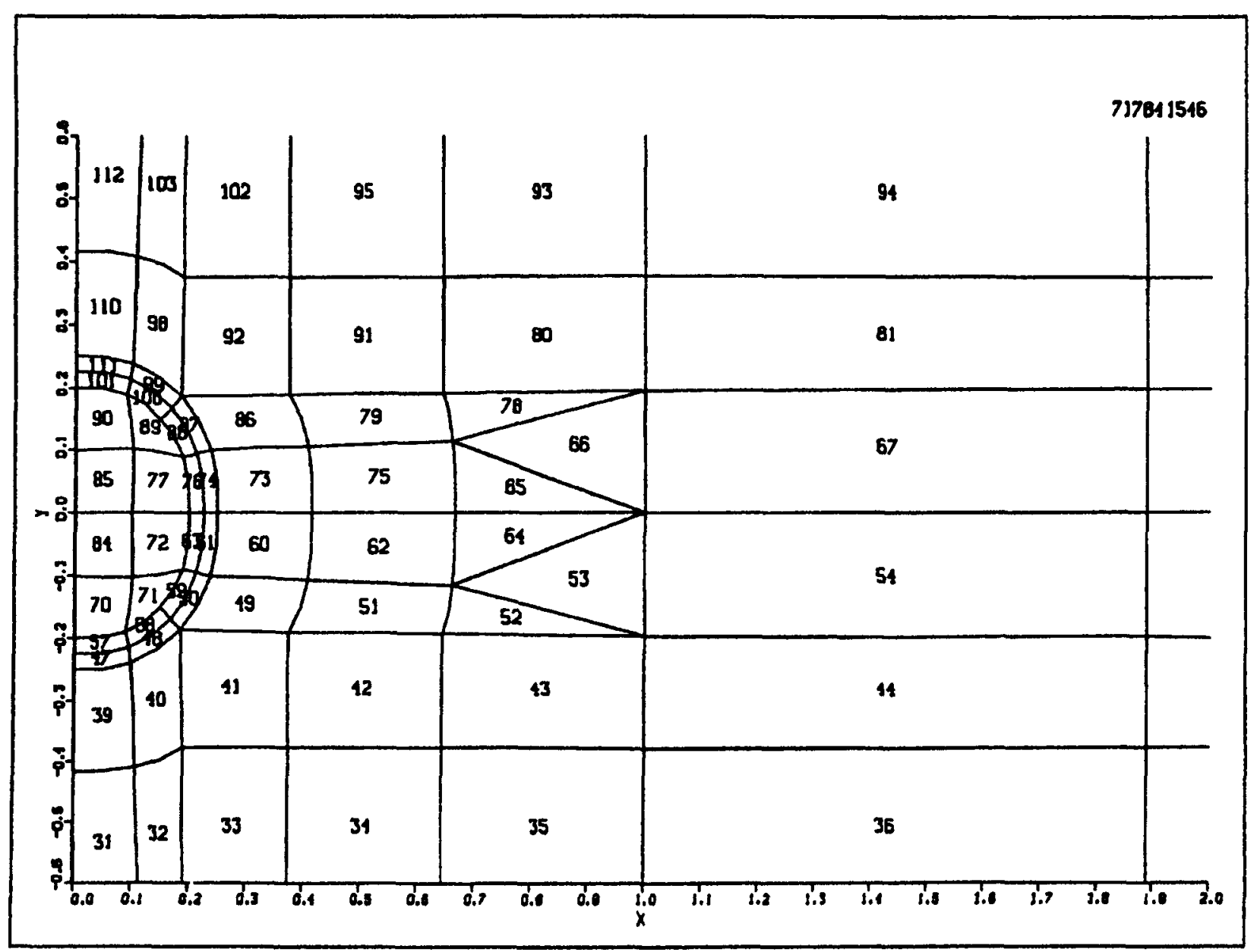

FIGURE D-4. Closeup View of Heat Source Gridding with Element Numbers for Test Case Two. 


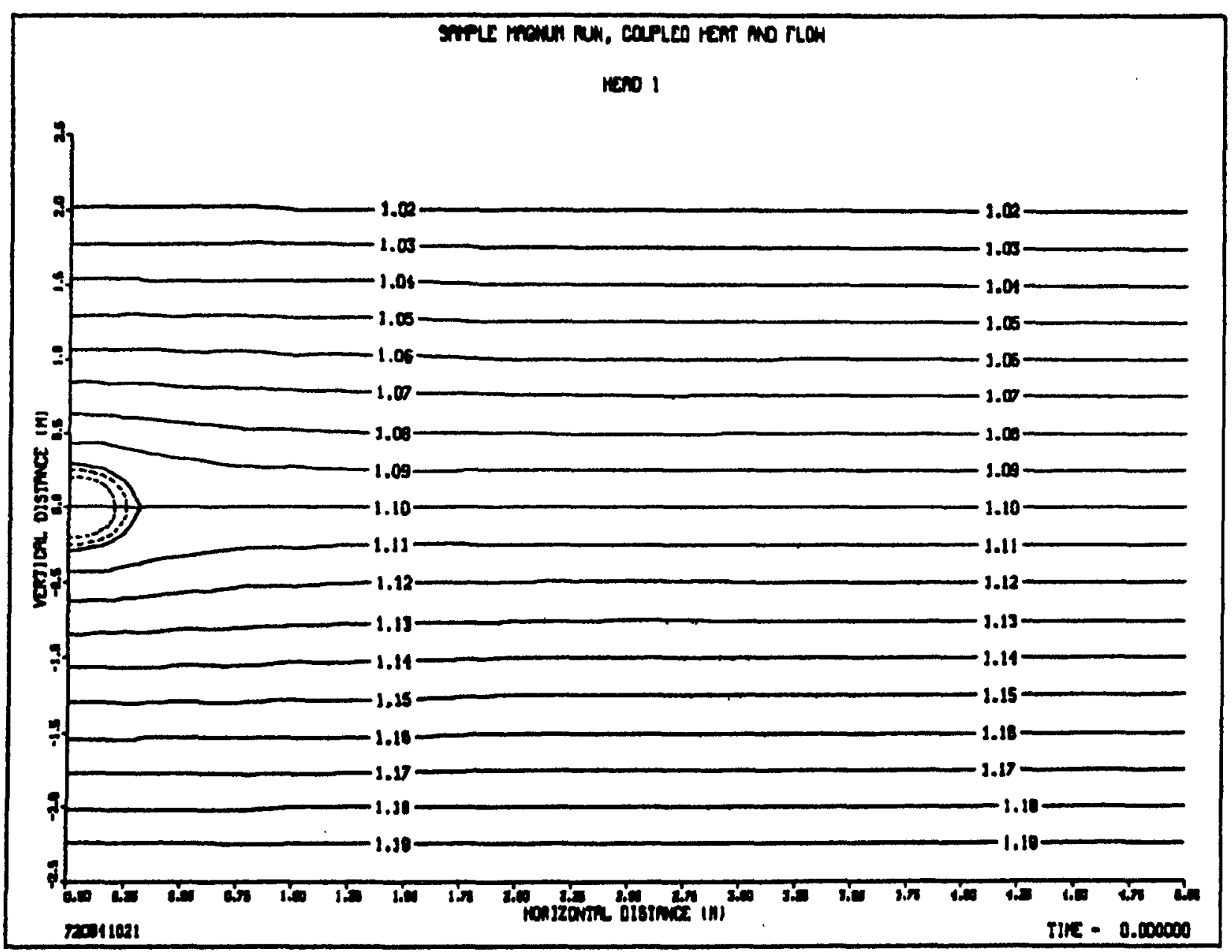

FIGURE D-5. Initial Hydraulic Head Contours for Test Case Two. 


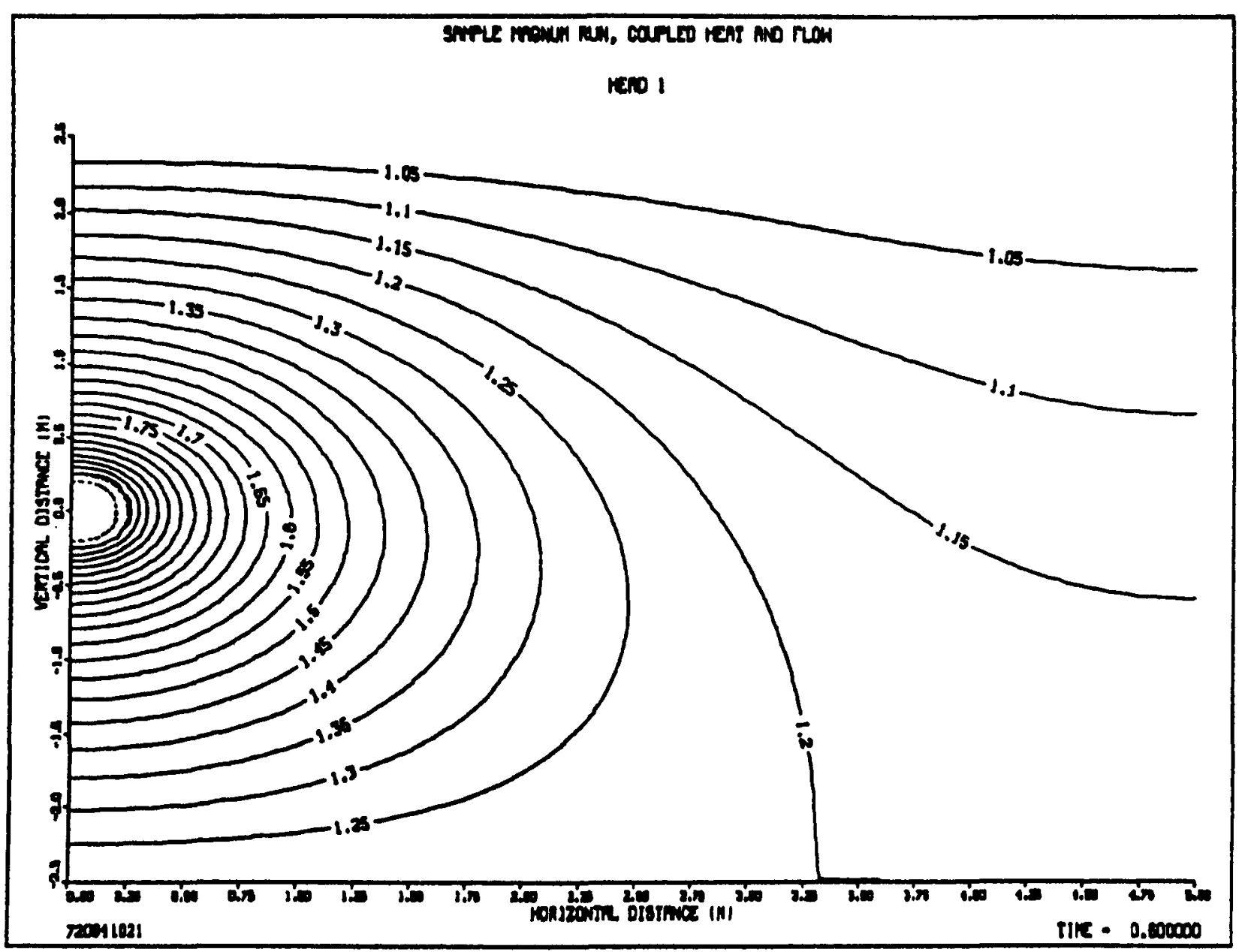

FIGURE D-6. Hydraulic Head Contours at 0.6 Year for Test Case Two. 


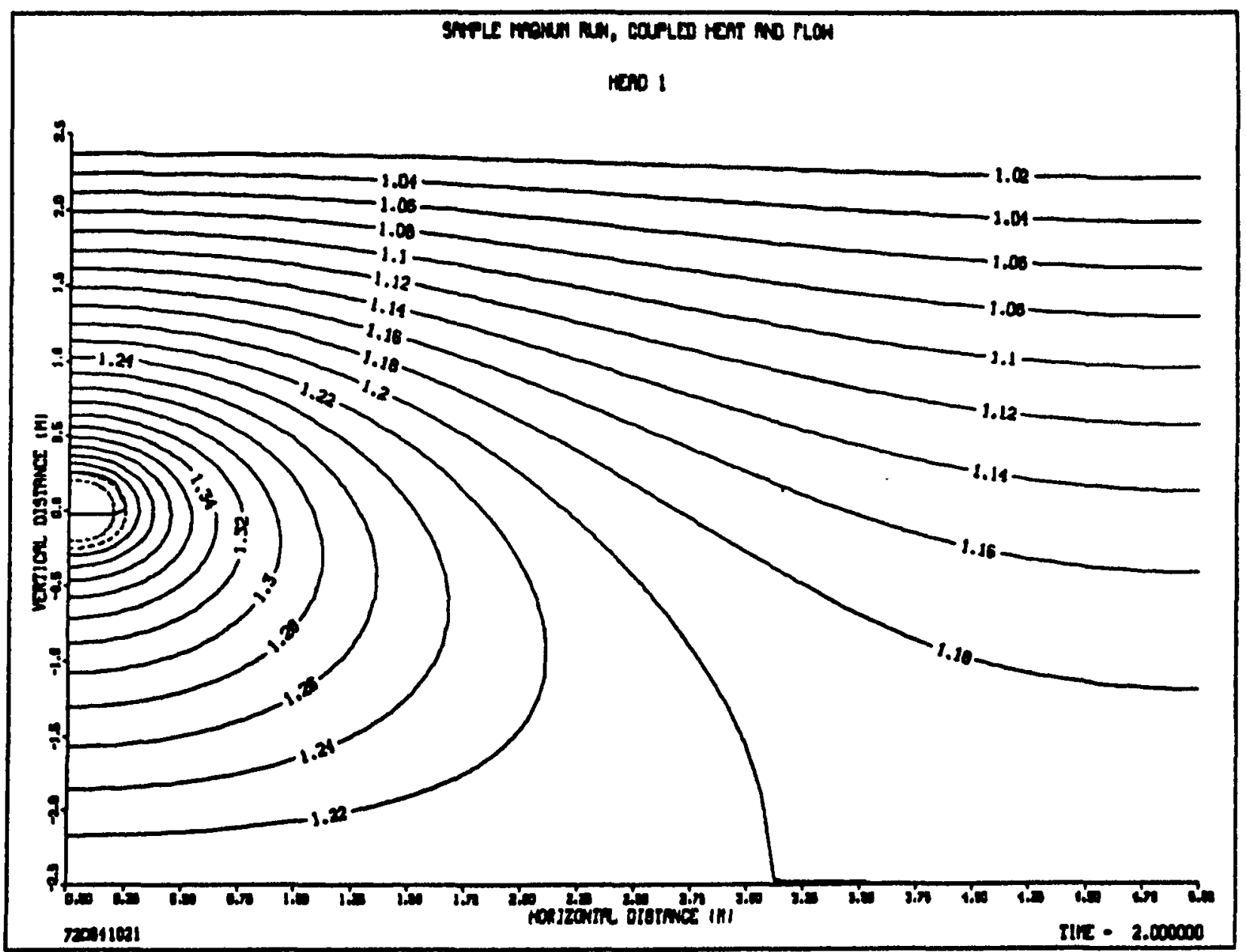

FIGURE D-7. Hydraulic Head Contours at Two Years for Test Case Two. 


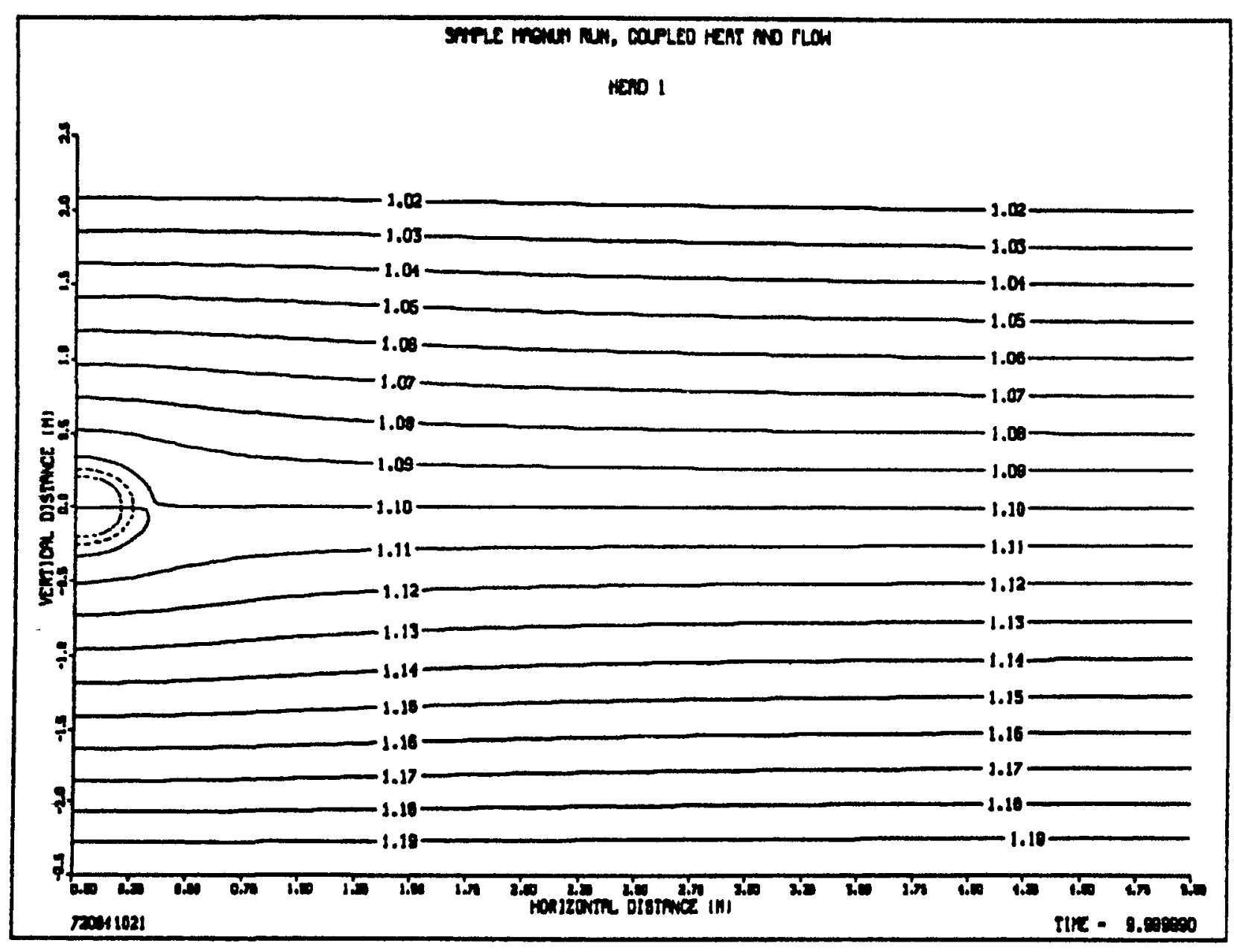

FIGURE D-8. Hydraulic Head Contours at 10 Years for Test Case Two. 


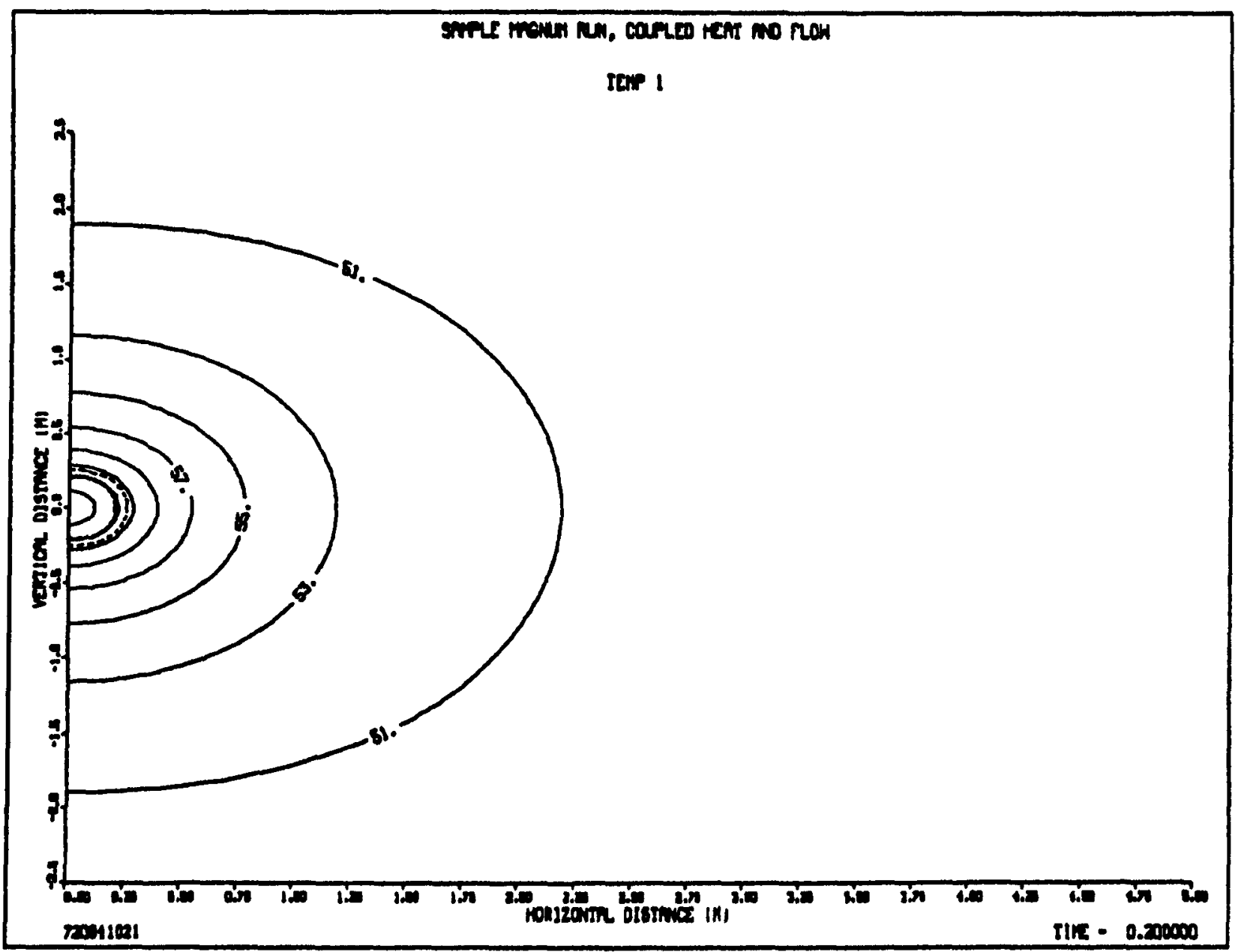

종
0
0
$\frac{1}{2}$
1
0
0
1
1
$\omega$
0
0

FIGURE D-9. Temperature Contours at 0.2 Year for Test Case Two. 


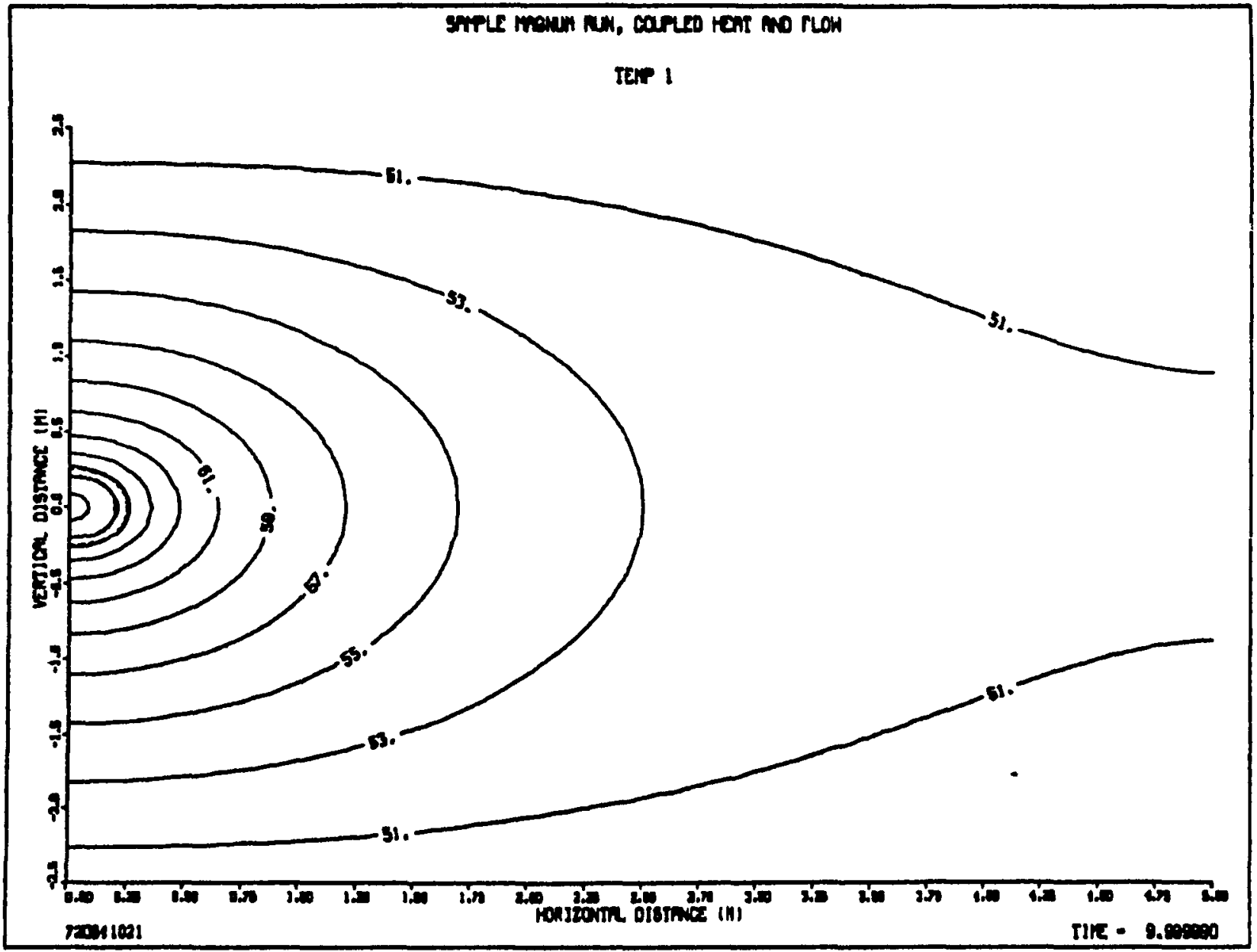

FIGURE D-10. Temperature Contours at 10 Years for Test Case Two. 


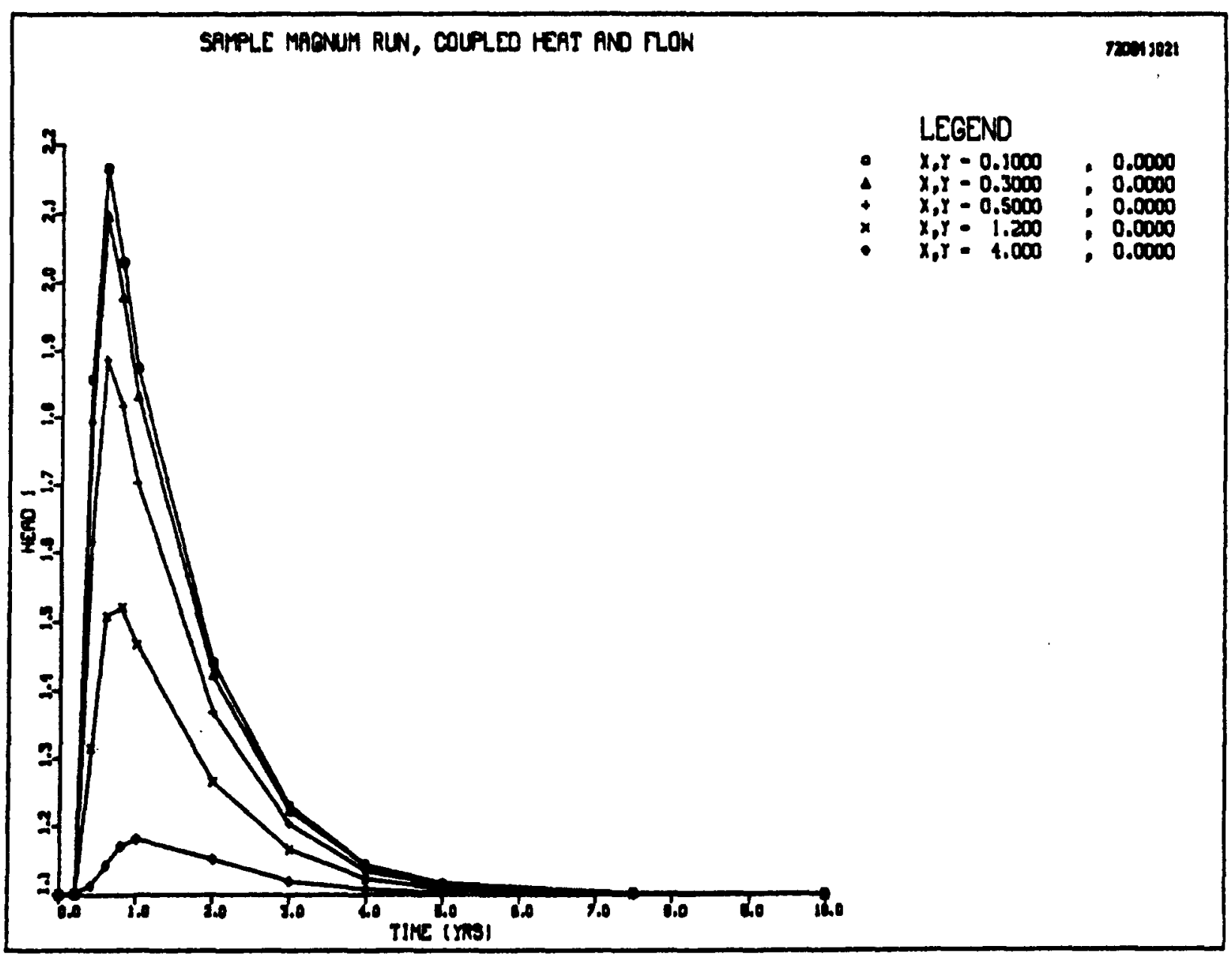

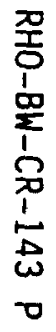

FIGURE D-11. Time History of Hydraulic Head at Selected Points for Test Case Two. 


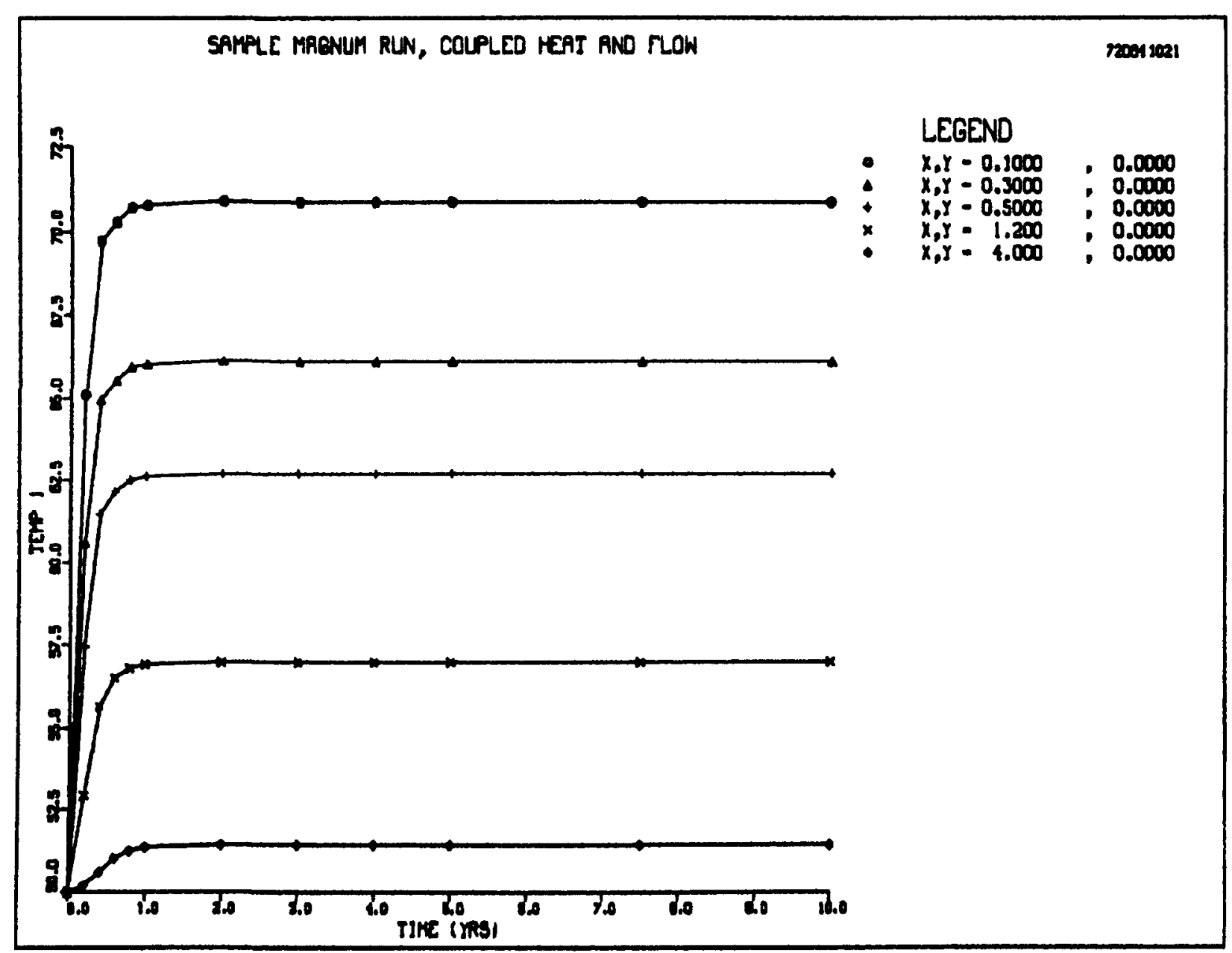

FIGURE D-12. Time History of Temperature at Selected Points for Test Case Two. 
LISTING D-1. Input Data File for Test Case One. (Sheet 1 of 3) ONE DIMENSION VERTICAL FLON WITH HEAT OENERATION

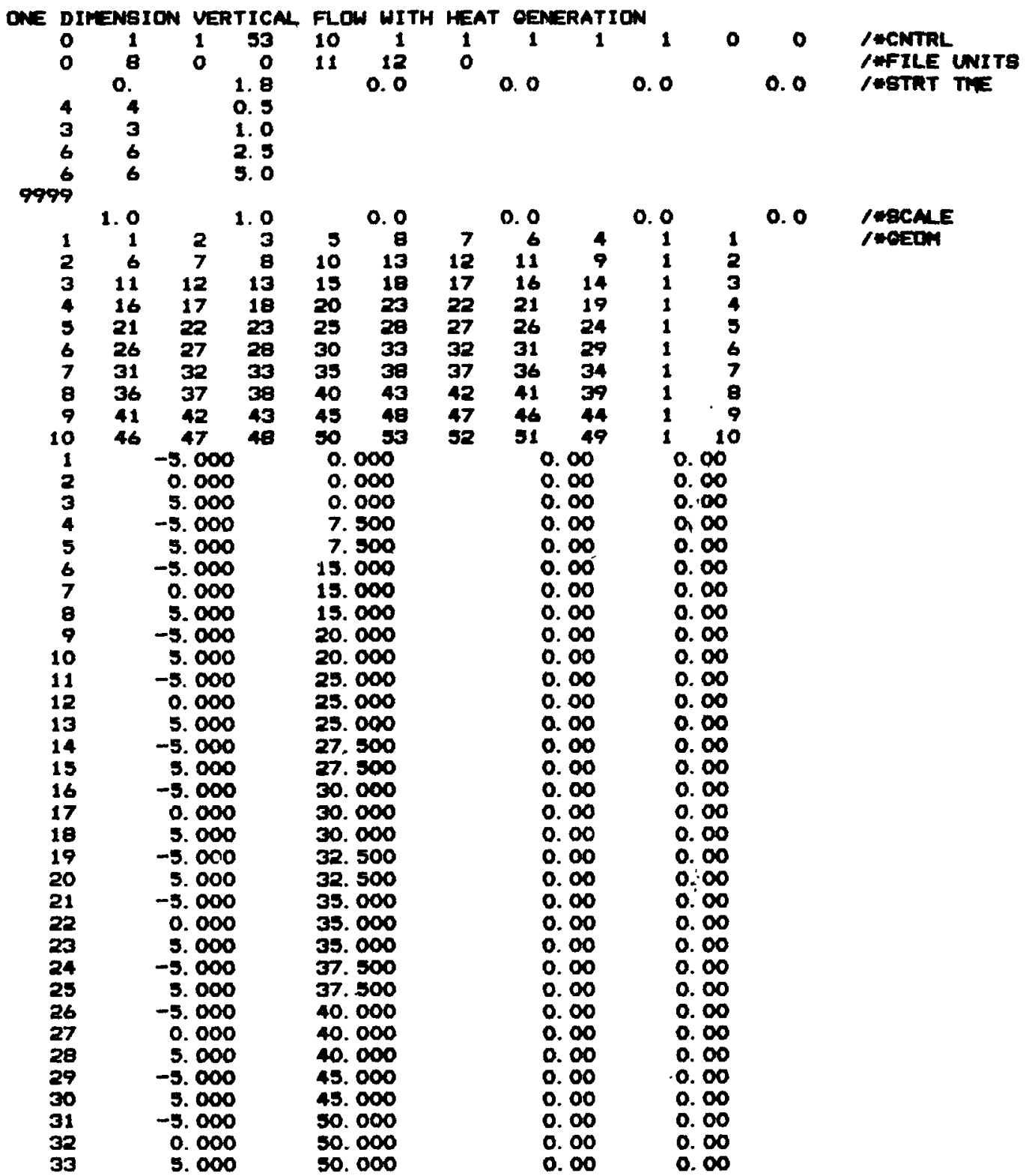


LISTING D-1. Input Data File for Test Case One. (Sheet 2 of 3) ONE DIMENBION VERTICAL FLOW WITH HEAT GENERATION

\begin{tabular}{|c|c|c|c|c|}
\hline $\begin{array}{r}3 \\
4 \\
5 \\
6 \\
7 \\
8 \\
9 \\
10 \\
11 \\
12 \\
13 \\
14\end{array}$ & $\begin{array}{r}-5.000 \\
5.000 \\
-5.000 \\
\text { 0. } 000 \\
5.000 \\
-5.000 \\
\text { 5. } 000 \\
-5.000 \\
\text { 0. } 000 \\
5.000 \\
-5.000 \\
5.000 \\
-5.000 \\
\text { 0. } 000 \\
5.000 \\
-5.000 \\
5.000 \\
-5.000 \\
0.000 \\
5.000 \\
52.00 \\
52.00 \\
52.00 \\
52.00 \\
52.00 \\
52.00 \\
52.00 \\
52.00 \\
52.00 \\
52.00 \\
52.00 \\
52.00 \\
52.00 \\
52.00 \\
52.00 \\
52.00 \\
52.00 \\
52.00 \\
52.00 \\
52.00 \\
52.00 \\
52.00 \\
52.00 \\
52.00 \\
52.00 \\
52.00 \\
52.00 \\
52.00 \\
52.00 \\
52.00 \\
52.00 \\
52.00 \\
52.00\end{array}$ & 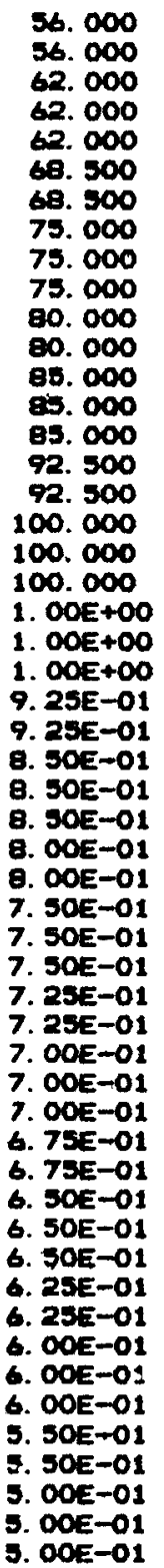 & $\begin{array}{l}0.00 \\
0.00 \\
0.00 \\
0.00 \\
0.00 \\
0.00 \\
0.00 \\
0.00 \\
0.00 \\
0.00 \\
0.00 \\
0.00 \\
0.00 \\
0.00 \\
0.00 \\
0.00 \\
0.00 \\
0.00 \\
0.00 \\
0.00\end{array}$ & $\begin{array}{l}0.00 \\
0.00 \\
0.00 \\
0.00 \\
0.00 \\
0.00 \\
0.00 \\
0.00 \\
0.00 \\
0.00 \\
0.00 \\
0.00 \\
0.00 \\
0.00 \\
0.00 \\
0.00 \\
0.00 \\
0.00 \\
0.00 \\
0.00\end{array}$ \\
\hline
\end{tabular}


LISTING D-1. Input Data File for Test Case One. (Sheet 3 of 3) ONE DIMENGION VERTICAL FLOW WITH HEAT OENERATION

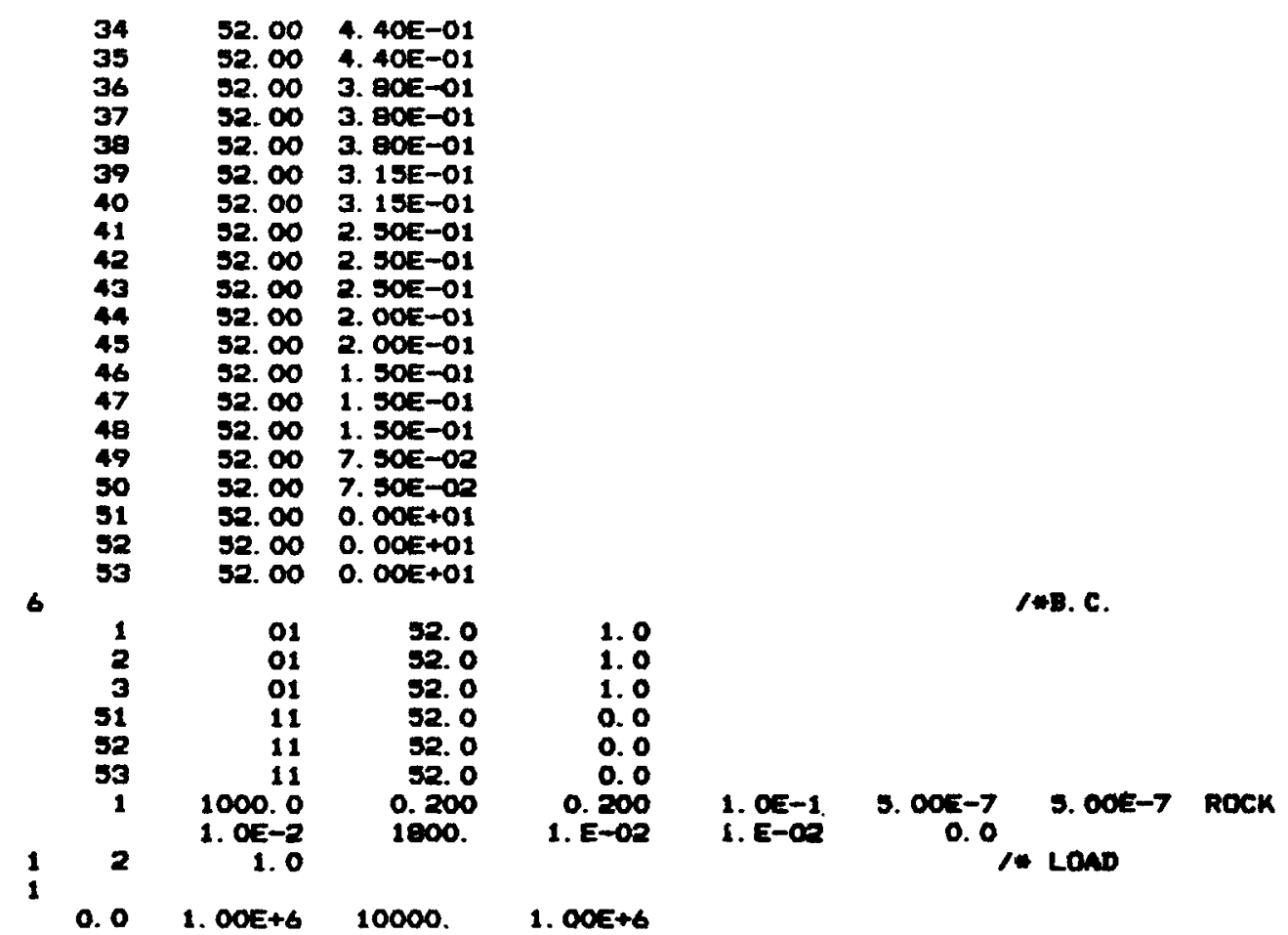


RHO-BW-CR-143 P

LISTING D-2. The PRIMOS Command File for Test Case One.

EAT BEERUN

EAT EEPRUN

EAT PRT

EAT RLT

COMO BEERUN

DATE

DELSEO ALI

TinE

OPEN DATA 11

OPEN PRT 23

OPEN WORKSPACE 143

OPEN RLT 43

CPEN OEOA 73

CPEN Val 103

SEO SYSTEMSDFEMDMAONUMD WMANUM

TIME

CLOBE HORKSPACE

EAT MORKBPACE

COMD - END

CLOBE ALL

Cons -TTY 
LISTING D-3. Output Report File for Test Case One. (Sheet 1 of 13)

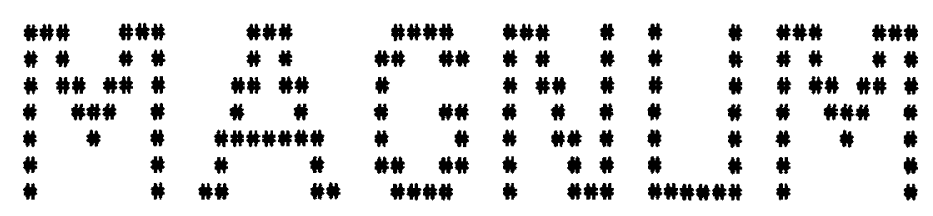

VERSION 3. 0 (ReVision 1.)

THU, JUL 121984

11: 13:09

$I D=712841113$ 
LISTING D-3. Output Report File for Test Case One. (Sheet 2 of 13)

ONE DIMENSION VERTICAL FLOW WITH HEAT GENERATION

TABLE 1. - PRINCIPAR PROBLEM gPECificationg

BIMULATION MODE (O-TIME VARYIM, . ME. O-BTEADY BTATE). . . .

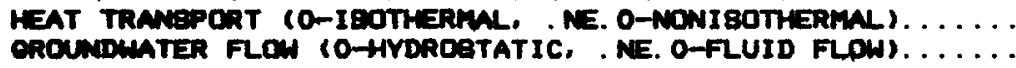
MHDER OF NoDEB.

MURER OF ELENENTS.

MURER OF ROCK TMES.

INITIAL CONDITION INOUTS (O-UNIFORM, 1-BPATIALLY VARVINO) IMOUT DATA PAINT GONTROL (O-PARTIAL ECHO, 1-TOTAL ECHO.

DIAONOBTIC PAINTOUT CO-NO ACTION 1-COMEROENCE INFO .... RESULTS FILE WF

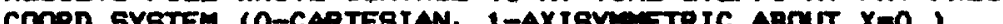

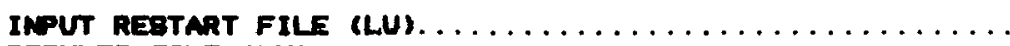

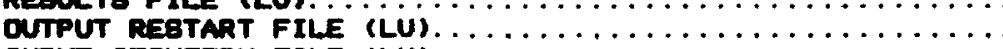

IMPUT CEOMETRY FILE (LU)

GUTPUT CEOTLTRY FILE (LU).

STREAM/PATKLINE DMTA FILE (LU).

TEMPERATURE INPUT FILE (TEMPERATIRE INACTIVE)

INITIAL CONDITIDN OUTPUT FILE (FORMATTED)

BCALE FACTOR FOR $X$ COORDIMATES.

BCALE FACTOR FOR Y COORDIMATEB.

SCALT BOUMDARY FOR CWAD EL EMENTS.

RIOHT BOUNDARY FOD CUAD EL EMENTE.

1.00
$\ldots \ldots \ldots \ldots$$\quad 1.00$

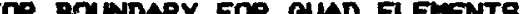

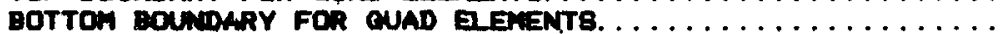

BTART TIME (VEARS).

ThT TIV E

Derent

0
1
1
23
10
1
1
1
1
1
0
0
0
8
0
0
11
12
0
0
1.00
1.00
0.00
0.00
0.00
0.00
0.00
1.8
0.0

TIME CONTROL MN RUN BPECIFICATIONB

NUMBER OF TIME BTEPS

4
3
6
6
PRINT INTERVAL

TIME STEP
0.5000
1.000
2.500
5.000

TIME(YEARS)
2. 000
5.000
20.00
50.00 
LISTING D-3. Output Report File for Test Case One. (Sheet 3 of 13)

TABLE 2. - NODE POINT COORDIMATEB

\begin{tabular}{|c|c|c|c|c|c|c|c|c|c|c|c|c|}
\hline $\begin{array}{r}\text { MODE } \\
1 \\
2 \\
3 \\
4 \\
5 \\
6 \\
7 \\
8 \\
9 \\
10 \\
11 \\
12 \\
13 \\
14\end{array}$ & $\begin{array}{r}\text { XCORD } \\
-5.00 \\
0.00 \\
5.00 \\
-5.00 \\
5.00 \\
-5.00 \\
0.00 \\
5.00 \\
-5.00 \\
5.00 \\
-5.00 \\
0.00 \\
5.00 \\
-5.00\end{array}$ & $\begin{array}{r}\text { YCOAD } \\
0.00 \\
0.00 \\
0.00 \\
7.50 \\
7.50 \\
15.00 \\
15.00 \\
15.00 \\
20.00 \\
20.00 \\
25.00 \\
25.00 \\
25.00 \\
27.50\end{array}$ & $\begin{array}{r}\text { NaDE } \\
15 \\
16 \\
17 \\
18 \\
19 \\
20 \\
21 \\
22 \\
23 \\
24 \\
25 \\
26 \\
27 \\
29\end{array}$ & $\begin{array}{r}\text { XCORD } \\
5.00 \\
-5.00 \\
0.00 \\
5.00 \\
-5.00 \\
5.00 \\
-5.00 \\
0.00 \\
5.00 \\
-5.00 \\
5.00 \\
-5.00 \\
0.00 \\
5.00\end{array}$ & $\begin{array}{l}\text { YCORD } \\
27.50 \\
30.00 \\
30.00 \\
30.00 \\
32.50 \\
32.50 \\
35.00 \\
35.00 \\
35.00 \\
37.50 \\
37.50 \\
40.00 \\
40.00 \\
40.00\end{array}$ & $\begin{array}{r}100 E \\
29 \\
30 \\
31 \\
32 \\
33 \\
34 \\
35 \\
36 \\
37 \\
38 \\
39 \\
40 \\
41 \\
42\end{array}$ & $\begin{array}{r}\text { xCORD } \\
-5.00 \\
5.00 \\
-5.00 \\
0.00 \\
5.00 \\
-5.00 \\
5.00 \\
-5.00 \\
0.00 \\
5.00 \\
-5.00 \\
5.00 \\
-5.00 \\
0.00\end{array}$ & $\begin{array}{l}\text { YCCRD } \\
45.00 \\
45.00 \\
50.00 \\
50.00 \\
50.00 \\
56.00 \\
56.00 \\
62.00 \\
62.00 \\
62.00 \\
66.50 \\
68.50 \\
75.00 \\
75.00\end{array}$ & r & $\begin{array}{r}\text { MODE } \\
43 \\
44 \\
45 \\
46 \\
47 \\
48 \\
49 \\
50 \\
51 \\
52 \\
53\end{array}$ & $\begin{array}{r}\text { XCOND } \\
5.00 \\
-5.00 \\
5.00 \\
-5.00 \\
0.00 \\
5.00 \\
-5.00 \\
5.00 \\
-5.00 \\
0.00 \\
5.00\end{array}$ & $\begin{array}{r}\text { YCORD } \\
75.00 \\
80.00 \\
80.00 \\
85.00 \\
85.00 \\
85.00 \\
92.50 \\
92.50 \\
100.00 \\
100.00 \\
100.00\end{array}$ \\
\hline
\end{tabular}

TABLE 3. - ELEMENT/MODE CONNECTIVITY

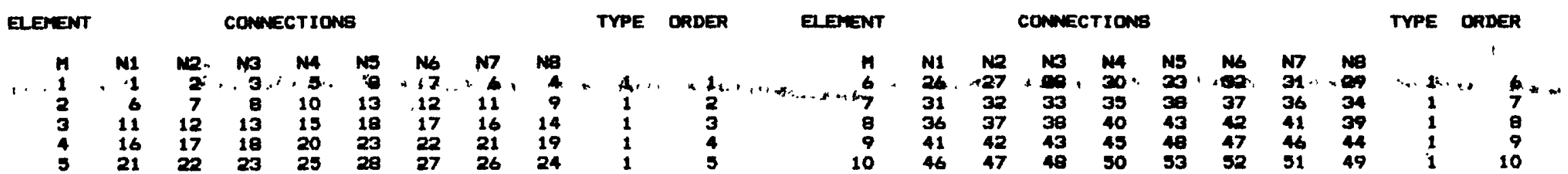


LISTING D-3. Output Report File for Test Case One. (Sheet 4 of 13)

TABLE 4. - INITIAL CONDITIONB

\begin{tabular}{|c|c|c|c|c|c|c|c|c|}
\hline $\begin{array}{c}\text { MOEE } \\
1 \\
2 \\
3 \\
4 \\
5 \\
6 \\
7 \\
8 \\
9 \\
10 \\
11 \\
12 \\
13 \\
14 \\
15 \\
16 \\
17 \\
18\end{array}$ & $\begin{array}{l}T(C) \\
52.00 \\
52.00 \\
32.00 . \\
52.00 \\
52.00 \\
52.00 \\
52.00 \\
52.00 \\
52.00 \\
52.00 \\
52.00 \\
52.00 \\
52.00 \\
52.00 \\
52.00 \\
52.00 \\
52.00 \\
52.00\end{array}$ & $\begin{array}{l}H(M) \\
1.00 \\
1.00 \\
1.00 \\
0.92 \\
0.92 \\
0.85 \\
0.85 \\
0.85 \\
0.80 \\
0.80 \\
0.75 \\
0.77 \\
0.75 \\
0.72 \\
0.72 \\
0.70 \\
0.70 \\
0.70\end{array}$ & $\begin{array}{l}\text { NODE } \\
19 \\
20 \\
21 \\
22 \\
23 \\
24 \\
25 \\
26 \\
27 \\
28 \\
29 \\
30 \\
31 \\
32 \\
33 \\
34 \\
35 \\
36\end{array}$ & $\begin{array}{l}7(c) \\
52.00 \\
32.00 \\
52.00 \\
52.00 \\
32.00 \\
52.00 \\
52.00 \\
52.00 \\
32.00 \\
32.00 \\
52.00 \\
52.00 \\
32.00 \\
52.00 \\
52.00 \\
52.00 \\
52.00 \\
52.00\end{array}$ & $\begin{array}{l}H(M) \\
0.67 \\
0.67 \\
0.65 \\
0.65 \\
0.65 \\
0.63 \\
0.63 \\
0.60 \\
0.60 \\
0.60 \\
0.55 \\
0.55 \\
0.50 \\
0.50 \\
0.50 \\
0.44 \\
0.44 \\
0.38\end{array}$ & $\begin{array}{r}\text { NODE } \\
37 \\
39 \\
39 \\
40 \\
41 \\
42 \\
43 \\
44 \\
45 \\
46 \\
47 \\
49 \\
49 \\
50 \\
51 \\
52 \\
53\end{array}$ & $\begin{array}{l}T(C) \\
52.00 \\
52.00 \\
52.00 \\
32.00 \\
52.00 \\
52.00 \\
52.00 \\
52.00 \\
52.00 \\
52.00 \\
52.00 \\
52.00 \\
52.00 \\
52.00 \\
52.00 \\
52.00 \\
52.00\end{array}$ & $\begin{array}{l}H(M) \\
0.30 \\
0.39 \\
0.31 \\
0.31 \\
0.25 \\
0.25 \\
0.25 \\
0.20 \\
0.20 \\
0.15 \\
0.15 \\
0.15 \\
0.07 \\
0.07 \\
0.00 \\
0.00 \\
0.00\end{array}$ \\
\hline
\end{tabular}

TABLE 5. - BPECIFIED DOUNOARY CONDITIONS

MUMBER OF GPECIFIED BOUNDARY MODES

MODE TYPE
1 (01)
2 (01)
3 (01)
51 (11)
$32(11)$
$53(11)$

$T(6)$
52.000
52.000
52.000
52.000
52.000
52.000

6

$H(M)$

1. 000

1. 000

0.000

o. 000

0.000 
LISTING D-3. Output Report File for Test Case One. (Sheet 5 of 13)

TABLE 6. - ROCK PROPERTIES

PMRALTER

1. EPECIFIC HEAT
(J/KO-C)

2. THERMAL CONDUCTIVITV IN $X$ $(J / E E C-M-C)$

3. THERMAL CONDUCTIVITY IN $Y$ $(J / E E C-H-C)$

4. EFFECTIVE POROBITY (FRACTION)

5. HYOAAULIC CONOUCTIVITY (KXX-Mresc)

6. HYDRACLIC CONDUCTIUITY (KZZ-M/BEC)

7. BPECIFIC BTORAOE (1/M)

8. ROCK DangITY (KO/MH+3)

9. LONOITUOINAL DIBPEABIVITY (M)

10. LATERAL DIEPEREIVITY (M)

11. FRACTURE/FAULT THICKNESg (H)

$$
\operatorname{Rock}^{1}
$$

1. $000 E+03$

2. $000 E-01$

2. $000 E-01$

1. $000 E-01$

5. $000 E-07$

5. $000 E-07$

1. $000 E-02$

1. $800 E+03$

1. $000 E-\infty 2$

1. $000 E-02$

0. 000E-01

ROCK TYPES 
LISTING D-3. Output Report File for Test Case One. (Sheet 6 of 13)

TABLE 7. - HEAT GENERATION HIsTOAY

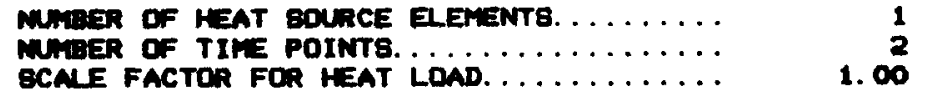

HEAT BOURCE ELENENT MUMEER

1

$\begin{array}{cc}\text { TIME (YR) } & \text { THERMAL LOAD (J/YR-M**3) } \\ & \\ 0.000 & 0.100 E+07 \\ 0.100 E+05 & 0.100 E+07\end{array}$

ONE DIMENBION VERTICAL FLOW WITH HEAT OEMERATION REgURTB ON VEAR 2.000

\begin{tabular}{|c|c|c|c|c|c|c|c|c|c|}
\hline MODE & $T(C)$ & HS & & MODE & $T(C)$ & $H(M)$ & NODE & $T(C)$ & $H(M)$ \\
\hline
\end{tabular}

ITERATION NUMBER

52.00

o. 3918

ITERATION

1. MAX REL CHANOE (TEMP) = 4.6735E-03.

MAX REL CORRECTION = 4.6107E-OS 
LISTING D-3. Output Report File for Test Case One. (Sheet 7 of 13)

ONE DIMENBION VERTICAL FLOW WITH HEAT GENERATION

$\begin{array}{lll}\text { RESULTS FOR VELOCITY (M/YR) OF YEAR } & 2.000\end{array}$

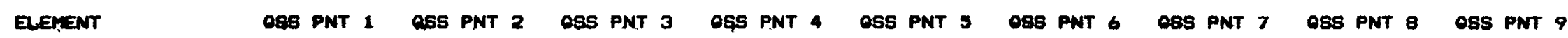

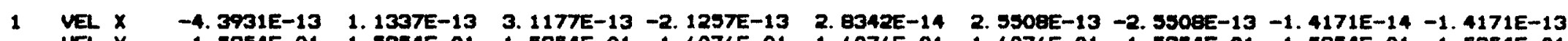
VEL $V$ 1.5954E-01 1.5954E-01 1.5954E-01 $1.6076 E-01 \quad 1.6076 E-01 \quad 1.6076 E-01 \quad 1.5954 E-01 \quad 1.5954 E-01 \quad 1.5954 E-01$

2 VEL $X \quad-1.4122 E-12 \quad 6.3233 E-14 \quad 1.2366 E-12-1.0117 E-12-4.2156 E-14 \quad 9.4147 E-13 \quad-5.4100 E-13 \quad 8.4311 E-14 \quad 3.8643 E-13$

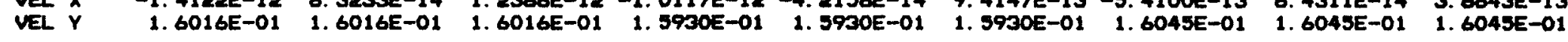

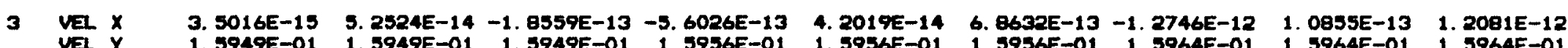

4VL $X \quad-1.4005 E-14$ 6.6524E-14 -1.5055E-13 $1.2605 E-13 \quad 2.8010 E-14-8.4030 E-14 \quad 1.8907 E-13 \quad 3.1511 E-14-3.4663 E-13$ VEL $V$ 1. 5934E-01 1.5934E-01 1.5934E-01 1.5940E-01 1.5940E-01 1.5940E-01 1.5946E-01 $1.5946 E-01$ 1. 5946E-01

5 VEL $X \quad 1.7506 E-14 \quad 1.0504 E-13-2.8010 E-14 \quad 2.8010 E-14 \quad 4.2014 E-14 \quad 8.4029 E-14 \quad-4.5516 E-14 \quad 4.2014 E-14-9.4532 E-14$

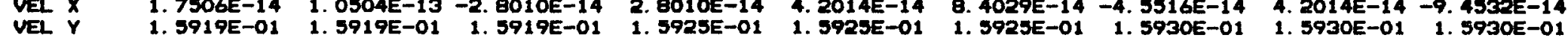

6 VEL $X \quad-7.0024 E-15 \quad 6.6523 E-14-2.1007 E-14-3.5012 E-14-1.4005 E-14 \quad 2.8010 E-14-1.0504 E-14 \quad 6.6523 E-14-6.3022 E-14$

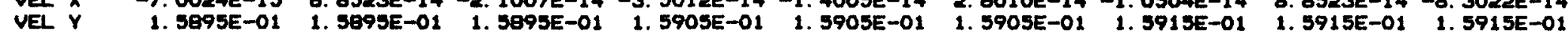

7 VEL $X \quad-4.5516 E-14 \quad 5.6019 E-14-5.6019 E-14-2.8010 E-14 \quad-6.3022 E-14 \quad 2.8010 E-14-1.7306 E-14 \quad 5.2518 E-14 \quad 2.8010 E-14$ VEL $Y$ 1. 5869E-01 1.5869E-01 1.5869E-01 1.5879E-01 1.5879E-01 $1.5879 E-01$ 1. 5889E-01 $1.5889 E-01$ 1. S899E-01

8 VEL $x \quad-1.4005 E-14 \quad 3.3261 E-14-1.7506 E-14$-2. $1007 E-14$-2. 1007E-14 $-1.4005 E-14$ 1.7506E-14 6. 6523E-14 $1.9257 E-14$

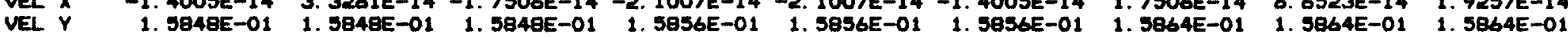

9 VEL $X \quad-1.5755 E-14 \quad 2.4508 E-14 \quad-2.4508 E-14-1.0504 E-14-1.4005 E-14 \quad 3.5012 E-15 \quad 7.0024 E-15 \quad 4.5516 E-14 \quad 1.7506 E-15$

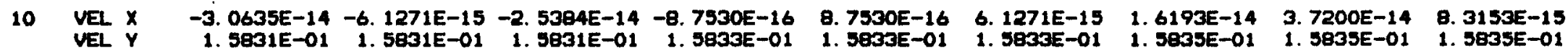


LISTING D-3. Output Report File for Test Case One. (Sheet 8 of 13)

ONE DIMENSION VERTICAL FLOW WITH HEAT GEMERATION

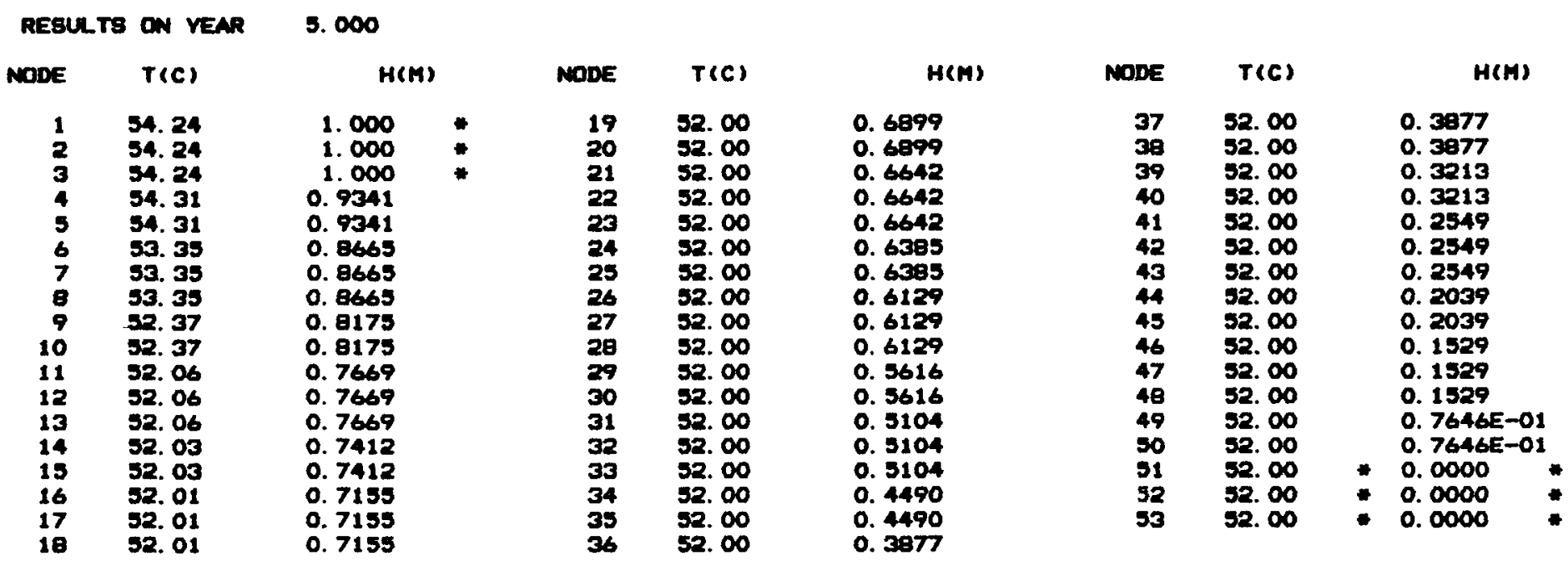

1. MAX REL CHAMOE (TEMP) $=9.0616 E-03$, MAX REL CORRECTION $=1.0331 E-04$
1. MAX REL CHANOE (HEAD) $=5.3353 E-03$, MAX REL CORRECTION $=5.7904 E-04$ ITERATIOM MUMBER 
LISTING D-3. Output Report File for Test Case One. (Sheet 9 of 13)

ONE DIMENSION VERTICAL FLOW WITH HEAT OENERATION

REQURTS FCR VELOCITY (M/YR) OF VEAR $\quad$ 5. 000

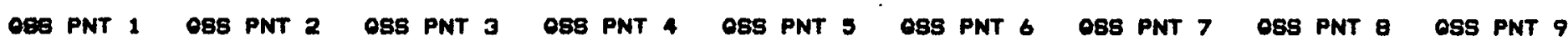

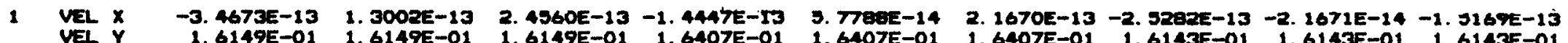

2 VEL $X \quad-7.7825 E-14 \quad 1.2735 E-13 \quad 1.4150 E-14-2.1225 E-13-4.2450 E-14 \quad 1.5565 E-13 \quad-3.6092 E-13 \quad 9.1974 E-14 \quad 1.8395 E-13$

VEI $Y$ 1.6314E-01 1.6314E-01 1.6314E-01 $1.6158 E-01$ 1.6158E-01 $1.6158 E-01$ 1.6337E-01 $1.6337 E-01$ 1.6337E-01

3 Val $x \quad-1.2612 E-13 \quad 3.5032 E-15-1.7516 E-13-7.0065 E-14-2.0026 E-14-1.4013 E-14-7.0065 E-15 \quad 1.2962 E-13 \quad 3.5032 E-15$ VEI $Y$ 1.6216E-01 1.6216E-01 1.6216E-01 1.6219E-01 $1.6219 E-01$ 1.6219E-01 $1.6233 E-01$ 1.6233E-01 $1.6233 E-01$

4 VEL $X \quad 3.1164 E-13 \quad 1.2606 E-13-2.6962 E-13 \quad 2.1009 E-13 \quad$ O. $4037 E-14-5.6025 E-14-1.4006 E-14 \quad 3.5016 E-14-1.2606 E-13$

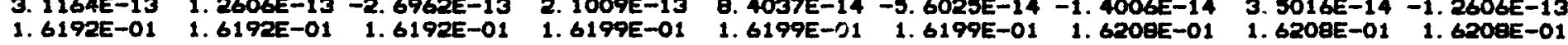

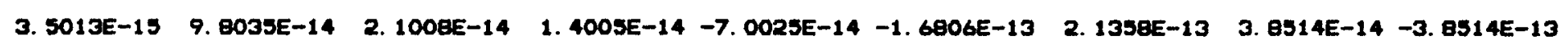
1.6174E-01 1.6174E-01 1.6174E-01 1.6181E-01 1.6181E-01 1.6181E-01 $1.6188 E-01$ 1.6188E-01 $1.6188 E-01$

S val $x$

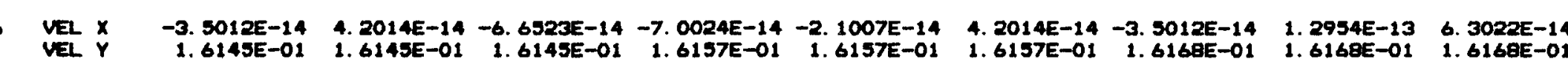

7 VEL $X \quad-4.9017 E-14 \quad$ 4. $9017 E-14-6.3022 E-14 \quad 2.1007 E-14-2.8010 E-14 \quad 3.5012 E-14-1.0504 E-14 \quad 4.5516 E-14 \quad 2.1007 E-14$ VEL $V$ 1.6116E-01 1.6116E-01 1.6116E-01 1.6127E-01 1.6127E-01 1.6127E-01 $1.6138 E-01$ 1.6138E-01 $1.6139 E-01$

8 VEL $X \quad-1.7506 E-14 \quad 3.3261 E-14-3.1511 E-14-7.0024 E-15$-7. 0024E-15 $7.0024 E-15-7.0024 E-15 \quad 4.5516 E-14 \quad-3.5012 E-15$ VE $Y$ 1.6093E-01 1.6093E-01 1.6093E-01 1.6101E-01 $1.6101 E-01$ 1.6101E-01 $1.6110 E-01 \quad 1.6110 E-01$ 1.6110E-01

9 VEL $X \quad-7.0024 E-15 \quad 2.2758 E-14-3.6763 E-14-1.4005 E-14-1.4005 E-14 \quad 0.0000 E-01 \quad 0.0000 E-01 \quad 3.6763 E-14-2.4508 E-14$ VEL $Y$ 1.6081E-01 1.6081E-01 1.6081E-01 1.6085E-01 $1.6085 E-01$ 1.6085E-01 $1.6089 E-01 \quad 1.6089 E-01 \quad 1.6089 E-01$

10 VELL

$-2.9323 E-14-4.8141 E-15-2.5394 E-14 \quad 0.0000 E-01 \quad 1.7506 E-15 \quad 5.2518 E-15 \quad 1.7068 E-14 \quad 3.2824 E-14-1.3129 E-15$

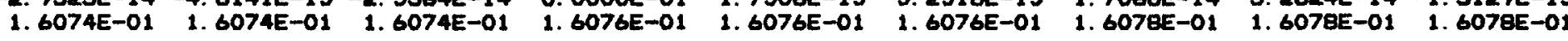


LISTING D-3. Output Report File for Test Case One. (Sheet 10 of 13) ONE DIMENGION VERTICAL FLOW WITH HEAT OENERATION

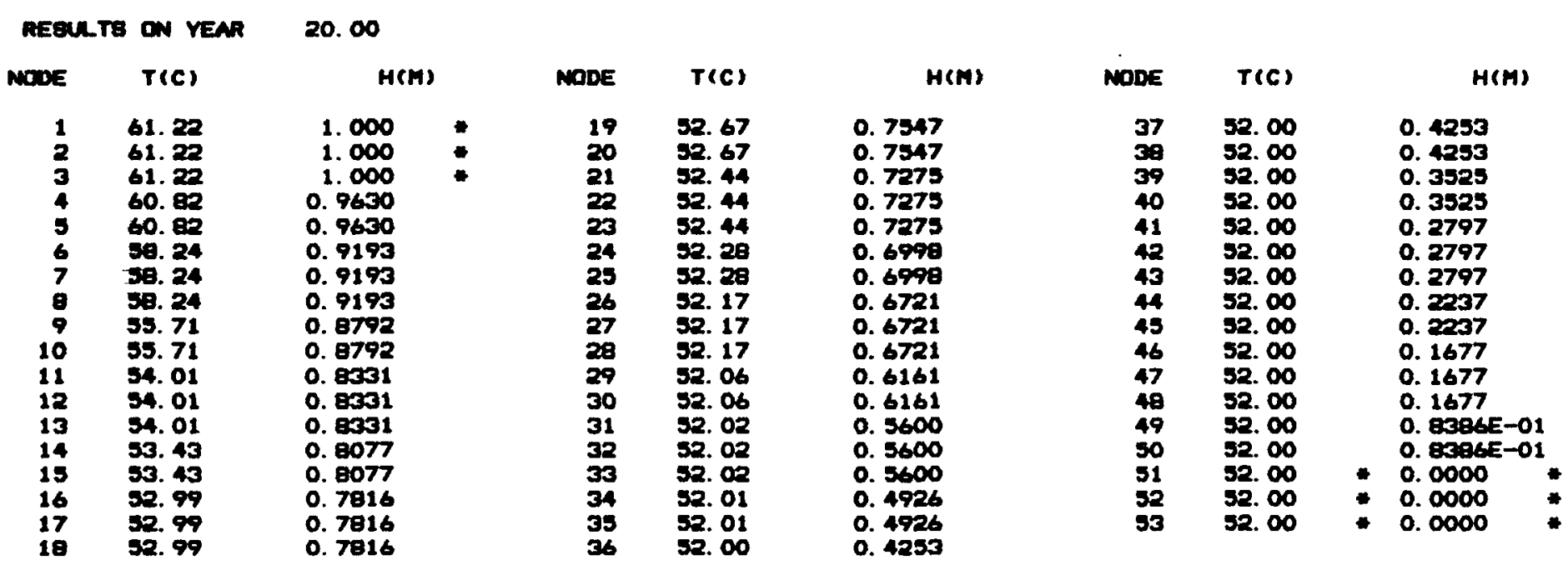

$\begin{array}{ll}\text { ITERATION MUMBER } & \text { 1. MAX REL CHANGE (TEMP) = 1. 8530E-02, MAX REL CORRECTION = 2. 8225E-04 } \\ \text { ITERATION MUMBER } & \text { 1. MAX REL CHANOE (HEAD) = 1.7203E-02, MAX REL CORRECTION }=2.7600 E-04\end{array}$ 
LISTING D-3. Output Report File for Test Case One. (Sheet 11 of 13)

ONE DIMENGION VERTICAL FLOW WITH HEAT GENERATION

REBULTB FOR VELOCITY (M/YR) OF YEAR 20.00

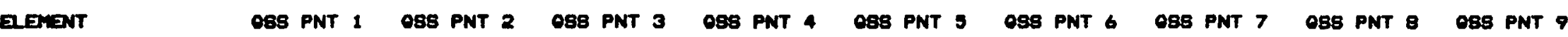

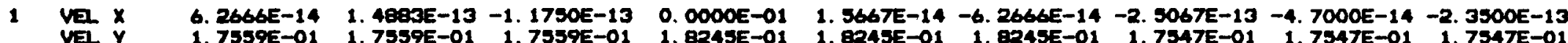

2 vel $x \quad-2.0087 E-13 \quad 5.2076 E-14 \quad 2.2316 E-14 \quad-5.9516 E-14 \quad-2.973 E E-14 \quad 7.4394 E-14 \quad 1.2647 E-13 \quad 1.3391 E-13-8.9273 E-14$ VEL $Y$ 1.7974E-01 $1.7974 E-01$ 1.7974E-01 $1.7713 E-01$ 1.7713E-01 $1.7713 E-01$ 1.7990E-01 $1.7990 E-01$ 1.7990E-01

3 Val $x \quad 0.0000 E-01 \quad 1.4349 E-13-1.4348 E-14-7.1740 E-14-1.4349 E-14 \quad 1.0044 E-13-2.1322 E-13 \quad 5.7392 E-14 \quad 2.1522 E-14$ vel $v$ 1.7849E-01 1.7849E-01 1.7849E-01 1.7819E-01 1.7819E-01 1.7819E-01 1.7864E-01 1.7864E-01 1.7864E-01

4 VEL $x$

$0.0000 E-01$ 1. $0991 E-13-4.9594 E-14-5.6679 E-14-5.6678 E-14-2.0339 E-14-7.0949 E-15 \quad 1.0627 E-13-1.1396 E-13$

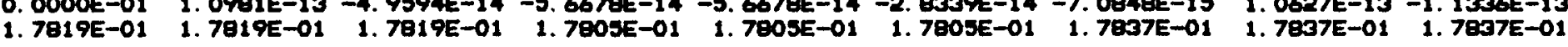

5 val $x$

-4. 5746E-14

1. $7790 E-01$

5. $9822 E-14-9.5011 E-14$
1. $7780 E-01$
1. $7789 E-01$

$\begin{array}{ll}\text { 2. } 8151 E-14 & \text { 2. } 8151 E-14 \\ \text { 1. } 7785 E-01 & \text { 1. } 7785 E-01\end{array}$

4. $2227 E-14$ 5. $6303 E-14$

1. $4780 E-13-7.0379 E-15$

-4. $9091 E-14$

4. $9091 E-14-1.1221 E-13-1.4026 E-14-7.0130 E-15$

1. 7607 -O1

1. 7807E-01 1. $7807 E-01$

vel $y$

$15165-14$

1. $7743 E-01$ 1. $7743 E-01$ 1.7745E-01 1. 7745E-01

$\begin{array}{lr}\text { 1. } 4026 E-14 & -6.3117 E-14 \\ \text { 1. } 7745 E-01 & 1.7779 E-01\end{array}$

4. $5384 E-14-1.0169 E-13$

VEL $X$

1. $76905-01$

7. $0035 E-14-4.9025 E-14$

$\begin{array}{lll}-4.9025 E-14 & 7.0035 E-15 & -2.8014 E-14 \\ 1.7692 E-01 & 1.7705 E-01 & 1.7705 E-01\end{array}$

$\begin{array}{lr}\text { 4. } 2021 E-14 & -2.8014 E-14 \\ \text { 1. } 7705 E-01 & 1.7725 E-01\end{array}$

vat $x$

$\rightarrow 7.0025 E-1$

1. $76925-01$

Q VEL $x$

1. $7637 E-0$

5. 6020E-14

OSOAE-14

$14-4.2015 E-14-2.0010 E-14-1.4005 E-14-7.0025 E-15$

VEL $x$

3. $5012 E-15$ 4. 3765E-14 -1. 0504E-14 -5. 2518E-14 -4. 9017E-14 -3. 8513E-14 1. 4005E-14

1. $7640 E-O 1$

4. 3765E-
1. $7640 E-01$

10 VEL $X$

-4. SO7eE-14

-1.

1. 7652E-01

5. $0767 E-14-3.5012 E-15$

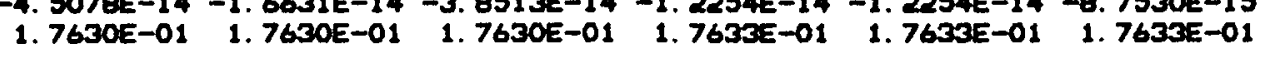

5. $4269 E-14$

1. $7636 E-01$

7. $0024 E-14$
1. $7636 E-01$ 
LISTING D-3. Output Report File for Test Case One. (Sheet 12 of 13)

ONE DIMENSION VERTICAL FLOW WITH HEAT OENERATION

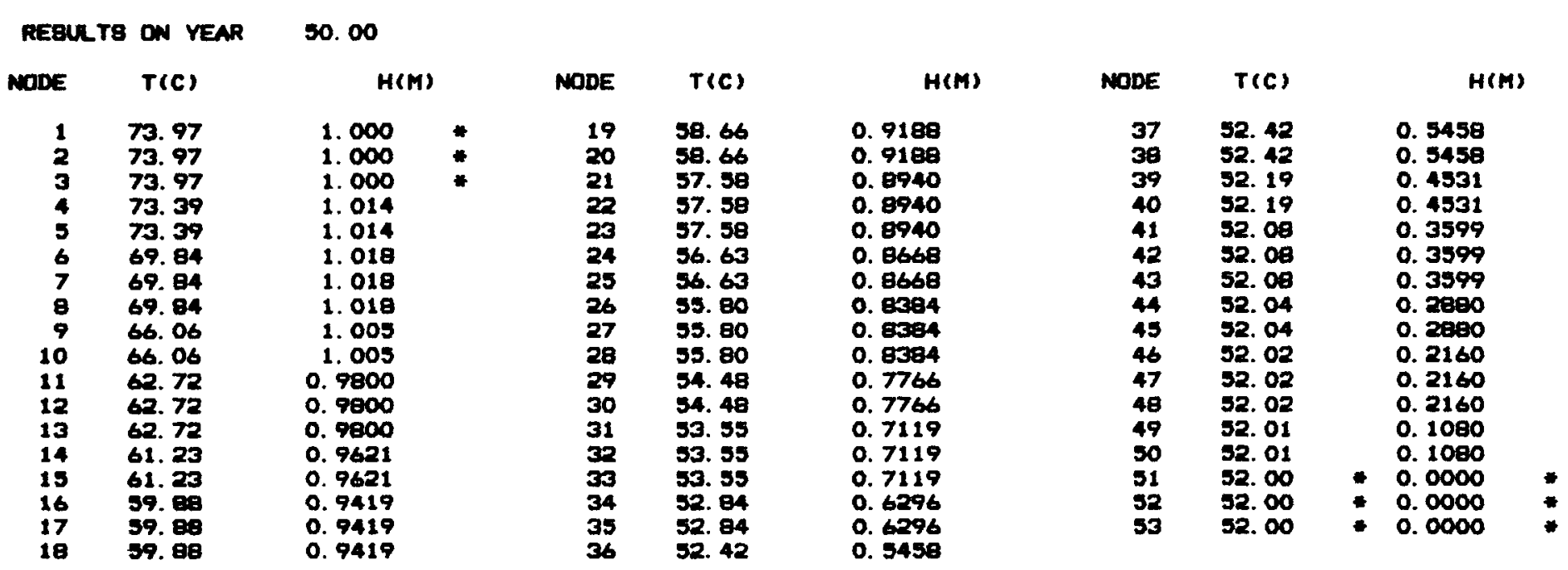

ITERATION NUMBER 1. MAX REL CHANOE (TEMP) - 3. 0525E-02. MAX REL CORRECTION - 9.7269E-04 ITERATION MUMBER 1, MAX REL CHANGE (HEAD) $=4.9391 E-02$, MAX REL CORRECTION = $1.1191 \mathrm{~N}-03$ 
LISTING D-3. Output Report File for Test Case One. (Sheet 13 of 13)

ONE DIMENBION VERTICAL FLOW WITH HEAT QENERATION

REBULTB FOR VELOCITY (M/YR) OF YEAR SO. 00

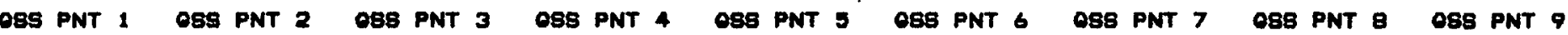

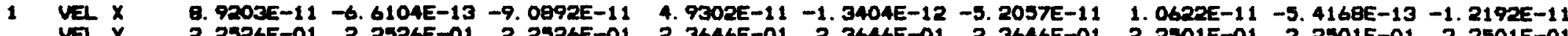

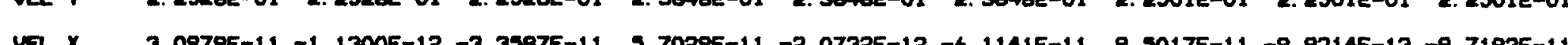

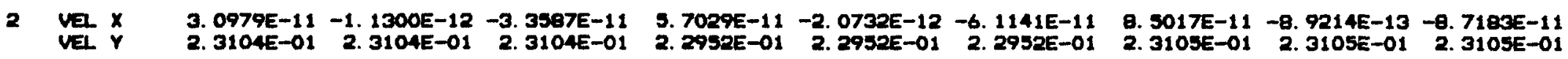

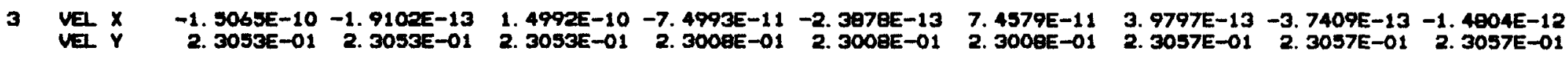

7. $5304 E-11-1.4660 E-10-1.7728 E-13 \quad 1.4588 E-10$

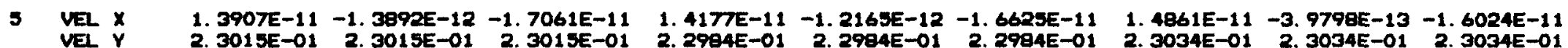

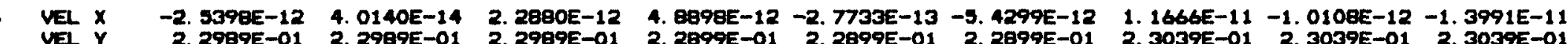

Vel $x \quad 6.1173 E-13 \quad 3.9123 E-14-7.5755 E-13-1.5791 E-12-4.2679 E-14 \quad 1.6645 E-12-3.9549 E-12 \quad 3.5566 E-15 \quad 3.8411 E-12$

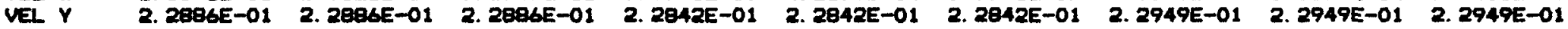

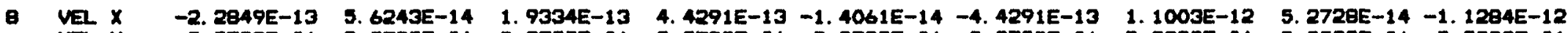
$\begin{array}{llllllllll}\text { VEL } y & \text { 2. } 2785 E-01 & 2.2785 E-01 & 2.2785 E-01 & 2.2783 E-01 & 2.2783 E-01 & \text { 2. } 2783 E-01 & 2.2839 E-01 & \text { 2. } 2839 E-01 & 2.2839 E-01\end{array}$

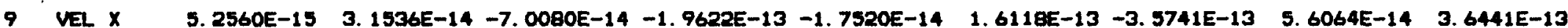
$\begin{array}{llllllllll}\text { VEL } X & 5.2560 E-15 & 3.1536 E-14 & -7.0080 E-14 & -1.9622 E-13 & -1.7520 E-14 & 1.6118 E-13 & -3.5741 E-13 & 5.6064 E-14 & 3.6441 E-13 \\ \text { VEL } V & 2.2734 E-01 & 2.2734 E-01 & 2.2734 E-01 & 2.2742 E-01 & 2.2742 E-01 & 2.2742 E-01 & 2.2760 E-01 & 2.2760 E-01 & 2.2760 E-01\end{array}$

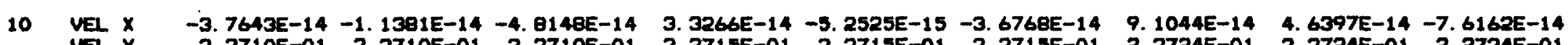

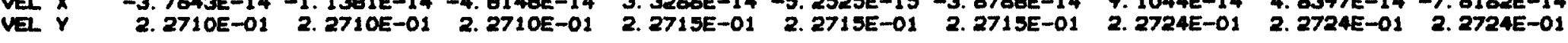


LISTING D-4. Input Data File for Test Case Two. (Sheet 1 of 6) SAMFLE PROBLEM, FLOW ARDUND A HEATED CANNISTER

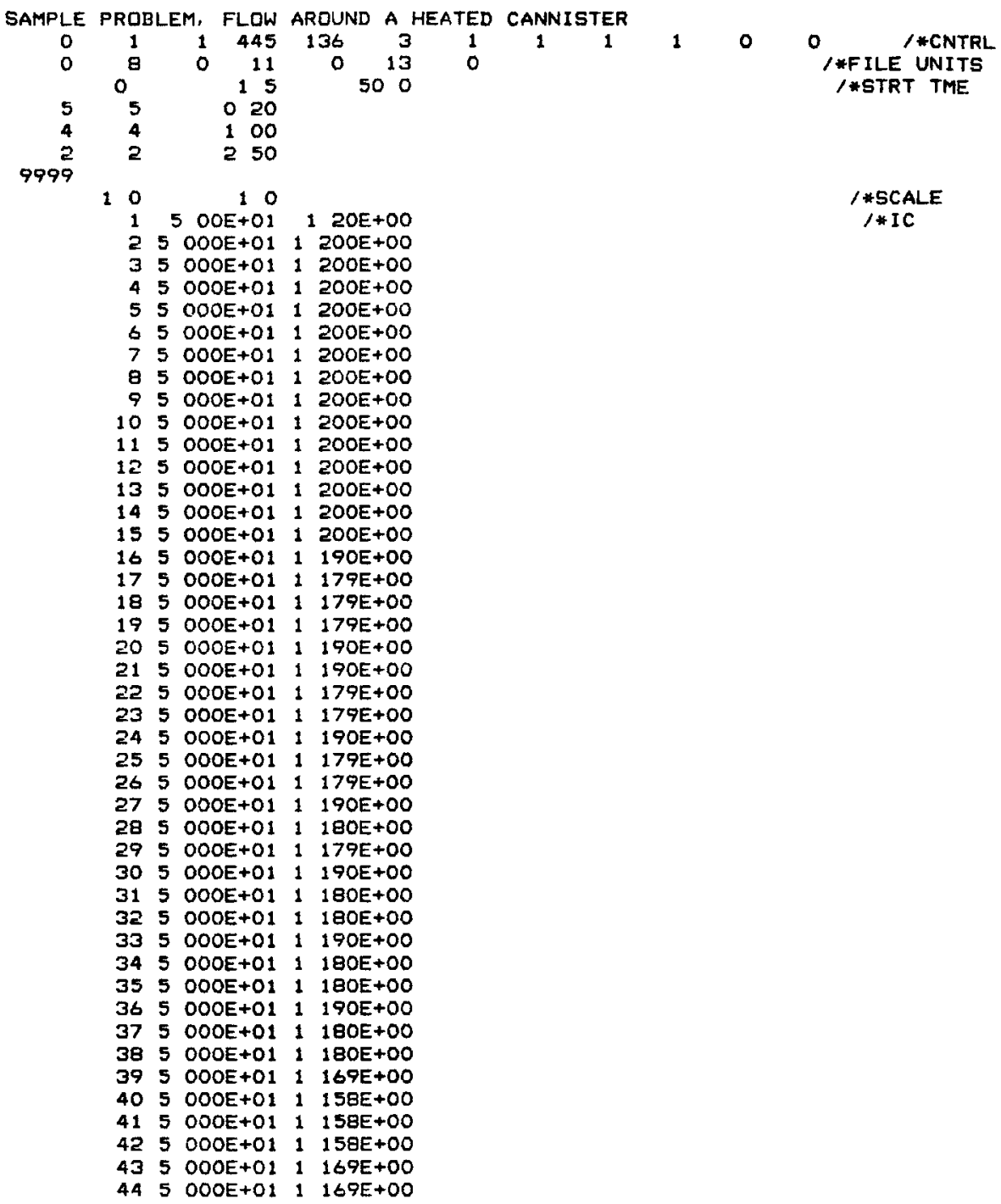




\section{LISTING D-4. Input Data File for Test Case Two. (Sheet 2 of 6)}

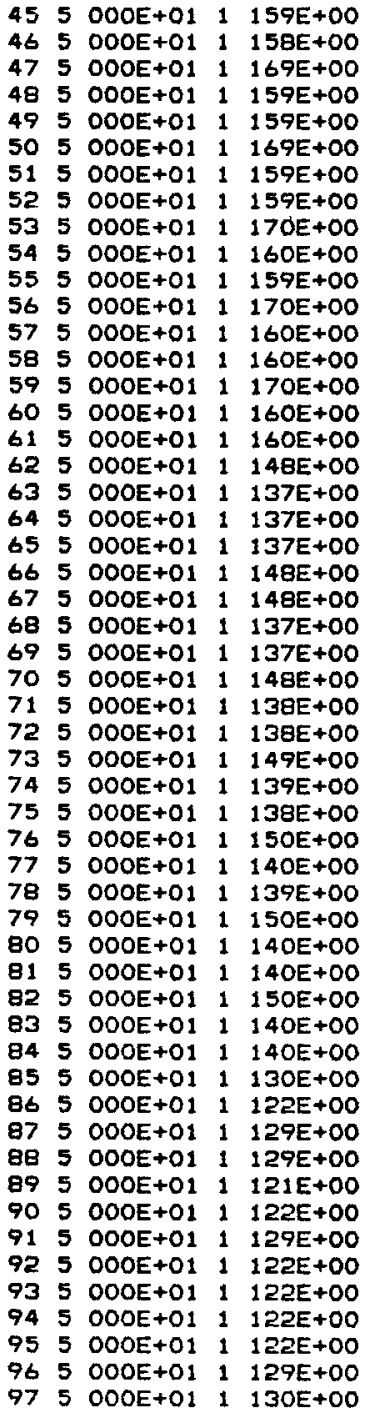

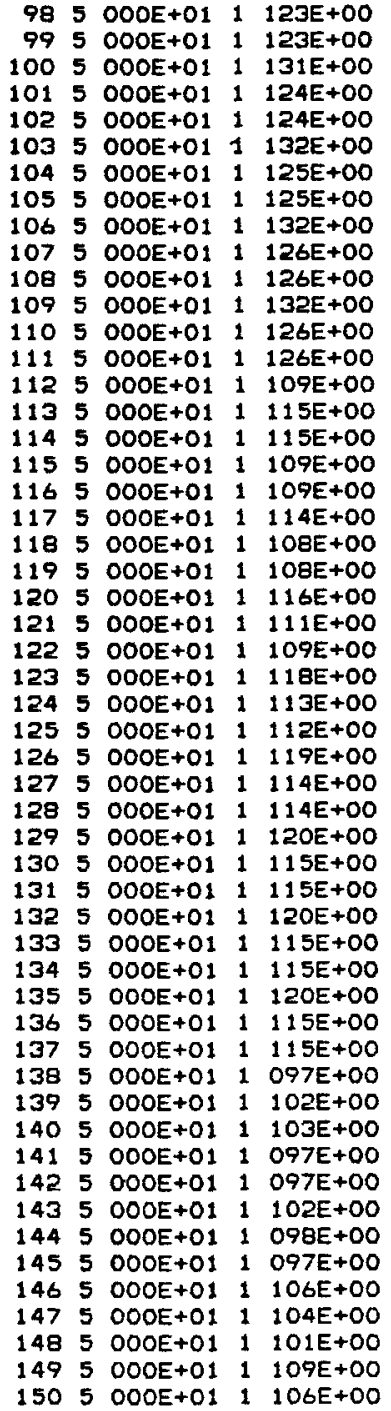


LISTING D-4. Input Data File for Test Case Two. (Sheet 3 of 6) SAMPLE PROBLEM, FLOW AROUND a HEATEd CANNISTER SAMPLE PROBLEM, FLDW AROUND a HEATED CANNISTER

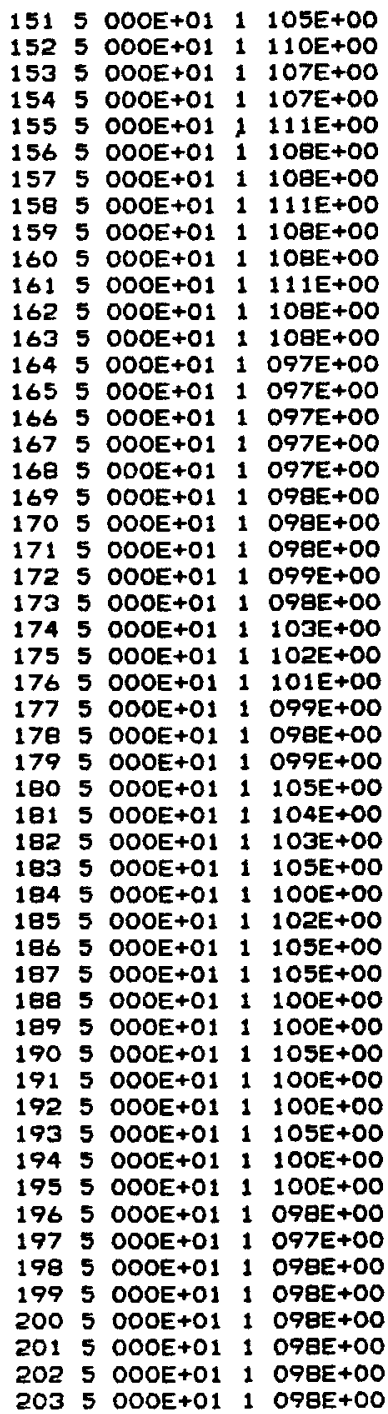

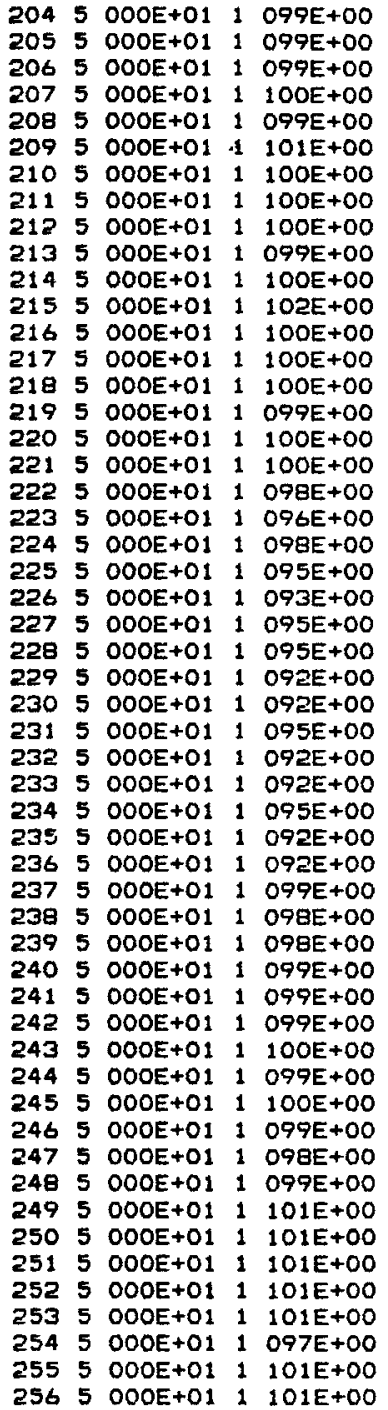

2045 OOOE+01 1 099E+00

2065 OOOE+01 1 O99E+00

5 OOOE+01 1 1OOE+OO

2085 OOOE+01 1 OOOE +00

2105 OOOE+01 1 LOOE +00

2115 OOOE+O1 1 1OOE+OO

2125 OOOE+01 1 10OE+0O

$\begin{array}{lllll}213 & 5 & 000 E+01 & 1 & 099 E+00 \\ 214 & 5 & 000 E+01 & 1 & 100 E+00\end{array}$

$2155000 E+011102 E+00$

2165 OOOE+O1 1 IOOE+OO

2175 OOOE+O1 1 1OOE +00

$2195 \mathrm{OOOE}+011 \mathrm{O} 1 \mathrm{OOE}+00$

2205 OOOE+01 1 1OOE +00

$2215000 E+011100 E+00$

2225 OOOE+01 1 O98E +00

$2545000 E+01+098 E+00$

$2255000 E+011095 E+00$

2265 OOOE+01 1 O93E+00

5 OOOE+01 1 O95E+OO

2295 OOOE+01 1 O9ZE +00

2305 OOOE+OI 1 O92E +00

$2315000 E+011095 E+00$

$2335000 E+01,092 E+00$

2345 OOOE+O1 1 O95E+OO

2355 OOOE+OI 1 O92E+OO

335 OOOE+01 1 O92E+0O

2375 OOOE +01 I O99E+OO

2395 OOOE+01 1 OOBE +OO

$2405000 E+011099 E+00$

2415 OOOE+01 1 O99E +00

2425 OOOE+01 1 099E+0O

$11100 E+00$

2455 OOOE +01 $1100 E+00$

2465 OOOE+01 1 O99E+00

S OOOE+01 1 O9BE+00

2495 OOOE+01 $1101 \mathrm{E}+00$

2505 OOOE+01 1 101E+00

2515 OOOE+01 1 101E+OO

2535 OOOE+01 $1101 E+00$

$2555000 E+011101 E+00$

2565 OOOE+O1 \& $101 E+00$ 
LISTING D-4. Input Data File for Test Case Two. (Sheet 4 of 6)

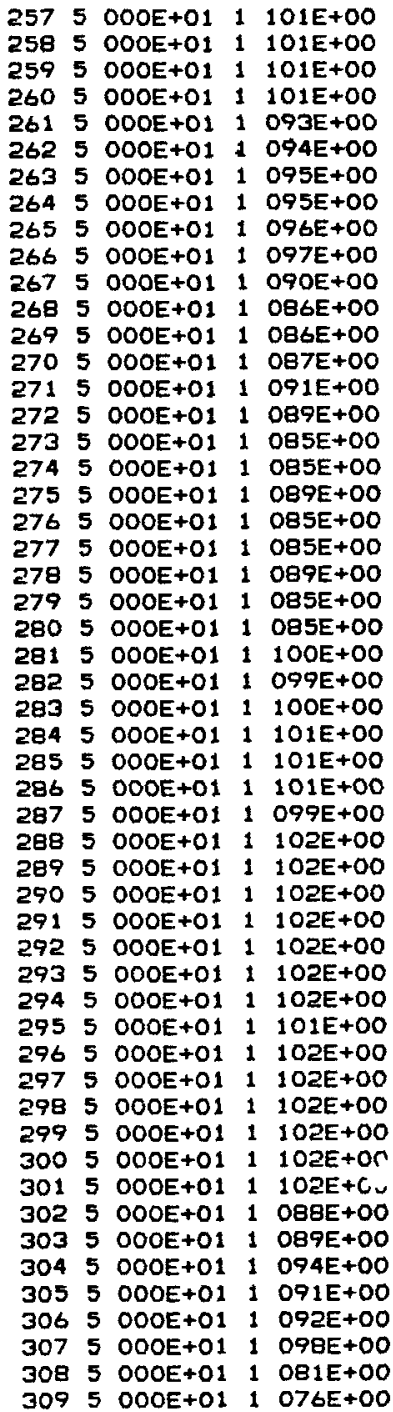

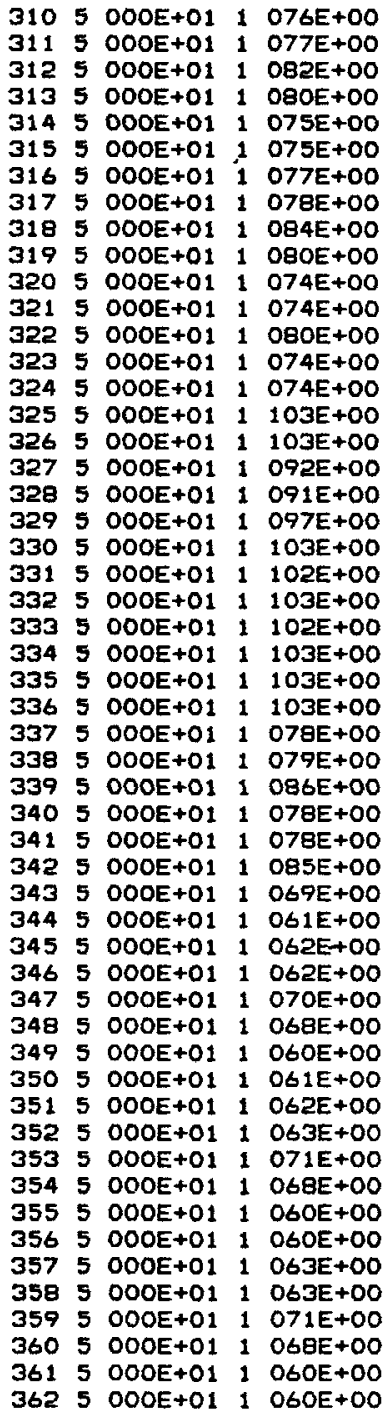




\section{LISTING D-4. Input Data File for Test Case Two. (Sheet 5 of 6)}

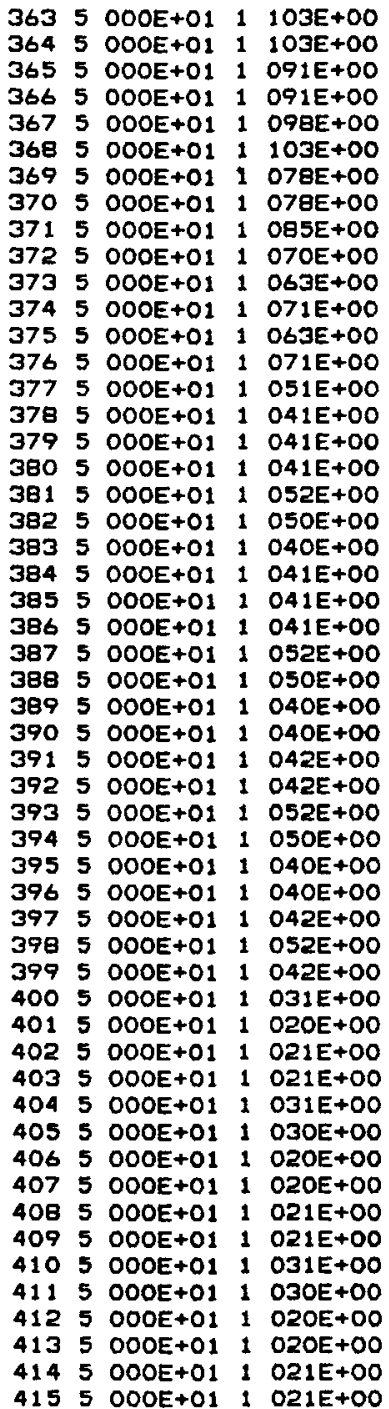

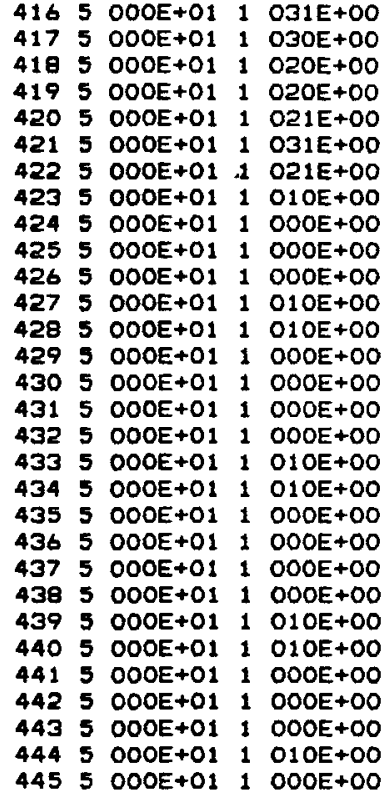

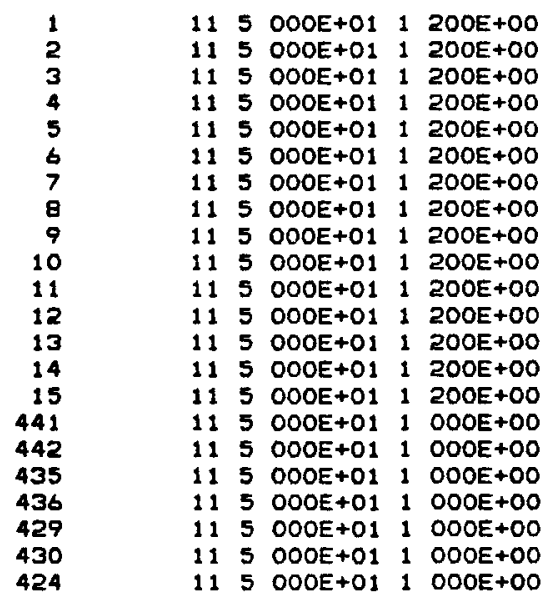


LISTING D-4. Input Data File for Test Case Two. (Sheet 6 of 6) EAMLE PROBLEM. FLOW AROUND A HEATED CANWIETER

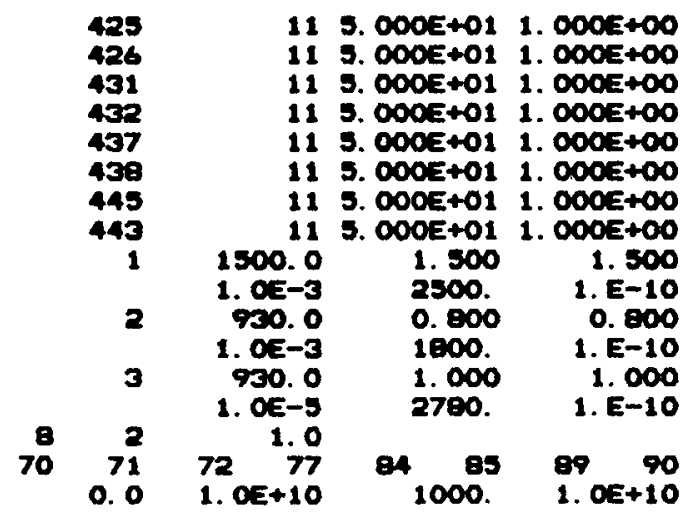

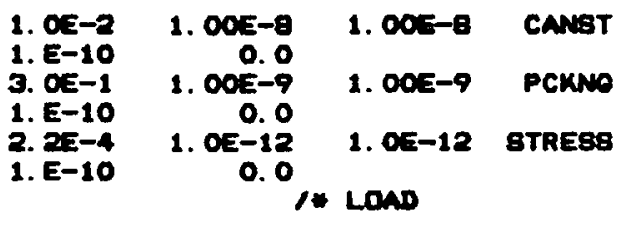


LISTING D-5. The PRIMOS Command

File for Test Case Two.

EAT EEERUN

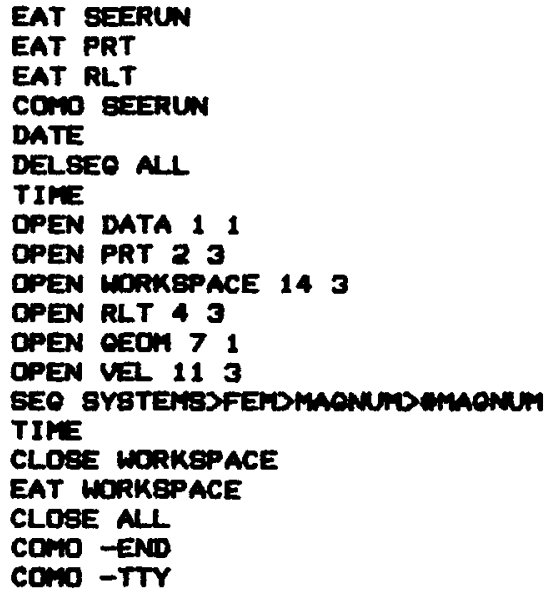


LISTING D-6. Output Report File for Test Case Two. (Sheet 1 of 48)

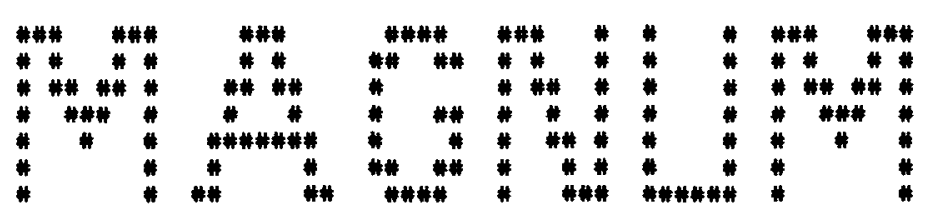

VERSION 3.0 (ReVision 1.)

FRI, JUL 201984

$10: 21: 29$

$I D=720041021$ 
LISTING D-6. Output Report File for Test Case Two. (Sheet 2 of 48)

SAMPLE PROBLEM, FLOW AROUND A HEATED CANNISTER

tABLE 1. - PRINCIPAl PROBLEM gPECIfICATIONB

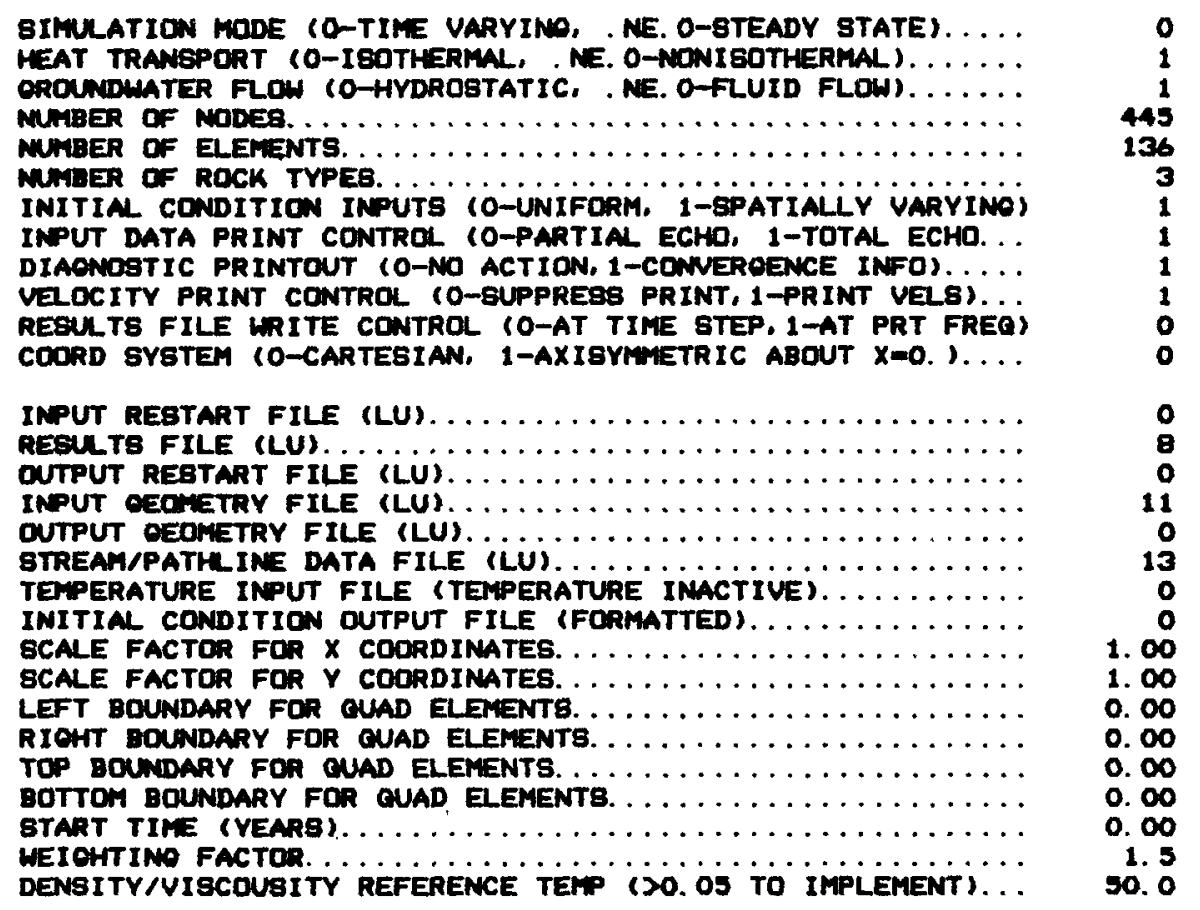

TIME CONTROL AND RUN BPECIFICATIONB

$\begin{array}{cccc}\text { MUMBER OF TIME BTEPS } & \text { PRINT INTERVAL } & \text { TIME STEP } & \text { TIME(YEARS) } \\ 5 & 5 & 0.2000 & 1.000 \\ 2 & 4 & 1.000 & 5.000 \\ 2 & 2 & 2.500 & 10.00\end{array}$


LISTING D-6. Output Report File for Test Case Two. (Sheet 3 of 48)

\begin{tabular}{|c|c|c|c|c|c|c|c|c|c|c|c|}
\hline $\begin{array}{r}\text { NODE } \\
1 \\
2 \\
3 \\
4 \\
5 \\
5 \\
6 \\
78 \\
8 \\
9 \\
10 \\
11 \\
12 \\
13 \\
14 \\
15 \\
16 \\
17 \\
18 \\
19 \\
20 \\
21 \\
22 \\
23 \\
24 \\
25 \\
26 \\
27 \\
28 \\
29 \\
30 \\
31 \\
32 \\
33 \\
34 \\
35 \\
36 \\
37 \\
38 \\
39 \\
40 \\
41 \\
42 \\
43 \\
44 \\
45 \\
46 \\
47 \\
48 \\
49 \\
50\end{array}$ & $\begin{array}{rl}x C O R D \\
0 & 00 \\
0 & 12 \\
0 & 20 \\
0 & 28 \\
0 & 38 \\
0 & 50 \\
0 & 64 \\
0 & 61 \\
1 & 01 \\
1 & 00 \\
1 & 39 \\
1 & 89 \\
2 & 50 \\
3 & 22 \\
4 & 06 \\
5 & 00 \\
0 & 20 \\
0 & 20 \\
0 & 12 \\
0 & 00 \\
0 & 00 \\
0 & 38 \\
0 & 38 \\
0 & 28 \\
0 & 64 \\
0 & 64 \\
0 & 50 \\
1 & 00 \\
1 & 00 \\
0 & 81 \\
1 & 89 \\
1 & 89 \\
1 & 39 \\
3 & 22 \\
3 & 22 \\
2 & 50 \\
5 & 00 \\
5 & 00 \\
4 & 06 \\
0 & 20 \\
0 & 20 \\
0 & 12 \\
0 & 00 \\
0 & 00 \\
0 & 38 \\
0 & 38 \\
0 & 28 \\
0 & 64 \\
0 & 64 \\
0 & 50 \\
1 & 00\end{array}$ & 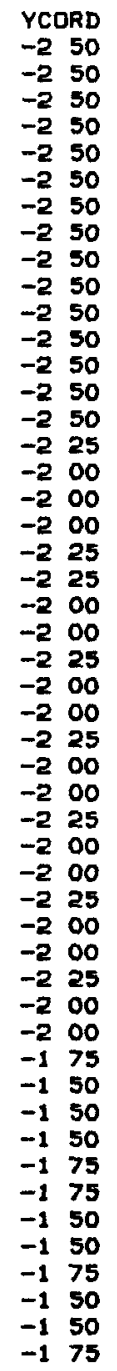 & $\begin{array}{c}\text { NODE } \\
51 \\
52 \\
53 \\
54 \\
54 \\
55 \\
56 \\
57 \\
58 \\
59 \\
60 \\
61 \\
62 \\
63 \\
64 \\
65 \\
66 \\
67 \\
68 \\
69 \\
70 \\
71 \\
72 \\
73 \\
74 \\
75 \\
76 \\
77 \\
78 \\
79 \\
80 \\
81 \\
81 \\
82 \\
83 \\
84 \\
85 \\
86 \\
87 \\
88 \\
89 \\
90 \\
91 \\
91 \\
92 \\
93 \\
94 \\
95 \\
96 \\
97 \\
98 \\
99 \\
99 \\
100\end{array}$ & 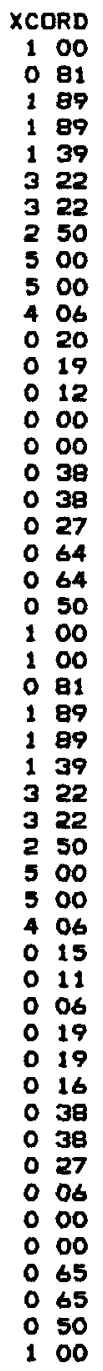 & 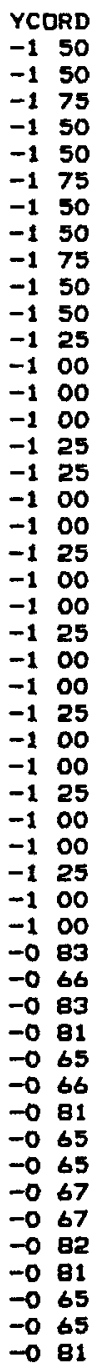 & $\begin{array}{r}\text { NODE } \\
101 \\
102 \\
103 \\
104 \\
105 \\
106 \\
107 \\
108 \\
109 \\
110 \\
111 \\
112 \\
113 \\
114 \\
115 \\
116 \\
117 \\
118 \\
119 \\
120 \\
121 \\
122 \\
123 \\
124 \\
125 \\
126 \\
127 \\
128 \\
129 \\
130 \\
131 \\
132 \\
133 \\
134 \\
135 \\
136 \\
137 \\
138 \\
139 \\
140 \\
141 \\
142 \\
143 \\
144 \\
145 \\
146 \\
147 \\
148 \\
149 \\
150\end{array}$ & 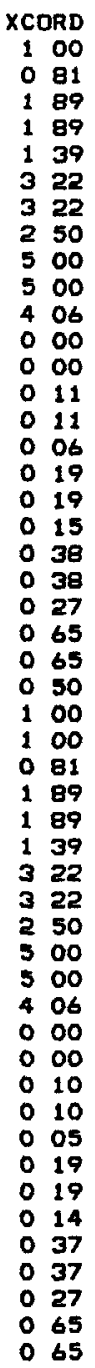 & $\begin{array}{ll}\text { YCORD } \\
-0 & 64 \\
-0 & 65 \\
-0 & 81 \\
-0 & 64 \\
-0 & 64 \\
-0 & 81 \\
-0 & 64 \\
-0 & 64 \\
-0 & 64 \\
-0 & 81 \\
-0 & 64 \\
-0 & 64 \\
-0 & 42 \\
-0 & 53 \\
-0 & 52 \\
-0 & 41 \\
-0 & 42 \\
-0 & 50 \\
-0 & 37 \\
-0 & 39 \\
-0 & 50 \\
-0 & 38 \\
-0 & 37 \\
-0 & 50 \\
-0 & 38 \\
-0 & 38 \\
-0 & 50 \\
-0 & 38 \\
-0 & 38 \\
-0 & 50 \\
-0 & 38 \\
-0 & 38 \\
-0 & 50 \\
-0 & 38 \\
-0 & 38 \\
-0 & 50 \\
-0 & 38 \\
-0 & 38 \\
-0 & 25 \\
-0 & 32 \\
-0 & 31 \\
-0 & 24 \\
-0 & 25 \\
-0 & 27 \\
-0 & 19 \\
-0 & 22 \\
-0 & 27 \\
-0 & 19 \\
-0 & 19 \\
-0 & 27 \\
-0 & 19\end{array}$ & $\begin{array}{r}\text { NODE } \\
151 \\
152 \\
153 \\
154 \\
155 \\
156 \\
157 \\
158 \\
159 \\
160 \\
161 \\
162 \\
163 \\
164 \\
165 \\
166 \\
167 \\
168 \\
169 \\
170 \\
171 \\
172 \\
173 \\
174 \\
175 \\
176 \\
177 \\
178 \\
179 \\
180 \\
181 \\
182 \\
183 \\
184 \\
185 \\
186 \\
187 \\
188 \\
189 \\
190 \\
191 \\
192 \\
193 \\
194 \\
195 \\
196 \\
197 \\
198 \\
199 \\
200\end{array}$ & $\begin{array}{rl}\text { XCORD } \\
0 & 50 \\
1 & 00 \\
1 & 00 \\
0 & 81 \\
1 & 89 \\
1 & 89 \\
1 & 39 \\
3 & 22 \\
3 & 22 \\
2 & 50 \\
5 & 00 \\
5 & 00 \\
4 & 06 \\
0 & 00 \\
0 & 00 \\
0 & 10 \\
0 & 10 \\
0 & 05 \\
0 & 18 \\
0 & 17 \\
0 & 13 \\
0 & 24 \\
0 & 22 \\
0 & 39 \\
0 & 41 \\
0 & 31 \\
0 & 21 \\
0 & 20 \\
0 & 23 \\
0 & 66 \\
0 & 66 \\
0 & 52 \\
0 & 83 \\
1 & 00 \\
0 & 83 \\
1 & 00 \\
1 & 89 \\
1 & 89 \\
1 & 39 \\
3 & 22 \\
3 & 22 \\
2 & 50 \\
5 & 00 \\
5 & 00 \\
4 & 06 \\
0 & 00 \\
0 & 00 \\
0 & 09 \\
0 & 09 \\
0 & 05\end{array}$ & $\begin{array}{rl}Y C O R D \\
-0 & 19 \\
-0 & 27 \\
-0 & 19 \\
-0 & 19 \\
-0 & 28 \\
-0 & 20 \\
-0 & 20 \\
-0 & 28 \\
-0 & 20 \\
-0 & 20 \\
-0 & 28 \\
-0 & 20 \\
-0 & 20 \\
-0 & 22 \\
-0 & 24 \\
-0 & 23 \\
-0 & 21 \\
-0 & 22 \\
-0 & 18 \\
-0 & 17 \\
-0 & 20 \\
-0 & 10 \\
-0 & 14 \\
-0 & 15 \\
-0 & 11 \\
-0 & 10 \\
-0 & 10 \\
-0 & 13 \\
-0 & 10 \\
-0 & 16 \\
-0 & 11 \\
-0 & 11 \\
-0 & 15 \\
0 & 00 \\
-0 & 06 \\
-0 & 12 \\
-0 & 12 \\
0 & 00 \\
0 & 00 \\
-0 & 12 \\
0 & 00 \\
0 & 00 \\
-0 & 12 \\
0 & 00 \\
0 & 00 \\
-0 & 20 \\
-0 & 21 \\
-0 & 20 \\
-0 & 19 \\
-0 & 20\end{array}$ \\
\hline
\end{tabular}


LISTING D-6. Output Report File for Test Case Two. (Sheet 4 of 48)

TABLE 2 - NODE POINT COORDINATES

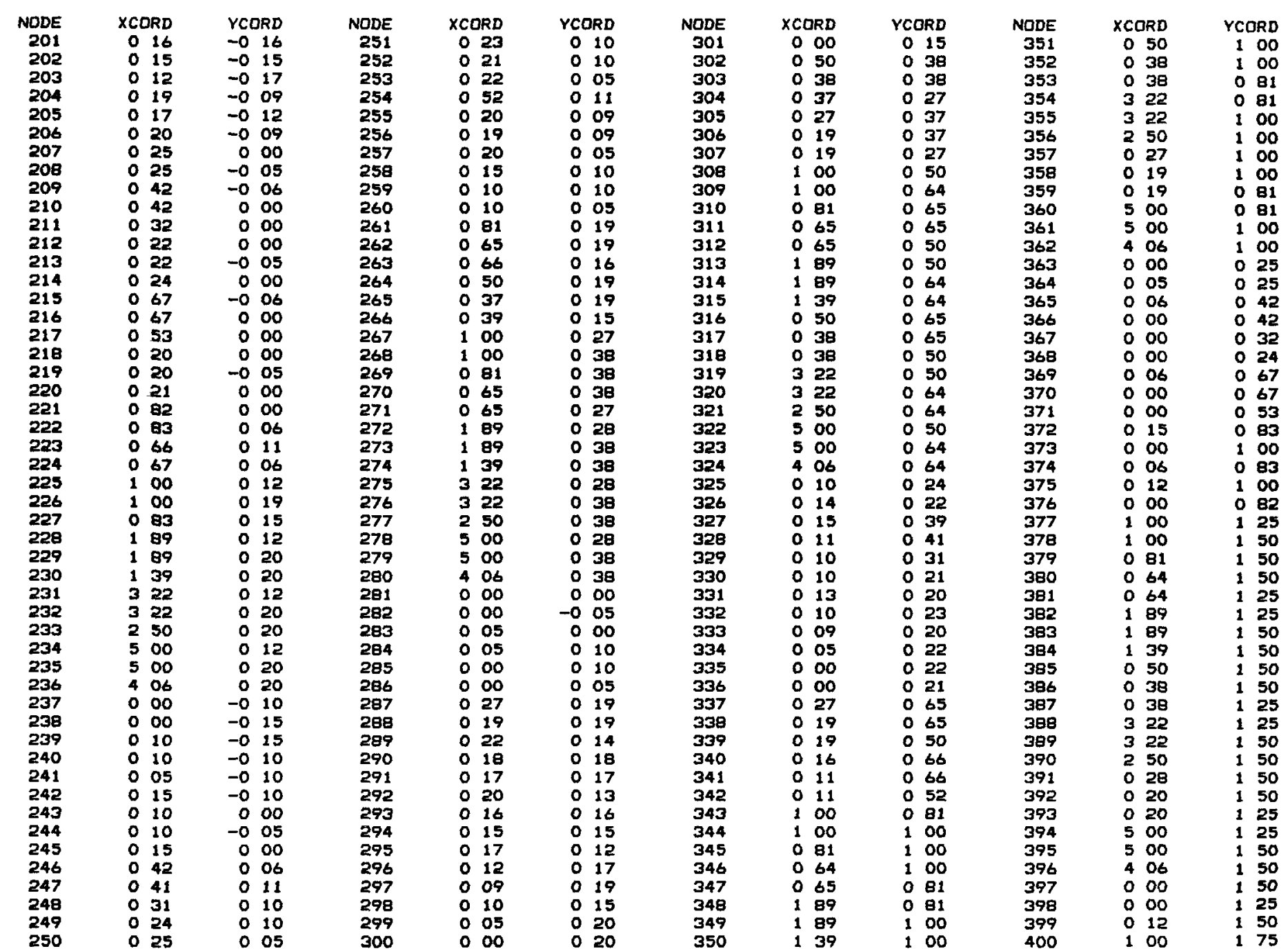


LISTING D-6. Output Report File for Test Case Two. (Sheet 5 of 48) TABLE 2. - NODE POINT COORDINATES

\begin{tabular}{|c|c|c|c|c|c|c|c|c|c|c|c|}
\hline $\begin{array}{r}\text { NDDE } \\
401 \\
402 \\
403 \\
404 \\
405 \\
406 \\
407 \\
408 \\
409 \\
410 \\
411 \\
412\end{array}$ & $\begin{array}{r}X C O R D \\
1.00 \\
0.81 \\
0.64 \\
0.64 \\
1.89 \\
1.89 \\
1.39 \\
0.50 \\
0.38 \\
0.38 \\
3.22 \\
3.22\end{array}$ & $\begin{array}{r}\text { YCORD } \\
2.00 \\
2.00 \\
2.00 \\
1.75 \\
1.75 \\
2.00 \\
2.00 \\
2.00 \\
2.00 \\
1.75 \\
1.75 \\
2.00\end{array}$ & $\begin{array}{r}\text { NODE } \\
413 \\
414 \\
415 \\
416 \\
417 \\
418 \\
419 \\
420 \\
421 \\
422 \\
423 \\
424\end{array}$ & $\begin{array}{r}X C O R D \\
2.50 \\
0.28 \\
0.20 \\
0.20 \\
5.00 \\
5.00 \\
4.06 \\
0.00 \\
0.00 \\
0.12 \\
1.00 \\
1.00\end{array}$ & $\begin{array}{r}\text { YCORD } \\
2.00 \\
2.00 \\
2.00 \\
1.75 \\
1.75 \\
2.00 \\
2.00 \\
2.00 \\
1.75 \\
2.00 \\
2.25 \\
2.50\end{array}$ & $\begin{array}{r}\text { NODE } \\
425 \\
426 \\
427 \\
429 \\
429 \\
430 \\
431 \\
432 \\
433 \\
434 \\
435 \\
436\end{array}$ & $\begin{array}{r}\text { XCORD } \\
0.81 \\
0.64 \\
0.64 \\
1.89 \\
1.89 \\
1.39 \\
0.50 \\
0.38 \\
0.38 \\
3.22 \\
3.22 \\
2.50\end{array}$ & $\begin{array}{r}\text { YCDRD } \\
2.50 \\
2.50 \\
2.25 \\
2.25 \\
2.50 \\
2.50 \\
2.50 \\
2.50 \\
2.25 \\
2.25 \\
2.50 \\
2.50\end{array}$ & $\begin{array}{r}\text { NODE } \\
437 \\
438 \\
439 \\
440 \\
441 \\
442 \\
443 \\
444 \\
445\end{array}$ & $\begin{array}{r}\text { XCORD } \\
0.28 \\
0.20 \\
0.20 \\
5.00 \\
5.00 \\
4.06 \\
0.00 \\
0.00 \\
0.12\end{array}$ & $\begin{array}{r}\text { YCARD } \\
\text { 2. 50 } \\
2.50 \\
2.25 \\
2.25 \\
2.50 \\
\text { 2. 50 } \\
\text { 2. 50 } \\
\text { 2. } 25 \\
2.50\end{array}$ \\
\hline
\end{tabular}


LISTING D-6. Output Report File for Test Case Two. (Sheet 6 of 48)

TABLE 3. - ELEMENT/NODE CONNECTIVITY

\begin{tabular}{|c|c|c|c|c|c|c|c|c|c|c|c|c|c|c|c|c|c|c|c|c|c|}
\hline \multirow{2}{*}{$\begin{array}{c}\text { ELEMENT } \\
M\end{array}$} & \multirow[b]{2}{*}{ N1 } & \multicolumn{4}{|c|}{ CONNECTIONS } & \multirow[b]{2}{*}{ NG } & \multirow[b]{2}{*}{ N7 } & \multirow[b]{2}{*}{ N8 } & \multirow[t]{2}{*}{ TYPE } & \multirow[t]{2}{*}{ ORDER } & \multicolumn{2}{|l|}{ ELEMENT } & \multicolumn{4}{|c|}{ CDNNECTIONS } & \multirow[b]{2}{*}{ N6 } & \multirow[b]{2}{*}{ N7 } & \multirow[b]{2}{*}{ NB } & TYPE & ORDER \\
\hline & & N2 & N3 & N4 & N5 & & & & & & $\mathbf{M}$ & N1 & N2 & N3 & N4 & NS & & & & & \\
\hline 1 & 1 & 2 & 3 & 16 & 17 & 18 & 19 & 20 & 3 & 1 & 51 & 175 & 174 & 147 & 151 & 150 & 180 & 181 & 182 & 3 & 51 \\
\hline 2 & 17 & 16 & 3 & 4 & 5 & 21 & 22 & 23 & 3 & 2 & 52 & 153 & 183 & 181 & 180 & 150 & 154 & 0 & 0 & 3 & 52 \\
\hline 3 & 22 & 21 & 5 & 6 & 7 & 24 & 25 & 26 & 3 & 3 & 53 & 184 & 185 & 181 & 183 & 153 & 186 & 0 & 0 & 3 & 53 \\
\hline 4 & 25 & 24 & 7 & B & 9 & 27 & 28 & 29 & 3 & 4 & 54 & 184 & 186 & 153 & 157 & 156 & 187 & 188 & 189 & 3 & 54 \\
\hline 5 & 28 & 27 & 9 & 10 & 11 & 30 & 31 & 32 & 3 & 5 & 55 & 188 & 187 & 156 & 160 & 159 & 190 & 191 & 192 & 3 & 55 \\
\hline 6 & 31 & 30 & 11 & 12 & 13 & 33 & 34 & 35 & 3 & $b$ & 56 & 191 & 190 & 159 & 163 & 162 & 193 & 194 & 195 & 3 & 56 \\
\hline 7 & 34 & 33 & 13 & 14 & 15 & 36 & 37 & 38 & 3 & 7 & 57 & 196 & 197 & 164 & 168 & 167 & 198 & 199 & 200 & 2 & 57 \\
\hline 8 & 19 & 18 & 17 & 39 & 40 & 41 & 42 & 43 & 3 & 8 & 58 & 199 & 198 & 167 & 171 & 170 & 201 & 202 & 203 & 2 & 58 \\
\hline 9 & 40 & 39 & 17 & 23 & 22 & 44 & 45 & 46 & 3 & 9 & 59 & 204 & 205 & 202 & 201 & 170 & 178 & 177 & 206 & 2 & 59 \\
\hline 10 & 45 & 44 & 22 & 26 & 25 & 47 & 48 & 49 & 3 & 10 & 60 & 207 & 208 & 172 & 176 & 175 & 209 & 210 & 211 & 3 & 60 \\
\hline 11 & 48 & 47 & 25 & 29 & 28 & 50 & 51 & 52 & 3 & 11 & 61 & 212 & 213 & 177 & 179 & 172 & 208 & 207 & 214 & 2 & 61 \\
\hline 12 & 51 & 50 & 28 & 32 & 31 & 53 & 54 & 55 & 3 & 12 & 62 & 210 & 209 & 175 & 182 & 181 & 215 & 216 & 217 & 3 & 62 \\
\hline 13 & 54 & 53 & 31 & 35 & 34 & 56 & 57 & 58 & 3 & 13 & 63 & 218 & 219 & 204 & 206 & 177 & 213 & 212 & 220 & 2 & 63 \\
\hline 14 & 57 & 56 & 34 & 38 & 37 & 59 & 60 & 61 & 3 & 14 & 64 & 216 & 215 & 181 & 185 & 184 & 221 & 0 & 0 & 3 & 64 \\
\hline 15 & 42 & 41 & 40 & 62 & 63 & 64 & 65 & 66 & 3 & 15 & 65 & 216 & 221 & 184 & 222 & 223 & 224 & 0 & 0 & 3 & 65 \\
\hline 16 & 63 & 62 & 40 & 46 & 45 & 67 & 68 & 69 & 3 & 16 & 66 & 184 & 225 & 226 & 227 & 223 & 222 & 0 & 0 & 3 & 66 \\
\hline 17 & 68 & 67 & 45 & 49 & 48 & 70 & 71 & 72 & 3 & 17 & 67 & 184 & 189 & 188 & 228 & 229 & 230 & 226 & 225 & 3 & 67 \\
\hline 18 & 71 & 70 & 48 & 52 & 51 & 73 & 74 & 75 & 3 & 18 & 68 & 188 & 192 & 191 & 231 & 232 & 233 & 229 & 228 & 3 & 68 \\
\hline $\begin{array}{l}19 \\
20\end{array}$ & $\begin{array}{l}74 \\
77\end{array}$ & $\begin{array}{l}73 \\
76\end{array}$ & $\begin{array}{l}51 \\
54\end{array}$ & $\begin{array}{l}55 \\
58\end{array}$ & $\begin{array}{l}54 \\
57\end{array}$ & $\begin{array}{l}76 \\
79\end{array}$ & $\begin{array}{l}77 \\
80\end{array}$ & $\begin{array}{l}78 \\
81\end{array}$ & $\begin{array}{l}3 \\
3\end{array}$ & $\begin{array}{l}19 \\
20\end{array}$ & $\begin{array}{l}69 \\
70\end{array}$ & 191 & 195 & 194 & 234 & $\begin{array}{l}235 \\
100\end{array}$ & 236 & 232 & 231 & 3 & 69 \\
\hline $\begin{array}{l}20 \\
21\end{array}$ & 80 & $\begin{array}{l}76 \\
79\end{array}$ & $\begin{array}{l}54 \\
57\end{array}$ & $\begin{array}{l}58 \\
61\end{array}$ & 60 & 82 & $\begin{array}{l}80 \\
83\end{array}$ & 84 & 3 & 21 & $\begin{array}{l}70 \\
71\end{array}$ & $\begin{array}{l}237 \\
240\end{array}$ & $\begin{array}{l}238 \\
239\end{array}$ & $\begin{array}{l}196 \\
199\end{array}$ & $\begin{array}{l}200 \\
203\end{array}$ & $\begin{array}{l}199 \\
202\end{array}$ & $\begin{array}{l}239 \\
205\end{array}$ & $\begin{array}{l}240 \\
204\end{array}$ & $\begin{array}{l}241 \\
242\end{array}$ & $\begin{array}{l}1 \\
1\end{array}$ & $\begin{array}{l}70 \\
71\end{array}$ \\
\hline 22 & 65 & 64 & 63 & 85 & 86 & 87 & 0 & 0 & 3 & 22 & 72 & 243 & 244 & 240 & 242 & 204 & 219 & 218 & 245 & 1 & 72 \\
\hline 23 & 86 & 85 & 63 & 日8 & 89 & 90 & 0 & 0 & 3 & 23 & 73 & 207 & 211 & 210 & 246 & 247 & 248 & 249 & 250 & 3 & 73 \\
\hline 24 & 89 & 88 & 63 & 69 & 68 & 91 & 92 & 93 & 3 & 24 & 74 & 212 & 214 & 207 & 250 & 249 & 251 & 252 & 253 & 2 & 74 \\
\hline 25 & 65 & 87 & 86 & 94 & 95 & 96 & 0 & 0 & 3 & 25 & 75 & 210 & 217 & 216 & 224 & 223 & 254 & 247 & 246 & 3 & 75 \\
\hline 26 & 92 & 91 & 68 & 72 & 71 & 97 & 98 & 99 & 3 & 26 & 76 & 218 & 220 & 212 & 253 & 252 & 255 & 256 & 257 & 2 & 76 \\
\hline 27 & 98 & 97 & 71 & 75 & 74 & 100 & 101 & 102 & 3 & 27 & 77 & 243 & 245 & 218 & 257 & 256 & 258 & 259 & 260 & 1 & 77 \\
\hline B & 101 & 100 & 74 & 78 & 77 & 103 & 104 & 105 & 3 & 28 & 78 & 226 & 261 & 262 & 263 & 223 & 227 & 0 & 0 & 3 & 78 \\
\hline 29 & 104 & 103 & 77 & 81 & 80 & 106 & 107 & 108 & 3 & 29 & 79 & 247 & 254 & 223 & 263 & 262 & 264 & 265 & 266 & 3 & 79 \\
\hline 30 & 107 & 106 & 80 & $B 4$ & 83 & 109 & 110 & 111 & 3 & 30 & 80 & 262 & 261 & 226 & 267 & 268 & 269 & 270 & 271 & 3 & 80 \\
\hline 31 & 112 & 113 & 95 & 94 & 86 & 114 & 115 & 116 & 3 & 31 & 81 & 226 & 230 & 229 & 272 & 273 & 274 & 268 & 267 & 3 & 81 \\
\hline 32 & 115 & 114 & 86 & 90 & 89 & 117 & 118 & 119 & 3 & 32 & 82 & 229 & 233 & 232 & 275 & 276 & 277 & 273 & 272 & 3 & 82 \\
\hline 33 & 118 & 117 & 89 & 93 & 92 & 120 & 121 & 122 & 3 & 33 & 83 & 232 & 236 & 235 & 278 & 279 & 280 & 276 & 275 & 3 & 83 \\
\hline 34 & 121 & 120 & 92 & 99 & 98 & 123 & 124 & 125 & 3 & 34 & 84 & 281 & 282 & 237 & 241 & 240 & 244 & 243 & 283 & 1 & 84 \\
\hline 35 & 124 & 123 & 98 & 102 & 101 & 126 & 127 & 128 & 3 & 35 & 85 & 281 & 283 & 243 & 260 & 259 & 284 & 285 & 286 & 1 & 85 \\
\hline 36 & 127 & 126 & 101 & 105 & 104 & 129 & 130 & 131 & 3 & 36 & 86 & 249 & 248 & 247 & 266 & 265 & 287 & 288 & 289 & 3 & 86 \\
\hline 37 & 130 & 129 & 104 & 108 & 107 & 132 & 133 & 134 & 3 & 37 & 87 & 252 & 251 & 249 & 289 & 288 & 290 & 291 & 292 & 2 & 87 \\
\hline 38 & 133 & 132 & 107 & 111 & 110 & 135 & 136 & 137 & 3 & 38 & 88 & 256 & 255 & 252 & 292 & 291 & 293 & 294 & 295 & 2 & 88 \\
\hline 39 & 138 & 139 & 112 & 116 & 115 & 140 & 141 & 142 & 3 & 39 & 89 & 259 & 258 & 256 & 295 & 294 & 296 & 297 & 298 & 1 & 89 \\
\hline 40 & 141 & 140 & 115 & 119 & 118 & 143 & 144 & 145 & 3 & 40 & 90 & 285 & 284 & 259 & 298 & 297 & 299 & 300 & 301 & 1 & 90 \\
\hline 41 & 144 & 143 & 118 & 122 & 121 & 146 & 147 & 148 & 3 & 41 & 91 & 265 & 264 & 262 & 271 & 270 & 302 & 303 & 304 & 3 & 91 \\
\hline 42 & 147 & 146 & 121 & 125 & 124 & 149 & 150 & 151 & 3 & 42 & 92 & 288 & 287 & 265 & 304 & 303 & 305 & 306 & 307 & 3 & 92 \\
\hline 43 & 150 & 149 & 124 & 128 & 127 & 152 & 153 & 154 & 3 & 43 & 93 & 270 & 269 & 268 & 308 & 309 & 310 & 311 & 312 & 3 & 93 \\
\hline 44 & 153 & 152 & 127 & 131 & 130 & 155 & 156 & 157 & 3 & 44 & 94 & 268 & 274 & 273 & 313 & 314 & 315 & 309 & 308 & 3 & 94 \\
\hline 45 & 156 & 155 & 130 & 134 & 133 & 158 & 159 & 160 & 3 & 45 & 95 & 303 & 302 & 270 & 312 & 311 & 316 & 317 & 318 & 3 & 95 \\
\hline 46 & 159 & 158 & 133 & 137 & 136 & 161 & 162 & 163 & 3 & 46 & 96 & 273 & 277 & 276 & 319 & 320 & 321 & 314 & 313 & 3 & 96 \\
\hline 47 & 164 & 165 & 138 & 142 & 141 & 166 & 167 & 168 & 2 & 47 & 97 & 276 & 280 & 279 & 322 & 323 & 324 & 320 & 319 & 3 & 97 \\
\hline 48 & 167 & 166 & 141 & 145 & 144 & 169 & 170 & 171 & 2 & 48 & 98 & 325 & 326 & 288 & 307 & 306 & 327 & 328 & 329 & 3 & 98 \\
\hline 49 & 172 & 173 & 144 & 148 & 147 & 174 & 175 & 176 & 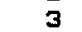 & 49 & 99 & 330 & 331 & 291 & 290 & 288 & 326 & 325 & 332 & 2 & 99 \\
\hline so & 177 & 178 & 170 & 169 & 144 & 173 & 172 & 179 & 2 & 50 & 100 & 297 & 296 & 294 & 293 & 291 & 331 & 330 & 333 & 2 & 100 \\
\hline
\end{tabular}


LISTING D-6. Output Report File for Test Case Two. (Sheet 7 of 48)

TABLE 3. - ELEMENT/NODE CONNECTIVITY

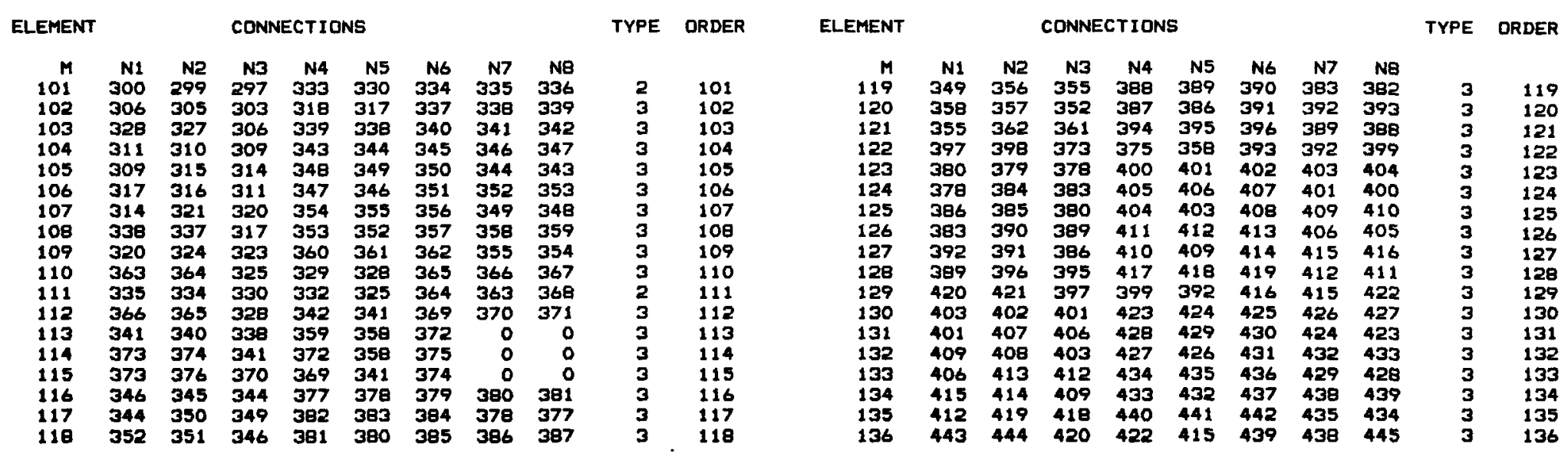


LISTING D-6. Output Report File for Test Case Two. (Sheet 8 of 48)

TABLE 4. - INITIAL CONDITIONS

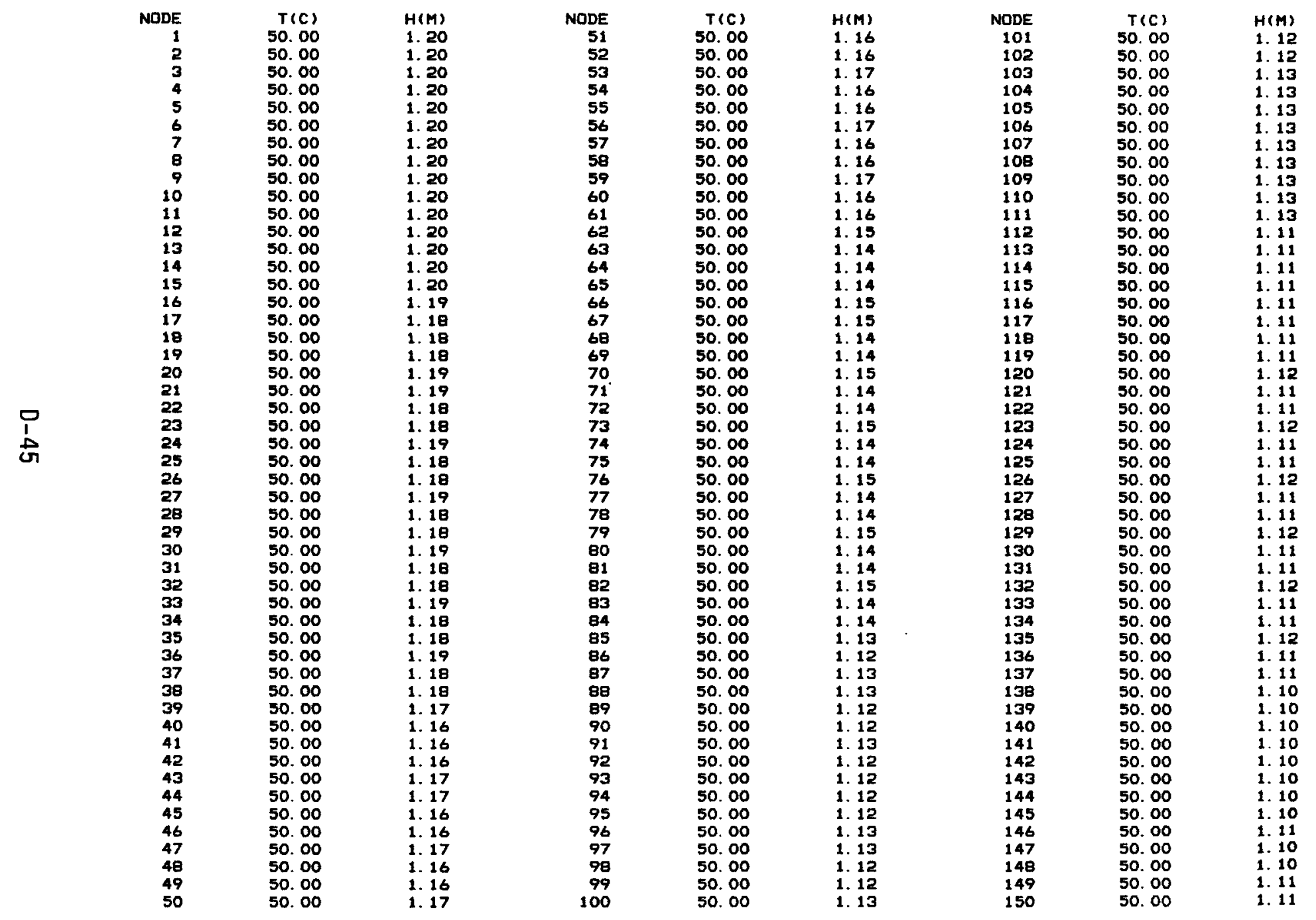


LISTING D-6. Output Report File for Test Case Two. (Sheet 9 of 48)

TABLE 4. - INITIAL CONDITIONS

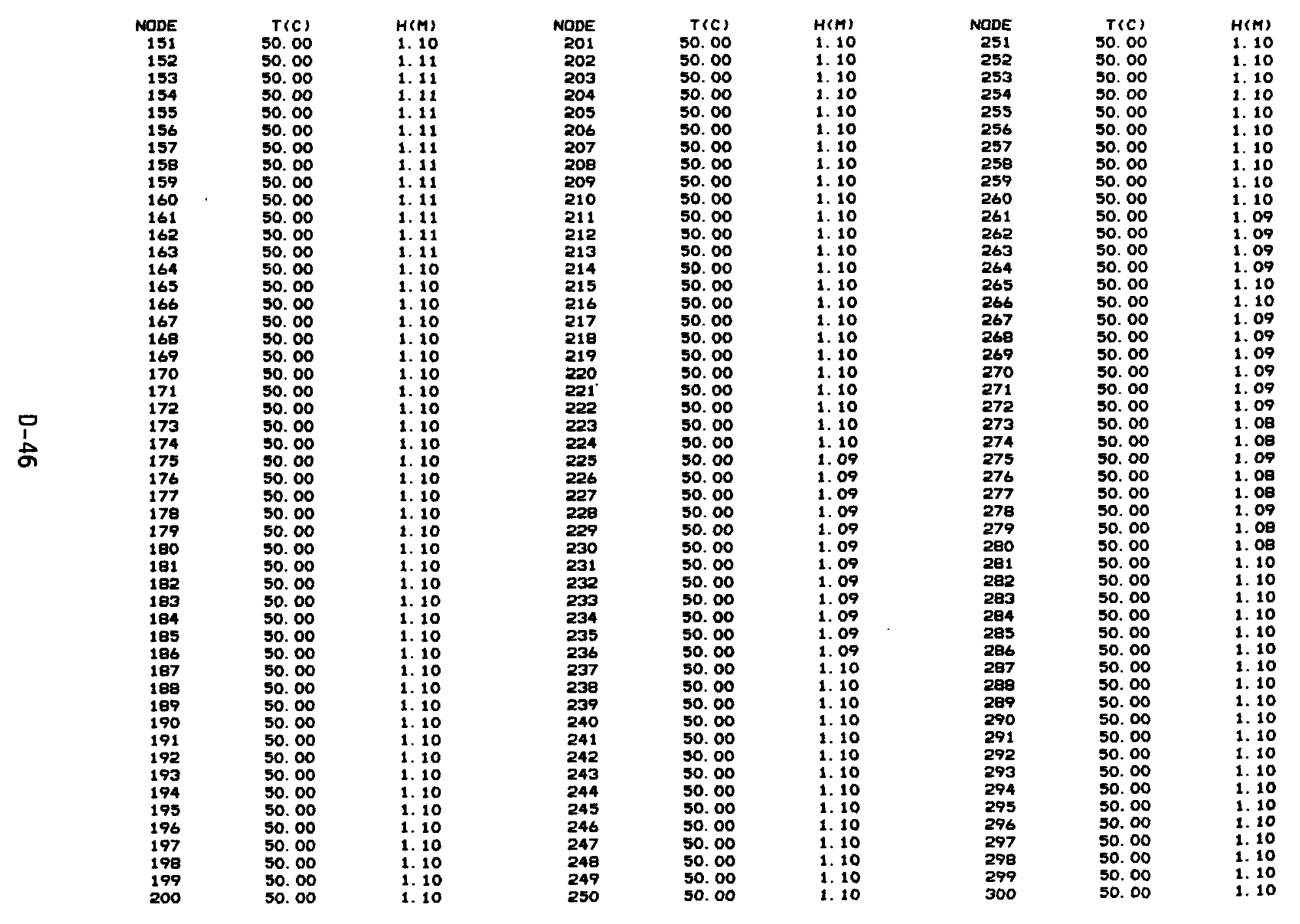


LISTING D-6. Output Report File for Test Case Two. (Sheet 10 of 48)

TABLE 4. - INITIAL CONDITIONS

\begin{tabular}{|c|c|c|c|c|c|}
\hline $\begin{array}{r}\text { NODE } \\
301 \\
302 \\
303 \\
304 \\
305 \\
306 \\
307 \\
308 \\
309 \\
310 \\
311 \\
312 \\
313 \\
314 \\
315 \\
316 \\
317 \\
318 \\
319 \\
320 \\
321 \\
322 \\
323 \\
324 \\
325 \\
326 \\
327 \\
328 \\
329 \\
330 \\
331 \\
332 \\
333 \\
334 \\
335 \\
336 \\
337 \\
338 \\
339 \\
340 \\
341 \\
342 \\
343 \\
344 \\
345 \\
346 \\
347 \\
348 \\
349\end{array}$ & $\begin{array}{r}T(C) \\
50.00 \\
50.00 \\
50.00 \\
50.00 \\
50.00 \\
50.00 \\
50.00 \\
50.00 \\
50.00 \\
50.00 \\
50.00 \\
50.00 \\
50.00 \\
50.00 \\
50.00 \\
50.00 \\
50.00 \\
50.00 \\
50.00 \\
50.00 \\
50.00 \\
50.00 \\
50.00 \\
50.00 \\
50.00 \\
50.00 \\
50.00 \\
50.00 \\
50.00 \\
50.00 \\
50.00 \\
50.00 \\
50.00 \\
50.00 \\
50.00 \\
50.00 \\
50.00 \\
50.00 \\
50.00 \\
50.00 \\
5000 \\
50000 \\
50.00 \\
50.00 \\
50.00 \\
50.00 \\
50.00 \\
50.00 \\
50.00\end{array}$ & $\begin{array}{l}H(M) \\
1.10 \\
1.09 \\
1.09 \\
1.09 \\
1.09 \\
1.09 \\
1.10 \\
1.08 \\
1.08 \\
1.08 \\
1.08 \\
1.08 \\
1.08 \\
1.07 \\
1.07 \\
1.08 \\
1.08 \\
1.08 \\
1.08 \\
1.07 \\
1.07 \\
1.08 \\
1.07 \\
1.07 \\
1.10 \\
1.10 \\
1.09 \\
1.09 \\
1.10 \\
1.10 \\
1.10 \\
1.10 \\
1.10 \\
1.10 \\
1.10 \\
1.10 \\
1.08 \\
1.08 \\
1.09 \\
1.08 \\
1.08 \\
1.08 \\
1.07 \\
1.06 \\
1.06 \\
1.06 \\
1.07 \\
1.07 \\
1.06\end{array}$ & $\begin{array}{r}\text { NODE } \\
350 \\
351 \\
352 \\
353 \\
354 \\
355 \\
356 \\
357 \\
358 \\
359 \\
360 \\
361 \\
362 \\
363 \\
364 \\
365 \\
366 \\
367 \\
368 \\
369 \\
370 \\
371 \\
372 \\
373 \\
374 \\
375 \\
376 \\
377 \\
378 \\
379 \\
380 \\
381 \\
382 \\
383 \\
384 \\
385 \\
386 \\
397 \\
388 \\
389 \\
390 \\
391 \\
392 \\
393 \\
394 \\
395 \\
396 \\
397 \\
398\end{array}$ & $\begin{array}{l}T(C) \\
50.00 \\
50.00 \\
50.00 \\
50.00 \\
50.00 \\
50.00 \\
50.00 \\
50.00 \\
50.00 \\
50.00 \\
50.00 \\
50.00 \\
50.00 \\
50.00 \\
50.00 \\
50.00 \\
50.00 \\
50.00 \\
50.00 \\
50.00 \\
50.00 \\
50.00 \\
50.00 \\
50.00 \\
50.00 \\
50.00 \\
50.00 \\
50.00 \\
50.00 \\
50.00 \\
50.00 \\
50.00 \\
50.00 \\
50.00 \\
50.00 \\
50.00 \\
50.00 \\
50.00 \\
50.00 \\
50.00 \\
50.00 \\
50.00 \\
50.00 \\
50.00 \\
50.00 \\
50.00 \\
50.00 \\
50.00 \\
50.00\end{array}$ & $\begin{array}{l}H(M) \\
1.06 \\
1.06 \\
1.06 \\
1.07 \\
1.07 \\
1.06 \\
1.06 \\
1.06 \\
1.06 \\
1.07 \\
1.07 \\
1.06 \\
1.06 \\
1.10 \\
1.10 \\
1.09 \\
1.09 \\
1.10 \\
1.10 \\
1.08 \\
1.08 \\
1.08 \\
1.07 \\
1.06 \\
1.07 \\
1.06 \\
1.07 \\
1.05 \\
1.04 \\
1.04 \\
1.04 \\
1.05 \\
1.05 \\
1.04 \\
1.04 \\
1.04 \\
1.04 \\
1.05 \\
1.05 \\
1.04 \\
1.04 \\
1.04 \\
1.04 \\
1.05 \\
1.05 \\
1.04 \\
1.04 \\
1.04 \\
1.05\end{array}$ \\
\hline
\end{tabular}

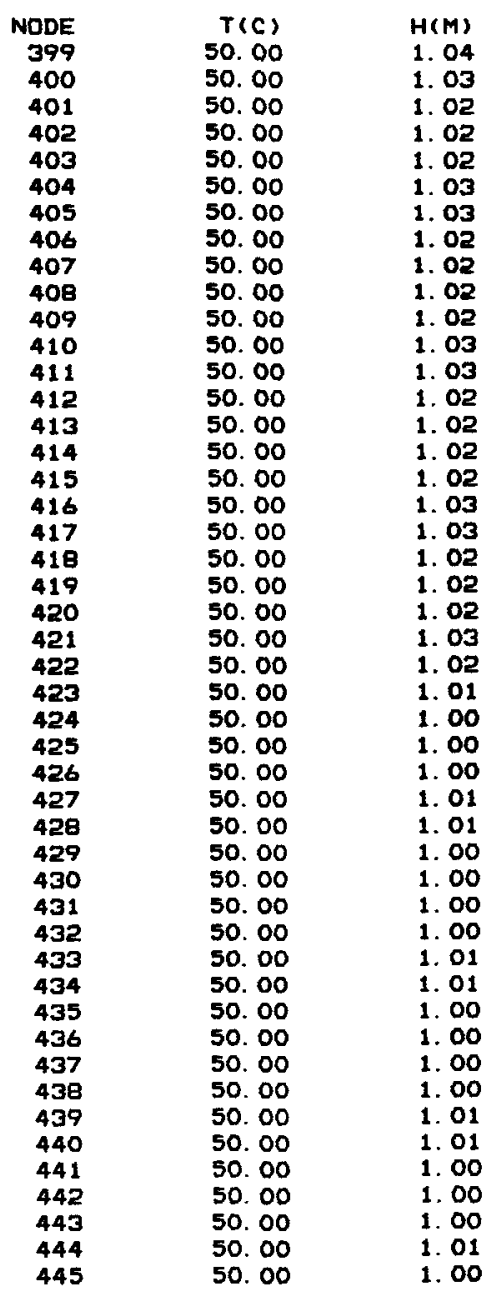


LISTING D-6. Output Report File for Test Case Two. (Sheet 11 of 48)

TABLE 5. - SPECIFIED BOUNDARY CONDITIONS

NUMBER OF SPECIFIED BOUNDARY NODES 30

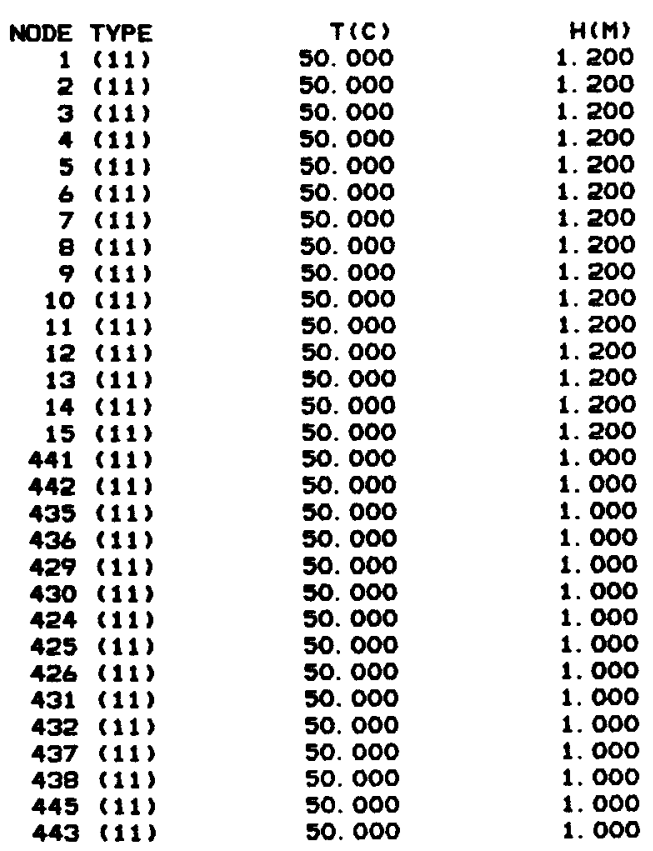


LISTING D-6. Output Report File for Test Case Two. (Sheet 12 of 48)

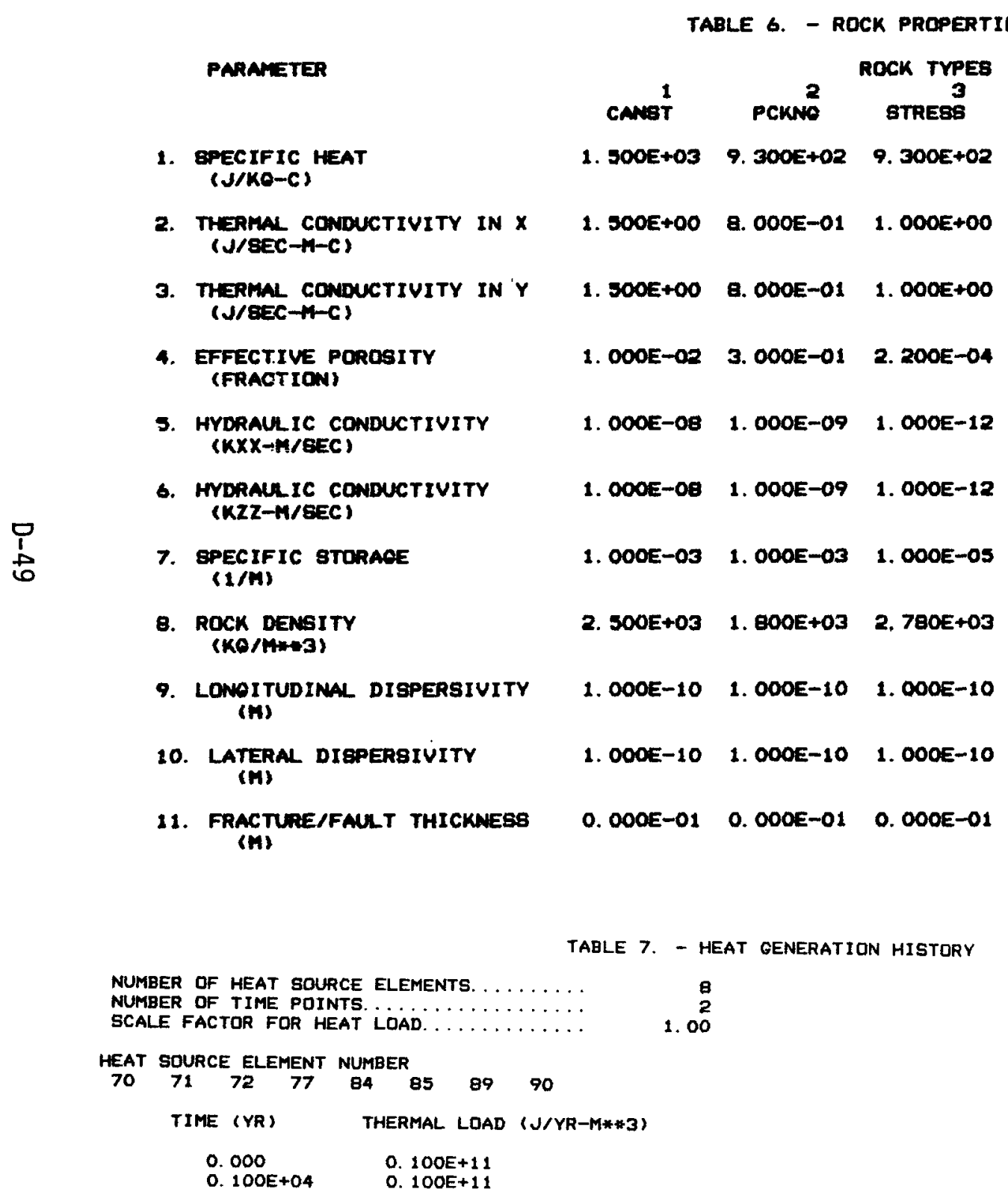


LISTING D-6. Output Report File for Test Case Two. (Sheet 13 of 48) SAMPLE PROBLEM, FLOW AROUND A hEATED CANNISTER

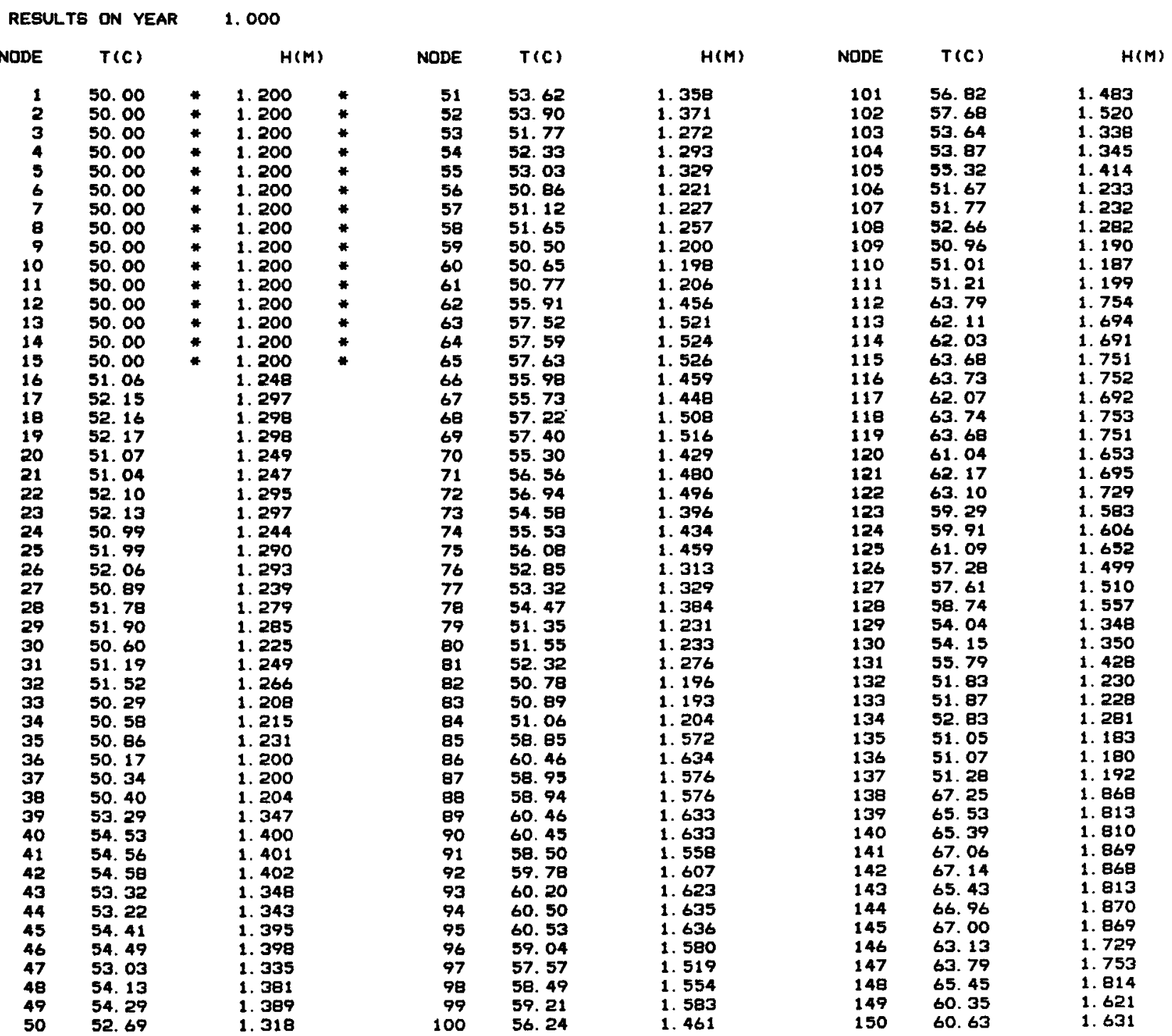


LISTING D-6. Output Report File for Test Case Two. (Sheet 14 of 48)

SAMPLE PROBLEM, FLOW AROUND A HEATED CANNISTER

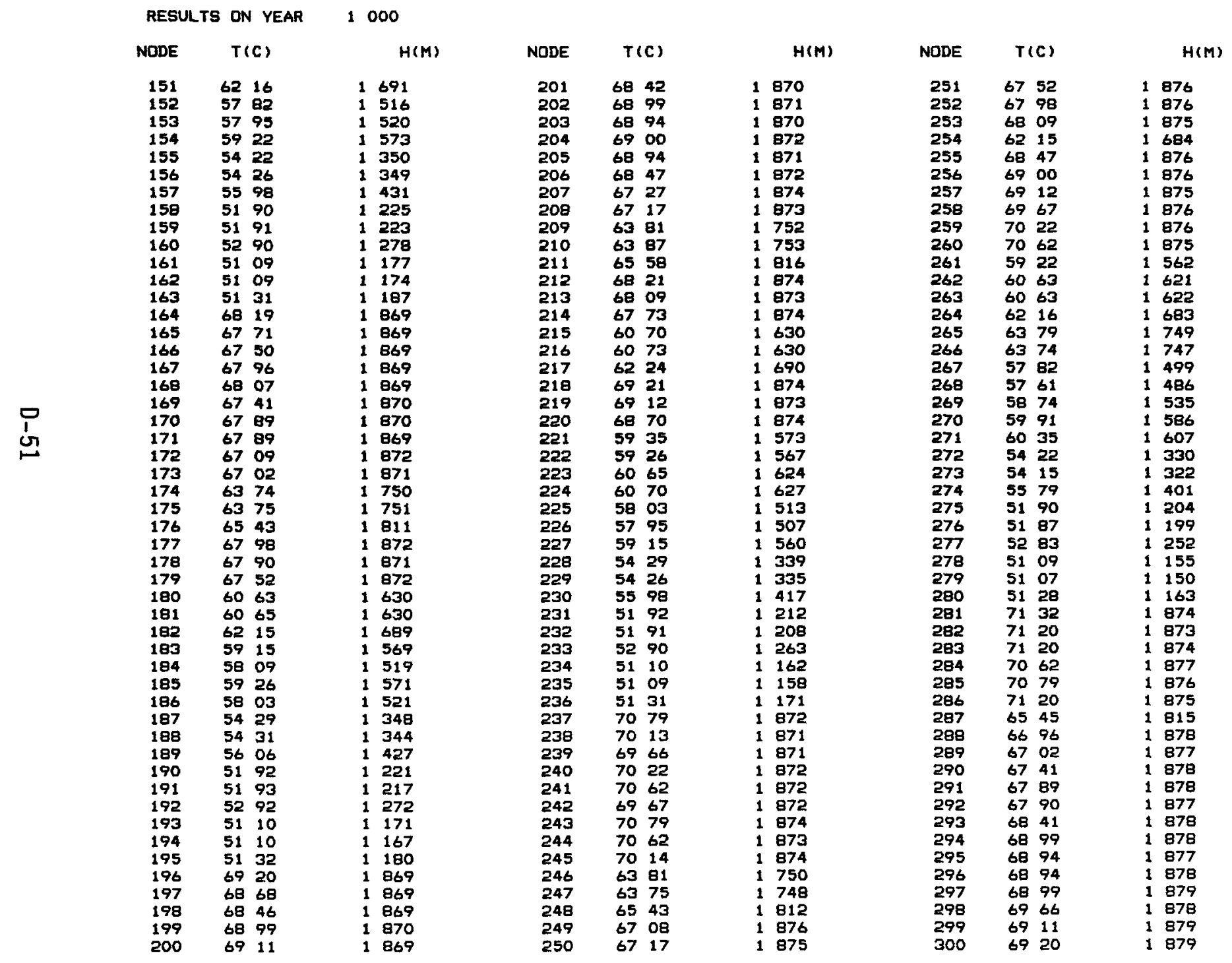


LISTING D-6. Output Report File for Test Case Two. (Sheet 15 of 48)

SAMPLE PROBLEM, FLOW AROUND A HEATED CANNISTER

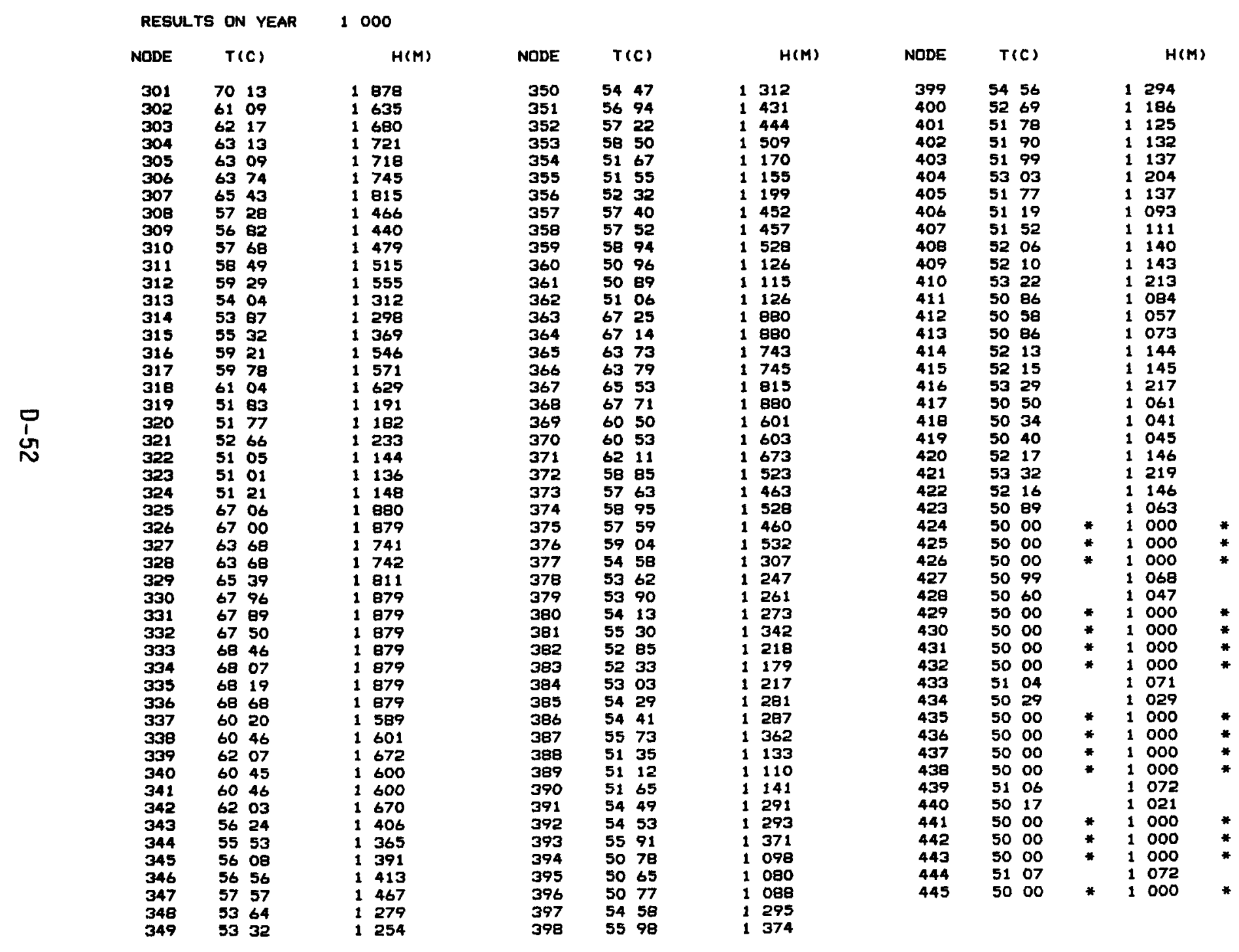

$\begin{array}{ll}\text { ITERATION NUMBER } & 11 \\ \text { ITERATION NUMBER CHANGE (TEMP) }=2 \text { 1629E-03, MAX REL CORRECTION }=42879 E-03 \\ \text { 1, MAX CHANGE (HEAD) }=7 \text { 6922E-02, MAX REL CORRECTION }=29814 E-02\end{array}$ 
LISTING D-6. Output Report File for Test Case Two. (Sheet 16 of 48)

SAMPLE PROBLEM, FLOW AROUND A HEATED CANNISTER

RESULTS FOR VELOCITY (M/YR) OF YEAR 1000 ELEMENT

GSS PNT 1 GSS PNT 2 GSS PNT 3 GSS PNT 4 GSS PNT 5 GSS PNT 6 GSS PNT 7 GSS PNT 8 GSS PNT 9

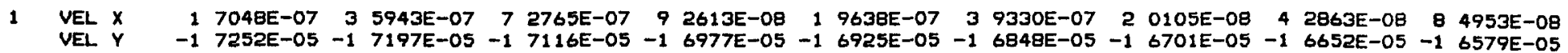

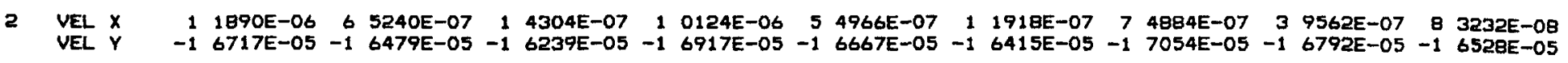

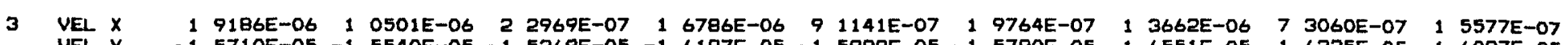
VEL $Y$ - 1 5710E-05 - 1 5540E-05 -1 5369E-05 -1 6187E-05 -1 5989E-05 -1 5790E-05 -1 $6551 E-05-1$ 6325E-05 -1 $6097 E-05$

4 VEL $x \quad 2$ 5867E-06 $14148 E-06 \quad 3 \quad 0921 E-07 \quad 2 \quad 3749 E-06 \quad 1 \quad 2922 E-06 \quad 2 \quad 8087 E-07 \quad 2 \quad 1171 E-06 \quad 1 \quad 1428 E-06 \quad 2 \quad 4632 E-07$ VEL $Y$ - 1 3761E-05 -1 3712E-05 -1 3662E-05 -1 4626E-05 -1 4527E-05 -1 4428E-05 - 1 5346E-05 - 5 5199E-05 -1 5050E-05

$5 \quad V E L X \quad 2 \quad 7972 E-06 \quad 1 \quad 5549 E-06 \quad 3 \quad 4567 E-07 \quad 27800 E-06 \quad 1 \quad 5411 E-06 \quad 3 \quad 4162 E-07 \quad 2 \quad 7544 E-06 \quad 1 \quad 5206 E-06 \quad 3 \quad 3562 E-07$ VEL $Y$ - $\quad-8$ 4737E-06 -8 5906E-06 -8 7073E-06 -1 0918E-05 -1 0970E-05 -1 1020E-05 -1 2931E-05 -1 2916E-05 -1 2900E-05

6 VEL $X \quad 1 \quad 6199 E-06 \quad 9 \quad 1389 E-07 \quad 2 \quad 0623 E-07 \quad 2 \quad 0561 E-06 \quad 1 \quad 1598 E-06 \quad 2 \quad 6170 E-07 \quad 2 \quad 6216 E-06 \quad 1 \quad 4787 E-06 \quad 3 \quad 3361 E-07$

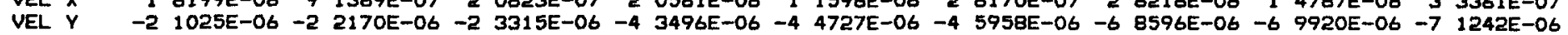

$7 \quad V E L \quad X \quad 1 \quad 7952 E-07 \quad 1 \quad 0418 E-07 \quad 2 \quad 4165 E-08 \quad 6 \quad 7210 E-07 \quad 3 \quad 8205 E-07 \quad 8 \quad 6864 E-08 \quad 1 \quad 2703 E-06 \quad 7 \quad 1950 E-07 \quad 1 \quad 6301 E-07$

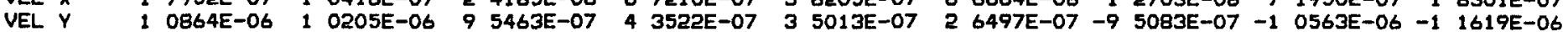

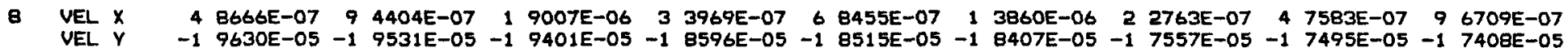

9 VEL $X \quad 3$ 0888E-06 2 2696E-06 1 5784E-06 2 6532E-06 1 9192E-06 1 3372E-06 $20115 E-06 \quad 14005 E-06 \quad 9$ 7844E-07

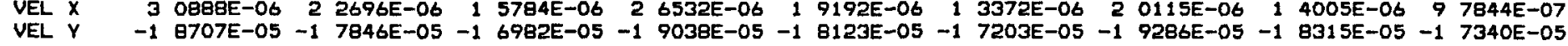

10 VEL $x \quad 4 \quad 9064 E-06 \quad 3 \quad 6198 E-06 \quad 2 \quad 5368 E-06 \quad 4 \quad 3364 E-06 \quad 3 \quad 1610 E-06 \quad 2 \quad 2140 E-06 \quad 3 \quad 5989 E-06 \quad 2 \quad 5663 E-06 \quad 1 \quad 7947 E-06$

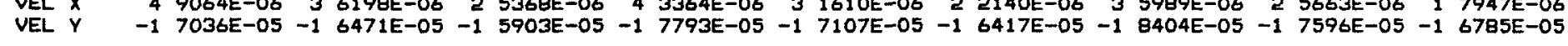

11 VEL $x \quad 6 \quad 3310 E-06 \quad 4 \quad 7330 E-06 \quad 3 \quad 3842 E-06 \quad 5 \quad 8891 E-06 \quad 4 \quad 3628 E-06 \quad 3 \quad 1079 E-06 \quad 5 \quad 3532 E-06 \quad 3 \quad 9132 E-06 \quad 2 \quad 7719 E-06$ VEL $Y$ - -1 4083E-05 -1 3991E-05 -1 3897E-05 -1 5335E-05 - 1 5052E-05 -1 4768E-05 -1 6428E-05 - 1 5955E-05 -1 5480E-05

12 VEL $X \quad 6 \quad 2221 E-06 \quad 4 \quad 8619 E-06 \quad 3 \quad 5976 E-06 \quad 6 \quad 3770 E-06 \quad 4 \quad 9297 E-06 \quad 3 \quad 5966 E-06 \quad 6 \quad 6064 E-06 \quad 5 \quad 0299 E-06 \quad 3 \quad 5952 E-06$

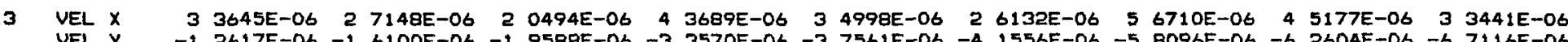

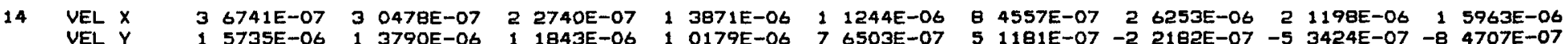

15 VEL $X \quad 1$ 1926E-06 2 2599E-06 4 6667E-06 8 1373E-07 1 5956E-06 3 3070E-06 5 9219E-07 $1 \quad 1566 E-06 \quad 2 \quad 3567 E-06$ VEL $Y$-2 5849E-05 -2 5576E-05 -2 5234E-05 -2 3140E-05 -2 2953E-05 -2 2703E-05 -2 0422E-05 -2 $0320 E-05-2$ 0159E-05

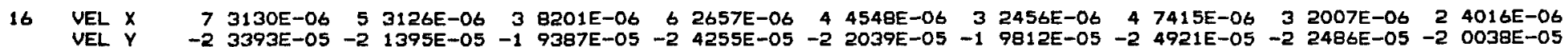


LISTING D-6. Output Report File for Test Case Two. (Sheet 17 of 48)

SAMPLE PROBLEM, FLOW AROUND A HEATED CANNISTER

RESULTS FOR VELOCITY (M/YR) OF YEAR 1.000

ELEMENT

17 VEL $X$

18 VEL $X$

19 VEL $X$

VEL $Y$

20 VEL $X$

21 VEL $X$

22 VEL $X$

23 VEL $X$

24 VEL $X$

25 VEL $x$

VEL $y$

26 VEL $X$

27 VEL $X$

28 VEL $X$

VEL $Y$

29 VEL $X$

30 VEL $X$ VEL Y

31 VEL $X$

32 VEL $X$
GSS PNT 1 GSS PNT 2 GSS PNT 3 GSS PNT 4 GSS PNT 5 GSS PNT 6 GSS PNT 7 GSS PNT 8 GSS PNT 9

$\begin{array}{lllllllll}1.0697 E-05 & 7.9920 E-06 & 5.9726 E-06 & 9.6360 E-06 & 7.0696 E-06 & 5.2722 E-06 & \text { 8. 2708E-06 } & 5.8804 E-06 & 4.3672 E-06\end{array}$ $-1.9489 E-05-1.8501 E-05-1.7508 E-05-2.1185 E-05-1.9787 E-05-1.8384 E-05-2.2628 E-05-2.0821 E-05-1.9006 E-05$

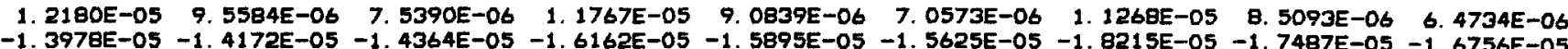
$\begin{array}{llllllllll}9.9379 E-06 & 9.4865 E-06 & 7.1582 E-06 & 1.0887 E-05 & 9.0884 E-06 & 7.4362 E-06 & 1.2293 E-05 & 9.9794 E-06 & 7.8478 E-06\end{array}$ -5. 5016E-06 -6. 4027E-06 -7. 3050E-06 -8. 7287E-06 -9. 3764E-06 -1. 0024E-05 -1. $2076 E-05$-1. $2471 E-05$-1.2865E-05

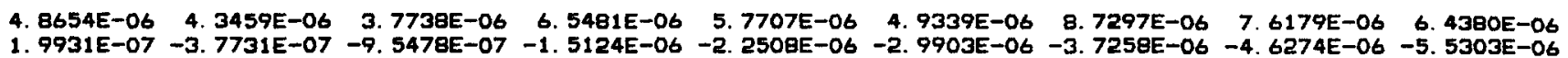
$\begin{array}{lllllllll}5.1939 E-07 & 4.7584 E-07 & 4.0913 E-07 & 1.9930 E-06 & 1.7811 E-06 & 1.5438 E-06 & 3.7827 E-06 & 3.3663 E-06 & 2.9218 E-06\end{array}$

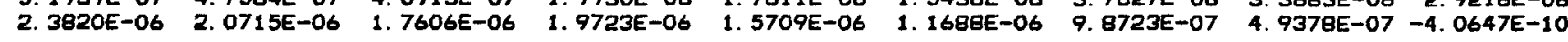
$\begin{array}{lllllll}3.6104 E-06 & 5.5274 E-06 & 3.0515 E-06 & 2.7628 E-06 & 1.6983 E-06 & 5.3690 E-06 & 5.0480 E-06\end{array}$ -2. $9921 E-05-3.0980 E-05-3.1776 E-05-2.7040 E-05$-2. $8189 E-05$-2. $6655 E-05-3.4950 E-05$

$\begin{array}{llllllll}7.8850 E-06 & 7.8811 E-06 & \text { 8. } 6322 E-06 & 6.6132 E-06 & 7.1700 E-06 & 4.7852 E-06 & 1.0336 E-05\end{array}$ $-3.3340 E-05-3.1666 E-05-3.6746 E-05-3.1853 E-05-3.6192 E-05-2.8328 E-05-3.6160 E-05$

$\begin{array}{lllllllll}1.5802 E-05 & 1.1956 E-05 & 8.9889 E-06 & 1.3850 E-05 & 1.0263 E-05 & 7.7107 E-06 & 1.1040 E-05 & 7.8147 E-06 & 5.8550 E-06\end{array}$ -3. $0503 E-05-2.7564 E-05-2.5127 E-05-3.3101 E-05-2.9389 E-05-2.6303 E-05-3.5172 E-05-3.0736 E-05-2.7039 E-05$

$\begin{array}{lllllll}\text { 1. } 5711 E-06 & 3.0733 E-06 & 1.5414 E-08 & 2.2476 E-06 & 4.0744 E-07 & 5.3086 E-06 & 7.7587 E-07\end{array}$

$\begin{array}{rrrrrrrrr}1.9959 E-05 & 1.6004 E-05 & 1.2792 E-05 & 1.8799 E-05 & 1.4805 E-05 & 1.1640 E-05 & 1.7315 E-05 & 1.3267 E-05 & 1.0159 E-05 \\ -2.1118 E-05 & -2.0636 E-05 & -2.0248 E-05 & -2.4962 E-05 & -2.3495 E-05 & -2.2288 E-05 & -2.8435 E-05 & -2.6023 E-05 & -2.4027 E-05\end{array}$ $\begin{array}{lllllllll}1.8848 E-05 & 1.6334 E-05 & 1.4032 E-05 & 1.9367 E-05 & 1.6443 E-05 & 1.3749 E-05 & 1.9995 E-05 & 1.6576 E-05 & 1.3406 E-05\end{array}$ -1. 1968E-05 - 1. 3022E-05 - 1. 3903E-05 - 1.5191E-05 -1.5712E-05 -1.6154E-05 -1.8604E-05 -1.85B1E-05 - $1.8572 E-05$

$\begin{array}{lllllllll}1.2646 E-05 & 1.1912 E-05 & 1.0865 E-05 & 1.4871 E-05 & 1.3550 E-05 & 1.2092 E-05 & 1.8165 E-05 & 1.6122 E-05 & 1.3908 E-05\end{array}$

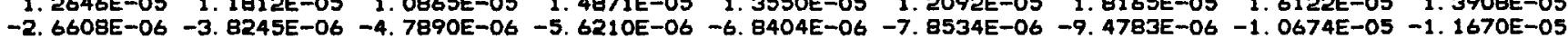
$\begin{array}{llllllllll}5.7319 E-06 & 5.4928 E-06 & 5.1641 E-06 & 7.9320 E-06 & 7.5137 E-06 & 6.9941 E-06 & 1.0785 E-05 & 1.0134 E-05 & 9.3667 E-06\end{array}$

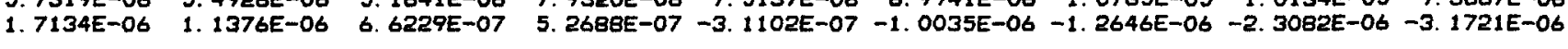
$\begin{array}{lllllllll}6.0301 E-07 & 5.8698 E-07 & 5.4641 E-07 & 2.3370 E-06 & 2.2330 E-06 & 2.1020 E-06 & 4.4429 E-06 & 4.2320 E-06 & 3.9911 E-06\end{array}$

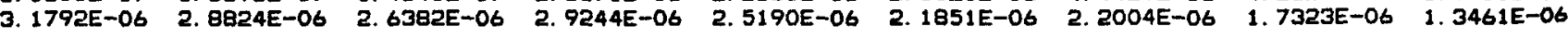
$\begin{array}{lllllllll}1.2363 E-05 & 9.2098 E-06 & 7.1037 E-06 & 6.9243 E-06 & 5.1363 E-06 & 3.6828 E-06 & 2.2928 E-06 & 1.7933 E-06 & 1.3287 E-06\end{array}$ -5. $6787 E-05-4.7694 E-05-4.0658 E-05$-5.7767E-05 -4.8344E-05 -4. $1095 E-05$-5. 8426E-05 -4. 8805E-05 -4. $1424 E-05$

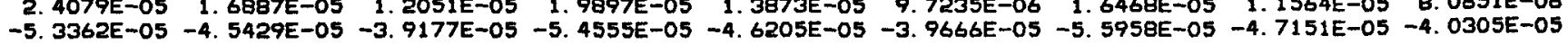


LISTING D-6. Output Report File for Test Case Two. (Sheet 18 of 48)

SAMPLE PROBLEM, FLOW AROUND A HEATED CANNISTER

RESULTS FOR VELDCITY (M/YR) OF YEAR 1000

ELEMENT

GSS PNT 1 GSS PNT 2 GSS PNT 3 GSS PNT 4 GSS PNT 5 GSS PNT 6 GSS PNT 7 GSS PNT 8 GSS PNT 9

33 VEL $X \quad 3$ 4073E-05 $25694 E-05 \quad 1 \quad 9220 E-05 \quad 3 \quad 0615 E-05 \quad 2 \quad 2638 E-05 \quad 1 \quad 6878 E-05 \quad 25703 E-05 \quad 1 \quad 8271 E-05 \quad 1 \quad 3514 E-05$

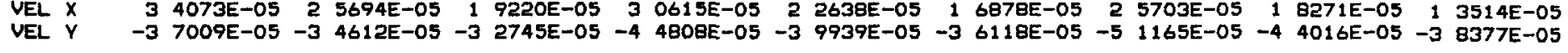

34 VEL $X \quad 3 \quad 1613 E-05 \quad 2 \quad 7009 E-05 \quad 2 \quad 2911 E-05 \quad 3 \quad 2680 E-05 \quad 2 \quad 7073 E-05 \quad 2 \quad 2017 E-05 \quad 3 \quad 4045 E-05 \quad 27159 E-05 \quad 2 \quad 0876 E-05$ -1 8445E-05 -1 9963E-05 -2 $1166 E-05$-2 4852E-05 -2 5027E-05 -2 5181E-05 -3 $1746 E-05$-3 0540E-05 -2 $9613 E-05$

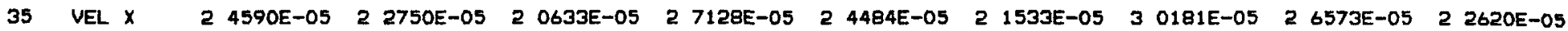
VEL $Y$ - $\quad-7$ 5119E-06 -9 5218E-06 -1 1094E-05 - 1 0733E-05 -1 2746E-05 - 1 4326E-05 -1 4896E-05 -1 6803E-05 -1 8306E-05

36 VEL $x \quad 14196 E-0513785 E-05 \quad 13199 E-05 \quad 1 \quad 7627 E-05 \quad 1 \quad 6782 E-05 \quad 1 \quad 5728 E-05 \quad 2 \quad 2706 E-05 \quad 2 \quad 1219 E-05 \quad 1 \quad 9472 E-05$ VEL $Y \quad 1$ 8914E-07 -9 9535E-07 -1 9152E-06 -1 8836E-06 -3 4943E-06 -4 7484E-06 -5 2851E-06 -7 1585E-06 -8 6214E-06

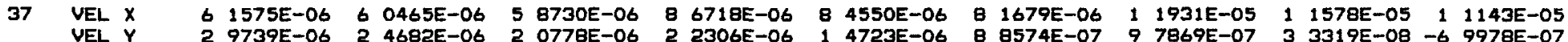

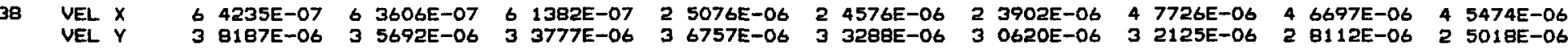

2 6730E-05 2 1229E-05 1 5602E-05 1 1711E-05 1 0978E-05 8 7996E-06 -1 5662E-06 $19427 E-06 \quad 27786 E-06$

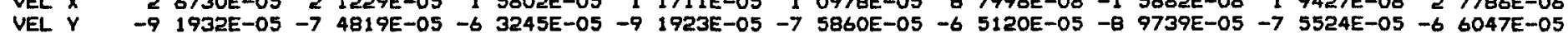

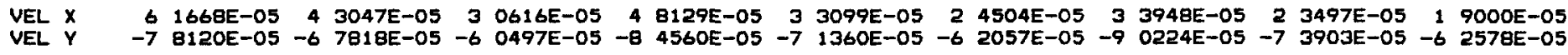

$41 \quad V E L X \quad 5$ B872E-05 4 8463E-05 4 0163E-05 6 3322E-05 4 9224E-05 $3 \quad 7477 E-05 \quad 6 \quad 9607 E-05 \quad 5 \quad 0308 E-05 \quad 3 \quad 3667 E-05$ VEL $Y$ - -3 2053E-05 -3 5466E-05 -3 7896E-05 -4 $9391 E-05$-4 $7365 E-05$-4 5963E-05 -6 8885E-05 -6 1205E-05 -5 5790E-05

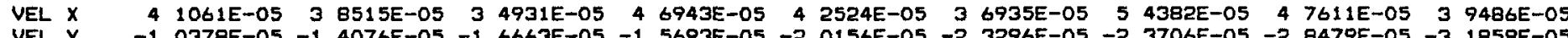
$27885 E-05$ (2)

44 VEL $X \quad 1$ 4884E-05 1 4738E-05 1 4460E-05 $19016 E-05 \quad 1$ 8641E-05 1 B108E-05 $25128 E-05 \quad 24415 E-05 \quad 23506 E-05$

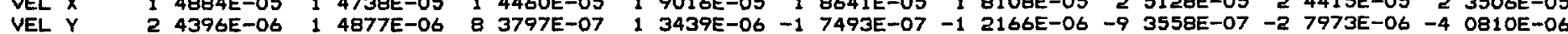
6 3337E-06 6 2923E-06 6 2184E-06 8 9928E-06 $899057 E-06 \quad 8$ 7823E-06 $12439 E-05 \quad 12294 E-05 \quad 12106 E-05$ 3 B755E-06 3 4976E-06 3 2430E-06 3 4685E-06 2 8999E-06 2 5149E-06 2 7092E-06 2 0205E-06 1 5517E-06

46 VEL $X$ 6 5827E-07 o 5657E-07 6 4639E-07 2 5785E-06 2 5594E-06 2 5312E-06 4 9100E-06 4 8701E-06 4 B199E-06

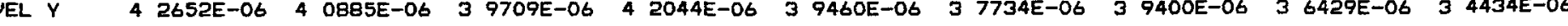

47 VEL $X$-2 $1876 E-05$-2 $4482 E-05$-2 $7196 E-05$-1 $1984 E-05$-1 $1896 E-05$-1 $1840 E-05$ - $23036 E-06 \quad 5 \quad 2846 E-07 \quad 3 \quad 5064 E-06$ VEL $Y$-7 $8169 E-05-9$ 2052E-05 -1 $0454 E-04-6$ 7419E-05 -8 1542E-05 -9 4539E-05 -5 2952E-05 -6 $6961 E-05$-8 $0090 E-05$

48 VEL $X$-5 9221E-06 -7 $3533 E-06 \quad-9$ 0241E-06 $-1 \quad 6321 E-05$-1 $7760 E-05$-1 $9357 E-05$-1 $9833 E-05$-2 $1152 E-05 \quad-2$ 2483E-05 VEL $Y \quad-1 \quad 1438 E-04-1 \quad 3105 E-04-1 \quad 4595 E-04-1 \quad 0003 E-04-1 \quad 1471 E-04-1 \quad 2772 E-04-8 \quad 4124 E-05-97697 E-05-1 \quad 0974 E-04$ 
LISTING D-6. Output Report File for Test Case Two. (Sheet 19 of 48)

SAMPLE PROBLEM, FLOW AROUND A HEATED CANNISTER

RESULTS FOR VELOCITY (M/YR) OF YEAR 1 OOO

GSS PNT 1 GSS PNT 2 GSS PNT 3 GSS PNT 4 GSS PNT 5 GSS PNT 6 GSS PNT 7 GSS PNT 8 GSS PNT 9

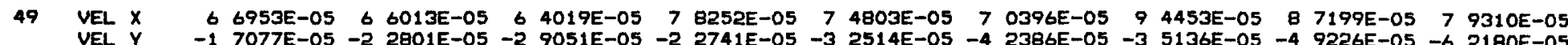

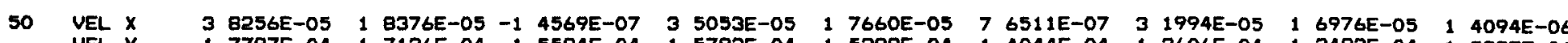

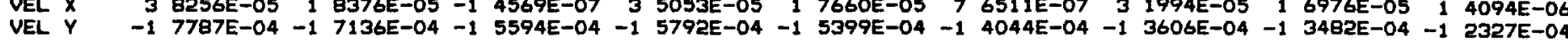

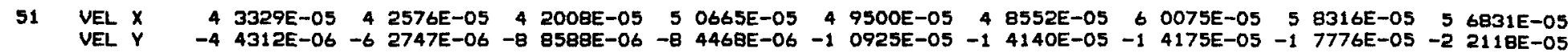

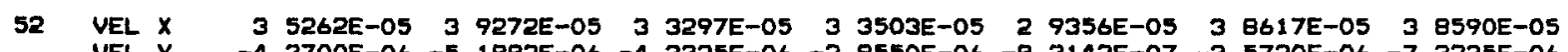
VEL $Y \quad-4 \quad 3700 E-06-5 \quad 1982 E-06-4$ 3325E-06 -2 9550E-06 -8 3142E-07 -3 5720E-06 -7 3235E-06

53 VEL $X \quad 3 \quad 1320 E-05 \quad 3 \quad 2559 E-05 \quad 2 \quad 7926 E-05 \quad 3 \quad 3518 E-05 \quad 2 \quad 9297 E-05 \quad 3 \quad 7260 E-05 \quad 27449 E-05$ VEL $Y$ 5 5265E-07 - 1 7532E-06 1 5269E-06 1 2663E-06 2 B407E-06 - 1 0877E-06 - 1 6550E-06

54 VEL $X \quad 1$ 5139E-05 1 5074E-05 1 4966E-05 1 9622E-05 $19427 E-05 \quad 19202 E-05 \quad 26228 E-05 \quad 2 \quad 5871 E-05 \quad 2 \quad 5471 E-05$

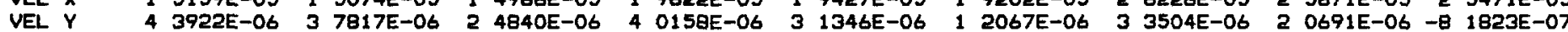

55 VEL $X$

6 4089E-06 6 3848E-06 6 3544E-06 $91342 E-06 \quad 90884 E-06 \quad 9 \quad 0349 E-06 \quad 12667 E-05 \quad 12594 E-05 \quad 12510 E-05$

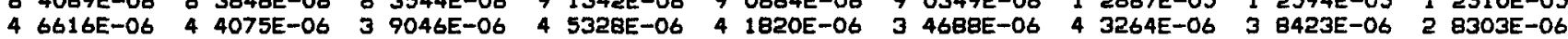

56 VEL $x \quad 6 \quad 6357 E-07 \quad 6 \quad 6230 E-07 \quad 6$ 58BOE-07 2 6097E-06 2 5997E-06 2 5872E-06 4 9731E-06 $49525 E-06 \quad 4 \quad 928 B E-06$ $46816 E-06 \quad 4 \quad 5474 E-06$ \& 2994E-06 4 6592E-06 4 4974E-06 4 1903E-06 4 5907E-06 4 3819E-06 $39751 E-06$

$\begin{array}{llllllllllllllllllllll}57 & \text { VEL } X & -1 & 8130 E-05 & -1 & 9362 E-05 & -2 & 1244 E-05 & -1 & 1820 E-05 & -1 & 1939 E-05 & -1 & 2410 E-05 & -4 & 7520 E-06 & -3 & 9988 E-06 & -3 & 3397 E-06 \\ \text { VEL } Y & -4 & 5616 E-05 & -5 & 8769 E-05 & -7 & 0123 E-05 & -2 & 9401 E-05 & -4 & 3740 E-05 & -5 & 6662 E-05 & -1 & 9066 E-05 & -3 & 3609 E-05 & -4 & 7149 E-05\end{array}$

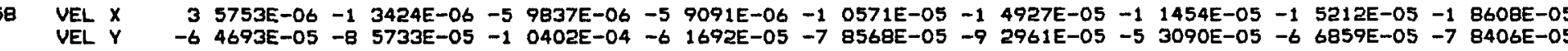

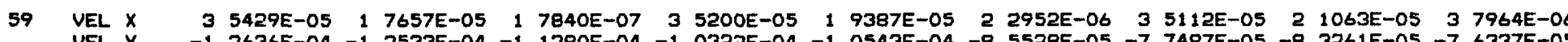

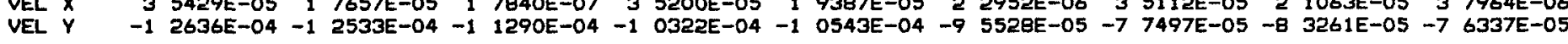

60 VEL $X \quad 7$ 2005E-05 7 0475E-05 6 7947E-05 8 8 $2307 E-05$ 8 $1725 E-05 \quad 7 \quad 9721 E-05 \quad 9 \quad 7702 E-05 \quad 9 \quad 8488 E-05 \quad 9 \quad 7069 E-05$ VEL $Y \quad 1$ 1662E-07 -6 3472E-06 - 1 3533E-05 -5 4083E-0B -9 7926E-06 -2 0602E-05 2 1182E-06 - $12168 E-05-2$ 7875E-05

61 VEL $X \quad 9 \quad 1053 E-05$ \& $2043 E-05 \quad 5 \quad 6833 E-05 \quad 8 \quad 5053 E-05 \quad 7 \quad 6881 E-05 \quad 5 \quad 1804 E-05 \quad 7 \quad 9064 E-05 \quad 7 \quad 1734 E-05 \quad 4 \quad 6676 E-05$ VEL $Y \quad-1$ B500E-04 -1 8172E-04 - 1 6852E-04 -1 5999E-04 -1 6084E-04 -1 5254E-04 -1 3382E-04 -1 3884E-04 -1 $3571 E-04$

62 VEL $X \quad 4 \quad 4828 E-05 \quad 4 \quad 4326 E-05 \quad 4 \quad 3757 E-05 \quad 5 \quad 3034 E-05 \quad 5 \quad 2265 E-05 \quad 5 \quad 1357 E-05 \quad 6 \quad 3708 E-05 \quad 6 \quad 2558 E-05 \quad 6 \quad 1149 E-05$ $\begin{array}{llllllll} & \end{array}$

63 VEL $X \quad 7 \quad 6609 E-05 \quad 6 \quad 0912 E-05 \quad 4 \quad 4793 E-05 \quad 6 \quad 9587 E-05 \quad 5 \quad 6594 E-05 \quad 4 \quad 2883 E-05 \quad 6 \quad 2577 E-05 \quad 5 \quad 2321 E-05 \quad 4 \quad 1027 E-05$ VEL $Y \quad-12091 E-04-12609 E-04-1$ 2580E-04 -9 6694E-05 -1 $01486 E-04$ - 1 0226E-04 -7 0762E-05 -7 4937E-05 -7 $6546 E-05$

64 VEL $X \quad 3 \quad 6664 E-05 \quad 3 \quad 4613 E-05 \quad 3 \quad 5011 E-05 \quad 4$ 0764E-05 4 O675E-05 3 9696E-05 3 O721E-05 
LISTING D-6. Output Report File for Test Case Two. (Sheet 20 of 48)

SAMPLE PROBLEM, FLOW AROUND A HEATED CANNISTER

RESULTS FOR VELOCITY (M/YR) OF YEAR 1000

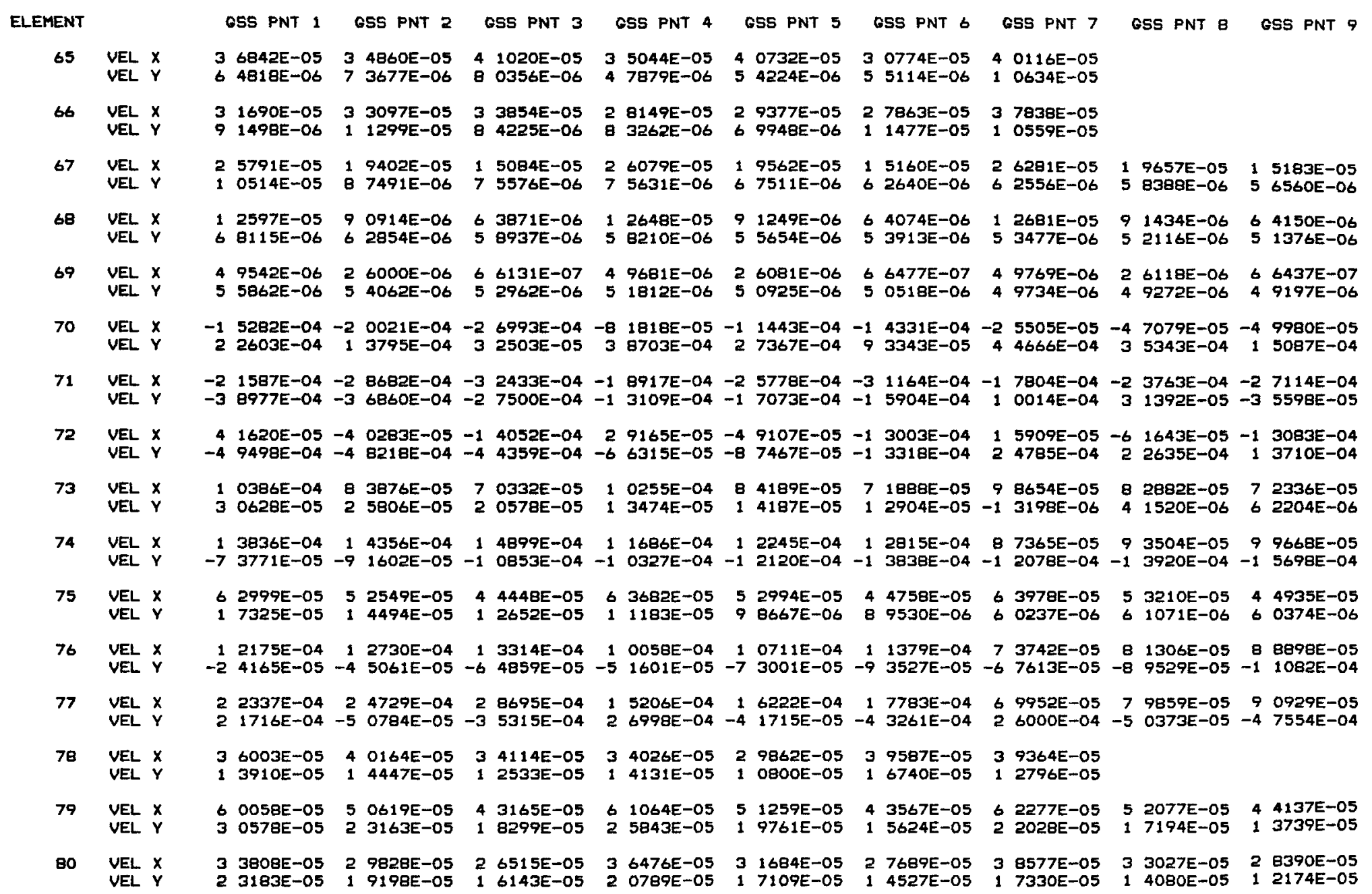


LISTING D-6. Output Report File for Test Case Two. (Sheet 21 of 48)

SAMPLE PROBLEM, FLOW AROUND A HEATED CANNISTER

RESULTS FOR VELOCITY (M/YR) OF YEAR 1000

ELEMENT GSS PNT 1 GSS PNT 2 GSS PNT 3 GSS PNT 4 GSS PNT 5 GSS PNT 6 GSS PNT 7 GSS PNT 9 GSS PNT 9

81 VEL $X \quad 2$ 4074E-05 1 8460E-05 1 4666E-05 2 4880E-05 1 8927E-05 $14905 E-05 \quad 2 \quad 5498 E-05 \quad 1 \quad 9244 E-05 \quad 1$ 5015E-05

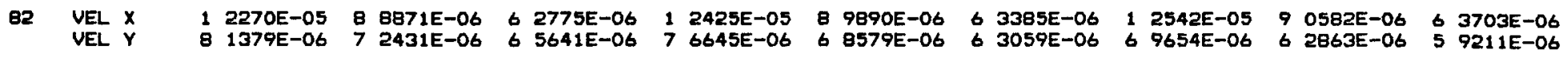

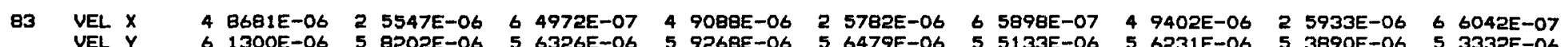

84 VEL $X \quad 1 \quad 6799 E-05$-4 $4225 E-05$ - 1 1458E-04 B 3314E-06 -2 5098E-05 -5 8905E-05 -2 5578E-07 -8 $1833 E-06-1 \quad 1775 E-05$

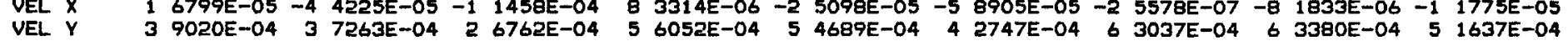

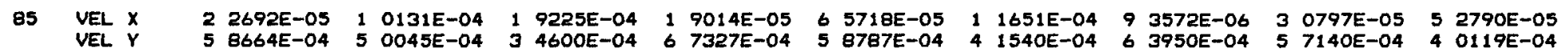

86 VEL $X \quad 9$ 0514E-05 $77675 E-05 \quad 6 \quad 8515 E-05$ 9 7083E-05 8 1118E-05 6 9840E-05 $10256 E-04 \quad 8 \quad 3291 E-05 \quad 6 \quad 9893 E-05$ VEL $Y \quad 7$ 1932E-05 $51190 E-05 \quad 37712 E-05$ 5 $5690 E-05$ 3 $9498 E-05 \quad 3$ O6B6E-05 3 8998E-05 2 B385E-05 $24449 E-05$

87 VEL $X \quad 1 \quad 5325 E-04 \quad 1 \quad 6150 E-04 \quad 1 \quad 7052 E-04 \quad 15466 E-04 \quad 1 \quad 6205 E-04 \quad 1 \quad 6984 E-04 \quad 1 \quad 4511 E-04 \quad 1 \quad 5088 E-04 \quad 15678 E-04$

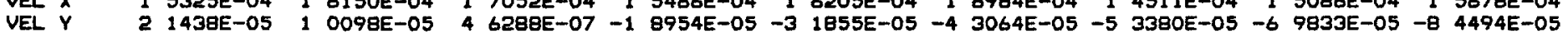

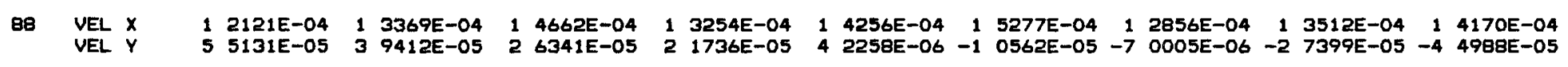

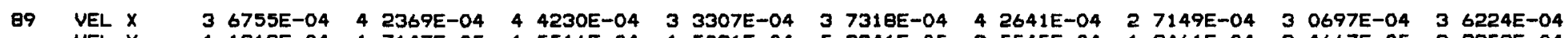
VEL $Y \quad 1$ 1312E-04 -1 7147E-05 - 1 5516E-04 1 5081E-04 -5 3841E-05 -2 5545E-04 1 9461E-04 -3 4667E-05 -2 9252E-04

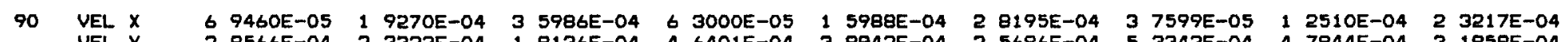

91 VEL $X \quad 4 \quad 2619 E-05 \quad 3 \quad 9283 E-05 \quad 3 \quad 6663 E-05 \quad 5 \quad 1012 E-05 \quad 4 \quad 4942 E-05 \quad 4 \quad 0158 E-05 \quad 5 \quad 7771 E-05 \quad 4 \quad 9181 E-05 \quad 4 \quad 2388 E-05$

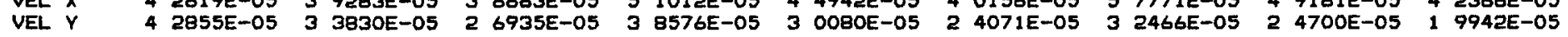

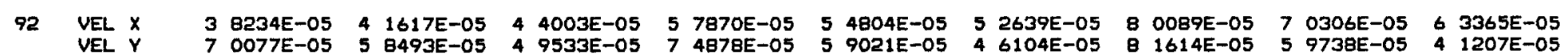

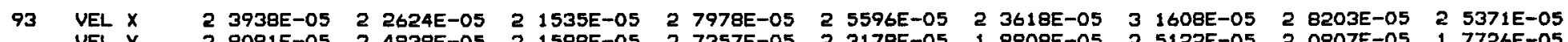
VEL $Y$ 2 $29091 E-052$ 4938E-05 2 1598E-05 2 7357E-05 2 3178E-05 1 9908E-05 2 5122E-05 2 O907E-05 1 7726E-05

94 VEL $X \quad 2$ 0216E-05 1 6222E-05 1 3525E-05 2 1904E-05 1 7227E-05 $14068 E-05 \quad 2 \quad 3323 E-05 \quad 1$ B015E-05 $14429 E-05$

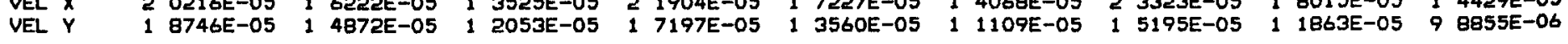

95 VEL $X \quad 2$ 2612E-05 $23613 E-05 \quad 2 \quad 4398 E-05 \quad 2 \quad 9450 E-05 \quad 2 \quad 8972 E-05 \quad 2 \quad 8601 E-05 \quad 3 \quad 6847 E-05 \quad 3 \quad 4845 E-05 \quad 3 \quad 3278 E-05$

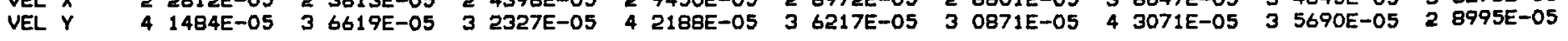

96 VEL $X \quad 1 \quad 1397 E-05 \quad 9 \quad 3332 E-06 \quad 5 \quad 9700 E-06 \quad 1 \quad 1795 E-05 \quad 8 \quad 5956 E-06 \quad 6 \quad 1277 E-06 \quad 1 \quad 2115 E-05 \quad 8 \quad 7895 E-06 \quad 6 \quad 2245 E-06$

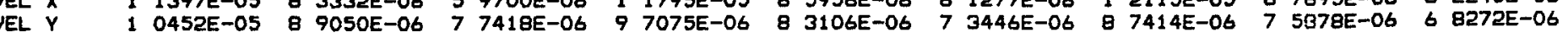


LISTING D-6. Output Report File for Test Case Two. (Sheet 22 of 48)

SAMPLE PROBLEM, FLOW AROUND A HEATED CANNISTER

RESULTS FOR VELOCITY (M/YR) OF YEAR 1000

\begin{tabular}{|c|c|c|c|c|c|c|c|c|c|c|}
\hline IENT & & & & & & & 6 & 7 & SS PNT 8 & GSS PNT 9 \\
\hline 97 & $\begin{array}{l}\text { VEL } X \\
\text { VEL } Y\end{array}$ & $\begin{array}{ll}4 & 6252 E-06 \\
7 & 0889 E-06\end{array}$ & $\begin{array}{ll}2 & 42 B 2 E-06 \\
6 & 5432 E-06\end{array}$ & $\begin{array}{ll}6 & 1918 E-07 \\
6 & 2328 E-06\end{array}$ & $\begin{array}{l}47355 E-06 \\
67741 E-06\end{array}$ & $\begin{array}{l}2 \quad 4897 E-06 \\
6 \quad 2740 E-06\end{array}$ & $\begin{array}{ll}6 & 4047 E-07 \\
6 & 0387 E-06\end{array}$ & $\begin{array}{l}4 \text { 8268E-06 } \\
63635 \mathrm{E}-06\end{array}$ & $\begin{array}{l}25342 E-06 \\
5 \quad 9222 E-06\end{array}$ & $\begin{array}{l}-07 \\
-06\end{array}$ \\
\hline 98 & $\begin{array}{l}\text { VEL } X \\
\text { VEL } Y\end{array}$ & $\begin{array}{l}2 \quad 1731 E-05 \\
7 \text { B608E-05 }\end{array}$ & $\begin{array}{l}29024 E-05 \\
77960 E-05\end{array}$ & $\begin{array}{ll}3 & 4846 E-05 \\
7 & 5897 E-05\end{array}$ & $\begin{array}{l}2 \quad 7338 E-05 \\
91618 E-05\end{array}$ & $\begin{array}{l}3 \text { 8595E-05 } \\
87958 E-05\end{array}$ & $\begin{array}{l}4 \quad 9907 E-05 \\
8 \quad 2967 E-05\end{array}$ & $\begin{array}{l}E-05 \\
E-04\end{array}$ & $\begin{array}{l}E-05 \\
E-04\end{array}$ & $\begin{array}{ll}7 & 2645 E-05 \\
9 & 2795 E-05\end{array}$ \\
\hline 99 & $\begin{array}{l}\text { VEL } X \\
\text { VEL } Y\end{array}$ & $\begin{array}{ll}1 & 1580 \mathrm{E}-04 \\
8 & 8889 \mathrm{E}-05\end{array}$ & $\begin{array}{ll}1 & 4714 E-04 \\
6 & 3428 E-05\end{array}$ & $\begin{array}{ll}1 & 6394 E-04 \\
2 & 6474 E-05\end{array}$ & $\begin{array}{ll}1 & 0930 E-04 \\
9 & 1753 E-05\end{array}$ & $\begin{array}{ll}1 & 3960 E-04 \\
6 & 7784 E-05\end{array}$ & $\begin{array}{ll}1 & 5668 E-04 \\
3 & 3026 E-05\end{array}$ & $\begin{array}{ll}1 & 0270 E-04 \\
9 & 6429 E-05\end{array}$ & $\begin{array}{ll}1 & 3215 E-04 \\
7 & 4229 E-05\end{array}$ & $\begin{array}{ll}1 & 4973 E-04 \\
4 & 1807 E-05\end{array}$ \\
\hline 100 & $\begin{array}{l}\text { VEL } X \\
\text { VEL } \\
Y\end{array}$ & $\begin{array}{ll}1 & 0035 E-04 \\
1 & 0230 E-04\end{array}$ & $\begin{array}{ll}12975 E-04 \\
79883 E-05\end{array}$ & $\begin{array}{ll}1 & 444 \\
4 & 410\end{array}$ & $\begin{array}{ll}9 & 174 \\
1 & 070\end{array}$ & $\begin{array}{ll}1206 \\
8563\end{array}$ & $\begin{array}{ll}1 & 35 \\
5 & 12\end{array}$ & $\begin{array}{ll}8 & 30 \\
1 & 14\end{array}$ & $\begin{array}{ll}1 & 1183 E-04 \\
9 & 3941 E-05\end{array}$ & $\begin{array}{l}E-04 \\
E-05\end{array}$ \\
\hline 101 & $\begin{array}{l}\text { VEL } X \\
\text { VEL } Y\end{array}$ & $\begin{array}{ll}1 & 3573 E-05 \\
1 & 2313 E-04\end{array}$ & $\begin{array}{l}45304 E-05 \\
1 \quad 2281 E-04\end{array}$ & $\begin{array}{ll}8 & 2562 E-05 \\
1 & 1197 E-04\end{array}$ & $\begin{array}{ll}1 & 1242 E-05 \\
1 & 2216 E-04\end{array}$ & $\begin{array}{l}4 \quad 0843 E-05 \\
12481 E-04\end{array}$ & $\begin{array}{ll}7 & 722 \\
1 & 155\end{array}$ & $\begin{array}{ll}7 & 914 \\
1 & 222\end{array}$ & $\begin{array}{ll}3 & 5681 E-05 \\
1 & 2842 E-04\end{array}$ & $\begin{array}{ll}7 & 1490 E-05 \\
1 & 2135 E-04\end{array}$ \\
\hline 102 & $\begin{array}{l}\text { VEL } x \\
\text { VEL } y\end{array}$ & $\begin{array}{ll}1 & 4891 E-05 \\
5 & 1455 E-05\end{array}$ & $\begin{array}{ll}1 & 8445 E-05 \\
4 & 8878 E-05\end{array}$ & $\begin{array}{l}20919 E-05 \\
4 \quad 5117 E-05\end{array}$ & $\begin{array}{l}2035 \\
5750\end{array}$ & $\begin{array}{ll}2 & 488 \\
5 & 284\end{array}$ & $\begin{array}{ll}2 & 805 \\
4 & 685\end{array}$ & $\begin{array}{l}288 \\
651\end{array}$ & $\begin{array}{l}3 \quad 3855 E-05 \\
5 \text { 7861E-05 }\end{array}$ & $\begin{array}{l}37362 E-05 \\
49040 E-05\end{array}$ \\
\hline 103 & $\begin{array}{l}\text { VEL } x \\
\text { VEL } Y\end{array}$ & $\begin{array}{ll}8 & 8747 E-06 \\
5 & 3719 E-05\end{array}$ & $\begin{array}{ll}1 & 0692 E-05 \\
5 & 2993 E-05\end{array}$ & $\begin{array}{l}13235 \\
52435\end{array}$ & $\begin{array}{ll}1 & 295 \\
6 & 137\end{array}$ & $\begin{array}{ll}1 & 547 \\
6 & 019\end{array}$ & $\begin{array}{ll}1 & 87 \\
5 & 92\end{array}$ & $\begin{array}{ll}1 & 885 \\
7 & 117\end{array}$ & $\begin{array}{l}2 \quad 2643 \\
69343\end{array}$ & $\begin{array}{l}27156 \mathrm{E}-05 \\
67774 \mathrm{E}-05\end{array}$ \\
\hline 104 & $\begin{array}{l}\text { VEL } X \\
\text { VEL } Y\end{array}$ & $\begin{array}{l}14303 E-05 \\
2 \quad 9679 E-05\end{array}$ & $\begin{array}{l}14592 E-05 \\
2 \\
2093 E-05\end{array}$ & $\begin{array}{ll}1 & 483 \\
2 & 471\end{array}$ & $\begin{array}{l}-05 \\
-05\end{array}$ & $\begin{array}{l}1738 \\
2656\end{array}$ & $\begin{array}{ll}1 & 71 \\
2 & 37\end{array}$ & $\begin{array}{ll}2 & 12 \\
2 & 95\end{array}$ & $\begin{array}{ll}2 & 039 \\
2 & 591\end{array}$ & $\begin{array}{ll}1 & 97 \\
2 & 25\end{array}$ \\
\hline 105 & $\begin{array}{l}\text { VEL } x \\
\text { VEL } y\end{array}$ & $\begin{array}{ll}1 & 4624 E-05 \\
2 & 2115 E-05\end{array}$ & $\begin{array}{l}1262 \\
1816\end{array}$ & $\begin{array}{l}1127 \\
1502\end{array}$ & $\begin{array}{ll}1 & 68 \mathrm{C} \\
2 & 103\end{array}$ & $\begin{array}{l}14079 E-05 \\
1 \quad 7086 E-05\end{array}$ & $\begin{array}{l}-05 \\
-05\end{array}$ & & $\begin{array}{ll}1 & 5 \\
1 & 5\end{array}$ & $\begin{array}{l}129 \\
128\end{array}$ \\
\hline 106 & $\begin{array}{l}\text { VEL } x \\
\text { VEL } y\end{array}$ & $\begin{array}{ll}1 & 0961 E-05 \\
3 & 5724 E-05\end{array}$ & $\begin{array}{ll}1 & 2497 E-05 \\
3 & 3824 E-05\end{array}$ & $\begin{array}{ll}1 & 3693 E-05 \\
3 & 1625 E-05\end{array}$ & $\begin{array}{ll}1 & 4334 E-05 \\
3 & 7822 E-05\end{array}$ & $\begin{array}{ll}1 & 5881 E-05 \\
3 & 5058 E-05\end{array}$ & 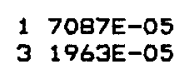 & $\begin{array}{ll}1 & 8726 E-05 \\
4 & 0334 E-05\end{array}$ & $\begin{array}{l}20164 E-05 \\
3 \quad 6533 E-05\end{array}$ & $\begin{array}{ll}2 & 128 \\
3 & 236\end{array}$ \\
\hline 107 & $\begin{array}{l}\text { VEL } x \\
\text { VEL } Y\end{array}$ & $\begin{array}{l}96864 \\
13038\end{array}$ & $\begin{array}{ll}7 & 209 \\
1 & 085\end{array}$ & $\begin{array}{ll}5 & 29 \\
9 & 18\end{array}$ & $\begin{array}{ll}1 & 0 \\
1 & 2\end{array}$ & & $\begin{array}{ll}5 & 6 \\
8 & 6\end{array}$ & & & \\
\hline 108 & $\begin{array}{l}\text { VEL } X \\
\text { VEL } Y\end{array}$ & $\begin{array}{l}6 \quad 3568 E-06 \\
3 \quad 9137 E-05\end{array}$ & $\begin{array}{l}8 \text { 3440E-06 } \\
3 \text { 8321E-05 }\end{array}$ & $\begin{array}{l}97130 E-06 \\
37023 E-05\end{array}$ & $\begin{array}{l}8 \text { 5242E-06 } \\
4 \quad 3144 E-05\end{array}$ & $\begin{array}{ll}1 & 1142 E-05 \\
4 & 1639 E-05\end{array}$ & $\begin{array}{ll}1 & 2953 E-05 \\
3 & 9610 E-05\end{array}$ & $\begin{array}{ll}1 & 2109 E-05 \\
4 & 7930 E-05\end{array}$ & $\begin{array}{ll}1 & 5100 E-05 \\
4 & 5608 E-05\end{array}$ & $\begin{array}{l}17178 E-05 \\
4 \quad 2707 E-05\end{array}$ \\
\hline 109 & $\begin{array}{l}\text { VEL } X \\
\text { VEL } Y\end{array}$ & $\begin{array}{ll}4 & 0973 \\
8 & 2803\end{array}$ & $\begin{array}{ll}2 & 1539 \\
7 & 4431\end{array}$ & $\begin{array}{l}5536 \\
6988\end{array}$ & $\begin{array}{l}432 \\
788\end{array}$ & $\begin{array}{l}227 \\
710\end{array}$ & 6738 & 7403 & $\begin{array}{ll}2 & 3 \\
6 & 6\end{array}$ & $\begin{array}{l}=-07 \\
=-06\end{array}$ \\
\hline 110 & $\begin{array}{l}\text { VELL } x \\
\text { VELL }\end{array}$ & $\begin{array}{l}3 \quad 2623 E-06 \\
8 \quad 2974 E-05\end{array}$ & $\begin{array}{ll}1 & 0139 E-05 \\
8 & 1907 E-05\end{array}$ & $\begin{array}{l}17854 E-05 \\
79479 E-05\end{array}$ & $\begin{array}{l}20976 E-06 \\
94333 E-05\end{array}$ & $\begin{array}{ll}1 & 2978 E-05 \\
9 & 4626 E-05\end{array}$ & $\begin{array}{l}2 \quad 5234 E-05 \\
9 \quad 3002 E-05\end{array}$ & $\begin{array}{cc}-2 & 0430 E-06 \\
1 & 1127 E-04\end{array}$ & $\begin{array}{ll}1 & 4315 E-05 \\
1 & 1354 E-04\end{array}$ & $\begin{array}{ll}3 & 2624 E-05 \\
1 & 1289 E-04\end{array}$ \\
\hline 111 & $\begin{array}{l}\text { VEL } x \\
\text { VEL } Y\end{array}$ & $\begin{array}{ll}2 & 5294 E-05 \\
1 & 1501 E-04\end{array}$ & $\begin{array}{l}5 \quad 5396 E-05 \\
1 \quad 2056 E-04\end{array}$ & $\begin{array}{ll}8 & 6595 E \\
1 & 0554 E\end{array}$ & $\begin{array}{ll}2 & 0768 E-05 \\
1 & 1606 E-04\end{array}$ & $\begin{array}{ll}5 & 1785 E-05 \\
1 & 2272 E-04\end{array}$ & $\begin{array}{ll}8 & 5182 E-05 \\
1 & 07499 E-04\end{array}$ & $\begin{array}{ll}1 & 5595 E-05 \\
1 & 1804 E-04\end{array}$ & $\begin{array}{l}4785 \\
12613\end{array}$ & $\begin{array}{ll}8 & 3966 E-05 \\
1 & 1095 E-04\end{array}$ \\
\hline 112 & $\begin{array}{l}\text { VEL } \underset{y}{X} \\
\text { VEL }\end{array}$ & $\begin{array}{ll}1 & 4590 E-06 \\
5 & 5039 E-05\end{array}$ & $\begin{array}{l}4 \quad 2735 E-06 \\
5 \quad 4649 E-05\end{array}$ & $\begin{array}{l}\text { 93E-06 } \\
31 E-05\end{array}$ & $\begin{array}{l}20405 E-06 \\
63395 E-05\end{array}$ & $\begin{array}{l}57586 E-06 \\
62828 E-05\end{array}$ & $\begin{array}{ll}1 & 0280 E-05 \\
6 & 2043 E-05\end{array}$ & 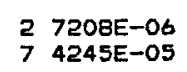 & $\begin{array}{l}79001 E-06 \\
7 \quad 3415 E-05\end{array}$ & $\begin{array}{ll}1 & 3964 E-05 \\
7 & 2223 E-05\end{array}$ \\
\hline
\end{tabular}


LISTING D-6. Output Report File for Test Case Two. (Sheet 23 of 48)

SAMPLE PROBLEM, FLOW AROUND A HEATED CANNISTER

RESULTS FOR VELOCITY (M/YR) OF YEAR 1000

ELEMENT

GSS PNT 1 GSS PNT 2 GSS PNT 3 GSS PNT 4 GSS PNT 5 CSS PNT 6 GSS PNT 7

GSS PNT 8 GSS PNT 9

113 VEL $X$

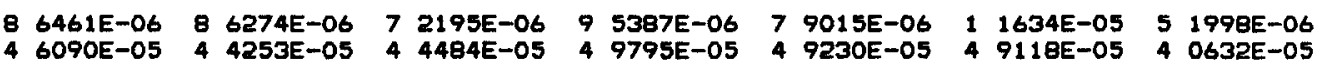

114 VEL $X \quad 3$ 9425E-06 $60344 E-06 \quad 30004 E-06 \quad 3 \quad 3472 E-06 \quad 1$ 8562E-06 5 5406E-06 5 8162E-06

115 VEL $X \quad 1 \quad 7288 E-06 \quad 3 \quad 3786 E-06 \quad 2 \quad 4775 E-06 \quad-2 \quad 1834 E-09 \quad 3 \quad 9770 E-07 \quad 8 \quad 4117 E-07 \quad 5 \quad 8561 E-06$

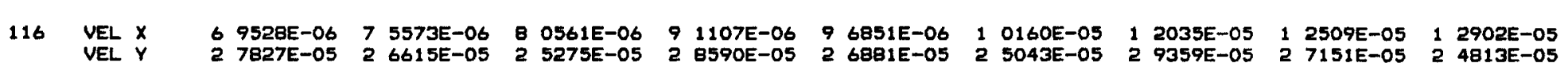

117 VEL $X \quad 8 \quad 3531 E-06 \quad 78666 E-06 \quad 7$ 5379E-06 1 0572E-05 $95640 E-06$ 8 8827E-06 $12964 E-05$ 1 $1400 E-05 \quad 10344 E-05$

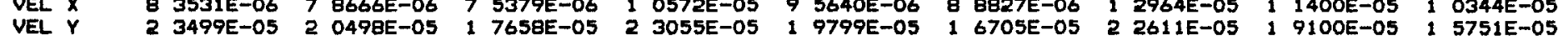

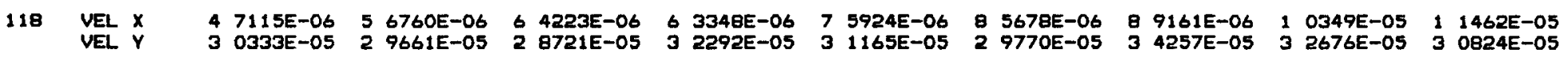

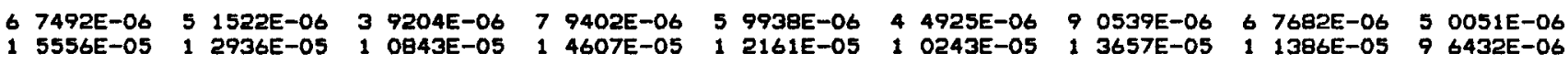

120 VEL $X \quad 25958 E-06 \quad 3 \quad 5049 E-06 \quad 4 \quad 1236 E-06 \quad 3 \quad 4549 E-06 \quad 4 \quad 8041 E-06 \quad 5 \quad 7268 E-06 \quad 5 \quad 1381 E-06 \quad 6 \quad 7717 E-06 \quad 7 \quad 8943 E-06$ VEL $Y$ 3 1492E-05 3 1249E-05 3 O790E-05 3 4160E-05 $33669 E-05$ 3 2962E-05 $336833 E-05$ 3 $6095 E-05$ 3 $5142 E-05$

121 VEL $X \quad 3 \quad 0374 E-06 \quad 16001 E-06 \quad 4 \quad 1658 E-07 \quad 3 \quad 4801 E-06 \quad 1 \quad 8371 E-06 \quad 4 \quad 8421 E-07 \quad 3 \quad 8928 E-06 \quad 2 \quad 0470 E-06 \quad 5 \quad 2715 E-07$

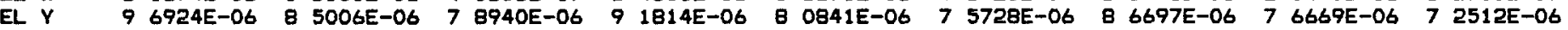

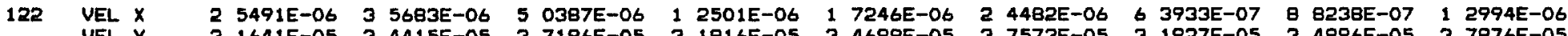

123 VEL $X \quad 3$ O021E-06 3 3606E-06 3 6555E-06 4 2171E-06 4 6919E-06 5 O829E-06 5 7571E-06 $6 \quad 3186 E-06 \quad 6 \quad 7815 E-06$

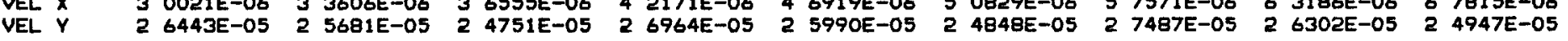

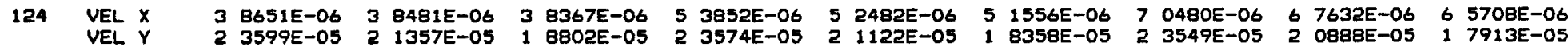

125 VEL $X \quad 1$ 9484E-06 2 4011E-06 2 7495E-06 2 7759E-06 3 4144E-06 3 9069E-06 3 8875E-06 4 6763E-06 5 2860E-06 VEL $Y \quad 2$ 7992E-05 2 7495E-05 2 6941E-05 2 8785E-05 2 8253E-05 2 7564E-05 2 9682E-05 2 9015E-05 $28191 E-05$

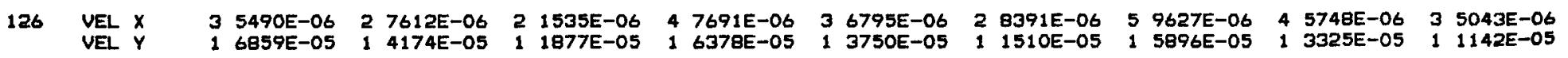

127 VEL $X \quad 1 \quad 0635 E-06 \quad 1 \quad 4529 E-06 \quad 1 \quad 7148 E-06 \quad 1 \quad 5165 E-06 \quad 2 \quad 0773 E-06 \quad 24562 E-06 \quad 2 \quad 1784 E-06 \quad 2 \quad 8698 E-06 \quad 3 \quad 3391 E-06$

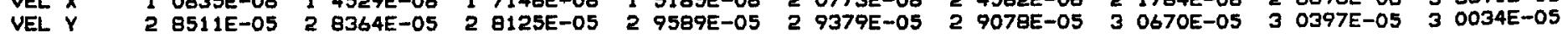

128 VEL $X$

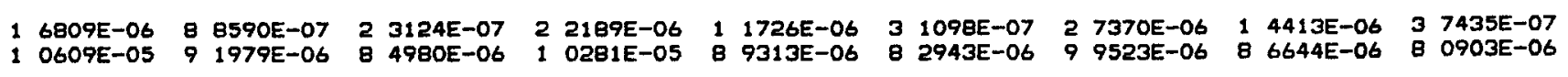


LISTING D-6. Output Report File for Test Case Two. (Sheet 24 of 48)

SAMPLE PROBLEM, FLOW AROUND A HEATED CANNISTER

RESULTS FOR VELOCITY (M/YR) OF YEAR 1000

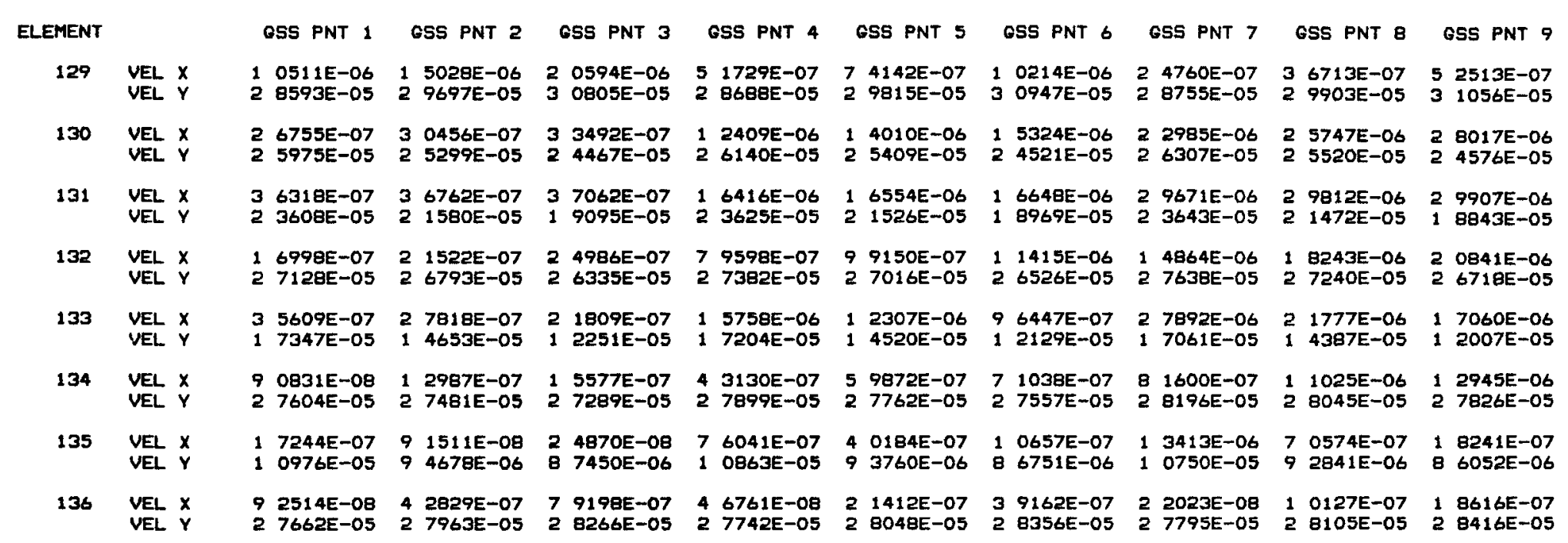


LISTING D-6. Output Report File for Test Case Two. (Sheet 25 of 48) SAMPLE PROBLEM, FLOW AROUND A HEATED CANNISTER

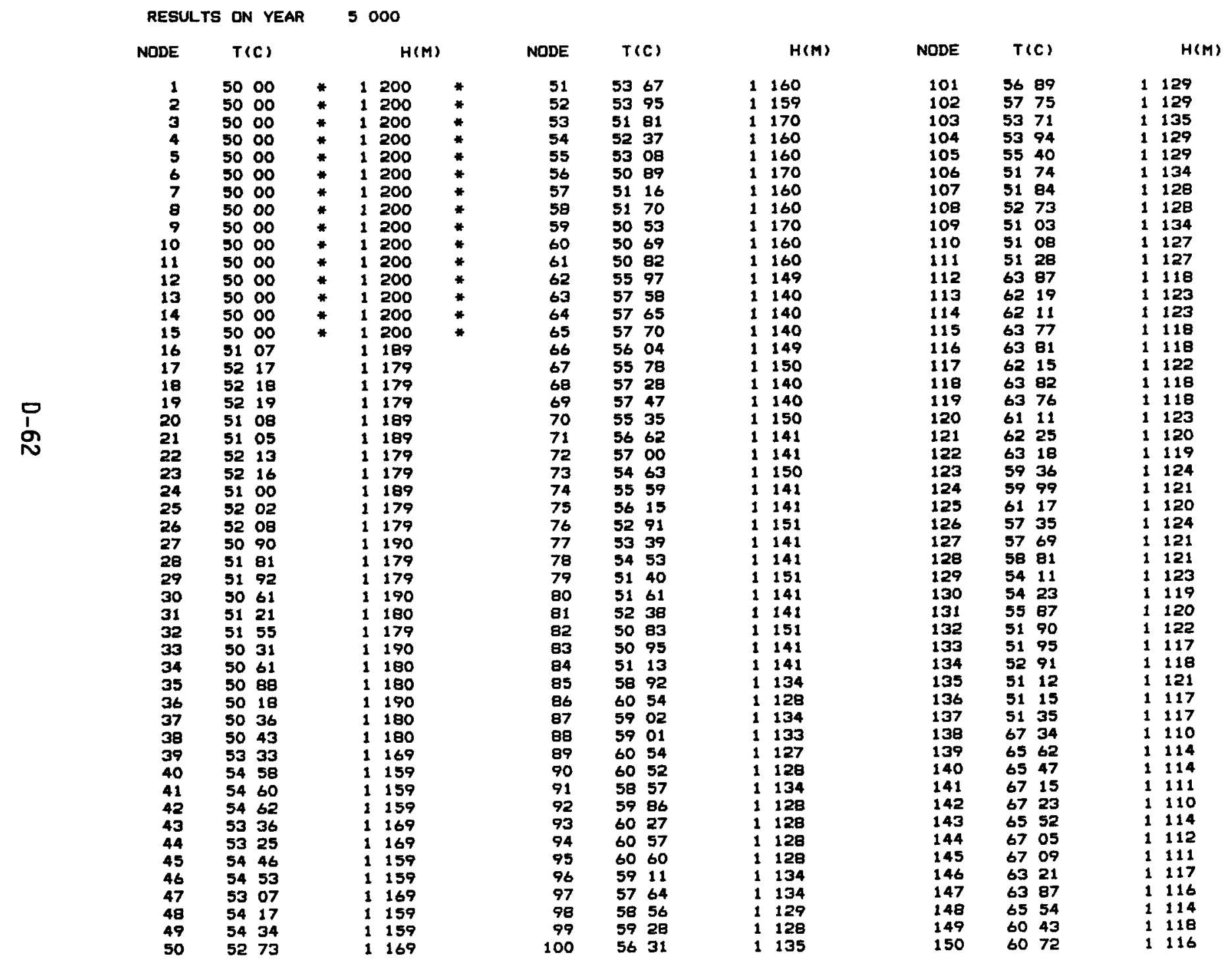


LISTING D-6. Output Report File for Test Case Two. (Sheet 26 of 48)

SAMPLE PROBLEM. FLOW ARDUNd a heated CANNISTER

RESULTS ON YEAR 5000

\begin{tabular}{|c|c|c|c|c|c|c|c|c|}
\hline NODE & $T(C)$ & $H(M)$ & NODE & $T(C)$ & $H(M)$ & NODE & $T(C)$ & $H(M)$ \\
\hline
\end{tabular}


LISTING 0-6. Output Report File for Test Case Two. (Sheet 27 of 48) SAMPLE PROBLEM. FLOW AROUND A HEATED CANNISTER

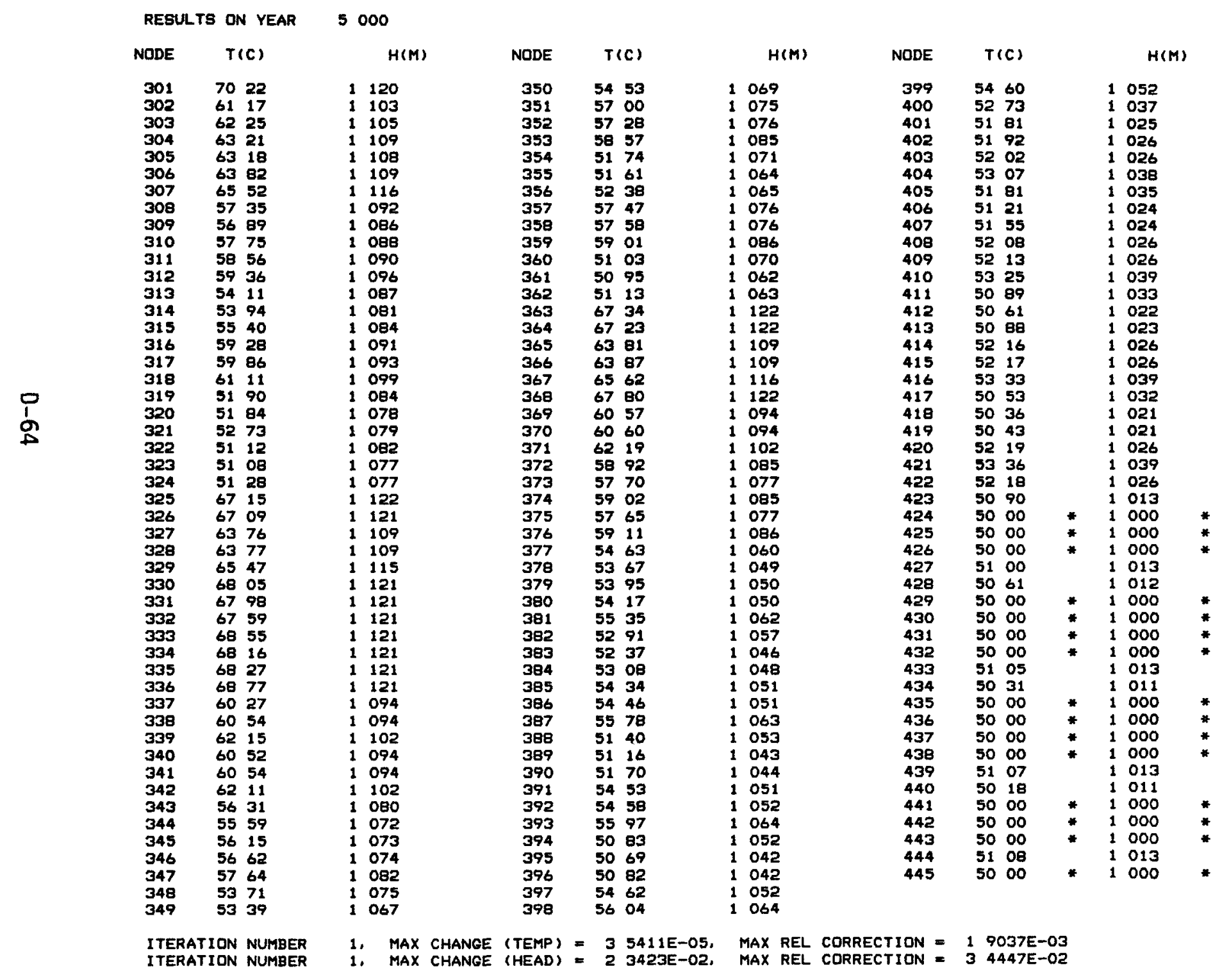


LISTING D-6. Output Report File for Test Case Two. (Sheet 28 of 48)

SAMPLE PROBLEM، FLOW ARDUND A HEATED CANNISTER

RESULTS FOR VELOCITY (M/YR) OF YEAR 5000

ELEMENT

1 VEL $X$

GSS PNT 1 GSS PNT 2

GSS PNT 3 GSS PNT 4 GSS PNT 5 GSS PNT 6 GSS PNT 7 GSS PNT 8 GSS PNT 9

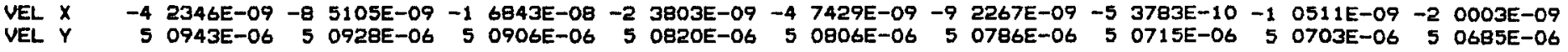

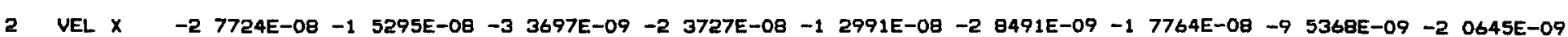
VEL $Y$ S 5 O785E-06 5 O679E-06 5 O590E-06 5 O840E-06 5 O727E-06 5 O632E-06 5 0877E-06 5 O760E-06 $50660 E-06$

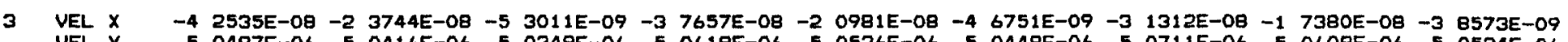

$4 \quad V E L X \quad-5 \quad 3494 E-08-2 \quad 9391 E-08$-6 $4454 E-09-5 \quad 0256 E-08$-2 $7519 E-08$-6 $0223 E-09-4 \quad 6316 E-08 \quad-2 \quad 5238 E-08$-5 $5065 E-09$

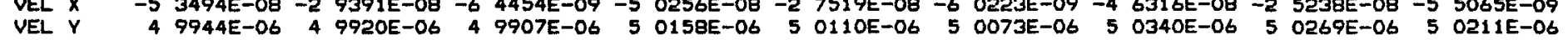

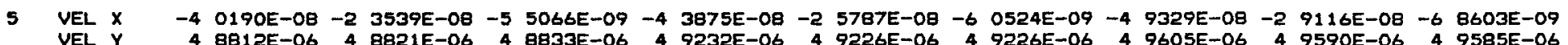

6 VEL $X \quad-1$ 1417E-08 -7 4313E-09 -1 8999E-09 -2 0111E-08 -1 2459E-08 -3 0623E-09 -3 1383E-08 -1 8978E-08 -4 5693E-09

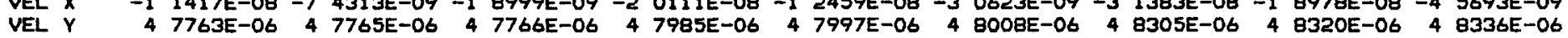

7 VEL $X \quad 1$ 9071E-09 $76658 E-10 \quad 1$ 0521E-10 -3 7865E-09 -2 4729E-09 -6 3387E-10 -1 0701E-08 $-6 \quad 4071 E-09-1 \quad 5314 E-09$

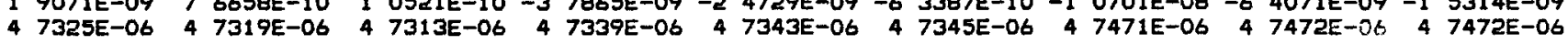

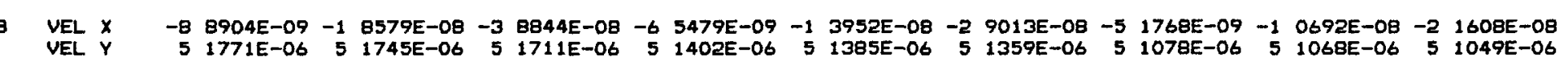

9 VEL $X \quad-5 \quad 9459 E-08-4 \quad 5264 E-08$-3 $4920 E-08$-5 $1910 E-08$-3 $8454 E-08$ - 2 9677E-08 -4 0542E-08 -2 8373E-08 $-2 \quad 1878 E-08$

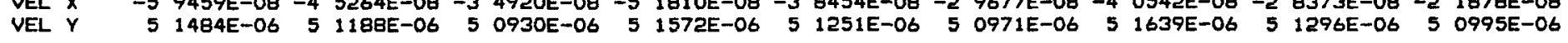

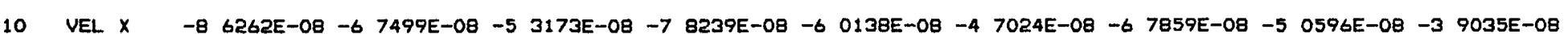

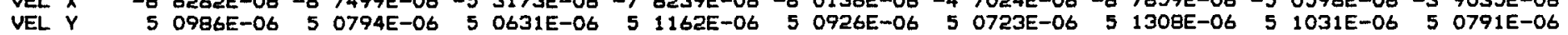

11 VEL $X \quad-9$ 3081E-08 $-7 \quad 6448 E-08$-6 $5092 E-08-9 \quad 1341 E-08$-7 3515E-08 $-6 \quad 1459 E-08$-8 $9231 E-08$-6 $9953 E-08-5 \quad 7042 E-08$

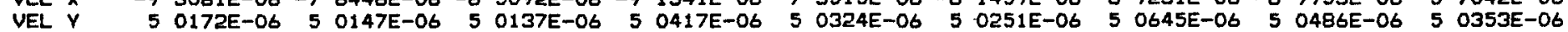

12 VEL $X \quad-4$ 8481E-08 -4 8568E-08 -4 6818E-08 -6 2682E-08 -5 8616E-08 -5 2357E-08 -8 3704E-08 -7 3489E-08 -6 0555E-08 VEL $Y \quad 4$ 8925E-06 4 8960E-06 4 8992E-06 4 9180E-06 4 9194E-06 $499214 E-06 \quad 49479 E-06 \quad 49479 E-06 \quad 49490 E-06$

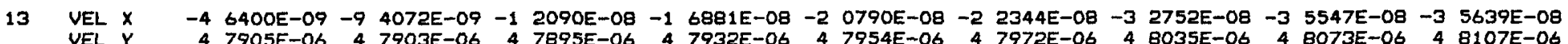

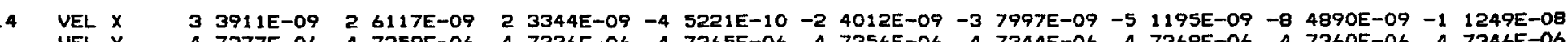

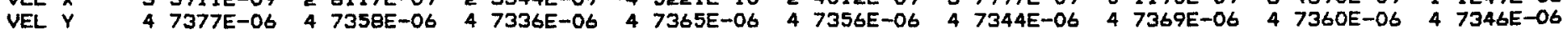

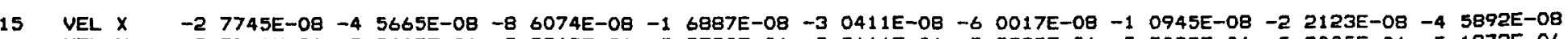

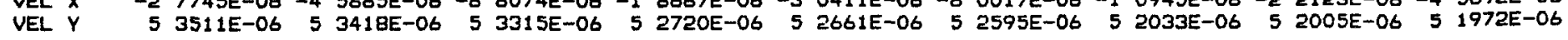

16 VEL $X$ - 1 3417E- $07-9 \quad 3658 E-08-7 \quad 0355 E-08-1 \quad 1891 E-07-7 \quad 9475 E-08-6 \quad 0431 E-08-9 \quad 6698 E-08$ - 5 8739E-08 -4 5851E-08

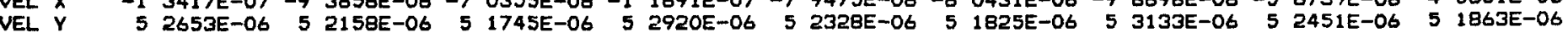


LISTING D-6. Output Report File for Test Case Two. (Sheet 29 of 48)

SAMPLE PROBLEM. FLOW AROUND A MEATED CANNISTER

RESULTS FDR VELOCITY (M/YR) OF YEAR 5000

ELEMENT

GSS PNT 1 GSS PNT 2 GSS PNT 3 GSS PNT 4 GSS PNT 5 GSS PNT 6 GSS PNT 7 GSS PNT 8 GSS PNT 9

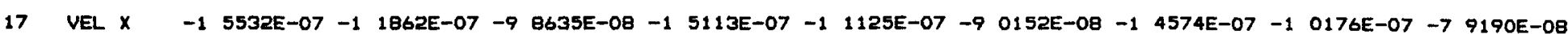

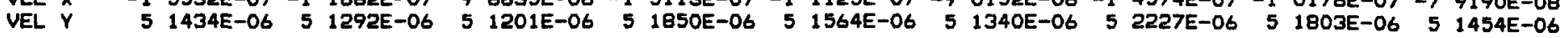

18 VEL $X$ - $10541 E-07-1 \quad 0056 E-07-1 \quad 0101 E-07-1 \quad 2321 E-07-1 \quad 0968 E-07-1 \quad 0195 E-07-1 \quad 4473 E-07-1 \quad 2071 E-07-1 \quad 0309 E-07$ VEL $Y \quad 5$ O124E-06 5 O244E-06 5 O378E-06 5 O427E-06 5 0451E-06 5 O502E-06 5 0766E-06 5 O695E-06 $50667 E-06$

19 VEL $X$-2 3752E-09 -2 6635E-08 -4 5026E-08 -3 3447E-08 -5 1736E-08 -6 3022E-08 -7 9443E-08 -8 8895E-08 -8 9661E-08

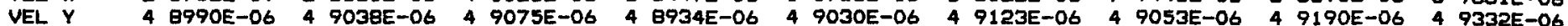

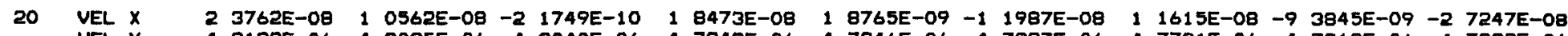
VEL Y 4 B122E-06 4 8085E-06 4 8040E-06 4 7943E-06 4 7946E-06 4 7937E-06 4 7791E-06 4 7818E-06 $47832 E-06$

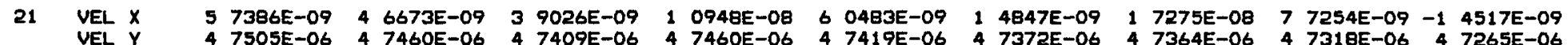

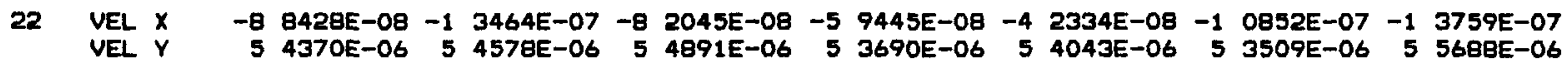

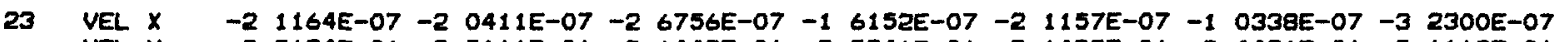

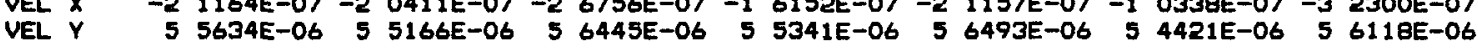

24 VEL $X$

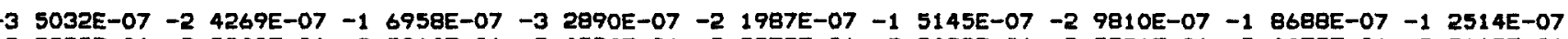

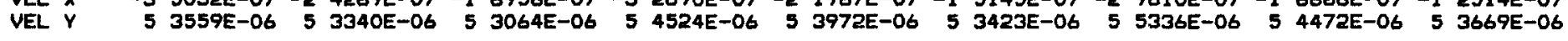

25 VEL $X$

-4 4731E-08 -8 6889E-08 9 2467E-09 $-6 \quad 6201 E-08 \quad 12843 E-08$ - 1 5981E-07 $-1 \quad 6038 E-08$

VEL $Y$ S $6240 E-06 \quad 5 \quad 7122 E-06 \quad 5$ SB89E-06 5 5777E-06 5 4911E-06 5 6923E-06 5 7081E-06

26 VEL

$\begin{array}{llllllllllllllllll}-2 & 4184 E-07 & -2 & 0223 E-07 & -1 & 7863 E-07 & -2 & 8323 E-07 & -2 & 2305 E-07 & -1 & 8074 E-07 & -3 & 3626 E-07 & -2 & 4979 E-07 & -1 & 8346 E-07\end{array}$

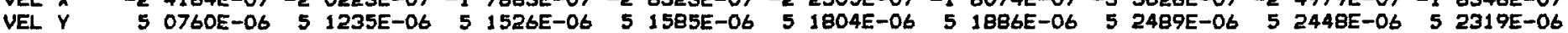

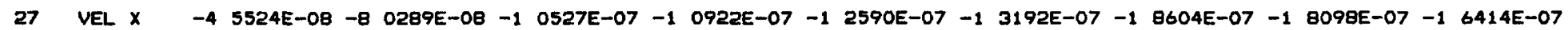

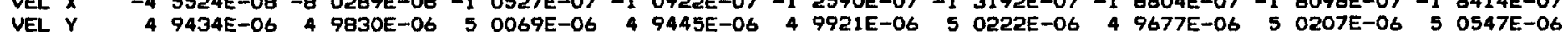

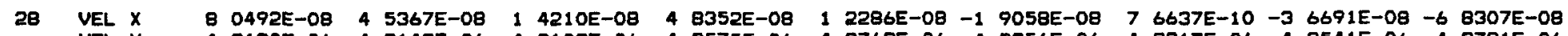
VEL $Y \quad 49130 E-06 \quad 49143 E-06 \quad 49109 E-06 \quad 4$ 8575E-06 4 B762E-06 4 8856E-06 4 B217E-06 4 8541E-06 4 B731E-06

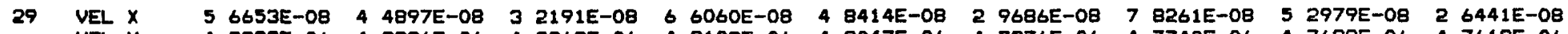
VEL $Y \quad 4 \quad 43382 E-06 \quad 4$ 8326E-06 4 8262E-06 4 8102E-06 4 8047E-06 4 7976E-06 4 7740E-06 $47693 E-06 \quad 47619 E-06$

30 VEL $X \quad 8 \quad 1071 E-09 \quad 7 \quad 4945 E-09 \quad 6 \quad 4934 E-09 \quad 2 \quad 3493 E-09 \quad 1$ 8954E-08 $14009 E-08 \quad 4 \quad 2183 E-08 \quad 32887 E-08 \quad 2 \quad 3137 E-08$ VEL Y 4 7666E-06 4 7613E-06 4 7560E-06 4 7614E-06 4 7550E-06 4 7486E-06 4 7445E-06 4 7386E-06 $47323 E-06$

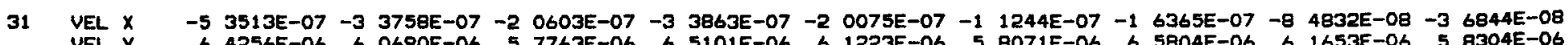
VEL $Y \quad 6$ 4256E-06 6 0690E-06 5 7763E-06 6 5101E-06 6 1223E-06 5 8071E-06 6 5804E-06 $61653 E-06 \quad 5$ 8304E-06

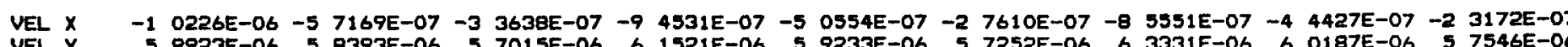
VEL $Y$ S $59923 E-06 \quad 5$ B393E-06 5 7015E-06 6 1521E-06 5 9233E-06 5 7252E-06 6 3331E-06 6 O187E-06 5 7546E-06 
LISTING D-6. Output Report File for Test Case Two. (Sheet 30 of 48)

SAMPLE PROBLEM, FLOW AROUND A HEATED CANNISTER

RESULTS FOR VELOCITY (M/YR) OF YEAR 5000

GSS PNT 1 GSS PNT 2 GSS PNT 3 GSS PNT 4 GSS PNT 5 GSS PNT 6 GSS PNT 7 GSS PNT 8 GSS PNT 9

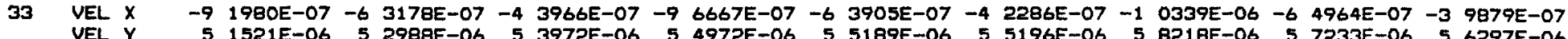

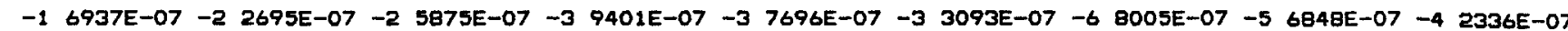
VEL $Y \quad 4$ B006E-06 4 9416E-06 5 0382E-06 4 8118E-06 4 9776E-06 5 0927E-06 $49117 E-06 \quad 5 \quad 0904 E-06 \quad 5 \quad 2146 E-06$

35 VEL $X \quad 1 \quad 1916 E-07 \quad 3 \quad 907 B E-08-20611 E-08 \quad 2 \quad 7837 E-08$-4 4004E-08 -9 3810E-08 -8 1839E-08 -1 4396E-07 -1 8201E-07

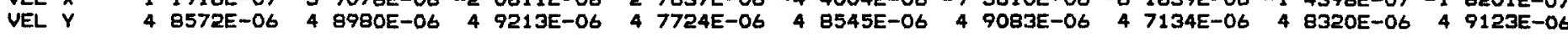

36 VEL $X \quad 1 \quad 6738 E-07 \quad 1 \quad 3503 E-07 \quad 1 \quad 0209 E-07 \quad 1 \quad 6419 E-07 \quad 1 \quad 1935 E-07 \quad 7 \quad 3755 E-08 \quad 1 \quad 5944 E-07 \quad 9 \quad 6141 E-08 \quad 3 \quad 1823 E-08$ VEL $Y \quad 4 \quad 9434 E-06 \quad 49364 E-06 \quad 49279 E-06 \quad 4$ 8557E-06 4 8631E-06 4 8640E-06 4 7532E-06 4 7757E-06 4 7861E-06

37 VEL $X \quad B \quad 3891 E-08 \quad 7 \quad 4833 E-0 B \quad 6 \quad 3771 E-08 \quad 1 \quad 1007 E-07 \quad 9 \quad 4624 E-08 \quad 7 \quad 6907 E-08 \quad 1 \quad 4399 E-07 \quad 1 \quad 2028 E-07 \quad 9 \quad 3944 E-08$ VEL $V \quad 4$ 8639E-06 4 8569E-06 4 8504E-06 4 8337E-06 4 8232E-06 4 8134E-06 4 7856E-06 $47746 E-06 \quad 4 \quad 7637 E-06$

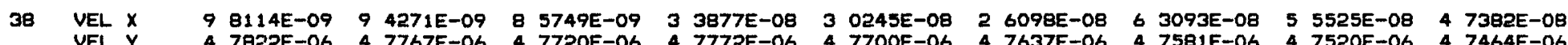

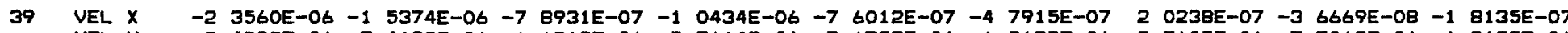

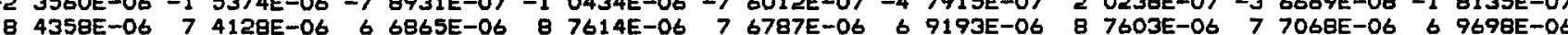

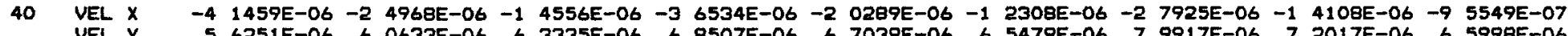

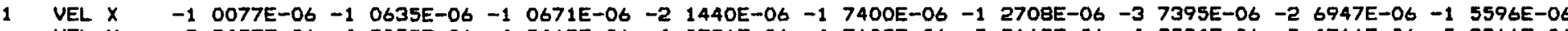
VEL Y 3 B457E-06 4 SO28E-06 $49418 E-06 \quad 4$ 0796E-06 4 7609E-06 5 2169E-06 4 8554E-06 5 4716E-06 5 8B16E-06

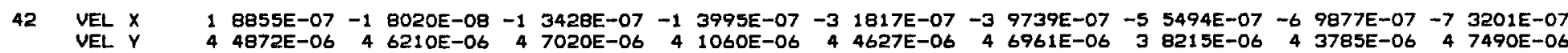

43 VEL $X \quad 3 \quad 2059 E-07 \quad 2 \quad 5006 E-07 \quad 1 \quad 7186 E-07 \quad 2 \quad 8645 E-07 \quad 1 \quad 9024 E-07 \quad 8 \quad 5380 E-08 \quad 2 \quad 4531 E-07 \quad 1 \quad 1837 E-07 \quad-1 \quad 8522 E-08$

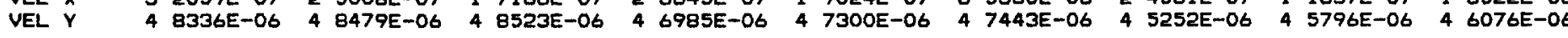

44 VEL $X \quad 2 \quad 3076 E-07 \quad 2 \quad 1068 E-07 \quad 1 \quad 8573 E-07 \quad 2 \quad 7058 E-07 \quad 2 \quad 3393 E-07 \quad 19143 E-07 \quad 3 \quad 2921 E-07 \quad 2 \quad 6819 E-07 \quad 1 \quad 9979 E-07$

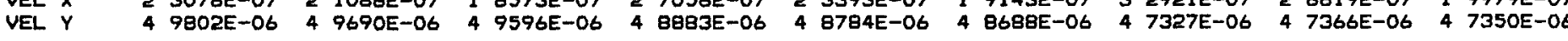

45 VEL $X \quad 1$ O214E-07 $96623 E-08$ \& $8961 E-08 \quad 1 \quad 4192 E-07 \quad 1 \quad 3146 E-07 \quad 1 \quad 1857 E-07 \quad 19339 E-07 \quad 1 \quad 7657 E-07 \quad 1 \quad 5694 E-07$ VEL $Y \quad 4$ 8844E-06 4 8783E-06 4 B736E-06 4 8563E-06 4 8446E-06 4 8358E-06 4 8024E-06 $47920 E-06 \quad 47837 E-06$

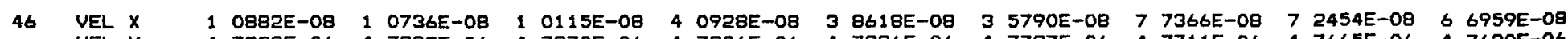
$47939 E-0647899 E-0647870 E-0647906 E-06 \quad 4 \quad 7836 E-06 \quad 4$ 7787E-06 $47711 E-06 \quad 4 \quad 7665 E-06 \quad 47630 E-06$

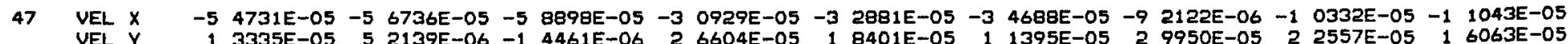

48 VEL $x \quad-7$ 9924E-05 -8 4222E-05 -8 8813E-05 -7 6458E-05 -8 $1015 E-05$-8 $5702 E-05$-6 $3238 E-05$-6 $7293 E-05$-7 $1307 E-05$

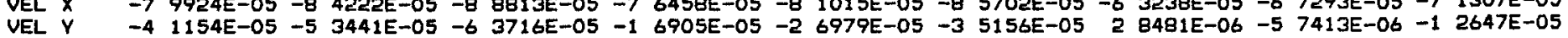


LISTING D-6. Output Report File for Test Case Two. (Sheet 31 of 48)

SAMPLE PROBLEM, FLOW AROUND A HEATED CANNISTER

RESULTS FOR VELOCITY (M/YR) DF YEAR 5000

GSS PNT 1 GSS PNT 2 GSS PNT 3 GSS PNT 4 GSS PNT 5 GSS PNT 6 GSS PNT 7 GSS PNT 9 GSS PNT 9

49 VEL $x \quad-7$ 8294E-08 -5 3398E-07 -9 0414E-07 -8 8271E-07 -1 5809E-06 -2 1457E-06 -2 0666E-06 -3 0870E-06 -3 8976E-06

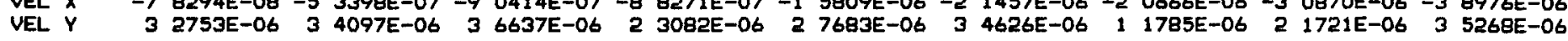

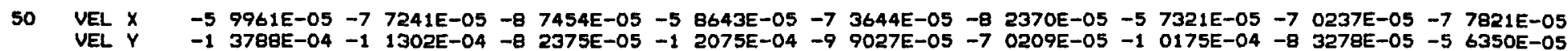

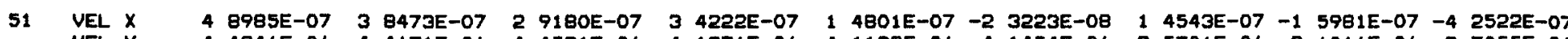
VEL $Y \quad 4 \quad 4846 E-06 \quad 4 \quad 4671 E-06 \quad 4 \quad 4581 E-06 \quad 4 \quad 1276 E-06 \quad 4 \quad 1199 E-06 \quad 4 \quad 1454 E-06 \quad 3 \quad 5706 E-06 \quad 36016 E-06 \quad 3 \quad 7055 E-06$

$52 \quad V E L X \quad 3 \quad 5679 E-07 \quad 3 \quad 6556 E-07 \quad 3 \quad 2257 E-07 \quad 3 \quad 8473 E-07 \quad 3 \quad 5045 E-07 \quad 4 \quad 2325 E-07 \quad 3 \quad 0039 E-07$

4 5982E-06 4 4389E-06 4 7247E-06 4 6454E-06 4 8797E-06 4 4604E-06 4 4769E-06

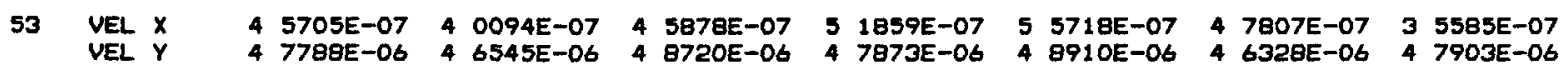

54 VEL $X \quad 2$ B851E-07 $25641 E-07 \quad 2 \quad 3860 E-07 \quad 3 \quad 7602 E-07 \quad 3 \quad 2361 E-07 \quad 2 \quad 8796 E-07 \quad 5 \quad 0557 E-07 \quad 4 \quad 2309 E-07 \quad 3 \quad 6067 E-07$

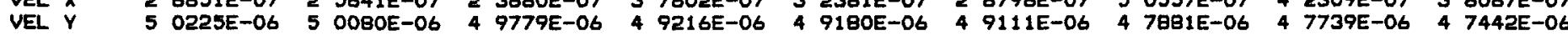

55 VEL $X \quad 1 \quad 1858 E-07 \quad 1 \quad 0998 E-07 \quad 1 \quad 0445 E-07 \quad 1 \quad 7218 E-07 \quad 1 \quad 5798 E-07 \quad 1 \quad 4713 E-07 \quad 2 \quad 4168 E-07 \quad 2 \quad 2020 E-07 \quad 2 \quad 0237 E-07$

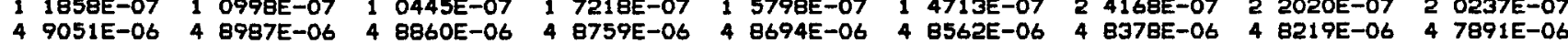

56 VEL $X \quad 1 \quad 1609 E-08 \quad 1 \quad 0785 E-08 \quad 1 \quad 0713 E-08 \quad 4 \quad 7666 E-08 \quad 4 \quad 4455 E-09 \quad 4 \quad 2058 E-08$ 9 $1457 E-08 \quad 8 \quad 5344 E-08 \quad$ B $0080 E-08$

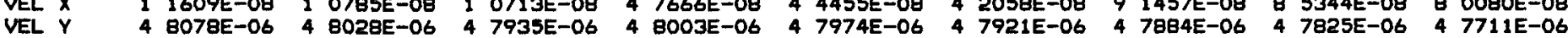

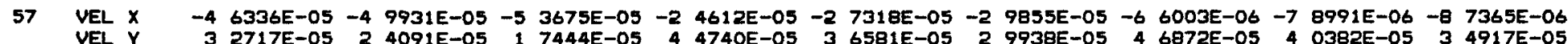

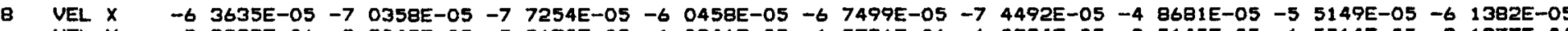

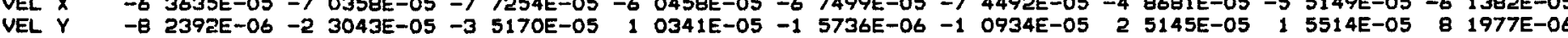

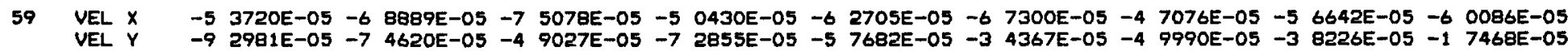

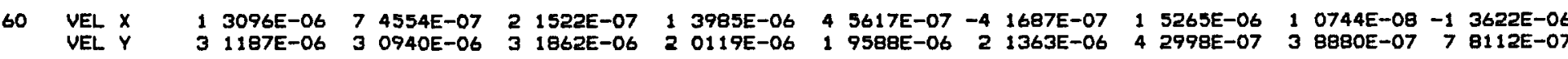

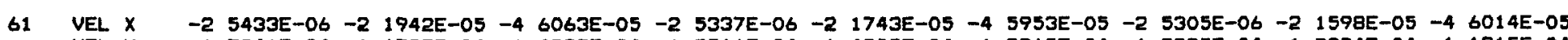
VEL $Y$ - $\quad-1$ 7946E-04 -1 6797E-04 -1 4529E-04 -1 5811E-04 -1 4902E-04 -1 2915E-04 -1 3585E-04 -1 2924E-04 -1 1215E-04

62 VEL $X \quad 8 \quad 6459 E-07 \quad 6 \quad 9446 E-07 \quad 5 \quad 5592 E-07 \quad 9 \quad 9860 E-07 \quad 7 \quad 1092 E-07 \quad 4 \quad 6495 E-07 \quad 1 \quad 1715 E-06 \quad 7 \quad 2713 E-07 \quad 3 \quad 4047 E-07$ VEL Y $\quad 4 \quad 5361 E-06 \quad 4 \quad 4992 E-06 \quad 4 \quad 4690 E-06 \quad 4 \quad 1036 E-06 \quad 4 \quad 0824 E-06 \quad 4 \quad 0962 E-06 \quad 3 \quad 4528 E-06 \quad 34402 E-06 \quad 35050 E-06$

63 VEL $X \quad-4 \quad 6043 E-06 \quad-2 \quad 5782 E-05$-4 4325E-05 -4 3890E-06 -2 4609E-05 -4 2308E-05 -4 1816E-06 -2 3483E-05 -4 O410E-05

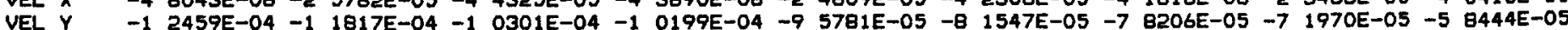

64 VEL $X$

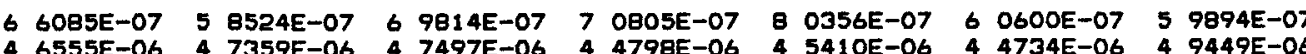


LISTING D-6. Output Report File for Test Case Two. (Sheet 32 of 48)

SAMPLE PROBLEM. FLOW AROUND A HEATED CANNISTER

RESULTS FOR VELOCITY (M/YR) OF YEAR 5000 ELEMENT

GSS PNT 1 GSS PNT 2 GSS PNT

OSS PNT

GSS PNT 5

GSS PNT

GSS PNT 7

GSS PNT 8 GSS PNT Q

65 VEL $X$

8 3943E-07 B 3140E-07 9 6396E-07 7 3048E-07 8 6059E-07 6 5211E-07 1 0252E-06 VEL $Y \quad 4 \quad 7306 E-06 \quad 4$ 8438E-06 4 6251E-06 4 7522E-06 4 5776E-06 4 9692E-06 4 7245E-06

66 VEL $X$

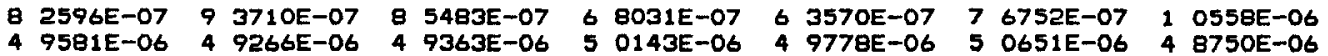

67 VEL $X$

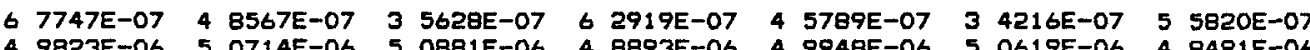
VEL $Y$

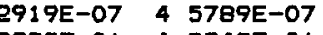

5820E-07 4 1140E-07 3 1222E-07 2 8956E-07 2 0350E-07 1 3719E-07 $27440 E-07,9436 E-07 \quad 1 \quad 3262 E-07 \quad 25504 E-07-1$

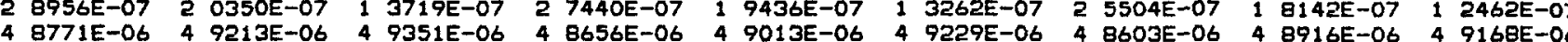

GB VEL $X$

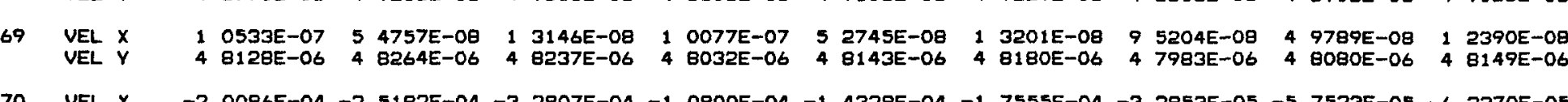

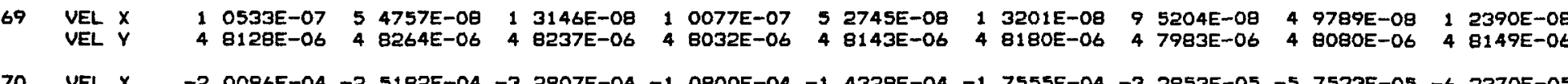

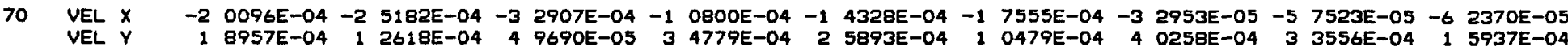

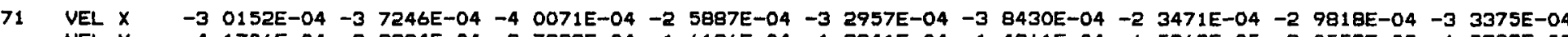
VEL $Y$-4 $1706 E-04-3$ 8334E-04 -2 7989E-04 -1 6186E-04 -1 8341E-04 -1 4861E-04 6 5868E-05 2 O559E-05 -1 8788E-05

72 VEL $X \quad-2 \quad 4256 E-05-1 \quad 1277 E-04 \quad-2 \quad 2253 E-04 \quad-2 \quad 5308 E-05$-1 $0953 E-04-1 \quad 9657 E-04 \quad-27386 E-05-1 \quad 1108 E-04-1 \quad 8474 E-04$

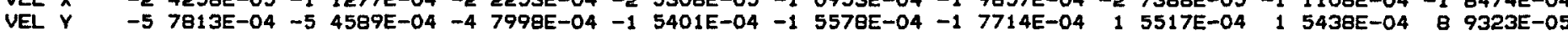

73 VEL $x \quad 5$ 4685E-06 $37612 E-06 \quad 2 \quad 6125 E-06 \quad 4 \quad 0966 E-06 \quad 2 \quad 9349 E-06 \quad 2 \quad 1653 E-06 \quad 2 \quad 4844 E-06 \quad 1 \quad 9774 E-06 \quad 1 \quad 6416 E-06$

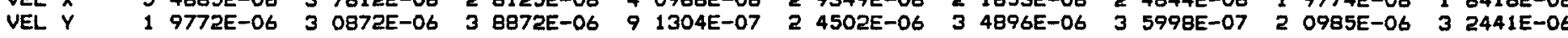

74 VEL $X \quad 5$ O026E-05 $50079 E-05 \quad 5 \quad 0302 E-05 \quad 2 \quad 5679 E-05 \quad 2 \quad 5941 E-05 \quad 2 \quad 6257 E-05 \quad 6 \quad 1669 E-06 \quad 6 \quad 3095 E-06 \quad 6 \quad 4591 E-06$ VEL $Y \quad-1 \quad 1097 E-04-1 \quad 2801 E-04-1$ 4420E-04 -1 2856E-04 -1 4828E-04 -1 6706E-04 -1 3560E-04 -1 5770E-04 -1 7890E-04

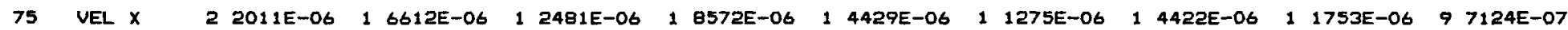

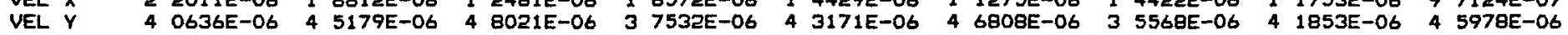

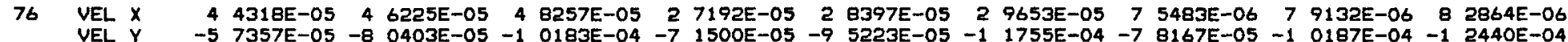

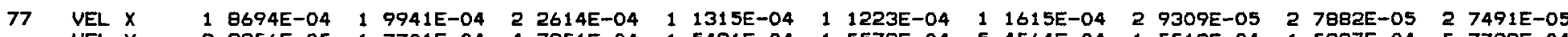
VEL $Y \quad 8$ 9256E-05 - 1 7701E-04 -4 7951E-04 1 5431E-04 -1 5572E-04 -5 4564E-04 1 5513E-04 -1 5397E-04 -5 7799E-04

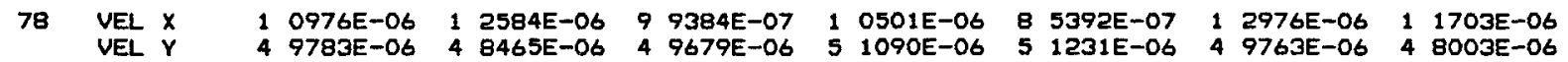

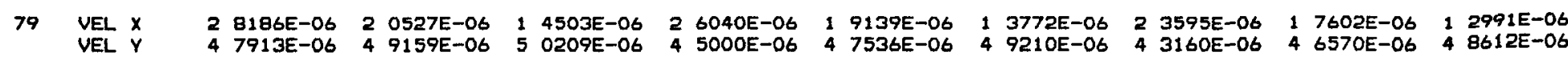

80 VEL $X \quad 1 \quad 3712 E-06 \quad 1 \quad 1086 E-06 \quad 8 \quad 9016 E-07 \quad 1 \quad 3472 E-06 \quad 1$ OB28E-06 8 6243E-07 1 3099E-06 $10445 E-06 \quad 0 \quad 2299 E-07$

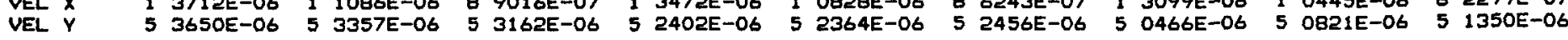


LISTING D-6. Output Report File for Test Case Two. (Sheet 33 of 48)

SAMPLE PROBLEM, FLOW AROUND A HEATED CANNISTER

RESULTS FOR VELOCITY (M/YR) OF YEAR 5 OOO ELEMENT

GSS PNT 1 GSS PNT 2 GSS PNT 3 GSS PNT 4 GSS PNT 5 GSS PNT 6 GSS PNT 7 GSS PNT 9 GSS PNT 9

$\begin{array}{lllllllllllllllllllll} & X & 7 & 6280 E-07 & 5 & 4065 E-07 & 3 & 9060 E-07 & 7 & 2954 E-07 & 5 & 1856 E-07 & 3 & 7608 E-07 & 6 & 9587 E-07 & 4 & 9604 E-07 & 3 & 6113 E-07\end{array}$ VEL $Y \quad 5 \quad 1130 E-06 \quad 5 \quad 1328 E-06 \quad 5 \quad 1423 E-06 \quad 5$ O594E-06 5 0976E-06 5 1231E-06 4 9752E-06 5 O41BE-06 5 0924E-06

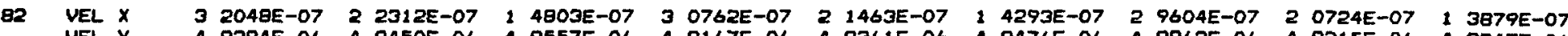
VEL $Y \quad 4 \quad 9294 E-06 \quad 49450 E-06 \quad 4 \quad 9557 E-06 \quad 4$ 9167E-06 4 9361E-06 4 9476E-06 4 8962E-06 $49215 E-06 \quad 49347 E-06$

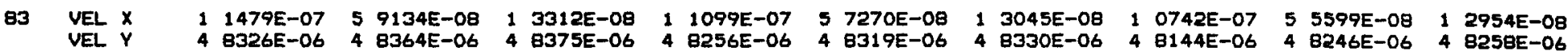

84 VEL $X$-1 $8110 E-05$-8 3466E-05 -1 6000E-04 -1 1347E-05 -4 7162E-05 -8 3527E-05 -4 9314E-06 -1 4140E-05 -1 7952E-05

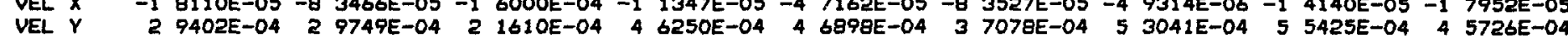

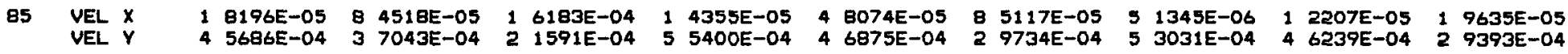

$86 \quad V E L X \quad 7 \quad 3727 E-06 \quad 5 \quad 1749 E-06 \quad 3 \quad 6150 E-06 \quad 6 \quad 8558 E-06 \quad 4 \quad 7697 E-06 \quad 3 \quad 3124 E-06 \quad 6 \quad 0939 E-06 \quad 4 \quad 1856 E-06 \quad 2 \quad 8768 E-06$ VEL $Y \quad 6 \quad 2720 E-06 \quad 5 \quad 3812 E-06 \quad 5 \quad 0355 E-06 \quad 4 \quad 3186 E-06 \quad 4$ 2446E-06 4 5007E-06 $26947 E-06 \quad 3 \quad 3567 E-06 \quad 4 \quad 1288 E-06$

87 VEL $X \quad 8 \quad 1188 E-05 \quad 8 \quad 5823 E-05 \quad 9 \quad 0997 E-05 \quad 7 \quad 3966 E-05 \quad 7 \quad 7453 E-05 \quad 8 \quad 1135 E-05 \quad 6 \quad 1172 E-05 \quad 6 \quad 2580 E-05 \quad 6 \quad 3988 E-05$ VEL $Y \quad-5$ 3458E-05 -6 7262E-05 -7 9372E-05 -8 0979E-05 -9 6654E-05 - 1 1057E-04 -1 0014E-04 -1 1907E-04 -1 3612E-04

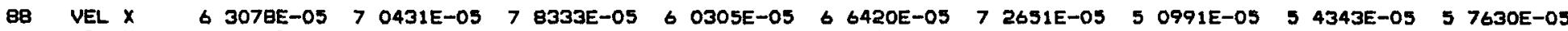

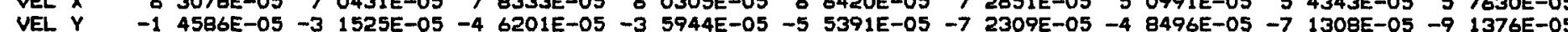

89 VEL $X \quad 3 \quad 3628 E-04 \quad 3 \quad 6716 E-04 \quad 4$ 0378E-04 3 0062E-04 3 3251E-04 $37608 E-04 \quad 2 \quad 3700 E-04 \quad 26176 E-04 \quad 3 \quad 0517 E-04$

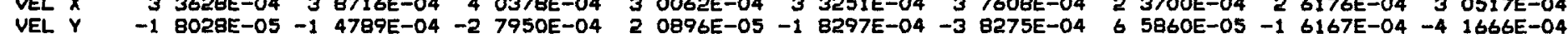

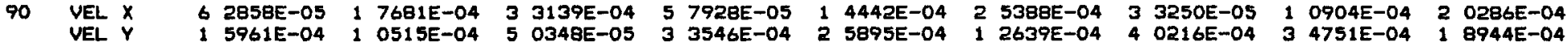

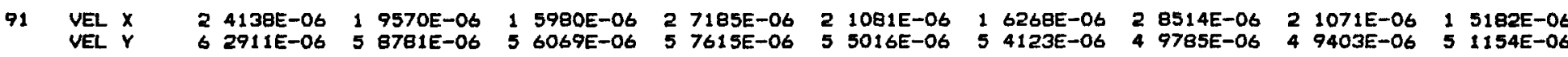

92 VEL $X \quad 3 \quad 0331 E-06 \quad 2 \quad 8910 E-06 \quad 2 \quad 7907 E-06 \quad 4 \quad 9102 E-06 \quad 3 \quad 8698 E-06 \quad 3 \quad 1329 E-06 \quad 6 \quad 8035 E-06 \quad 4 \quad 8783 E-06 \quad 3 \quad 5084 E-06$

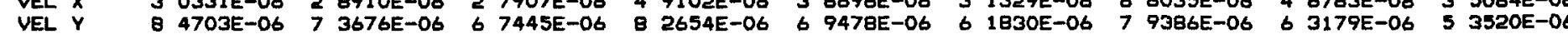

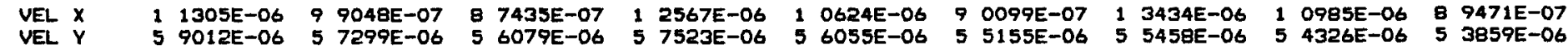

94 VEL $X \quad 7 \quad 6894 E-07 \quad 5 \quad 6430 E-07 \quad 4 \quad 2606 E-07 \quad 7 \quad 7500 E-07 \quad 5 \quad 6062 E-07 \quad 4 \quad 1579 E-07 \quad 7 \quad 7136 E-07 \quad 5 \quad 4908 E-07 \quad 3 \quad 9891 E-07$

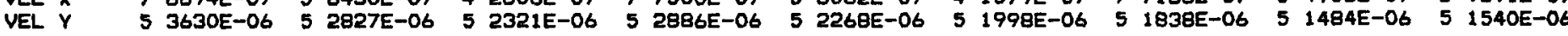

95 VEL $X \quad 1 \quad 3129 E-06 \quad 1 \quad 2628 E-06 \quad 1 \quad 2238 E-06 \quad 1 \quad 7274 E-06 \quad 1 \quad 5227 E-06 \quad 1 \quad 3625 E-06 \quad 2 \quad 1320 E-06 \quad 1 \quad 7754 E-06 \quad 1 \quad 4955 E-06$ YEL $Y \quad 6 \quad 6909 E-06$ o $3780 E-06$ 6 $1527 E-06$ o 5976E-06 6 2491E-06 5 9993E-06 6 4586E-06 $60658 E-06 \quad 5$ 7857E-06

96 VEL $X \quad 3 \quad 4707 E-07 \quad 2 \quad 4195 E-07 \quad 1 \quad 6086 E-07 \quad 3 \quad 3720 E-07 \quad 2 \quad 3495 E-07 \quad 1 \quad 5609 E-07 \quad 3 \quad 2686 E-07 \quad 2 \quad 2755 E-07 \quad 1 \quad 5095 E-07$

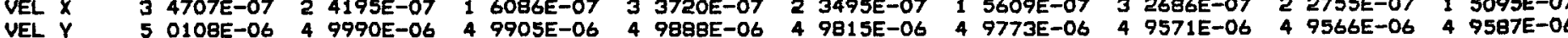


LISTING D-6. Output Report File for Test Case Two. (Sheet 34 of 48)

SAMPLE PROBLEM, FLOW AROUND A HEATED CANNISTER

RESULTS FOR VELOCITY (M/YR) OF YEAR 5000

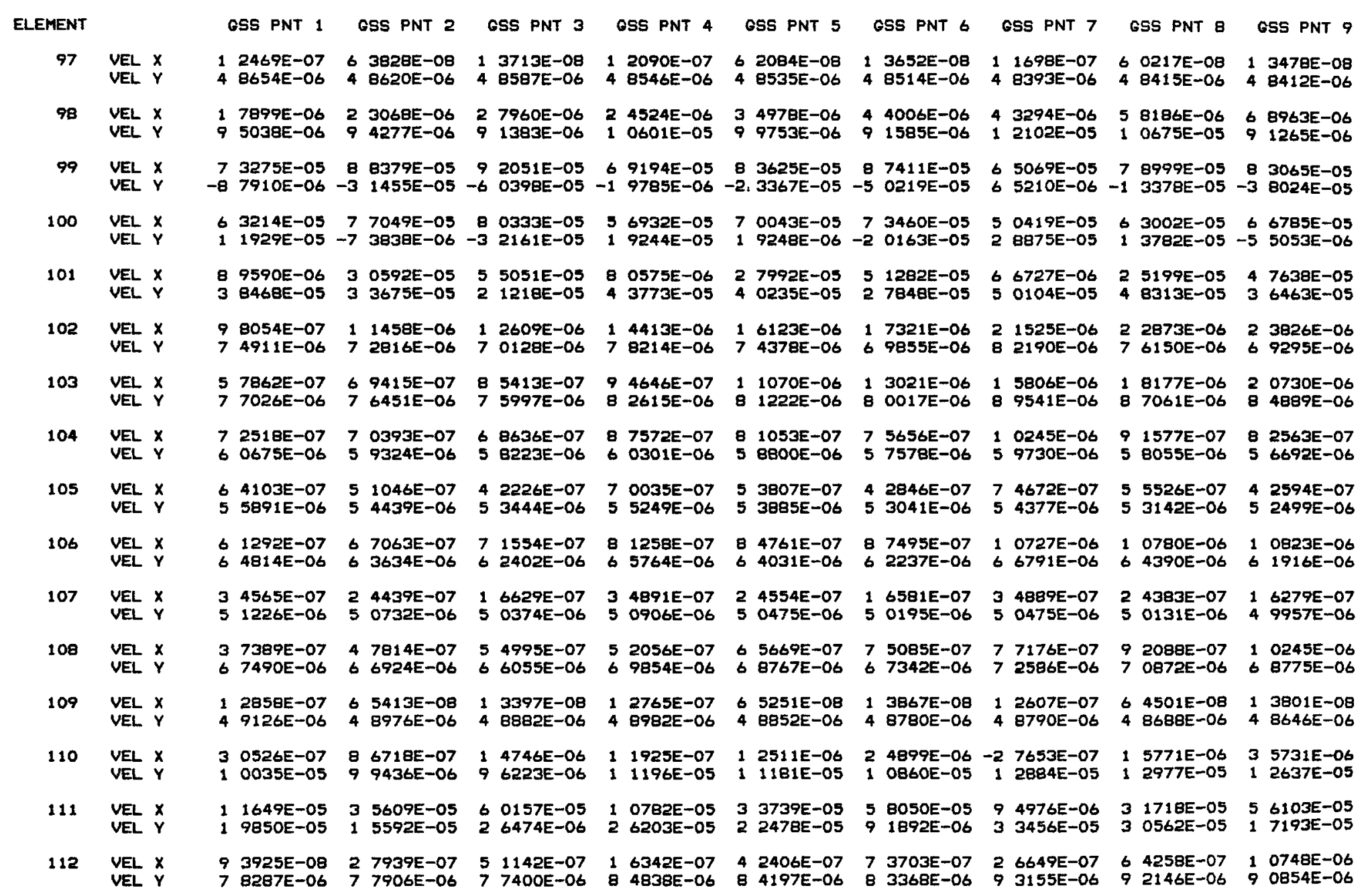


LISTING D-6. Output Report File for Test Case Two. (Sheet 35 of 48)

SAMPLE PROBLEM, FLOW AROUND A HEATED CANNISTER

RESULTS FOR VELOCITY (M/YR) OF YEAR 5 OOO

\begin{tabular}{|c|c|c|c|c|c|c|c|c|c|c|}
\hline MENT & & GSS PNT 1 & GSS PNT 2 & GSS PNT 3 & GSS PNT 4 & GSS PNT 5 & GSS PNT 6 & GSS PNT 7 & CSS PNT B & GSS PNT \\
\hline 113 & $\begin{array}{l}\text { VEL } x \\
\text { VEL } y\end{array}$ & $\begin{array}{l}4956 E-07 \\
2150 E-06\end{array}$ & $\begin{array}{l}5 \quad 4127 E-07 \\
70967 E-06\end{array}$ & $\begin{array}{ll}4 & 4406 E-07 \\
7 & 1231 E-06\end{array}$ & $\begin{array}{l}63970 E-07 \\
74405 E-06\end{array}$ & $\begin{array}{ll}5 & 2019 E-07 \\
7 & 4229 E-06\end{array}$ & $\begin{array}{l}7 \text { 7677E-07 } \\
73817 \mathrm{E}-06\end{array}$ & $\begin{array}{l}3 \quad 0687 E-07 \\
6 \quad 8812 E-06\end{array}$ & & \\
\hline 114 & $\begin{array}{l}\text { VEL } X \\
\text { VEL } Y\end{array}$ & $\begin{array}{l}2 \quad 4256 E-07 \\
6 \quad 9417 E-06\end{array}$ & $\begin{array}{l}37068 E-07 \\
70071 E-06\end{array}$ & $\begin{array}{l}17678 E-07 \\
67516 E-06\end{array}$ & $\begin{array}{ll}2 & 1280 E-07 \\
7 & 0730 E-06\end{array}$ & $\begin{array}{ll}1 & 1479 E-07 \\
6 & 8365 E-06\end{array}$ & $\begin{array}{l}35415 E-07 \\
7 \text { 2873E-06 }\end{array}$ & $\begin{array}{l}3 \text { 3622E-07 } \\
67165 E-06\end{array}$ & & \\
\hline 115 & $\begin{array}{l}\text { VEL } X \\
\text { VEL } Y\end{array}$ & $\begin{array}{ll}1 & 1230 E-07 \\
7 & 3239 E-06\end{array}$ & $\begin{array}{ll}2 & 1892 E-07 \\
7 & 5583 E-06\end{array}$ & $\begin{array}{l}16292 E-07 \\
7 \quad 2058 E-06\end{array}$ & $\begin{array}{r}-9 \\
72180 E-09 \\
72285 E-06\end{array}$ & $\begin{array}{l}3 \quad 3019 E-09 \\
6 \quad 9790 E-06\end{array}$ & $\begin{array}{l}4 \quad 9151 E-08 \\
7 \quad 5485 E-06\end{array}$ & $\begin{array}{l}38831 E-07 \\
75029 E-06\end{array}$ & & \\
\hline 116 & $\begin{array}{l}\text { VEL } x \\
\text { VEL } y\end{array}$ & $\begin{array}{l}37213 E-07 \\
6 \quad 0116 E-06\end{array}$ & $\begin{array}{l}39406 E-07 \\
59477 E-06\end{array}$ & $\begin{array}{l}4 \quad 1215 E-07 \\
5 \quad 8820 E-06\end{array}$ & $\begin{array}{l}4 \quad 7516 E-07 \\
6 \quad 0422 E-06\end{array}$ & $\begin{array}{l}4 \quad 8615 E-07 \\
5 \quad 9504 E-06\end{array}$ & $\begin{array}{l}4 \quad 9523 E-07 \\
58573 E-06\end{array}$ & \begin{tabular}{l|l}
6 & $1551 E-07$ \\
6 & $0770 E-06$
\end{tabular} & $\begin{array}{ll}6 & 1 \\
5 & 5\end{array}$ & $\begin{array}{l}60937 \\
58331\end{array}$ \\
\hline 117 & $\begin{array}{l}\text { VEL } x \\
\text { VEL } y\end{array}$ & $\begin{array}{ll}4 & 1227 E-07 \\
5 & 7113 E-06\end{array}$ & $\begin{array}{l}3 \quad 652 \mathrm{BE}-07 \\
5 \quad 5732 E-06\end{array}$ & $\begin{array}{l}3 \quad 3354 E-07 \\
5 \quad 43 B 1 E-06\end{array}$ & $\begin{array}{l}4 \quad 9947 E-07 \\
5 \quad 6763 E-06\end{array}$ & $\begin{array}{l}42103 E-07 \\
5 \quad 5323 E-06\end{array}$ & $\begin{array}{l}36803 E-07 \\
5 \quad 4120 E-06\end{array}$ & $\begin{array}{ll}5 & 8555 E-07 \\
5 & 6420 E-06\end{array}$ & $\begin{array}{l}45587 E-07 \\
5 \\
5911 E-06\end{array}$ & $\begin{array}{l}40177 E-07 \\
5 \quad 3648 E-06\end{array}$ \\
\hline 118 & $\begin{array}{l}\text { VEL } x \\
\text { VEL } y\end{array}$ & $\begin{array}{ll}2 & 61608-07 \\
6 & 1873 E-06\end{array}$ & $\begin{array}{ll}3 & 0988 E-07 \\
6 & 1496 \mathrm{E}-06\end{array}$ & $\begin{array}{ll}3 & 4718 E-07 \\
6 & 0988 E-06\end{array}$ & $\begin{array}{l}3 \quad 4831 E-07 \\
6 \quad 2972 E-06\end{array}$ & $\begin{array}{l}4 \quad 0679 E-07 \\
6 \quad 2290 E-06\end{array}$ & $\begin{array}{ll}4 & 5214 E-07 \\
6 & 1470 E-06\end{array}$ & $\begin{array}{l}4442 E-07 \\
6 \quad 4146 E-06\end{array}$ & $\begin{array}{ll}5 & 5583 E-07 \\
6 & 3147 E-06\end{array}$ & $\begin{array}{l}6035 \\
6200\end{array}$ \\
\hline 119 & $\begin{array}{l}\text { VEL } x \\
\text { VEL } Y\end{array}$ & $\begin{array}{ll}2 & 8409 E-07 \\
5 & 2561 E-06\end{array}$ & $\begin{array}{ll}2 & 0625 E-07 \\
5 & 1662 E-06\end{array}$ & $\begin{array}{ll}1 & 4620 E-07 \\
5 & 0975 E-06\end{array}$ & $\begin{array}{ll}3 & 1270 E-07 \\
5 & 2122 E-00\end{array}$ & $\begin{array}{ll}2 & 2485 E-07 \\
5 & 1309 E-06\end{array}$ & $\begin{array}{l}15709 E-07 \\
5 \quad 0721 E-06\end{array}$ & $\begin{array}{ll}3 & 3544 E-07 \\
5 & 1669 E-06\end{array}$ & $\begin{array}{l}2 \quad 3834 E-07 \\
5 \quad 0944 E-06\end{array}$ & $\begin{array}{ll}1 & 6345 E-07 \\
5 & 0459 E-06\end{array}$ \\
\hline 120 & $\begin{array}{l}\text { VEL } x \\
\text { YEL } Y\end{array}$ & $\begin{array}{ll}1 & 4643 E-07 \\
6 & 2730 E-06\end{array}$ & $\begin{array}{ll}1 & 9617 E-07 \\
6 & 2596 E-06\end{array}$ & $\begin{array}{l}2 \quad 3003 E-07 \\
6 \quad 2337 E-06\end{array}$ & $\begin{array}{ll}1 & 9321 E-07 \\
6 & 4346 E-06\end{array}$ & $\begin{array}{l}2 \quad 6654 E-07 \\
6 \quad 4030 E-06\end{array}$ & $\begin{array}{l}3 \quad 1669 E-07 \\
6 \quad 3583 E-06\end{array}$ & $\begin{array}{l}29747 E-07 \\
6 \quad 6054 E-06\end{array}$ & $\begin{array}{l}3 \quad 8358 E-07 \\
6 \quad 5551 E-06\end{array}$ & $\begin{array}{l}4 \quad 4275 E-07 \\
6 \quad 4911 E-06\end{array}$ \\
\hline 121 & $\begin{array}{l}\text { VEL } X \\
\text { VEL } Y\end{array}$ & $\begin{array}{ll}1 & 1325 E-07 \\
4 & 9791 E-06\end{array}$ & $\begin{array}{l}57191 E-08 \\
4 \quad 9458 E-06\end{array}$ & $\begin{array}{l}1 \quad 1026 E-08 \\
49273 E-06\end{array}$ & $\begin{array}{l}12069 E-07 \\
49579 E-06\end{array}$ & $\begin{array}{l}6 \quad 1465 E-08 \\
4 \quad 9274 E-06\end{array}$ & $\begin{array}{l}112699 E-08 \\
4 \quad 9127 E-06\end{array}$ & $\begin{array}{l}12668 E-07 \\
49360 E-06\end{array}$ & $\begin{array}{l}6 \quad 4434 E-08 \\
49083 E-06\end{array}$ & $\begin{array}{l}13182 E-08 \\
4 \quad 8975 E-06\end{array}$ \\
\hline 122 & $\begin{array}{l}\text { VEL } x \\
\text { VEL } y\end{array}$ & $\begin{array}{ll}1 & 4460 E-07 \\
6 & 2994 E-06\end{array}$ & $\begin{array}{ll}1 & 9905 E-07 \\
6 & 4586 E-06\end{array}$ & $\begin{array}{ll}2 & 8321 E-07 \\
6 & 6375 E-06\end{array}$ & $\begin{array}{l}70553 E-08 \\
62996 E-06\end{array}$ & $\begin{array}{l}97548 E-08 \\
6 \quad 4760 E-06\end{array}$ & $\begin{array}{ll}1 & 4132 E-07 \\
6 & 6626 E-06\end{array}$ & $\begin{array}{l}3 \quad 5735 E-08 \\
6 \quad 3067 E-06\end{array}$ & $\begin{array}{ll}5 & 1182 E-08 \\
6 & 4900 E-06\end{array}$ & $\begin{array}{l}7 \quad 8400 E-08 \\
6 \quad 6837 E-06\end{array}$ \\
\hline 123 & $\begin{array}{l}\text { VEL } X \\
\text { VEL } Y\end{array}$ & $\begin{array}{l}17185 E-07 \\
5 \quad 9314 E-06\end{array}$ & $\begin{array}{l}18984 E-07 \\
58918 E-06\end{array}$ & $\begin{array}{l}2 \quad 0463 E-07 \\
58446 E-06\end{array}$ & $\begin{array}{l}23196 E-07 \\
59629 E-06\end{array}$ & $\begin{array}{l}25359 E-07 \\
59089 E-06\end{array}$ & $\begin{array}{l}27139 E-07 \\
58470 E-06\end{array}$ & $\begin{array}{l}3 \quad 1140 E-07 \\
5 \quad 9969 E-06\end{array}$ & $\begin{array}{l}3 \quad 3489 E-07 \\
5 \quad 9281 E-06\end{array}$ & $\begin{array}{l}35424 E-07 \\
5 \quad 8510 E-06\end{array}$ \\
\hline 124 & $\begin{array}{l}\text { VEL } X \\
\text { VEL } Y\end{array}$ & $\begin{array}{l}2 \text { OB222E-07 } \\
57370 E-06\end{array}$ & $\begin{array}{l}1 \quad 9873 E-07 \\
5 \quad 6235 E-06\end{array}$ & $\begin{array}{l}19235 \\
5503 E\end{array}$ & $\begin{array}{l}28002 E-07 \\
57324 E-06\end{array}$ & $\begin{array}{l}25898 E-07 \\
5 \quad 6094 E-06\end{array}$ & $\begin{array}{l}2 \quad 4476 E-07 \\
5 \quad 4799 E-06\end{array}$ & $\begin{array}{l}35509 E-07 \\
57289 E-06\end{array}$ & $\begin{array}{l}32185 E-07 \\
5 \quad 5959 E-06\end{array}$ & $\begin{array}{l}2 \quad 9940 E-07 \\
5 \quad 4558 E-06\end{array}$ \\
\hline 125 & $\begin{array}{l}\text { VEL } X \\
\text { VEL } Y\end{array}$ & $\begin{array}{ll}1 & 1362 E-07 \\
6 & 0305 E-06\end{array}$ & $\begin{array}{ll}1 & 3889 E-07 \\
6 & 0084 E-06\end{array}$ & $\begin{array}{ll}1 & 5833 E-07 \\
5 & 9779 E-06\end{array}$ & $\begin{array}{ll}1 & 5732 E-07 \\
6 & 0874 E-06\end{array}$ & $\begin{array}{ll}1 & 9137 E-07 \\
6 & 0562 E-06\end{array}$ & $\begin{array}{ll}2 & 1763 E-07 \\
6 & 0163 E-06\end{array}$ & $\begin{array}{ll}2 & 1805 E-07 \\
6 & 1479 E-06\end{array}$ & $\begin{array}{ll}2 & 5875 E-07 \\
6 \quad 1074 E-06\end{array}$ & $\begin{array}{ll}2 & 9020 E-07 \\
6 & 0577 E-06\end{array}$ \\
\hline 126 & $\begin{array}{l}\text { VEL } X \\
\text { VEL } Y\end{array}$ & $\begin{array}{ll}1 & 6965 E-07 \\
5 & 3431 E-06\end{array}$ & $\begin{array}{ll}1 & 2573 E-07 \\
5 & 2283 E-06\end{array}$ & $\begin{array}{ll}9 & 1850 E-08 \\
5 & 1348 E-06\end{array}$ & 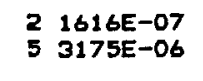 & $\begin{array}{ll}1 & 5891 E-07 \\
5 & 2062 E-06\end{array}$ & $\begin{array}{ll}1 & 1475 E-07 \\
5 & 1171 E-06\end{array}$ & & & \\
\hline 127 & $\begin{array}{l}\text { VEL } x \\
\text { VEL } Y\end{array}$ & $\begin{array}{l}6 \quad 2596 E-08 \\
6 \quad 0745 E-06\end{array}$ & $\begin{array}{ll}8 & 5292 E-08 \\
6 & 0664 E-06\end{array}$ & $\begin{array}{l}1 \quad 0055 E-07 \\
6 \quad 0531 E-06\end{array}$ & $\begin{array}{ll}8 & 6698 E-08 \\
6 & 1447 E-06\end{array}$ & $\begin{array}{ll}1 & 1834 E-07 \\
6 & 1321 E-06\end{array}$ & $\begin{array}{ll}1 & 3972 E-07 \\
6 & 1141 E-06\end{array}$ & $\begin{array}{ll}1 & 2475 E-07 \\
6 & 2191 E-06\end{array}$ & $\begin{array}{ll}1 & 6263 E-07 \\
6 & 2018 E-06\end{array}$ & $\begin{array}{ll}1 & 8834 E-07 \\
6 & 1789 E-06\end{array}$ \\
\hline 128 & $\begin{array}{l}\text { VEL } X \\
\text { VEL } \\
Y\end{array}$ & $\begin{array}{ll}7 & 2787 E-08 \\
5 & 0342 E-06\end{array}$ & $\begin{array}{l}3 \quad 6128 E-08 \\
49822 E-06\end{array}$ & $\begin{array}{l}59409 E-09 \\
49560 E-06\end{array}$ & $\begin{array}{l}89905 E-08 \\
50186 E-06\end{array}$ & $\begin{array}{l}45271 E-08 \\
49687 E-06\end{array}$ & $\begin{array}{l}85175 E-09 \\
49457 E-06\end{array}$ & $\begin{array}{ll}1 & 0571 E-07 \\
5 & 0025 E-06\end{array}$ & $\begin{array}{l}5 \text { 3229E-08 } \\
4 \quad 9548 E-06\end{array}$ & $\begin{array}{ll}1 & 0013 E-08 \\
4 & 9351 E-06\end{array}$ \\
\hline
\end{tabular}


LISTING D-6. Output Report File for Test Case Two. (Sheet 36 of 48)

SAMPLE PROBLEM, FLOW AROUND A HEATED CANNISTER

RESULTS FOR VELOCITY (M/YR) OF YEAR 5000

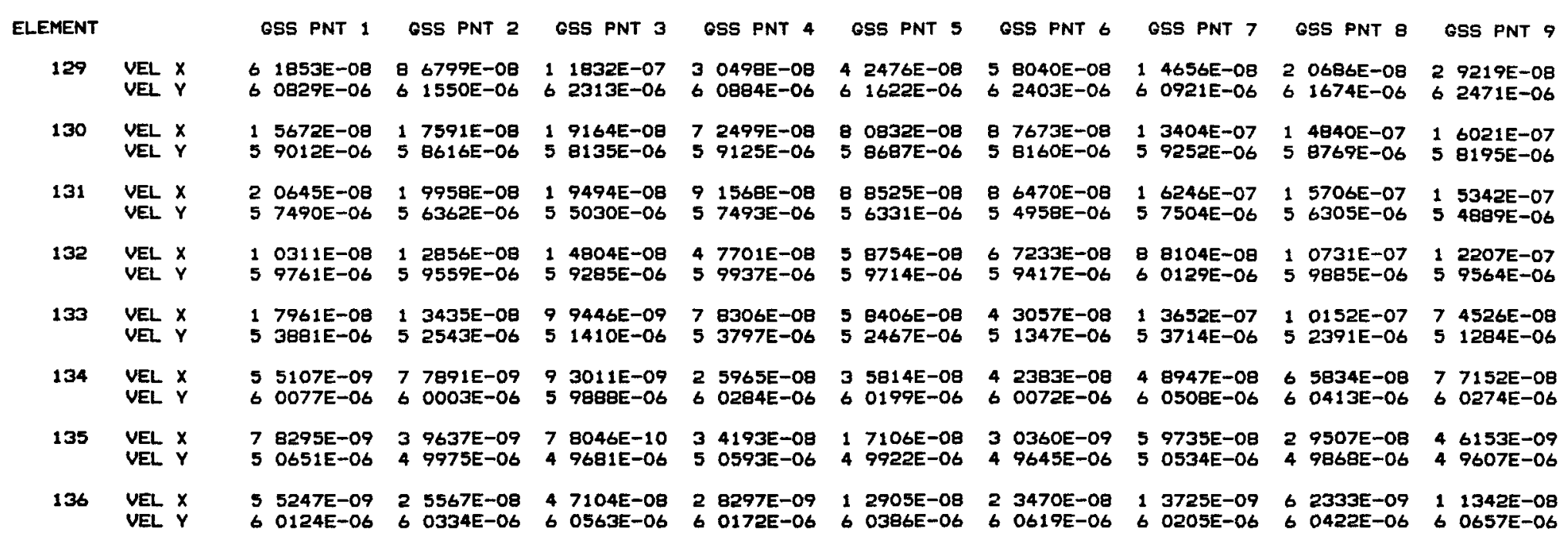


LISTING D-6. Output Report File for Test Case Two. (Sheet 37 of 48)

SAMPLE PROBLEM, FLOW AROUND A HEATED CANNISTER

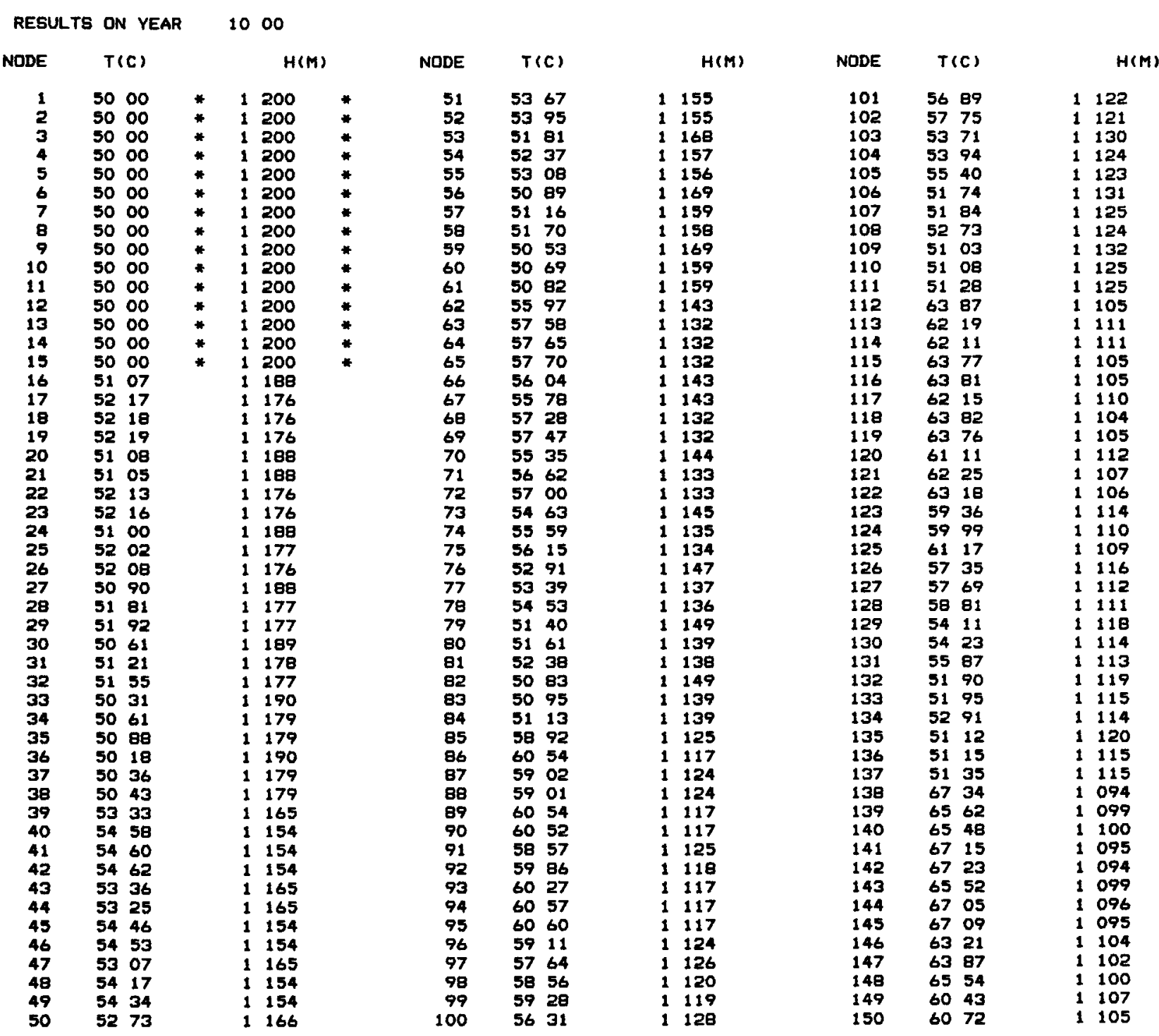


LISTING D-6. Output Report File for Test Case Two. (Sheet 38 of 48)

SAMPLE PROBLEM, FLOW AROUND A HEATED CANNISTER

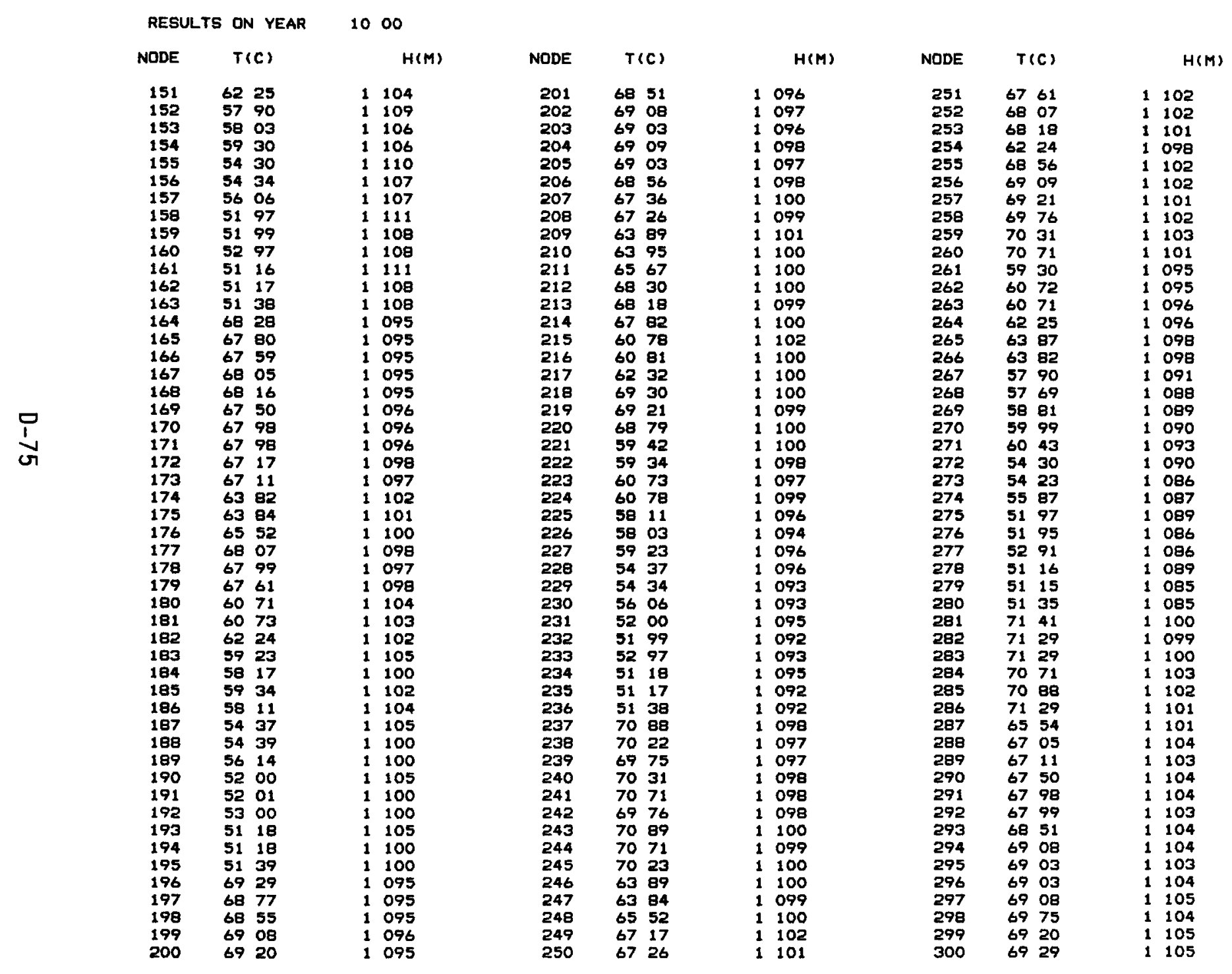


LISTING D-6. Output Report File for Test Case Two. (Sheet 39 of 48) SAMPLE PROBLEM, FLOW AROUND A HEATED CANNISTER

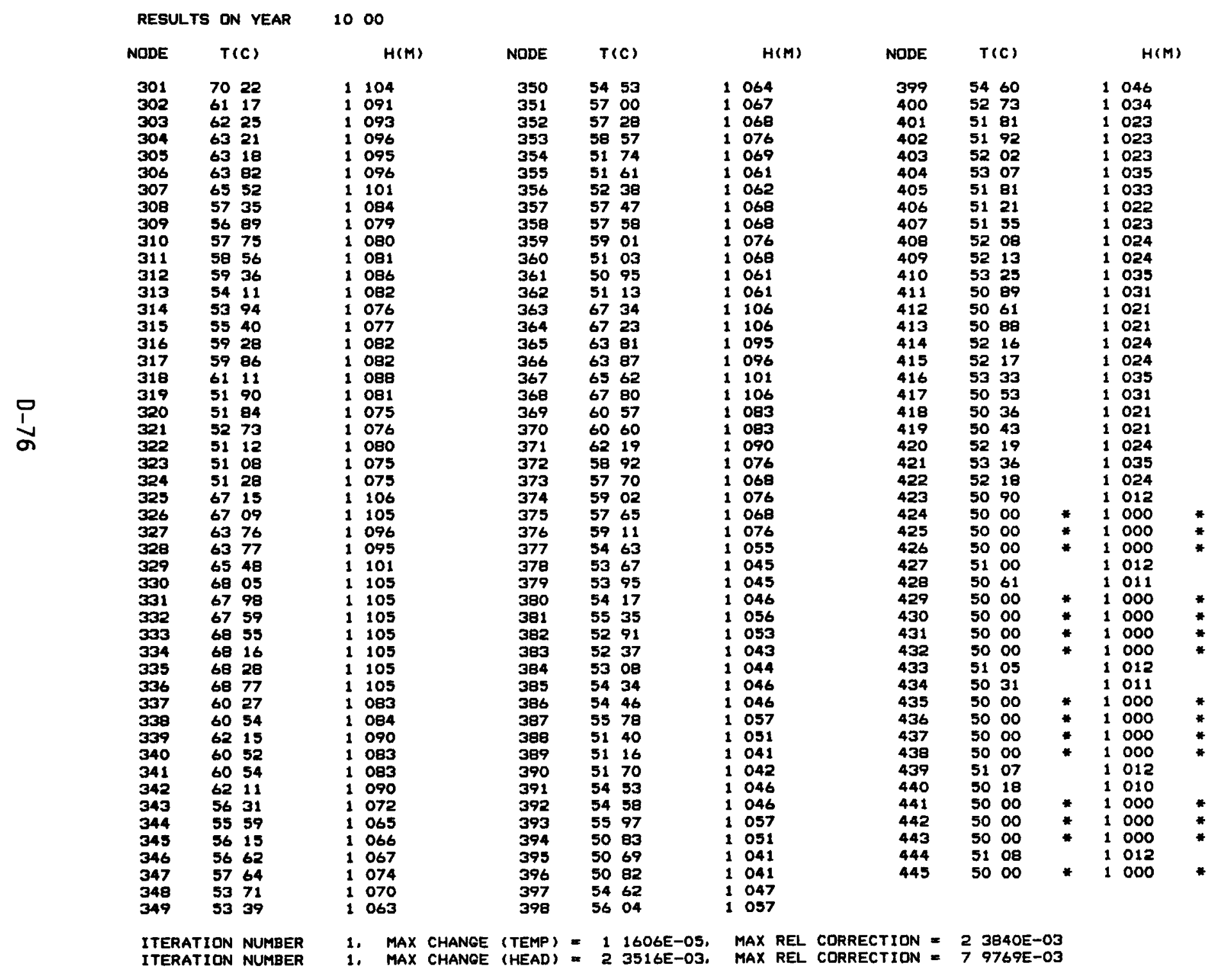


LISTING D-6. Output Report File for. Test Case Two. (Sheet 40 of 48)

SAMPLE PROBLEM, FLOW AROUND A HEATED CANNISTER

RESULTS FOR VELOCITY (M/YR) OF YEAR 10 OO

GSS PNT 1 GSS PNT 2 GSS PNT 3 GSS PNT 4 GSS PNT 5 GSS PNT 6 GSS PNT 7 GSS PNT B GSS PNT 9

1 VEL $X \quad-7$ 7625E-09 -1 5937E-08 -3 1866E-08 -4 2930E-09 -8 7949E-09 -1 7339E-08 -9 5220E-10 -1 $9341 E-09-3 \quad 7501 E-09$

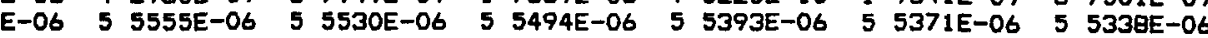

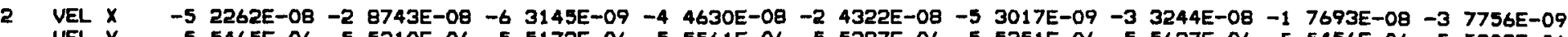

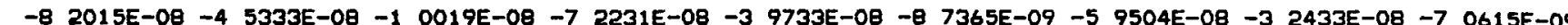

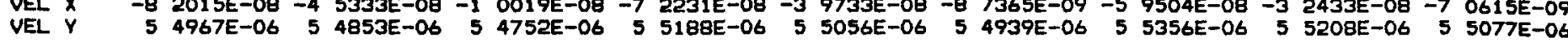

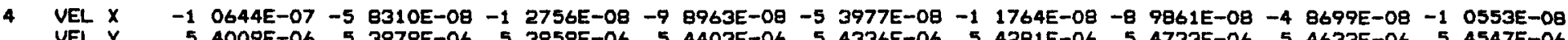

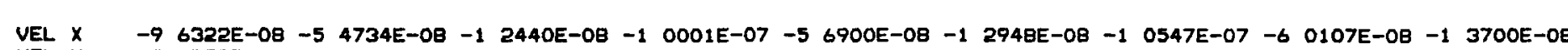

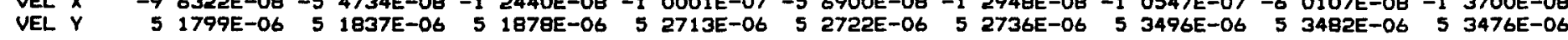

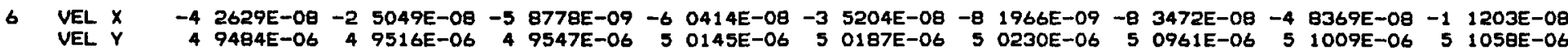

7 VEL $X \quad-1$ 3203E-09 $-1 \quad 1146 E-09-3 \quad 3284 E-10$-1 $6504 E-08$-9 7081E-09 -2 2902E-09 -3 4944E-08 -2 0144E-08 -4 6451E-09 VEL $Y \quad 4$ 8434E-06 4 8449E-06 4 8463E-06 4 B570E-06 4 8598E-06 4 8624E-06 4 8966E-06 $48995 E-06 \quad 4 \quad 9023 E-06$

B VEL $X$-1 $8979 E-08-3 \quad 8162 E-08$-7 $8287 E-08$-1 3565E-08 -2 8110E-08 -5 7694E-08 -9 8825E-09 -2 0524E-08 -4 1587E-08

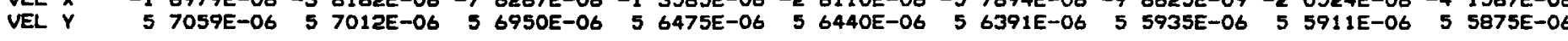

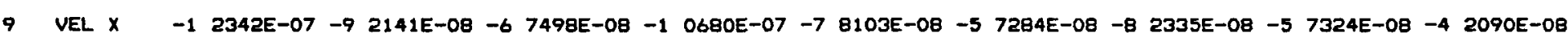

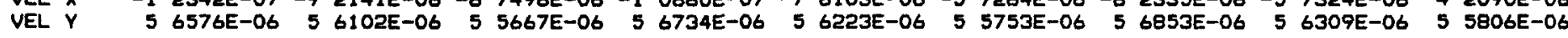

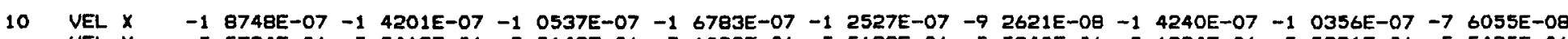
VEL $Y \quad 5 \quad 5724 E-06 \quad 55419 E-06 \quad 5 \quad 5143 E-06 \quad 5$ 6059E-06 5 5683E-06 5 5340E-06 5 6334E-06 5 5891E-06 5 5485E-06

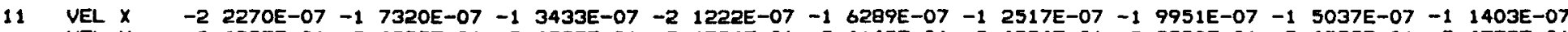
VEL $Y$ S $S$ 4287E-06 5 4252E-06 5 4233E-06 5 4794E-06 5 4649E-06 5 4524E-06 5 5250E-06 5 4998E-06 5 4773E-06

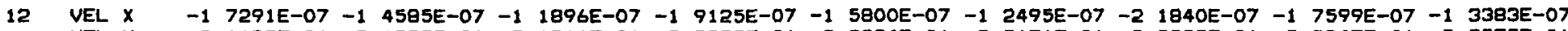
VEL $Y$ S 5 1699E-06 5 1833E-06 5 1966E-06 5 2522E-06 5 2594E-06 5 2671E-06 5 3333E-06 $53347 E-06 \quad 53373 E-06$

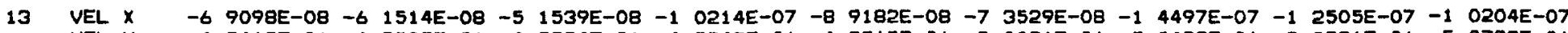
$49415 E-06 \quad 49502 E-06 \quad 4$ 9584E-06 4 9848E-06 4 9969E-06 5 0086E-06 5 0435E-06 5 0581E-06 $50723 E-06$

14 VEL $X \quad-3 \quad 2406 E-09-2 \quad 8941 E-09-1 \quad 7602 E-09-2 \quad 6556 E-08$-2 $3603 E-08$-1 $9786 E-08$-5 $4871 E-08$-4 $8752 E-08$-4 $1677 E-00$ VEL $Y \quad 4$ B337E-06 4 8379E-06 4 B417E-06 4 8429E-06 4 8492E-06 4 8551E-06 4 B667E-06 4 B740E-06 4 8809E-06

15 VEL $X$-5 2897E-08 -9 3160E-08 $-1 \quad 8395 E-07-3 \quad 3908 E-08$-6 3735E-08 -1 2903E-07 -2 3247E-08 -4 6156E-08 -9 4875E-08 VEL $Y \quad 6 \quad 0116 E-06 \quad 59964 E-06 \quad 5$ 9788E-06 5 8750E-06 5 8650E-06 5 8531E-06 5 7487E-06 $57438 E-06 \quad 57371 E-06$

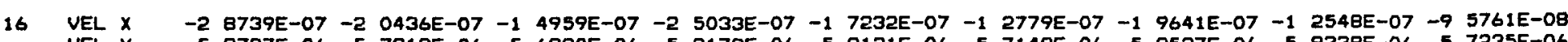

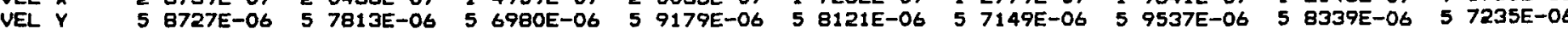


LISTING D-6. Output Report File for Test Case Two. (Sheet 41 of 48)

SAMPLE PROBLEM, FLOW AROUND a HEATED CANNISTER

RESULTS FOR VELOCITY (M/YR) OF YEAR 10.00 ELEMENT

GSS PNT 1 GSS PNT 2 GSS PNT 3 GSS PNT 4 GSS PNT 5 GSS PNT 6 GSS PNT 7 GSS PNT 9 GSS PNT 9

$\begin{array}{llrrrrrrrrr}17 & \text { VEL } X & -3.7788 E-07 & -2.8417 E-07 & -2.2199 E-07 & -3.5208 E-07 & -2.5795 E-07 & -1.9920 E-07 & -3.1887 E-07 & -2.2413 E-07 & -1.6975 E-07 \\ \text { VEL } Y & 5.6668 E-06 & 5.6327 E-06 & 5.6037 E-06 & 5.7446 E-06 & 5.6971 E-06 & 5.6359 E-06 & 5.8133 E-06 & 5.7331 E-06 & 5.6604 E-06\end{array}$

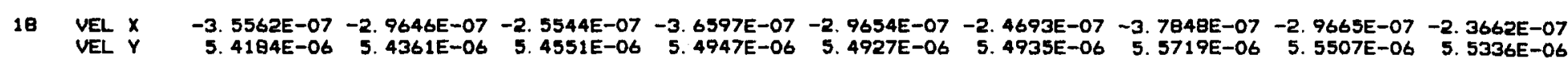

19 VEL $X \quad-2.0052 E-07-1.9597 E-07-1.8811 E-07-2.5301 E-07-2.3497 E-07-2.1298 E-07 \quad-3.3072 E-07-2.9271 E-07-2.4979 E-07$

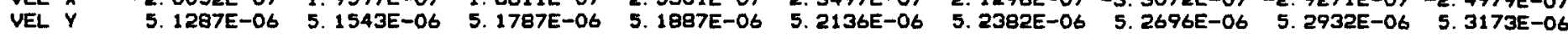

20 VEL $X \quad-6.8879 E-08-7.2393 E-08-7.2446 E-08-1.0876 E-07-1.1044 E-07-1.0820 E-07-1.6046 E-07-1.5976 E-07-1.5456 E-07$ VEL $Y$ 4. $\quad$. $9268 E-06 \quad 4.9377 E-06 \quad 4.9478 E-06 \quad 4.9419 E-06 \quad 4.9598 E-06 \quad 4.9766 E-06 \quad 4.9701 E-06 \quad 4.9937 E-06 \quad 5.0159 E-06$

21 VEL $X \quad-3.6227 E-09-3.9243 E-09-3.4833 E-09-2.6347 E-08-2.7350 E-08-2.7539 E-08-5.3944 E-08-5.5799 E-08-5.6752 E-08$

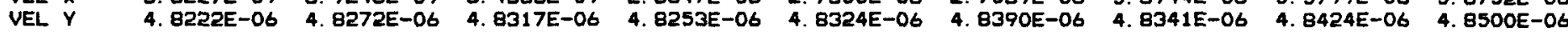

22 VEL $X \quad-1.6503 E-07-2.5197 E-07-1.4705 E-07-1.1772 E-07-7.8330 E-08-2.2162 E-07-2.4528 E-07$

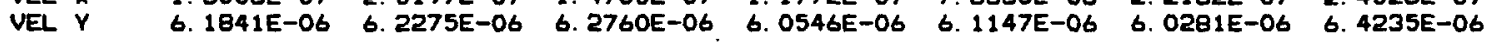

23 VEL $X \quad-3.7981 E-07-3.7184 E-07-4.5271 E-07-3.0208 E-07-3.6508 E-07-2.0426 E-07-5.4889 E-07$

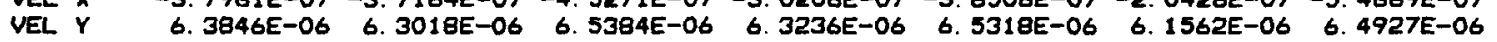

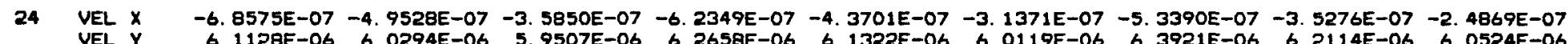

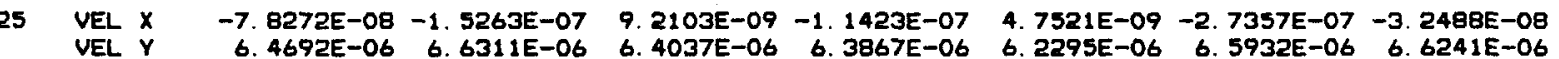

26 VEL $X \quad-6.5976 E-07-5.3651 E-07-4.4527 E-07-6.7852 E-07 \quad-5.3343 E-07 \quad-4.2404 E-07 \quad-7.0262 E-07 \quad-5.2951 E-07 \quad-3.9676 E-07$

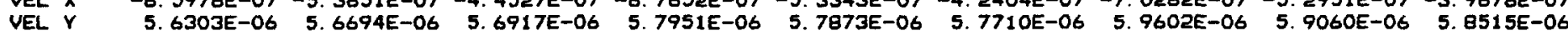

27 VEL $X \quad-4.3314 E-07-4.1618 E-07-3.9381 E-07-5.1007 E-07-4.6600 E-07-4.1597 E-07-6.0287 E-07-5.2617 E-07-4.4276 E-07$

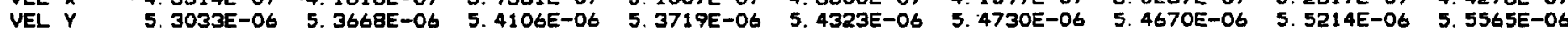

28 VEL $X \quad-1.7082 E-07-1.8974 E-07-2.0234 E-07-2.5135 E-07-2.6092 E-07 \quad-2.6296 E-07 \quad-3.7057 E-07-3.6631 E-07 \quad-3.5269 E-07$ $\begin{array}{llllllllll}\text { VEL } Y & 5.0794 E-06 & 5.1067 E-06 & 5.1247 E-06 & 5.0835 E-06 & \text { 5. 1295E-06 } & \text { 5. } 1615 E-06 & \text { 5. } 1270 E-06 & 5.1862 E-06 & \text { 5. } 2274 E-06\end{array}$

29 VEL $X \quad-5.1953 E-08-5.9382 E-08-6.6033 E-08-8.7498 E-08-9.7241 E-00-1.0611 E-07-1.3358 E-07-1.4632 E-07-1.5806 E-07$ VEL Y $Y$ 4.9156E-06 $4.9244 E-06 \quad 4.9298 E-06 \quad 4.9101 E-06.4 .9242 E-06 \quad 4.9331 E-06 \quad 4.9089 E-06 \quad 4.9277 E-06 \quad 4.9396 E-06$

30 VEL $X \quad-2.7330 E-09-3.0801 E-09-3.3479 E-09-2.0049 E-08-2.2711 E-08-2.5287 E-08-4.1074 E-08-4.6548 E-08-5.1928 E-08$ 31 VEL $x \quad-8.0458 E-07-5.3675 E-07-3.5821 E-07-4.9041 E-07-3.1212 E-07-1.9564 E-07-2.1505 E-07-1.2406 E-07-6.5292 E-08$

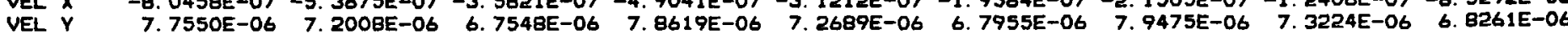

$\begin{array}{llrrrrrrrrr} & \text { VEL } X & -1.5471 E-06 & -9.3592 E-07 & -5.9425 E-07 & -1.3809 E-06 & -8.0554 E-07 & -4.8427 E-07 & -1.2176 E-06 & -6.9482 E-07 & -4.0443 E-07 \\ \text { VEL } Y & 7.2406 E-06 & 6.9187 E-06 & 6.6474 E-06 & 7.4289 E-06 & 7.0208 E-06 & 6.6818 E-06 & 7.6432 E-06 & 7.1391 E-06 & 6.7253 E-06\end{array}$ 
LISTING D-6. Output Report File for Test Case Two. (Sheet 42 of 48)

SAMPLE PROBLEM, FLOW AROUND A HEATED CANNISTER

RESULTS FOR VELOCITY (M/YR) OF YEAR 10 O0

ELEMENT

GSS PNT 1 GSS PNT 2 GSS PNT 3 GSS PNT 4 GSS PNT 5 GSS PNT 6 GSS PNT 7 GSS PNT 8 GSS PNT 9

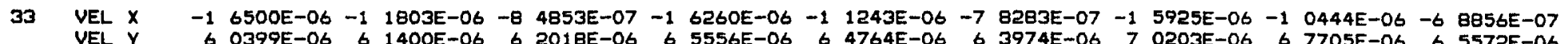

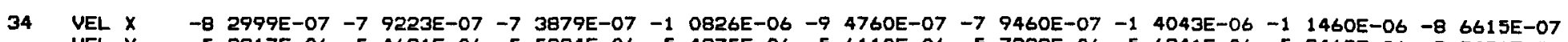

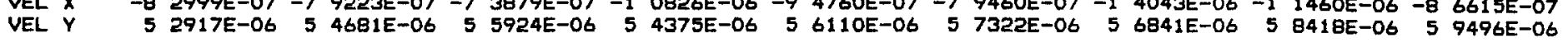

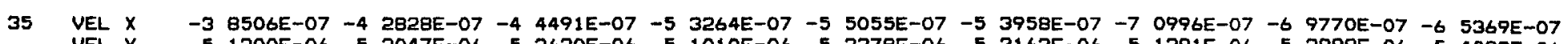

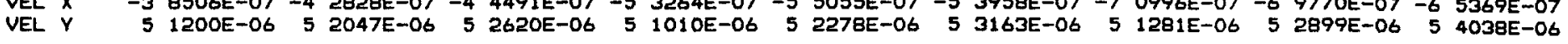

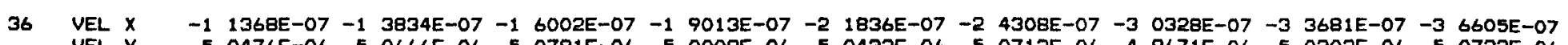

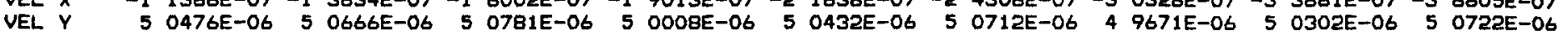

37 VEL $X \quad-3 \quad 2332 E-08-3 \quad 9456 E-08$-4 $7403 E-08$ - 5 7247E-08 $-6 \quad 8703 E-08$-8 $1099 E-08$-8 $95598-08$ - $1 \quad 0662 E-07 \quad-1 \quad 2479 E-07$ VEL $Y$ S $49106 E-06 \quad 49161 E-06 \quad 49193 E-06 \quad 4 \quad 8943 E-06 \quad 4$ 9012E-06 4 9048E-06 4 8704E-06 4 8804E-06 4 8857E-06

38 VEL $X$-1 7138E-09 -1 9938E-09 -2 4539E-09 -1 2687E-08 -1 5445E-08 -1 8401E-08 $-2 \quad 6020 E-08$-3 $1779 E-08$-3 $7764 E-08$ VEL Y 4 B112E-06 4 8133E-06 4 8144E-06 4 B088E-06 4 8110E-06 4 8119E-06 4 7981E-06 4 8024E-06 4 8048E-06

39 VEL $X$

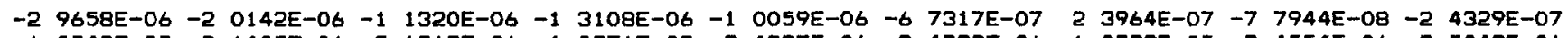

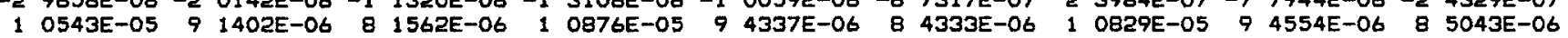

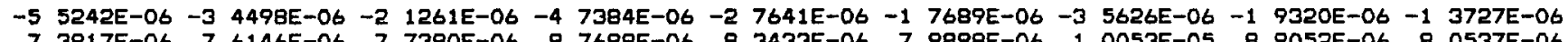
VEL $Y \quad 7$ 3817E-06 7 6146E-06 7 7380E-06 B 7689E-06 8 3433E-06 7 9898E-06 1 0053E-05 8 $9052 E-06 \quad 80537 E-06$

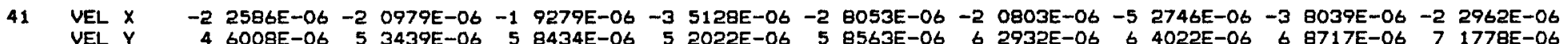

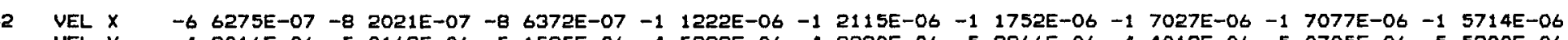
VEL $Y \quad 4 \quad 48016 E-06 \quad 5 \quad 0162 E-06 \quad 5 \quad 1535 E-06 \quad 4 \quad 5238 E-06 \quad 4 \quad 9820 E-06 \quad 5 \quad 2866 E-06 \quad 4 \quad 4013 E-06 \quad 5 \quad 0705 E-06 \quad 5 \quad 5200 E-06$

43 VEL $X \quad-2 \quad 4849 E-07-3 \quad 0345 E-07-3 \quad 5641 E-07-3 \quad 7647 E-07 \quad-4 \quad 4363 E-07-5 \quad 0894 E-07 \quad-5 \quad 2993 E-07 \quad-6 \quad 1190 E-07 \quad-6 \quad 9222 E-07$ VEL $Y \quad 49839 E-06 \quad 5$ O459E-06 5 0830E-06 4 8901E-06 4 9824E-06 5 0388E-06 4 7860E-06 $49093 E-06 \quad 49853 E-06$

44 VEL $X \quad-6$ 3030E-08 $-8 \quad 0566 E-08$ - $1 \quad 0032 E-07-1 \quad 1036 E-07-1 \quad 3995 E-07-1 \quad 7226 E-07 \quad-1 \quad 8063 E-07 \quad-2 \quad 2796 E-07 \quad-2 \quad 7879 E-07$

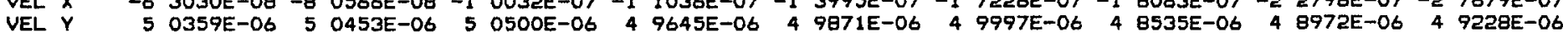

45 VEL $X$-1 $7093 E-08$-2 $1934 E-08$-2 $8327 E-08$-3 $1117 E-08$-4 $0060 E-08$-5 $0765 E-08$-4 $9380 E-08$-6 $3602 E-08$-7 $9872 E-08$

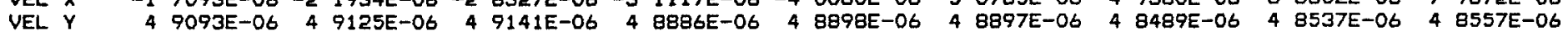

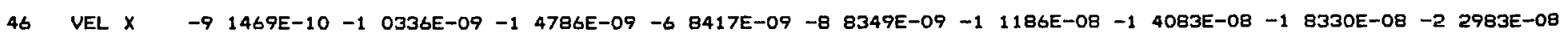

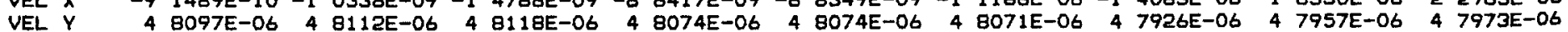

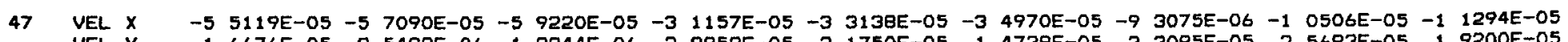

48 VEL $X \quad-8 \quad 1054 E-05-8 \quad 5368 E-05$-8 $9974 E-05$-7 $7312 E-05$-8 $1893 E-05$-8 $6602 E-05$-6 $3805 E-05$-6 $7884 E-05$-7 $1921 E-05$

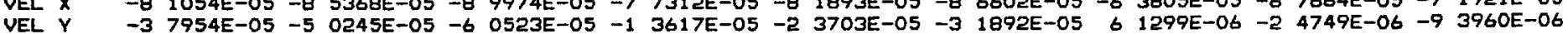


LISTING D-6. Output Report File for Test Case Two. (Sheet 43 of 48)

SAMPLE PROBLEM, FLOW AROUND A HEATED CANNISTER

RESULTS FOR VELOCITY (M/YR) OF YEAR 1000

ELEMENT

49

so

51 VEL $X$

52 VEL $X$

53 VEL $X$

VEL $Y$

54 VEL $X$

55 VEL $X$

56 VEL $X$

57 VEL $X$

VEL $Y$

58

VEL $\stackrel{x}{Y}$

59 VEL $X$

60 VEL $X$

VEL $Y$

61 VEL $X$

62 VEL

63 VEL $X$

64 VEL $X$

GSS PNT 1 GSS PNT 2 GSS PNT 3 GSS PNT 4 GSS PNT 5 GSS PNT 6 GSS PNT 7 GSS PNT 8 GSS PNT 9 -1 4784E-06 - 1 9241E-06 -2 2604E-06 -2 5364E-06 -3 1775E-06 -3 6624E-06 -4 0846E-06 -4 9755E-06 -5 $6390 E-06$

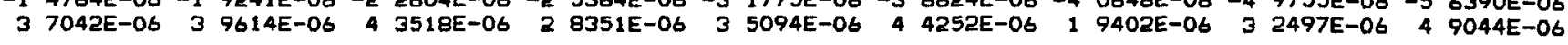
-6 $1670 E-05$-7 $8798 E-05$-8 $8779 E-05$-6 $0291 E-05$-7 $5156 E-05$-8 $3658 E-05$-5 $8911 E-05$-7 $1707 E-05$-7 $9073 E-05$ $-13513 E-04-1 \quad 1004 E-04-7$ 9259E-05 -1 $1802 E-04$-9 6054E-05 -6 7077E-05 -9 9038E-05 -8 0310E-05 -5 3202E-05

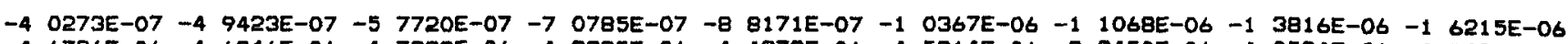

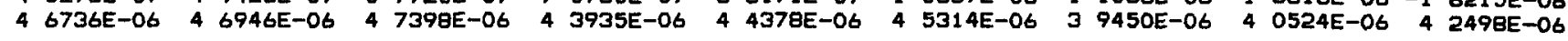

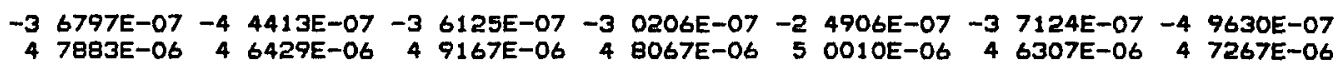

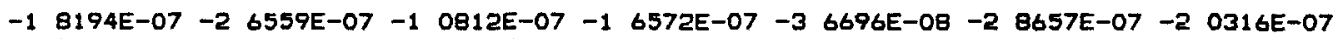

4 B687E-06 4 7907E-06 4 9433E-06 4 8622E-06 4 9348E-06 4 7543E-06 4 9275E-06

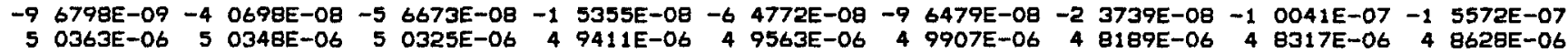

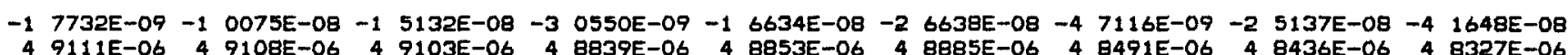
$-2 \quad 7009 E-10-1 \quad 0871 E-09-1 \quad 0957 E-09-5 \quad 6361 E-10 \quad-3 \quad 6483 E-09-5$ 8544E-09 -9 1743E-10 $-6 \quad 7587 E-09-1 \quad 1674 E-08$ $48115 E-06 \quad 4$ B104E-06 4 B085E-06 4 8043E-06 4 8060E-06 4 B091E-06 4 7935E-06 4 7929E-06 4 7918E-06

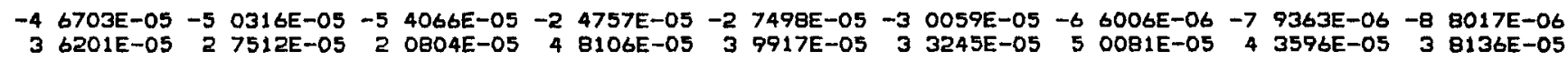
-6 $4787 E-05$-7 $1479 E-05$-7 $8355 E-05$-6 $1344 E-05$-6 $8371 E-05$-7 $5356 E-05$-4 $9240 E-05$-5 $5713 E-05$-6 $1954 E-05$

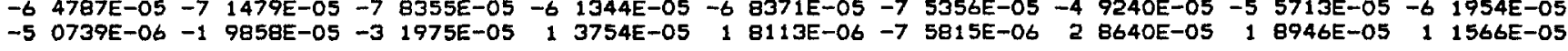

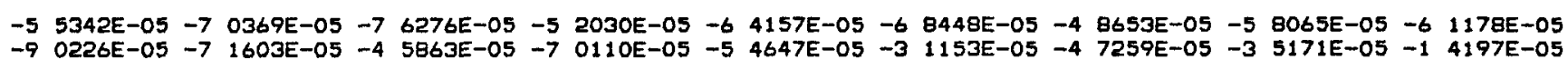

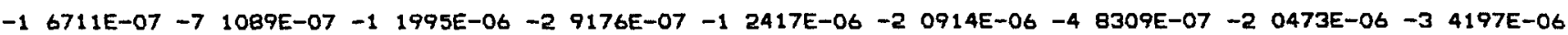

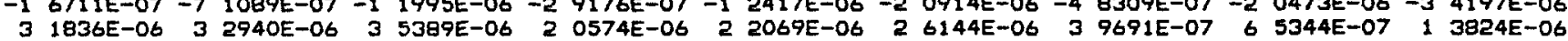

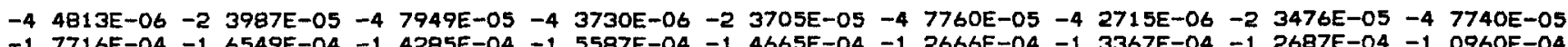
4 (1)

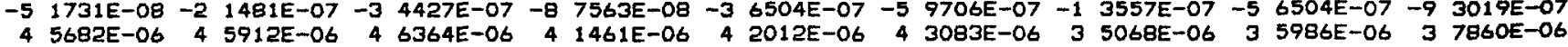
-6 3377E-06 -2 7513E-05 -4 6002E-05 -5 9958E-06 -2 6258E-05 -4 3944E-05 -5 6620E-06 -2 5052E-05 -4 2009E-05

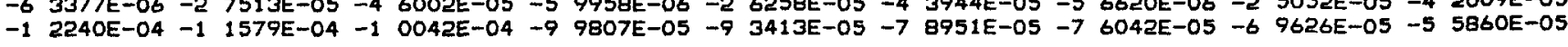

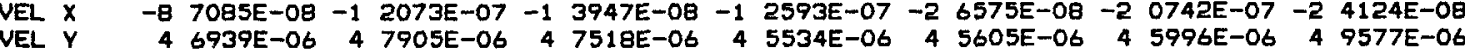


LISTING D-6. Output Report File for Test Case Two. (Sheet 44 of 48)

SAMPLE PROBLEM, FLOW AROUND A HEATED CANNISTER

RESULTS FOR VELOCITY (M/YR) OF YEAR 10 00

$\begin{array}{lllllllllllll}\text { ELEMT } & \text { GSS PNT } 1 & \text { GSS PNT } 2 & \text { GSS PNT } 3 & \text { GSS PNT } 4 & \text { GSS PNT } 5 & \text { GSS PNT } 6 & \text { GSS PNT } 7 & \text { GSS PNT } 8 & \text { GSS PNT } 9\end{array}$

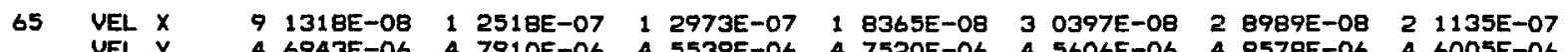

66 VEL $X \quad 1$ B659E-07 2 7003E-07 1 7022E-07 1 1315E-07 4 1740E-08 $20902 E-07 \quad 2 \quad 9061 E-07$

4 B697E-06 4 7922E-06 4 8630E-06 4 9442E-06 4 9353E-06 4 9293E-06 4 7555E-06

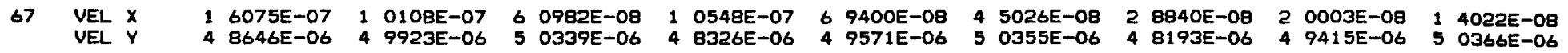

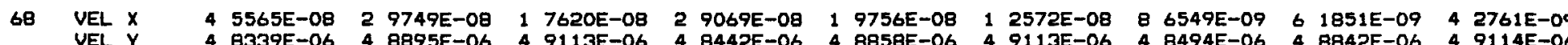

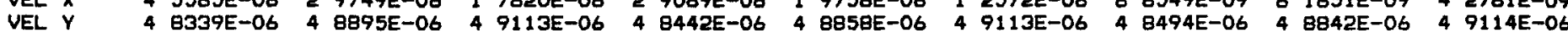

69 VEL $X \quad 1 \quad 3574 E-08$ o $8434 E-09 \quad 13347 E-09 \quad 8 \quad 6651 E-09 \quad 4 \quad 6409 E-09 \quad 1 \quad 3273 E-09 \quad 2$ 8290E-09 $1 \quad 5586 E-09 \quad 5 \quad 1036 E-10$ VEL $Y \quad 4$ 7927E-06 4 8099E-06 4 8093E-06 4 7934E-06 4 8064E-06 4 8108E-06 4 7937E-06 4 8045E-06 4 8117E-06

70 VEL $X \quad-20003 E-04-2 \quad 5143 E-04-3 \quad 2837 E-04-1 \quad 0794 E-04-1 \quad 4305 E-04-1 \quad 7520 E-04 \quad-3 \quad 2918 E-05-5 \quad 7404 E-05 \quad-6 \quad 2265 E-05$

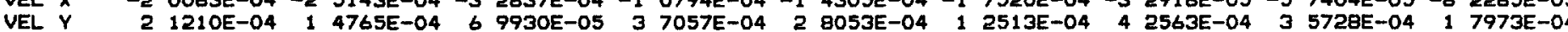

71 VEL $X$

$-30158 E-04-3$ 7205E-04 -3 9992E-04 -2 5885E-04 -3 2914E-04 -3 8355E-04 -2 $3455 E-04-2 \quad 9769 E-04 \quad-33308 E-04$

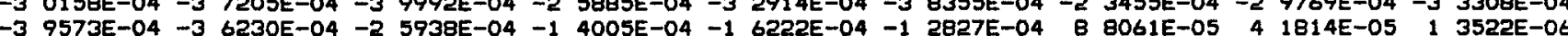

72 VEL $X$

-2 5612E-05 -1 1372E-04 -2 2300E-04 -2 6411E-05 -1 1025E-04 -1 9687E-04 - 2 8235E-05 -1 $1155 E-04$ - 1 8484E-04 VEL $Y$ - $\quad-5$ 5606E-04 -5 2384E-04 -4 5807E-04 -1 3154E-04 -1 3333E-04 -1 5477E-04 1 7803E-04 1 7722E-04 $11209 E-04$

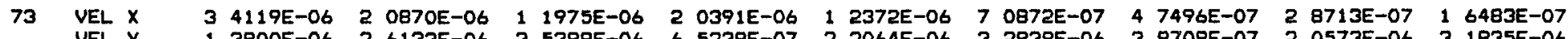
VEL $Y$ S $\quad 1$ 3800E

74 VEL $X$

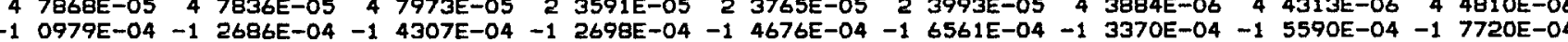

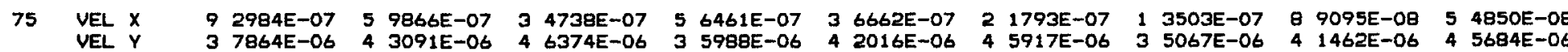

76 VEL $X \quad 4$ 2369E-05 4 4208E-05 4 6168E-05 25 5410E-05 2 6518E-05 2 7674E-05 6 0186E-06 6 2529E-06 $6 \quad 49525-06$ VEL $Y$ - 5 5992E-05 -7 $9110 E-05-1$ 0060E-04 -6 $9708 E-05$-9 3507E-05 -1 $1590 E-04$-7 $6083 E-05-9$ 9847E-05 -1 $2244 E-04$

77 VEL $x \quad 1 \quad 8500 E-04 \quad 1 \quad 9714 E-04 \quad 2 \quad 2343 E-04 \quad 1 \quad 1157 E-04 \quad 1 \quad 1042 E-04 \quad 1 \quad 1406 E-04 \quad 26181 E-05 \quad 26516 E-05 \quad 2 \quad 5879 E-05$ VEL $Y$ 1 D925E-04 -1 5738E-04 -4 6041E-04 1 7563E-04 -1 3478E-04 -5 2512E-04 1 7755E-04 -1 3201E-04 -5 5650E-04

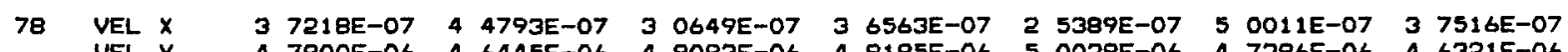

79 VEL $X \quad 1 \quad 6213 E-06 \quad 1 \quad 0383 E-06 \quad 5 \quad 8029 E-07 \quad 1 \quad 3813 E-06 \quad 8 \quad 8335 E-07 \quad 4 \quad 9736 E-07 \quad 1 \quad 1065 E-06 \quad 7 \quad 0947 E-07 \quad 4 \quad 0584 E-07$ 4 .

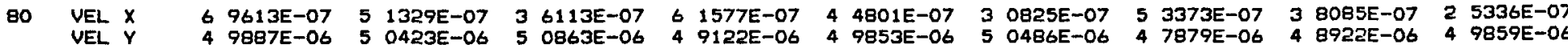


LISTING D-6. Output Report File for Test Case Two. (Sheet 45 of 48)

SAMPLE PROBLEM, FLOW AROUND A HEATED CANNISTER

RESULTS FOR VELOCITY (M/YR) OF YEAR 10 OO

ELEMENT $\quad$ GSS PNT 1 GSS PNT 2 GSS PNT 3 GSS PNT 4 GSS PNT 5 GSS PNT 6 GSS PNT 7 GSS PNT 8 GSS PNT 9

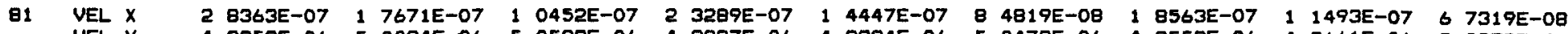

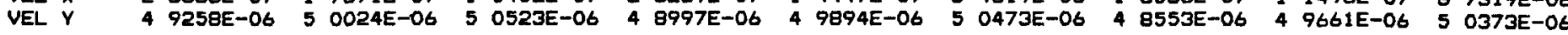

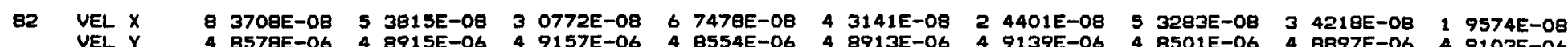

83 VEL $X \quad 2 \quad 4849 E-08 \quad 1 \quad 2157 E-08 \quad 1 \quad 7128 E-09 \quad 20212 E-08 \quad 9 \quad 8152 E-09 \quad 1 \quad 2714 E-09 \quad 1 \quad 5977 E-0878280 E-09 \quad 1 \quad 1534 E-09$

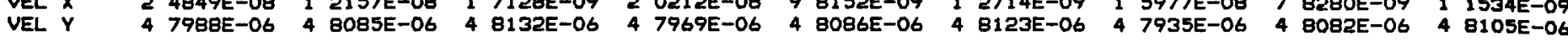

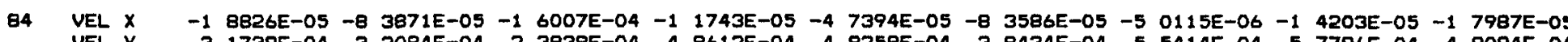

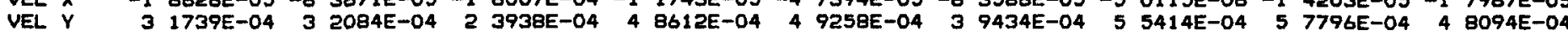

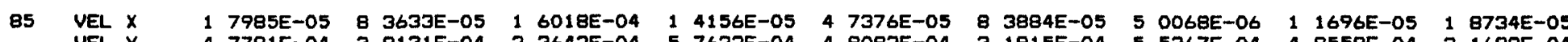
VEL $Y$ 4 7791E-04 3 9131E-04 2 3642E-04 5 7622E-04 4 9082E-04 3 1915E-04 5 5367E-04 4 B55BE-04 $31688 E-04$

86 VEL $X \quad 5 \quad 6331 E-06 \quad 3 \quad 6588 E-06 \quad 2 \quad 2584 E-06 \quad 4 \quad 9688 E-06 \quad 3 \quad 1736 E-06 \quad 19221 E-06 \quad 4 \quad 0771 E-06 \quad 2 \quad 5322 E-06 \quad 1 \quad 4765 E-06$ VEL Y 4 8996E-06 4 4232E-06 4 3515E-06 3 2457E-06 3 5079E-06 $39611 \mathrm{E}-06 \quad 1$ 9373E-06 $28341 \mathrm{E}-06 \quad 3 \quad 7041 \mathrm{E}-06$

87 VEL $X$

7 9217E-05 \& 3768E-05 8 8852E-05 7 1846E-05 7 5252E-05 7 8949E-05 5 9047E-05 6 O378E-05 6 1707E-05

88 VEL $X \quad 6 \quad 1470 E-05 \quad 6 \quad 8684 E-05 \quad 7$ 6449E-05 5 8401E-05 $64414 E-05 \quad 7$ 0543E-05 4 9011E-05 5 22095E-05 $55513 E-05$ VEL $Y$ Y $\quad-1$ 4291E-05 -3 1320E-05 -4 6099E-05 -3 5273E-05 -5 4807E-05 -7 1820E-05 -4 7389E-05 -7 O277E-05 -9 0429E-05

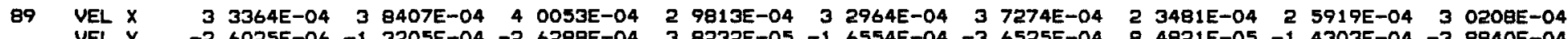

90 VEL $X \quad 6$ 2359E-05 1 7545E-04 3 2886E-04 5 7481E-05 1 4324E-04 2 5178E-04 $32956 E-05 \quad 1 \quad 0804 E-04 \quad 2 \quad 0100 E-04$

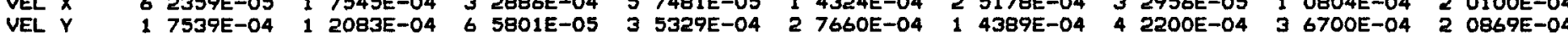

91 VEL $X \quad 1$ 5727E-06 $117777 E-06 \quad 8 \quad 6705 E-07 \quad 1 \quad 7083 E-06 \quad 12135 E-06 \quad 8$ 2339E-07 $117026 E-06 \quad 1 \quad 1238 E-06 \quad 6 \quad 65825-07$ VEL Y 5 S224E-06 5 2896E-06 5 1570E-06 5 O722E-06 4 9845E-06 5 O190E-06 4 4019E-06 4 5253E-06 4 8034E-06

92 VEL $X \quad 2$ 2957E-06 2 OBO4E-06 11 9285E-06 3 8014E-06 2 B041E-06 2 O976E- $06 \quad 5$ 2698E-06 $35099 E-06 \quad 22570 E-06$

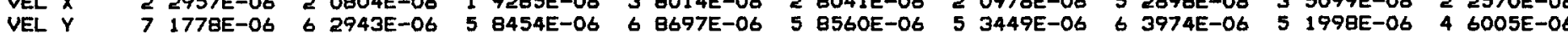

93 VEL $x \quad 6 \quad 5740 E-07 \quad 5 \quad 4358 E-07 \quad 4 \quad 4915 E-07 \quad 7 \quad 0153 E-07 \quad 554471 E-07 \quad 4 \quad 3273 E-07 \quad 7 \quad 1383 E-07 \quad 5 \quad 3691 E-07 \quad 3 \quad 8966 E-07$

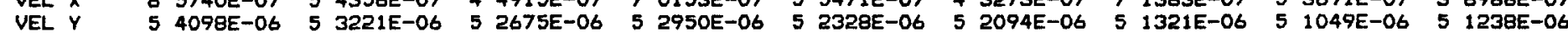

94 VEL $x \quad 3 \quad 7039 E-07 \quad 2 \quad 4717 E-07 \quad 1 \quad 6394 E-07 \quad 3 \quad 4138 E-07 \quad 2 \quad 2261 E-07 \quad 1 \quad 4238 E-07 \quad 3 \quad 0802 E-07 \quad 19450 E-07 \quad 11792 E-07$

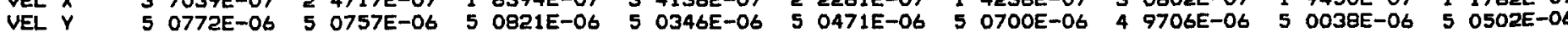

95 VEL $X \quad 8 \quad 6851 E-07 \quad 79755 E-07 \quad 7 \quad 4220 E-07 \quad 1 \quad 1481 E-06 \quad 95047 E-07 \quad 7 \quad 9569 E-07 \quad 1 \quad 4060 E-06 \quad 1 \quad 0852 E-06 \quad 8 \quad 3337 E-07$

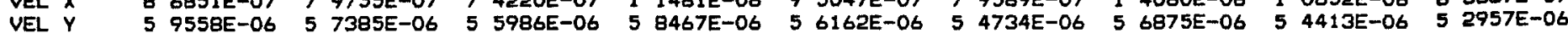

96 VEL $X \quad 1$ 2840E-07 8 3991E-08 $49730 E-08 \quad 1 \quad 1034 E-07 \quad 7 \quad 1670 E-08 \quad 4 \quad 1840 E-08$ 9 3355E-08 6 O268E-08 3 4755E-08

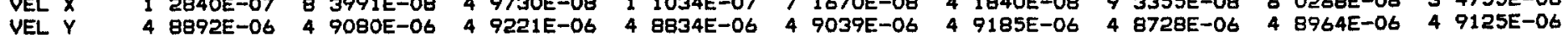


LISTING D-6. Output Report File for Test Case Two. (Sheet 46 of 48)

SAMPLE PROBLEM, FLOW AROUND A HEATED CANNISTER

RESULTS FDR VELOCITY (M/YR) OF YEAR 10 O0

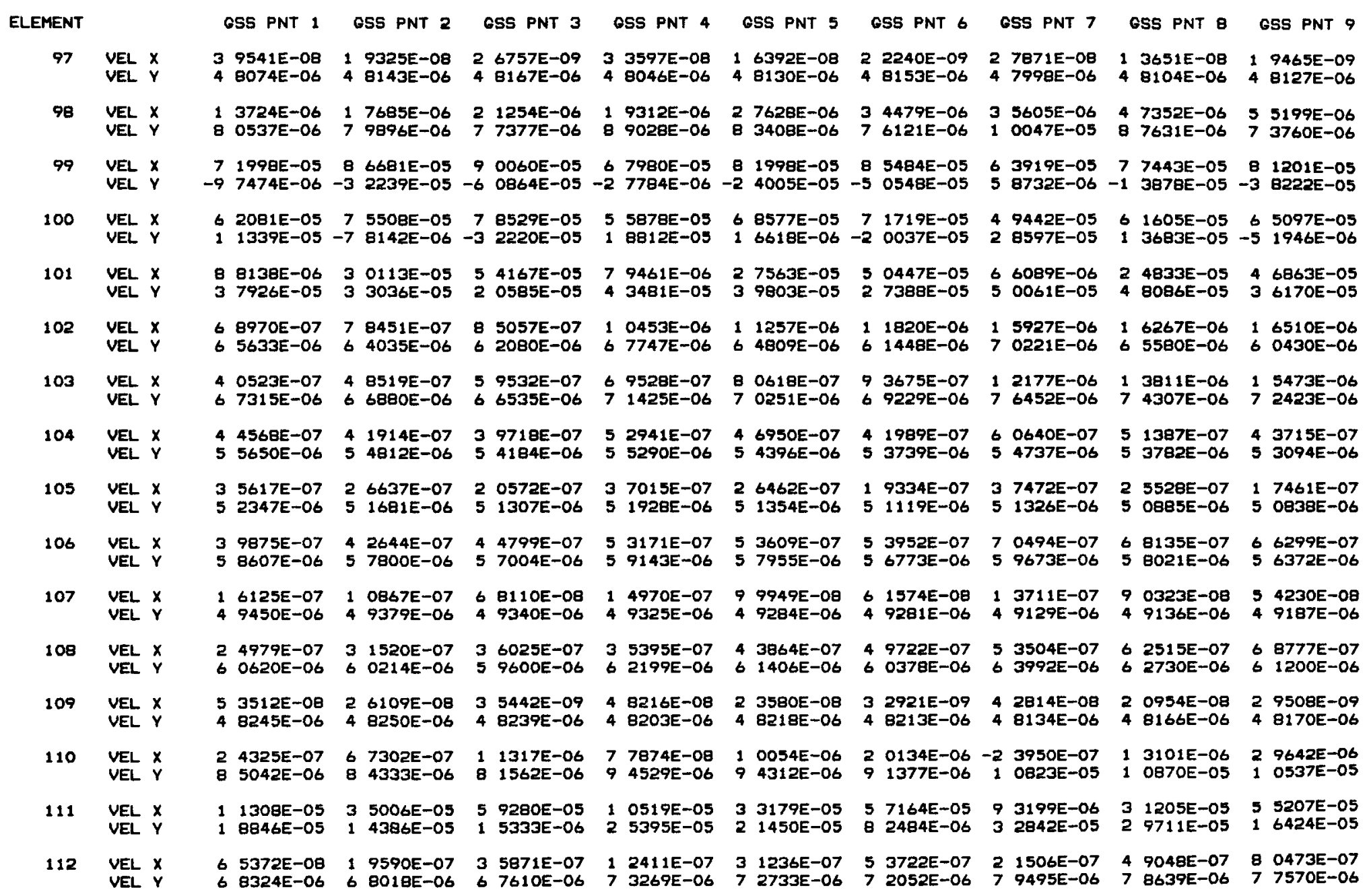


LISTING D-6. Output Report File for Test Case Two. (Sheet 47 of 48)

SAMPLE PROBLEM. FLOW AROUND A HEATED CANNISTER

RESULTS FOR VELOCITY (M/YR) OF YEAR 10 OO

\begin{tabular}{|c|c|c|c|c|c|c|c|c|c|c|c|c|c|c|c|}
\hline ELEMENT & & & GSS PNT 1 & CSS PNT 2 & & OSS PNT 3 & & CSS PNT 4 & & ASS PNT 5 & & DSS PNT 6 & GSS PNT 7 & GSS PNT $B$ & GSS PNT 9 \\
\hline 113 & $\begin{array}{l}\text { VEL } X \\
\text { VEL } Y\end{array}$ & & $\begin{array}{l}8072 E-07 \\
3927 E-06\end{array}$ & $\begin{array}{ll}3 & 7288 E-07 \\
6 & 3103 E-06\end{array}$ & & $\begin{array}{l}0293 E-07 \\
3322 E-06\end{array}$ & & $\begin{array}{l}5373 E-07 \\
5456 E-06\end{array}$ & & $\begin{array}{l}6597 E-07 \\
5393 E-06\end{array}$ & & $\begin{array}{l}4998 E-07 \\
4999 E-06\end{array}$ & $\begin{array}{ll}2 & 0547 \mathrm{E}-07 \\
6 & 1656 \mathrm{E}-06\end{array}$ & & \\
\hline 114 & $\begin{array}{l}\text { VEL } x \\
\text { VEL } Y\end{array}$ & $\begin{array}{l}1 \\
6\end{array}$ & $\begin{array}{l}6562 E-07 \\
1932 E-06\end{array}$ & $\begin{array}{ll}2 & 5283 E-07 \\
6 & 2361 E-06\end{array}$ & 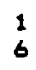 & $\begin{array}{l}1824 E-07 \\
0644 E-06\end{array}$ & $\begin{array}{l}1 \\
6\end{array}$ & $\begin{array}{l}4751 E-07 \\
2847 E-06\end{array}$ & $\begin{array}{l}7 \\
6\end{array}$ & $\begin{array}{l}8638 E-08 \\
1245 E-06\end{array}$ & & $\begin{array}{l}4597 E-07 \\
4313 E-06\end{array}$ & $\begin{array}{ll}2 & 2262 E-07 \\
6 & 0377 E-06\end{array}$ & & \\
\hline 115 & $\begin{array}{l}\text { VEL } X \\
\text { VEL } Y\end{array}$ & $\begin{array}{l}7 \\
6\end{array}$ & $\begin{array}{l}8571 E-08 \\
4774 E-06\end{array}$ & $\begin{array}{ll}1 & 5291 E-07 \\
6 & 6384 E-06\end{array}$ & 6 & $\begin{array}{l}1463 E-07 \\
3954 E-06\end{array}$ & $\begin{array}{r}-9 \\
6\end{array}$ & $\begin{array}{l}1043 E-09 \\
4123 E-06\end{array}$ & $\begin{array}{r}-4 \\
6\end{array}$ & $\begin{array}{l}7939 E-09 \\
2390 E-06\end{array}$ & 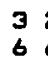 & $\begin{array}{l}2604 E-08 \\
6314 E-06\end{array}$ & $\begin{array}{l}27410 E-07 \\
6 \quad 6007 E-06\end{array}$ & & \\
\hline 116 & $\begin{array}{l}\text { VEL } X \\
\text { VEL } Y\end{array}$ & $\begin{array}{l}2 \\
5\end{array}$ & $\begin{array}{l}3837 E-07 \\
5442 E-06\end{array}$ & $\begin{array}{ll}2 & 4889 E-07 \\
5 & 5039 E-06\end{array}$ & $\begin{array}{l}2 \\
5\end{array}$ & $\begin{array}{l}\text { 5757E-07 } \\
4651 E-06\end{array}$ & $\begin{array}{l}2 \\
5\end{array}$ & $\begin{array}{l}9878 E-07 \\
5605 E-06\end{array}$ & $\frac{2}{5}$ & $\begin{array}{l}9891 E-07 \\
5023 E-06\end{array}$ & 5 & $\begin{array}{l}9901 E-07 \\
4453 E-06\end{array}$ & $\begin{array}{l}38107 E-07 \\
5 \text { 5810E-06 }\end{array}$ & $\begin{array}{ll}3 & 6880 E-07 \\
5 & 5034 E-06\end{array}$ & $\begin{array}{ll}3 & 5865 E-07 \\
5 & 4268 E-06\end{array}$ \\
\hline 117 & $\begin{array}{l}\text { VEL } X \\
\text { VEL } \\
Y\end{array}$ & $\begin{array}{l}2 \\
5\end{array}$ & $\begin{array}{l}5204 E-07 \\
3269 E-06\end{array}$ & $\begin{array}{ll}2 & 1533 E-07 \\
5 & 2471 E-06\end{array}$ & $\begin{array}{l}1 \\
5\end{array}$ & $\begin{array}{l}9053 E-07 \\
1869 E-06\end{array}$ & $\begin{array}{l}2 \\
5\end{array}$ & $\begin{array}{l}9542 E-07 \\
3019 E-06\end{array}$ & $\begin{array}{l}2 \\
5\end{array}$ & $\begin{array}{l}3773 E-07 \\
2217 E-06\end{array}$ & $\begin{array}{l}1 \\
5\end{array}$ & $\begin{array}{l}9975 E-07 \\
1616 E-06\end{array}$ & $\begin{array}{ll}3 & 3389 E-07 \\
5 & 2776 E-06\end{array}$ & $\begin{array}{ll}2 & 5616 E-07 \\
5 & 1959 E-06\end{array}$ & $\begin{array}{ll}2 & 0366 E-07 \\
5 & 1352 E-06\end{array}$ \\
\hline 118 & $\begin{array}{l}\text { VEL } x \\
\text { VEL } y\end{array}$ & $\begin{array}{l}1 \\
5\end{array}$ & $\begin{array}{l}7089 E-07 \\
6715 E-06\end{array}$ & $\begin{array}{ll}2 & 0060 E-07 \\
5 & 6469 E-06\end{array}$ & $\begin{array}{l}2 \\
5\end{array}$ & $\begin{array}{l}2359 E-07 \\
6145 E-06\end{array}$ & $\begin{array}{l}2 \\
5\end{array}$ & $\begin{array}{l}2554 E-07 \\
7435 E-06\end{array}$ & $\begin{array}{l}2 \\
5\end{array}$ & $\begin{array}{l}5968 E-07 \\
6974 E-06\end{array}$ & 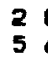 & $\begin{array}{l}8615 E-07 \\
6428 E-06\end{array}$ & $\begin{array}{ll}3 & 2062 E-07 \\
5 & 8230 E-06\end{array}$ & $\begin{array}{ll}3 & 5419 E-07 \\
5 & 7542 E-06\end{array}$ & $\begin{array}{ll}3 & 8028 E-07 \\
5 & 6761 E-06\end{array}$ \\
\hline 119 & $\begin{array}{l}\text { VEL } x \\
\text { VEL } y\end{array}$ & $\begin{array}{l}1 \\
5\end{array}$ & $\begin{array}{l}5691 E-07 \\
0234 E-06\end{array}$ & $\begin{array}{ll}1 & 1011 E-07 \\
4 & 9833 E-06\end{array}$ & 4 & $\begin{array}{l}\text { 4007E-08 } \\
9537 E-06\end{array}$ & $\begin{array}{l}1 \\
5\end{array}$ & $\begin{array}{l}6245 E-07 \\
0004 E-06\end{array}$ & $\begin{array}{l}1 \\
4\end{array}$ & $\begin{array}{l}1261 E-07 \\
9658 E-06\end{array}$ & $\begin{array}{l}7 \\
4\end{array}$ & $\begin{array}{l}4171 E-08 \\
9430 E-06\end{array}$ & $\begin{array}{ll}1 & 6347 E-07 \\
4 & 9760 E-06\end{array}$ & $\begin{array}{ll}1 & 1118 E-07 \\
4 & 9471 E-06\end{array}$ & $\begin{array}{ll}7 & 0848 E-08 \\
4 & 9315 E-06\end{array}$ \\
\hline 120 & $\begin{array}{l}\text { VEL } X \\
\text { VEL } Y\end{array}$ & $\begin{array}{l}9 \\
5\end{array}$ & $\begin{array}{l}6383 E-08 \\
7349 E-06\end{array}$ & $\begin{array}{ll}1 & 2864 E-07 \\
5 & 7263 E-06\end{array}$ & 5 & $\begin{array}{l}5059 E-07 \\
7093 E-06\end{array}$ & $\begin{array}{l}1 \\
5\end{array}$ & $\begin{array}{l}2624 E-07 \\
8446 E-06\end{array}$ & $\begin{array}{l}1 \\
5\end{array}$ & $\begin{array}{l}7337 E-07 \\
8227 E-06\end{array}$ & & $\begin{array}{l}0561 E-07 \\
7919 E-06\end{array}$ & $\begin{array}{ll}1 & 9735 E-07 \\
5 & 9638 E-06\end{array}$ & $\begin{array}{ll}2 & 5162 E-07 \\
5 & 9279 E-06\end{array}$ & $\begin{array}{ll}2 & 8892 E-07 \\
5 & 8826 E-06\end{array}$ \\
\hline 121 & $\begin{array}{l}\text { VEL } X \\
\text { VEL } Y\end{array}$ & $\begin{array}{l}5 \\
4\end{array}$ & $\begin{array}{l}7941 E-08 \\
8555 E-06\end{array}$ & $\begin{array}{ll}2 & 8155 E-08 \\
4 & B 440 E-06\end{array}$ & 4 & $\begin{array}{l}6283 E-09 \\
8365 E-06\end{array}$ & $\begin{array}{l}5 \\
4\end{array}$ & $\begin{array}{l}7153 E-08 \\
8473 E-06\end{array}$ & $\begin{array}{l}2 \\
4\end{array}$ & $\begin{array}{l}\text { 8055E-08 } \\
8369 E-06\end{array}$ & 4 & $\begin{array}{l}0947 E-09 \\
8315 E-06\end{array}$ & $\begin{array}{ll}5 & 5451 E-08 \\
4 & 8384 E-06\end{array}$ & $\begin{array}{ll}2 & 7130 E-08 \\
4 & 8292 E-06\end{array}$ & $\begin{array}{l}3 \text { 6089E-09 } \\
48260 E-06\end{array}$ \\
\hline 122 & $\begin{array}{l}\text { VEL } x \\
\text { VEL } Y\end{array}$ & $\begin{array}{l}9 \\
5\end{array}$ & $\begin{array}{l}5487 E-08 \\
7485 E-06\end{array}$ & $\begin{array}{ll}1 & 2979 E-07 \\
5 & 8638 E-06\end{array}$ & 5 & $\begin{array}{l}8491 E-07 \\
9889 E-06\end{array}$ & $\begin{array}{l}4 \\
5\end{array}$ & $\begin{array}{l}6455 E-08 \\
7553 E-06\end{array}$ & $\begin{array}{l}6 \\
5\end{array}$ & $\begin{array}{l}\text { 4107E-08 } \\
8759 E-06\end{array}$ & $\begin{array}{l}9 \\
6\end{array}$ & $\begin{array}{l}3625 E-08 \\
0066 E-06\end{array}$ & $\begin{array}{ll}2 & 3399 E-08 \\
5 & 7602 E-06\end{array}$ & $\begin{array}{ll}3 & 4102 E-08 \\
5 & 8058 E-06\end{array}$ & $\begin{array}{ll}5 & 3144 E-08 \\
6 & 0218 E-06\end{array}$ \\
\hline 123 & $\begin{array}{l}\text { VEL } X \\
\text { VEL } Y\end{array}$ & $\begin{array}{l}1 \\
5\end{array}$ & $\begin{array}{l}1487 E-07 \\
4892 E-06\end{array}$ & $\begin{array}{ll}1 & 2614 E-07 \\
5 & 4641 E-06\end{array}$ & $\begin{array}{l}1 \\
5\end{array}$ & $\begin{array}{l}3541 E-07 \\
4347 E-06\end{array}$ & $\begin{array}{l}1 \\
5\end{array}$ & $\begin{array}{l}5151 E-07 \\
5112 E-06\end{array}$ & $\begin{array}{l}1 \\
5\end{array}$ & $\begin{array}{l}6419 E-07 \\
4760 E-06\end{array}$ & $\begin{array}{l}1 \\
5\end{array}$ & $\begin{array}{l}7463 E-07 \\
4362 E-06\end{array}$ & $\begin{array}{ll}2 & 0099 E-07 \\
5 & 5360 E-06\end{array}$ & $\begin{array}{ll}2 & 1390 E-07 \\
5 & 4901 E-06\end{array}$ & $\begin{array}{ll}2 & 2454 E-07 \\
5 & 4391 E-06\end{array}$ \\
\hline 124 & $\begin{array}{l}\text { VEL } X \\
\text { VEL } Y\end{array}$ & $\begin{array}{l}1 \\
5\end{array}$ & $\begin{array}{l}3498 E-07 \\
3484 E-06\end{array}$ & $\begin{array}{ll}1 & 2620 E-07 \\
5 & 2775 E-06\end{array}$ & $\begin{array}{l}1 \\
5\end{array}$ & $\begin{array}{l}2027 E-07 \\
2062 E-06\end{array}$ & $\begin{array}{l}1 \\
5\end{array}$ & $\begin{array}{l}7753 E-07 \\
3453 E-06\end{array}$ & $\begin{array}{l}1 \\
5\end{array}$ & $\begin{array}{l}5965 E-07 \\
2693 E-06\end{array}$ & $\begin{array}{l}1 \\
5\end{array}$ & $\begin{array}{l}4757 E-07 \\
1924 E-06\end{array}$ & $\begin{array}{ll}2 & 2035 E-07 \\
5 & 3433 E-06\end{array}$ & $\begin{array}{l}1 \quad 9332 E-07 \\
5 \\
2615 E-06\end{array}$ & $\begin{array}{ll}1 & 7505 E-07 \\
5 & 1784 E-06\end{array}$ \\
\hline 125 & $\begin{array}{l}\text { VEL } X \\
\text { VEL } Y\end{array}$ & $\begin{array}{l}7 \\
5\end{array}$ & $\begin{array}{l}6589 E-08 \\
5607 E-06\end{array}$ & $\begin{array}{ll}9 & 3288 E-00 \\
5 & 5462 E-06\end{array}$ & $\begin{array}{l}1 \\
5\end{array}$ & $\begin{array}{l}0614 E-07 \\
5263 E-06\end{array}$ & $\begin{array}{l}1 \\
5\end{array}$ & $\begin{array}{l}0429 E-07 \\
6009 E-06\end{array}$ & $\begin{array}{l}1 \\
5\end{array}$ & $\begin{array}{l}2618 E-07 \\
5800 E-06\end{array}$ & $\begin{array}{l}1 \\
5\end{array}$ & $\begin{array}{l}4306 E-07 \\
5534 E-06\end{array}$ & $\begin{array}{ll}1 & 4336 E-07 \\
5 & 6448 E-06\end{array}$ & $\begin{array}{ll}1 & 6901 E-07 \\
5 & 6172 E-06\end{array}$ & $\begin{array}{ll}1 & 8884 E-07 \\
5 & 5835 E-06\end{array}$ \\
\hline 126 & $\begin{array}{l}\text { VEL } X \\
\text { VEL } Y\end{array}$ & $\begin{array}{l}1 \\
5\end{array}$ & $\begin{array}{l}0334 E-07 \\
0812 E-06\end{array}$ & $\begin{array}{ll}7 & 4586 E-08 \\
5 & 0166 E-06\end{array}$ & $\begin{array}{l}5 \\
4\end{array}$ & $\begin{array}{l}2411 E-08 \\
9655 E-06\end{array}$ & $\begin{array}{l}1 \\
5\end{array}$ & $\begin{array}{l}2676 E-07 \\
0665 E-06\end{array}$ & $\begin{array}{l}9 \\
5\end{array}$ & $\begin{array}{l}0573 E-08 \\
0044 E-06\end{array}$ & $\begin{array}{l}6 \\
4\end{array}$ & $\begin{array}{l}2659 E-08 \\
9569 E-06\end{array}$ & $\begin{array}{ll}1 & 4707 E-07 \\
5 & 0514 E-06\end{array}$ & $\begin{array}{ll}1 & 0384 E-07 \\
4 & 9919 E-06\end{array}$ & $\begin{array}{l}7 \text { O499E-OB } \\
49478 E-06\end{array}$ \\
\hline 127 & $\begin{array}{l}\text { VEL } X \\
\text { VEL } Y\end{array}$ & $\begin{array}{l}4 \\
5\end{array}$ & $\begin{array}{l}2379 E-08 \\
5930 E-06\end{array}$ & $\begin{array}{ll}5 & 7681 E-0 B \\
5 & 5877 E-06\end{array}$ & $\begin{array}{l}6 \\
5\end{array}$ & $\begin{array}{l}\text { 7967E-08 } \\
5790 E-06\end{array}$ & $\begin{array}{l}5 \\
5\end{array}$ & $\begin{array}{l}7716 E-08 \\
6429 E-06\end{array}$ & $\begin{array}{l}7 \\
5\end{array}$ & $\begin{array}{l}8645 E-08 \\
6343 E-06\end{array}$ & $\begin{array}{l}9 \\
5\end{array}$ & $\begin{array}{l}2783 E-08 \\
6221 E-06\end{array}$ & $\begin{array}{ll}8 & 2858 E-08 \\
5 & 6970 E-06\end{array}$ & $\begin{array}{ll}1 & 0751 E-07 \\
5 & 6850 E-06\end{array}$ & $\begin{array}{ll}1 & 2425 E-07 \\
5 & 6691 E-06\end{array}$ \\
\hline 128 & $\begin{array}{l}\text { VEL } X \\
\text { VEL } Y\end{array}$ & $\begin{array}{l}4 \\
4\end{array}$ & $\begin{array}{l}2343 E-08 \\
8875 E-06\end{array}$ & $\begin{array}{ll}2 & 0130 E-08 \\
4 & 8611 E-06\end{array}$ & $\begin{array}{l}1 \\
4\end{array}$ & $\begin{array}{l}\text { 8389E-09 } \\
8475 E-06\end{array}$ & $\begin{array}{l}4 \\
4\end{array}$ & $\begin{array}{l}9626 E-08 \\
8802 E-06\end{array}$ & $\begin{array}{l}2 \\
4\end{array}$ & $\begin{array}{l}4057 E-08 \\
8548 E-06\end{array}$ & $\begin{array}{l}3 \\
4\end{array}$ & $\begin{array}{l}0014 E-09 \\
8433 E-06\end{array}$ & $\begin{array}{ll}5 & 5945 E-08 \\
4 & 8725 E-06\end{array}$ & $\begin{array}{l}27112 E-08 \\
48482 E-06\end{array}$ & $\begin{array}{l}3 \text { 3702E-09 } \\
4 \text { B388E-06 }\end{array}$ \\
\hline
\end{tabular}


LISTING D-6. Output Report File for Test Case Two. (Sheet 48 of 48)

SAMPLE PROBLEM, FLOW ARDUND A HEATED CANNISTER

RESULTS FOR VELOCITY (M/YR) OF YEAR 10.00

\begin{tabular}{|c|c|c|c|c|c|c|c|c|c|c|}
\hline ELEMENT & & ESS PNT 1 & OSS PNT 2 & GSS PNT 3 & GSS PNT 4 & GSS PNT 5 & GSS PNT 6 & GSS PNT 7 & GSS PNT B & GSS PNT \\
\hline 129 & $\begin{array}{l}\text { VEL } X \\
\text { VEL } Y\end{array}$ & $\begin{array}{l}\text { 4. } 1871 E-08 \\
\text { 5. } 5999 E-06\end{array}$ & $\begin{array}{l}\text { 5. } 8084 E-08 \\
5.6512 E-06\end{array}$ & $\begin{array}{l}\text { 7. } 8800 E-08 \\
\text { 5. } 7067 E-06\end{array}$ & $\begin{array}{l}\text { 2. } 0664 E-08 \\
\text { 5. } 6036 E-06\end{array}$ & $\begin{array}{l}\text { 2. } 8301 E-08 \\
\text { 5. } 6561 E-06\end{array}$ & $\begin{array}{l}\text { 3. } 8414 E-08 \\
\text { 5. } 7129 E-06\end{array}$ & $\begin{array}{l}9.9494 E-09 \\
5.6060 E-06\end{array}$ & $\begin{array}{l}\text { 1. } 3659 E-08 \\
5.6596 E-06\end{array}$ & $\begin{array}{l}\text { 1. } 9106 E-08 \\
\text { 5. } 7176 E-06\end{array}$ \\
\hline 130 & $\begin{array}{l}\text { VEL } x \\
\text { VEL } Y\end{array}$ & $\begin{array}{l}\text { 1. } 0633 E-08 \\
\text { 5. } 4672 E-06\end{array}$ & $\begin{array}{l}\text { 1. } 1856 E-08 \\
\text { 5. } 4404 E-06\end{array}$ & $\begin{array}{l}\text { 1. } 2859 E-08 \\
\text { 5. } 4079 E-06\end{array}$ & $\begin{array}{l}\text { 4. } 9058 E-08 \\
\text { 5. } 4756 E-06\end{array}$ & $\begin{array}{l}\text { 5. } 4393 E-08 \\
\text { 5. } 4456 E-06\end{array}$ & $\begin{array}{l}\text { 5. } 1772 E-08 \\
\text { 5. } 4097 E-06\end{array}$ & $\begin{array}{l}\text { 9. } 0513 E-0 B \\
\text { 5. } 4854 E-06\end{array}$ & $\begin{array}{l}\text { 9. } 9714 E-08 \\
5.4521 E-06\end{array}$ & $\begin{array}{l}1.0728 E-07 \\
5.4126 E-06\end{array}$ \\
\hline 131 & $\begin{array}{l}\text { VEL } x \\
\text { VEL } Y\end{array}$ & $\begin{array}{l}\text { 1. } 3813 E-08 \\
\text { 5. } 3594 E-06\end{array}$ & $\begin{array}{l}\text { 1. } 3072 E-08 \\
\text { 5. } 2847 E-06\end{array}$ & $\begin{array}{l}\text { 1. } 2572 E-08 \\
\text { 5. } 1980 E-06\end{array}$ & $\begin{array}{l}\text { 6. } 0608 E-08 \\
\text { 5. } 3597 E-06\end{array}$ & $\begin{array}{l}\text { 5. } 7451 E-08 \\
\text { 5. } 2831 E-06\end{array}$ & $\begin{array}{l}\text { 5. } 5317 E-08 \\
\text { 5. } 1937 E-06\end{array}$ & $\begin{array}{l}\text { 1. } 0636 E-07 \\
\text { 5. } 3609 E-06\end{array}$ & $\begin{array}{l}\text { 1. } 0099 E-07 \\
\text { 5. } 2820 E-06\end{array}$ & $\begin{array}{l}\text { 9. } 7357 E-08 \\
\text { 5. } 1897 E-06\end{array}$ \\
\hline 132 & $\begin{array}{l}\text { VEL } X \\
\text { VEL } Y\end{array}$ & $\begin{array}{l}\text { 7. } 1111 E-09 \\
\text { 5. 5205E-06 }\end{array}$ & $\begin{array}{l}\text { 8. } 7994 E-09 \\
\text { 5. 5066E-06 }\end{array}$ & $\begin{array}{l}\text { 1. } 0092 E-08 \\
\text { 5. } 4878 E-06\end{array}$ & $\begin{array}{l}\text { 3. } 2659 E-08 \\
\text { 5. } 5334 E-06\end{array}$ & $\begin{array}{l}\text { 4. } 0017 E-08 \\
\text { 5. 5181E-06 }\end{array}$ & $\begin{array}{l}\text { 4. } 5661 E-08 \\
\text { 5. } 4976 E-06\end{array}$ & $\begin{array}{l}\text { 5. } 9915 E-08 \\
\text { 5. } 5480 E-06\end{array}$ & $\begin{array}{l}\text { 7. } 2743 \mathrm{E}-08 \\
\text { 5. } 5312 \mathrm{E}-06\end{array}$ & $\begin{array}{l}\text { 8. } 2605 E-08 \\
\text { 5. } 5090 E-06\end{array}$ \\
\hline 133 & $\begin{array}{l}\text { VEL } X \\
\text { VEL } Y\end{array}$ & $\begin{array}{l}\text { 1. } 1336 E-08 \\
\text { 5. } 1153 E-06\end{array}$ & $\begin{array}{l}\text { 8. } 3051 E-09 \\
\text { 5. } 0315 E-06\end{array}$ & $\begin{array}{l}\text { 5. } 9674 E-09 \\
\text { 4. } 9622 E-06\end{array}$ & $\begin{array}{l}\text { 4. } 8954 E-08 \\
\text { 5. } 1102 E-06\end{array}$ & $\begin{array}{l}\text { 3. } 5681 E-08 \\
\text { 5. } 0271 E-06\end{array}$ & $\begin{array}{l}\text { 2. } 5443 E-08 \\
\text { 4. } 9590 E-06\end{array}$ & $\begin{array}{l}\text { 8. } 4501 E-08 \\
\text { 5. } 1053 E-06\end{array}$ & $\begin{array}{l}\text { 6. } 1252 E-08 \\
\text { 5. } 0226 E-06\end{array}$ & $\begin{array}{l}\text { 4. } 3320 E-O \\
\text { 4. } 9557 E-0\end{array}$ \\
\hline 134 & $\begin{array}{l}\text { VEL } X \\
\text { VEL } Y\end{array}$ & $\begin{array}{l}\text { 3. } 8021 E-09 \\
\text { 5. } 5431 E-06\end{array}$ & $\begin{array}{l}\text { 5. } 3389 E-09 \\
\text { 5. 5380E-06 }\end{array}$ & $\begin{array}{l}\text { 6. } 3587 E-09 \\
\text { 5. } 5301 E-06\end{array}$ & $\begin{array}{l}\text { 1. } 7815 E-08 \\
\text { 5. } 5583 E-06\end{array}$ & $\begin{array}{l}\text { 2. } 4490 E-08 \\
\text { 5. } 5525 E-06\end{array}$ & $\begin{array}{l}\text { 2. } 8942 E-08 \\
\text { 5. } 5437 E-06\end{array}$ & $\begin{array}{l}\text { 3. } 3468 E-08 \\
\text { 5. } 5753 E-06\end{array}$ & $\begin{array}{l}\text { 4. } 4934 E-08 \\
\text { 5. } 5687 E-06\end{array}$ & $\begin{array}{l}\text { 5. } 2620 E-0 \\
\text { 5. } 5590 E-0\end{array}$ \\
\hline 135 & $\begin{array}{l}\text { VEL } X \\
\text { VEL } Y\end{array}$ & $\begin{array}{l}\text { 4. } 7136 E-09 \\
4.9093 E-06\end{array}$ & $\begin{array}{l}\text { 2. } 3158 E-09 \\
\text { 4. } 8689 E-06\end{array}$ & $\begin{array}{l}\text { 3. } 4133 E-10 \\
\text { 4. } 8525 E-06\end{array}$ & $\begin{array}{l}\text { 2. } 0447 E-08 \\
\text { 4. } 9064 E-06\end{array}$ & $\begin{array}{l}\text { 9. } 8645 E-09 \\
\text { 4. } 8661 E-06\end{array}$ & $\begin{array}{l}\text { 1. } 1508 E-09 \\
\text { 4. } 8509 E-06\end{array}$ & $\begin{array}{l}\text { 3. } 5477 E-08 \\
\text { 4. } 9033 E-06\end{array}$ & $\begin{array}{l}\text { 1. } 6779 E-08 \\
\text { 4. } 8632 E-06\end{array}$ & $\begin{array}{l}\text { 1. } 3819 E-0 \\
\text { 4. } 8493 E-0\end{array}$ \\
\hline 136 & $\begin{array}{l}\text { VEL } X \\
\text { VEL } Y\end{array}$ & $\begin{array}{l}\text { 3. } 7762 E-09 \\
\text { 5. } 5467 E-06\end{array}$ & $\begin{array}{l}\text { 1. } 7458 E-08 \\
\text { 5. } 5622 E-06\end{array}$ & $\begin{array}{l}\text { 3. } 2083 E-08 \\
\text { 5. } 5795 E-06\end{array}$ & $\begin{array}{l}\text { 1. } 9475 E-09 \\
\text { 5. } 5500 E-06\end{array}$ & $\begin{array}{l}\text { 8. } 8549 E-09 \\
\text { 5. } 5658 E-06\end{array}$ & $\begin{array}{l}\text { 1. } 6045 E-08 \\
\text { 5. } 5834 E-06\end{array}$ & $\begin{array}{l}\text { 9. } 5869 \mathrm{E}-10 \\
\text { 5. } 5523 \mathrm{E}-06\end{array}$ & $\begin{array}{l}\text { 4. } 3218 E-09 \\
\text { 5. } 5683 E-06\end{array}$ & $\begin{array}{l}\text { 7. } 8138 E-09 \\
\text { 5. } 5861 E-06\end{array}$ \\
\hline
\end{tabular}


RHO-BW-CR-143 P

This page intentionally left blank. 


\section{APPENDIX E}

\section{DIAGNOSTIC MESSAGES}

The MAGNUM-2D computer code has evolved to the current version ( 3.1$)$ over a number of years and has been tested with a variety of problems. It is therefore expected to provide trouble-free operation. However, for a computer program of such complexity, it is possible that difficulties may be encountered in its application. Moreover, any such problems are likely to arise from a lack of familiarity with the various features and input formats. Hence, MAGNUM-2D has the additional capability of diagnosing some possible input errors and a few run-time errors and generating appropriate warning/error messages.

The possible diagnostic messages as printed by MAGNUM-2D are reproduced in Table E-1 along with possible causes and/or corrective user action. Furthermore, since the input to MAGNUM-2D is in fixed format, the foremost remedial action is simply an exhaustive search of the inputs for incorrect data formatting. If unresolvable difficulties are encountered in the application of MAGNUM-2D to a we11-posed problem, please contact the authors. 
TABLE E-1: MAGNUM-2D Diagnostics. (Sheet 1 of 4 )

\begin{tabular}{|c|c|}
\hline MESSAGE & CAUSE/CORRECTIVEACTION \\
\hline \multicolumn{2}{|l|}{ 1) PROGRAM CONTROL (CARD TYPES B, C, D) } \\
\hline $\begin{array}{l}\text { THE TEMPERATURE INPUT OPTION REQUIRES } \\
\text { THAT A TEMPERATURE INPUT FILE BE SPECIFIED. } \\
\text { ERROR STOP IN ROUTINE INPUTS. }\end{array}$ & $\begin{array}{l}\text { The temperature input file option has been } \\
\text { selected, but no logical unit for the } \\
\text { temperature input file has been specified. }\end{array}$ \\
\hline $\begin{array}{l}\text { BOTH TEMPERATURE AND MOISTURE ARE } \\
\text { INACTIVE. } \\
\text { ERROR STOP IN ROUTINE INPUTS. }\end{array}$ & $\begin{array}{l}\text { Neither heat transfer nor fluid flow has been } \\
\text { selected. }\end{array}$ \\
\hline $\begin{array}{l}\text { TOO MANY NODES REQUESTED. LIMIT IS n. } \\
\text { ERROR STOP IN ROUTINE INPUTS. }\end{array}$ & $\begin{array}{l}\text { Either decrease the problem size or increase the } \\
\text { node limit (MAXP). }\end{array}$ \\
\hline $\begin{array}{l}\text { TOO MANY ELEMENTS REQUESTED. LIMIT IS n. } \\
\text { ERROR STOP IN ROUTINE INPUTS. }\end{array}$ & $\begin{array}{l}\text { Either decrease the problem size or increase the } \\
\text { element limit (MAXE). }\end{array}$ \\
\hline $\begin{array}{l}\text { TOO MANY MATERIAL TYPES REQUESTED. LIMIT } \\
\text { IS } n \text {. } \\
\text { ERROR STOP IN ROUTINE INPUTS. }\end{array}$ & $\begin{array}{l}\text { Either decrease the problem size or increase the } \\
\text { material type limit (MAXMAT). }\end{array}$ \\
\hline $\begin{array}{l}\text { **WARNING: THE INTEGRATION CONSTANT ** } \\
\text { * IS OUT OF THE SUGGESTED RANGE }(1 \text { TO } 2)^{*}\end{array}$ & $\begin{array}{l}\text { Check the value of the integration constant } \\
\text { echoed in the report file. }\end{array}$ \\
\hline \multicolumn{2}{|l|}{ II) TIME STEPS (CARD TYPE E) } \\
\hline $\begin{array}{l}\text { TOO MANY TIME STEPPING DEFINITION CARDS } \\
\text { ARE PRESENT IN THE INPUT DATA FILE. THE } \\
\text { PROGRAM LIMIT IS N. } \\
\text { ERROR STOP IN ROUTINE INPUTS. }\end{array}$ & $\begin{array}{l}\text { Decrease the number of time step cards or } \\
\text { increase the limit (NTT). Terminator card may } \\
\text { have been omitted. }\end{array}$ \\
\hline \multicolumn{2}{|l|}{$\begin{array}{l}\text { III) GEOMETRY INPUT (CARD TYPES G, H, OR } \\
\text { EXTERNAL FILE) }\end{array}$} \\
\hline $\begin{array}{l}\text { GEOMETRY HAS N NODES THIS DOES NOT } \\
\text { EQUAL THE NUMBER GIVEN IN THE PROBLEM } \\
\text { SPECIFICATIONS DATA. } \\
\text { ERROR STOP IN ROUTINE INPUTS. }\end{array}$ & $\begin{array}{l}\text { The number of nodes, } n \text {, in the geometry input } \\
\text { does not equal the number specified on card } \\
\text { type } B \text {. }\end{array}$ \\
\hline $\begin{array}{l}\text { GEOMETRY HAS } ~ E L E M E N T S \text {. THIS DOES NOT } \\
\text { EQUAL THE NUMBER GIVEN IN THE PROBLEM } \\
\text { SPECIFICATION DATA. } \\
\text { ERROR STOP IN ROUTINE INPUTS. }\end{array}$ & $\begin{array}{l}\text { The number of elements, } n \text {, in the geometry } \\
\text { input does not equal the number specified on } \\
\text { card type } B \text {. }\end{array}$ \\
\hline $\begin{array}{l}\text { THE CHOICE OF AXISYMMETRIC COORDINATES } \\
\text { IS INCOMPATIBLE WITH THE GEOMETRY. } \\
\text { MINIMUMX < O. } \\
\text { ERROR STOP IN ROUTINE INPUTS. }\end{array}$ & $\begin{array}{l}\text { For an axisymmetric radial coordinate system } \\
\text { the axis of symmetry is the line } x=0 \text {, and hence, } \\
\text { all } x \text {-coordinates should be nonnegative. }\end{array}$ \\
\hline $\begin{array}{l}\text { ERROR AT ELEMENT } m \text { MATERIAL TYPE } n \text { IS OUT } \\
\text { OF RANGE. } \\
\text { ERROR STOP IN ROUTINE INPUTS. }\end{array}$ & $\begin{array}{l}\text { For element number } m \text { the material type } \\
\text { index } n \text { is greater than the number of material } \\
\text { types specified in card type } B \text {. }\end{array}$ \\
\hline $\begin{array}{l}\text { ERROR IN THE ORDERING ARRAY, ELEMENT } n \\
\text { DOES NOT APPEAR. } \\
\text { ERROR STOP IN ROUTINE INPUTS. }\end{array}$ & $\begin{array}{l}\text { Element number } n \text { is not assigned an ordering } \\
\text { index in card type } G \text {. }\end{array}$ \\
\hline
\end{tabular}


TABLE E-1: MAGNUM-2D Diagnostics. (Sheet 2 of 4 )

\begin{tabular}{|c|c|}
\hline MESSAGE & CAUSE/CORRECTIVE ACTION \\
\hline $\begin{array}{l}\text { IV) INITIAL CONDITIONS (CARD TYPES }\rfloor 1, J 2 \text {, AND } \\
\text { EXTERNAL FILE) }\end{array}$ & \\
\hline $\begin{array}{l}\text { THE RESTART FILE HAS } m 1 \text { NODES AND } n 1 \\
\text { RECORDS THE CURRENT PROBLEM HAS m2 } \\
\text { NODES AND } 2 \text { RECORDS CHANGING THESE } \\
\text { NUMBERS IS NOT PERMITTED ON RESTART } \\
\text { ERROR STOP IN ROUTINE INPUTS }\end{array}$ & $\begin{array}{l}\text { The restart file contains problem size } \\
\text { specifications that are incompatible with those } \\
\text { contained in card type B }\end{array}$ \\
\hline $\begin{array}{l}\text { ERROR IN THE INITIAL CONDITION INPUT, NODE } \\
\text { IS OUT OF RANGE } \\
\text { ERROR STOP IN ROUTINE INPUTS }\end{array}$ & $\begin{array}{l}\text { Node number } n \text { is assigned initial values, but } \\
\text { does not exist in the problem geometry }\end{array}$ \\
\hline $\begin{array}{l}\text { ERROR IN THE INITIAL CONDITION INPUT, NODE } \\
\text { DOES NOT GET INITIALIZED } \\
\text { ERROR STOP IN ROUTINE INPUTS }\end{array}$ & $\begin{array}{l}\text { Initial conditions are being input on a nodal } \\
\text { basis (Eq } 11 \text { ), but no initial values are assigned } \\
\text { to node number } n\end{array}$ \\
\hline $\begin{array}{l}\text { V) BOUNDARY CONDITIONS (CARD TYPES K1, } \\
\text { K2) }\end{array}$ & \\
\hline $\begin{array}{l}\text { TOO MANY BOUNDARY NODES, } m \text { REQUESTED, } \\
\text { PROBLEM ONLY HAS } N \text { NODES } \\
\text { ERROR STOP IN ROUTINE INPUTS }\end{array}$ & $\begin{array}{l}\text { The number, } m \text {, of specified boundary } \\
\text { conditions exceeds the total number, } n \text {, of } \\
\text { nodes }\end{array}$ \\
\hline $\begin{array}{l}\text { ERROR IN BOUNDARY CONDITIONS, NODE } n \text { IS } \\
\text { OUT OF RANGE } \\
\text { ERROR STOP IN ROUTINE INPUTS }\end{array}$ & $\begin{array}{l}\text { Node number } n \text { is assigned a boundary value, } \\
\text { but does not exist in the problem geometry }\end{array}$ \\
\hline $\begin{array}{l}\text { ERROR IN BOUNDARY CONDITIONS, NODE } m \text { IS A } \\
\text { DUPLICATE, LINE N OF BOUNDARY NODE LIST } \\
\text { ERROR STOP IN ROUTINE INPUTS }\end{array}$ & $\begin{array}{l}\text { Node number } m \text { is twice assigned a boundary } \\
\text { value for one transport variable }\end{array}$ \\
\hline $\begin{array}{l}\text { * } \text { WARNING ELEMENT n CONSISTS SOLELY * * } \\
\text { * OF SPECIFIED NODES }\end{array}$ & $\begin{array}{l}\text { All nodal values in element } n \text { are fixed and will } \\
\text { not change during the simulation }\end{array}$ \\
\hline VI) MATERIAL PROPERTIES (CARD TYPE M) & \\
\hline $\begin{array}{l}\text { ERROR IN ROCK PROPERTIES INPUT, MATERIAL } \\
\text { TYPE } n \text { IS OUT OF RANGE } \\
\text { ERROR STOP IN ROUTINE INPUTS }\end{array}$ & $\begin{array}{l}\text { Material type number } n \text { is greater than the } \\
\text { number of material types specified on card } \\
\text { type } B\end{array}$ \\
\hline $\begin{array}{l}\text { ERROR IN ROCK PROPERTIES INPUT, ELEMENT } m \text {, } \\
\text { MATERIAL TYPE N NO MATERIAL PROPERTY } \\
\text { DATA HAS BEEN READ FOR THIS MATERIAL TYPE } \\
\text { ERROR STOP IN ROUTINE INPUTS }\end{array}$ & $\begin{array}{l}\text { Element number } m \text { is assigned a nonexistent } \\
\text { material type }\end{array}$ \\
\hline $\begin{array}{l}\text { ** WARNING LINE ELEMENTS OF ZERO FRAC- } \\
\text { * TURE WIDTH HAVE BEEN FOUND THESE } \\
\text { **ELEMENT WIDTHS WILL BE SET TO UNITY } \\
\star\end{array}$ & $\begin{array}{l}\text { The default fracture aperture for a line element } \\
\text { is one length unit }\end{array}$ \\
\hline $\begin{array}{l}\text { ERROR IN ROCK PROPERTIES INPUT CONTINUUM } \\
\text { ELEMENT NUMBER M HAS NON-ZERO FRACTURE } \\
\text { WIDTH ERROR STOP IN ROUTINE INPUTS }\end{array}$ & $\begin{array}{l}\text { Fracture aperture has no meanıng for a two- } \\
\text { dımensional element ( } c f \text { card type } M \text { ) }\end{array}$ \\
\hline
\end{tabular}


TABLE E-1: MAGNUM-2D Diagnostics. (Sheet 3 of 4)

\begin{tabular}{l} 
MESSAGE \\
\hline VII) GEOMETRY FILE READ ERRORS \\
ERROR READING GEOMETRY FILE HEADER \\
RECORD. \\
ERROR STOP IN ROUTINE INPUTS. \\
ERROR READING GEOMETRY ELEMENT \\
RECORDS. \\
ERROR STOP IN ROUTINE INPUTS. \\
ERROR READING GEOMETRY NODE \\
COORDINATES. \\
ERROR STOP IN ROUTINE INPUTS. \\
\hline VIII) HEAT SOURCE (CARD TYPE P, R1, R2) \\
ERROR, M HEAT SOURCE ELEMENTS EXCEEDS \\
PROGRAM MAXIMUM OF $~$ \\
ERROR STOP IN ROUTINE LOADQ. \\
ERROR, M THERMAL LOAD POINTS EXCEED THE \\
PROGRAM MAXIMUM OF $~$ \\
ERROR STOP IN ROUTINE LOADQ. \\
* * WARNING: THERMAL LOADS ARE SET TO * * \\
* ZERO FOR STEADY STATE RUNS.
\end{tabular}

IX) TEMPERATURE INPUT FILE ERRORS

ERROR, $n$ COMPONENTS ON TEMPERATURE

INPUT FILE. INPUT REQUIRES ONLY ONE

COMPONENT ON THIS FILE.

ERROR STOP IN ROUTINE HEADR.

ERROR, $M$ DATA POINTS ON TEMPERATURE

INPUT FILE. INPUT REQUIRES $\cap$ NODES TO

MATCH CURRENT GEOMETRY SIZE.

ERROR STOP IN ROUTINE HEADR.

**WARNING: TEMPERATURE INPUT FILE HAS $* *$

* MOISTURE DATA ON IT, OR WAS NOT GENER-*

**ATED BY MAGNUM-2D

A read error or EOF occurred while reading the geometry file header record.

A read error or EOF occurred while reading the geometry file connectivity records.

A read error or EOF occurred while reading the geometry file nodal coordinate records.

ERROR OR END OF FILE ENCOUNTERED AT

TEMPERATURE INPUT FILE HEADER READ.

ERROR STOP IN ROUTINE HEADR.

THE INPUT TEMPERATURE FILE BEGINS AT

TIME X, WHICH EXCEEDS THE SIMULATION

INITIAL TIME.

ERROR STOP IN MAIN ROUTINE.

THE INPUT TEMPERATURE FILE ENDS AT TIME $X$, AFTER READING $\cap$ RECORDS.

ERROR STOP IN MAIN ROUTINE.

ERROR READING TEMPERATURE FILE AT TIME $x$, AFTER READING $\cap$ RECORDS.

ERROR STOP IN MAIN ROUTINE.

Either decrease the number of heat source elements or increase the program limit (MAXH).

Either decrease the number of points defining the source profile or increase the program limit (MAXT).

Heat source options may not be used with steady-state runs. (cf. Section 3.5).

The temperature input file must contain temperature data only.

There must be a one-to-one correspondence between the number of nodal temperatures in the temperature input file and the number of nodes in the current geometry.

The temperature input file header does not correspond to the expected format.

A read error or EOF occurred while reading the temperature input file header record.

The temperature input file contains data for times that do not correspond to current simulation times.

The temperature file ends prematurely.

Read error occurred while reading data records from the temperature input file. 
TABLE E-1: MAGNUM-2D Diagnostics. (Sheet 4 of 4)

\begin{tabular}{|c|c|}
\hline MESSAGE & CAUSE/CORRECTIVE ACTION \\
\hline \multicolumn{2}{|l|}{ X) EXECUTION ERRORS } \\
\hline $\begin{array}{l}\text { NO ACTIVE ELEMENTS FOUND IN GEOMETRY. } \\
\text { ERROR STOP IN ROUTINE SETUP. }\end{array}$ & Every node is a boundary node. \\
\hline $\begin{array}{l}\text { ERROR IN NODE SEQUENCING. } m \text { NODES } \\
\text { PERMITTED. TWICE THAT NUMBER OF } \\
\text { EQUATIONS ARE PERMITTED. n EQUATIONS } \\
\text { HAVE BEEN SET UP FOR THIS PROBLEM. } \\
\text { ERROR STOP IN ROUTINE SETUP. }\end{array}$ & $\begin{array}{l}\text { Array storage is overutilized by the solver. } \\
\text { Check geometry and especially the element } \\
\text { ordering. }\end{array}$ \\
\hline $\begin{array}{l}\text { TEMPERATURE INPUT TO FPROP IS OUT OF } \\
\text { RANGE AT NODE } \mathrm{m} \text {, TEMPERATURE IS } \mathrm{x} \text {. } \\
\text { ALLOWABLE RANGE IS FROM Y TO } z \text {. } \\
\text { SIMULATION TIME IS } \mathrm{t} \text {. } \\
\text { ERROR STOP IN ROUTINE FPROP. }\end{array}$ & $\begin{array}{l}\text { Empirical relations employed in updating } \\
\text { temperature-dependent material properties } \\
\text { are only valid in the indicated range. }\end{array}$ \\
\hline $\begin{array}{l}\text { NELL }=m \text { IS GREATER THAN MAXE }(=n) . \text { ERROR } \\
\text { STOP IN ROUTINE FRONT. }\end{array}$ & $\begin{array}{l}\text { Possible incompatibility between element } \\
\text { connectivity and element ordering. }\end{array}$ \\
\hline $\begin{array}{l}\text { LCOL }=m, \text { NELL }=n \text {. } \\
\text { THE DIFFERENCE (NMAX-NCRIT) IS NOT } \\
\text { SUFFICIENTLY LARGE TO PERMIT THE ASSEMBLY } \\
\text { OF THE NEXT ELEMENT. EITHER INCREASE NMAX } \\
\text { OR LOWER NCRIT. (POSSIBLE GEOMETRY BAND- } \\
\text { WIDTH/ORDERING ERROR). ERROR STOP IN } \\
\text { ROUTINE FRONT. }\end{array}$ & $\begin{array}{l}\text { The frontwidth requires adjustment to arrange } \\
\text { storage as indicated, or optimization of } \\
\text { element ordering. }\end{array}$ \\
\hline $\begin{array}{l}\text { END OF FILE ENCOUNTERED ON FILE } n . \\
\text { ERROR STOP IN ROUTINE RED. }\end{array}$ & $\begin{array}{l}\text { An EOF occurred while reading the scratch file } \\
\text { used by the solver. }\end{array}$ \\
\hline $\begin{array}{l}\text { WARNING: MATRIX SINGULAR OR ILL- } \\
\text { CONDITIONED, X IS LESS THAN Y, EQUATION } \\
\text { NUMBER } m \text {. ERROR IN FRONT AT LOCATION } n \text {. } \\
\text { ERROR STOP IN ROUTINE FRONT. }\end{array}$ & $\begin{array}{l}\text { Either the material properties are zero or highly } \\
\text { contrasting. }\end{array}$ \\
\hline $\begin{array}{l}\text { BINARY READ SIZE ERROR. } \\
\text { ROUTINE BININ MUST BE MODIFIED SO THAT } m \\
\text { OR MORE RECORDS CAN BE READ AT ONCE. } \\
\text { ERROR STOP IN ROUTINE BININ. }\end{array}$ & $\begin{array}{l}\text { Direct l/O block size is not large enough for } \\
\text { scratch file. }\end{array}$ \\
\hline $\begin{array}{l}\text { BINARY WRITE ERROR. } \\
\text { ROUTINE BINOUT MUST BE MODIFIED SO THAT } \\
\text { M OR MORE RECORDS CAN BE WRITTEN AT } \\
\text { ONCE. } \\
\text { ERROR STOP IN ROUTINE BINOUT. }\end{array}$ & $\begin{array}{l}\text { Direct } 1 / O \text { block size is not large enough for } \\
\text { scratch file. }\end{array}$ \\
\hline
\end{tabular}


RHO-BW-CR-143P

This page intentionally left blank. 
DISTRIBUTION

Number of copies

OFFSITE

Analytical and Computational Research, Inc.

A. K. Runcha 1

1

Analytical Sciences Corporation

J. W. Bartlett

3

Atomic Energy of Canada Research Company

R. B. Lyon

E. L. J. Rosinger

B. J. S. Wilkins

7

Battelle-Office of Nuclear Waste Isolation

S. Gupta

P. L. Hofmann

Library (5)

1

BCS Seatt le, Inc.

K. J. Ekblad

1

Commissariat a 1 'Energie Atomique

A. Barbreau

1

Confederated Tribes of the Umatilla Indian Reservation

E. H. Patawa

1

D'Appolonia Consulting Engineers, Inc.

J. B. Case

1

Envirosphere, Inc.

R. Mahan

1

GeoTrans, Inc.

P. Huyakorn 
RHO-BW-CR-143P

Number of copies

1

Holcomb Research Institute

P. K. M. van der Heijde

1

Institut fur Kerntechnik

R. Storck

1

Institut fur Tieflagerung

E. Uerpmann

1

Institute for Geological Sciences

N. A. Chapman

3

Lawrence Berkeley Laboratory

T. N. Narasimhan

M. Shimo

Library

1

Lawrence Livermore Laboratory

Library

3

Los Alamos Scientific Laboratory

B. Crowe

B. J. Travis

Library

1

Massachusetts Institute of Technology

L. W. Gelhar

2

Montana College of Mineral Science and

Technology

V. W. Daniel

E. Van Eeckhout

1

NAGRA-National Cooperative for the Storage of Radioactive Waste

C. McCombie

2

National Radiological Protection Board

P. D. Grimwood

M. D. Hill

Distr. 
RHO-BW-CR-143P

Number of copies

1

1

1

1

2

1

1

1

2

1

1

1
New Mexico Institute of Mining and Technology

D. B. Stephens

Nez Perce Tribal Executive Committee of the Nez Perce Tribal Council

A. Pinkham

Nuclear Energy Agency

P. Johnston

Nuclear Waste Policy and Review Board

W. Bishop

Office of Crystalline Repository Development

A. Brandstetter

W. F. Ubbes

Ontario Hydro

K. K. Tsui

OTHA, Inc.

J. A. Lieberman

Principia Recherche Developpement

P. Bardey

Princeton University

G. F. Pinder

Library

Purdue University

D. Gray

Resource Management Associates

I. P. King

Royal Institute of Technology

R. Thunvik

Distr. 
Number of copies

2

6

2

2

1

1

6

1

1

2
SKBF/KBS

F. D. B. Karlsson

T. Tarandi

Sandia Laboratories
R. M. Cranwell
N. Ortiz
R. L. Hunter
L. D. Tyler
J. W. Nuciato
Library

Siting/Licensing Overview Committee

P. Domenico

F. Parker

Stanford University

I. Remson

Library

State of Texas Attorney General's Office

M. Plaster

Swedish Geological Company

A. Winberg

U.S. Department of Energy-Headquarters

D. Alexander J. J. Fiore

E. S. Burton M. W. Frei

C. R. Cooley R. Stein

U.S. Department of EnergyNevada Operations Office

D. L. Vieth

U.S. Department of Energy-Public Reading Room

Seattle, Washington

U.S. Environmental Protection Agency

Headquarters Librarian

Region $X$ Librarian 
RHO-BW-CR-143P

Number of copies

2

11

5

1

1

4

2
U.S. Geological Survey

D. B. Grove

K. L. Kipp

U.S. Nuclear Regulatory Commission

Branch Chief, High-Level Waste Technical Development Branch

Branch Chief, High-Level Waste Licensing Management Branch

Director, Division of Waste Management

Docket Control Center-Division of Waste

Management (4)

M. Dunkelman

D. Goode

M. Gordon

Library

University of Arizona

D. R. Davis

S. N. Davis

L. S. Leonhart

S. P. Neuman

Library

University of Californil, Berkeley

T. H. Pigford

University of Water 100

E. 0. Frind

Washington State Department of Ecology

A. Beatty Riniker

D. 0. Provost

J. Rense 1

D. W. Stevens

Washington State Department of Natural Resources

B. J. Boyle

Library 
Number of copies

1

1
Washington State Department of Social \& Health Services

K. Rahm

Washington State Energy Facility Site Evaluation Council

C. Eschels

Washington State Energy Office

R. H. Watson

Washington State House of Representatives Energy and Utilities Committee

Washington State Joint Legislative Committee on

Science and Technology

Washington State Library

Documents Section

Washington State Senate Energy and Utilities Committee

Washington State University

L. C. Chow

W. H. Funk

A. H. Marcus

E. P. Poeter

Science and Engineering Library

Weston Designer Consultants

W. L. Lee

L. Rickertsen

Yakima Indian Nation

J. B. Hovis

L. Lehman

Tribal Council 
Number of copies

ONSITE

18

BCS Richland, Inc.

D. R. Aichele

N. W. Kline (10)

C. Bromley

D. W. Langford

R. B. Doggett

J. J. Ratcliffe

R. L. England

RLSEC

S. A. Estey

Joint Center for Graduate Study

W. Kinsel

11

Pacific Northwest Laboratory

M. K. Altenhoffen

B. Kuhn

M. J. Budden

R. W. Nelson

H. C. Burkholder

A. E. Reisenauer

C. R. Cole

S. C. Sneider

F. H. Dove

Library

L. L. Eyler

2

U.S. Departmenmt of Energy-Public Reading Room Richland, Washington

3

U.S. Department of Energy-

Richland Operations Office
A. J. Knepp
P. E. Lamont
0. L. Olson

40

Rockwell Hanford Operations
E. B. Ash
R. C. Arnett
A. H. Lu
R. G. Baca
J. Ludwick (2)
M. S. Bensky
S. P. Luttre 11
$Y$. Chien
C. F. McLane
P. M. Clifton
D. L. Oliver
E. A. Fredenburg
B. Sagar
R. E. Gephart
D. H. Sandoz
J. Graham
J. C. Sonnichsen
Basalt Waste Isolation Project
Document Control (2)
Publications Services Department-Station 2 (2)
Records Retention (2) 
RHO-BW-CR-143P

\section{Number of copies}

1

UNC

W. D. Wittekind

Distr. 